\title{
GREEN RESINS FROM RENEWABLE RESOURCES
}

\author{
By \\ Justin James Stephen Kosalka \\ Bachelor of Science in Chemistry, \\ Ryerson University, Toronto Canada, 2011
}

\author{
A thesis \\ presented to Ryerson University \\ in partial fulfilment of the \\ requirements for the degree of \\ Master of Applied Science \\ in the Program of
}

Environmental Applied Science and Management

Toronto, Ontario, Canada, 2014

C(Justin James Stephen Kosalka) 


\section{AUTHOR'S DECLARATION}

I hereby declare that I am the sole author of this thesis. This is a true copy of the thesis, including any required final revisions, as accepted by my examiners.

I authorize Ryerson University to lend this thesis to other institutions or individuals for the purpose of scholarly research.

I further authorize Ryerson University to reproduce this thesis by photocopying or by other means, in total or in part, at the request of other institutions or individuals for the purpose of scholarly research.

I understand that my thesis may be made electronically available to the public. 


\title{
GREEN RESINS FROM RENEWABLE RESOURCES
}

Justin James Stephen Kosalka, Master of Applied Science, Environmental Applied Science and Management, Ryerson University, 2014

\begin{abstract}
This work was aimed at exploring bio-based materials for the purpose of toner production on an industrial scale. Polyester and polyether based resins were prepared in good yields from naturally occurring phenolic compounds with desired thermal and physical properties. Phenols with varying functionality such as guaiacol, eugenol and vanillin along with two synthetically produced phenolic compounds modelling the $\beta-\mathrm{O}-4$ linkage found in softwood lignins were explored as suitable precursors to synthetic, "green", resins. Phenols were transformed into diols using glycerine carbonate and a base catalyzed reaction. Diols were then polymerized with dicarboxylic acids in an acid catalyzed, transesterfication, reaction. A novel, bio-based polyether was synthesized in a one pot, one step polymerization using vanillin. Thermal properties $\left(\mathrm{T}_{\mathrm{g}}\right)$ and $\left(\mathrm{T}_{\mathrm{s}}\right)$ of resulting resins were evaluated. Resulting compounds and polymers were characterized using ${ }^{1} \mathrm{H}$ and ${ }^{13} \mathrm{C}$ NMR spectroscopy, high resolution mass spectrometry, elemental analysis, X-ray crystallography, DSC and GPC.
\end{abstract}




\section{ACKNOWLEDGEMENTS}

I would like to thank everyone who helped and supported me throughout this work.

First and foremost I would like to express my gratitude to my supervisor Dr. Daniel Foucher as this work would have not been possible without his constant support. His commitment and encouragement throughout this project was evident. His door was always open and he always made time to chat.

I would like to thank Dr. Guerino Sacripante who was my supervisor at XRCC. He always had a positive attitude and was always full of ideas. He introduced me to XRCC and ensured that everything went as smoothly as possible throughout my stay there.

I would like to thank my co-supervisor Dr. Robert Gossage who was always ready to offer suggestions and provide advice.

I would like to thank the laboratory staff at XRCC, in particular Brita, for collecting data. I would also like to thank Dr. Alan Lough from collecting crystallographic data and Dr. Mathew Forbes for collecting mass spectrometry data, both from the University of Toronto. I would also like to thank my colleagues, in particular, Jon, Aman, Lukasz, Jessey, Maja, Shane, Kamelsh, Michelle, Khrystyna and Grace for their day to day help and suggestions.

I would like to express my deepest gratitude to my parents and grandparents who have constantly supported me throughout everything that I do. I would not be where I am without them. I would also like express my gratitude and appreciation to Milena Ciccone for her constant encouragement and support. 


\section{Dedication}

I would like to dedicate this thesis to my parents Sabina and Stephen and to my grandparents Wladyslawa and Frank. 


\section{Table of Contents}

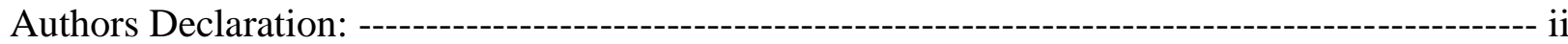

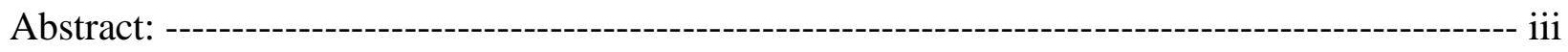

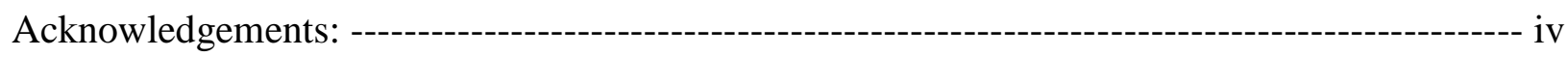

Dedications: ----------------------------------------------------------------------------------------------------- V

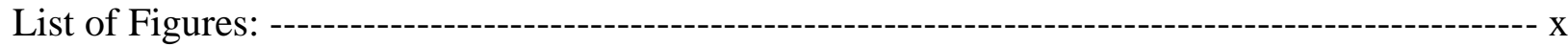

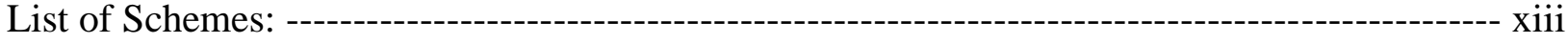

List of Tables: ---------------------------------------------------------------------------------------------------- xiv

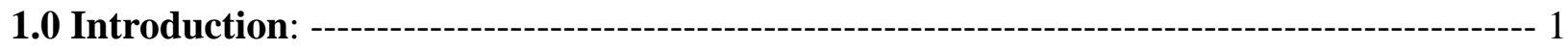

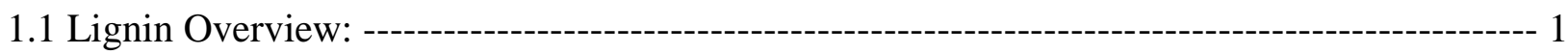

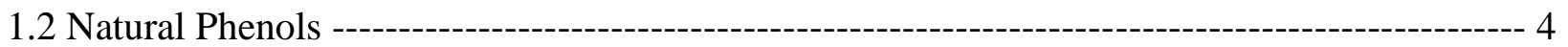

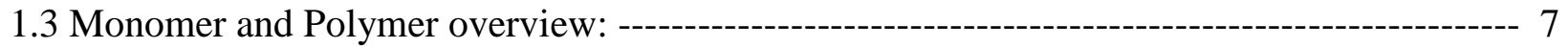

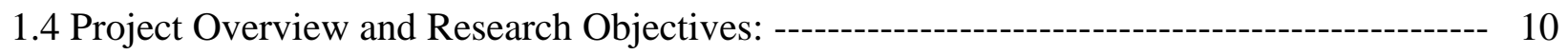

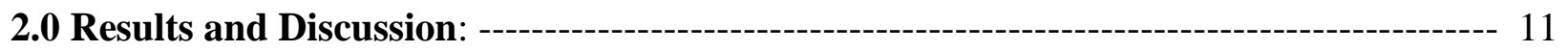

2.1 Modelling the $\beta$-O-4 Aryl Ether Linkage Found in Lignin: ------------------------------------ 11

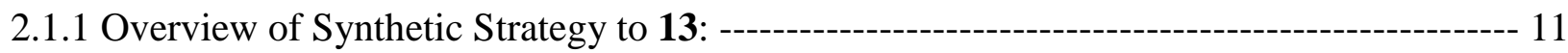

2.1.2 Synthesis and Characterization of 2-(4-(tert-butoxy)phenyl)ethan-1-ol, 5: ---------------- 14

2.1.3 Synthesis and Characterization of 4-(tert-butoxy)phenethyl 4-methylbenzene

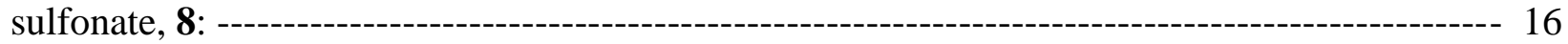

2.1.4 Synthesis and Characterization of 1-(4-(tert-butoxy)phenethoxy)-2-methoxybenzene,

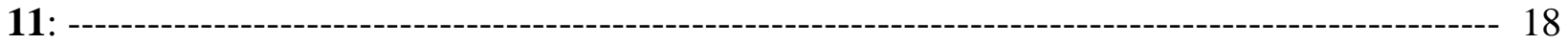

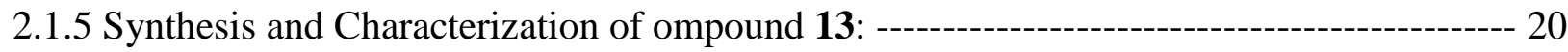

2.2 Preparation of 2-methoxy-4-(2-(2-methoxyphenoxy)propyl)phenol 25: -------------------- 25

2.2.1 Attempted synthesis of 3-(2-methoxy-4-(2-(2-methoxyphenoxy)propyl)phenoxy) propane-1,2-diol 18: ---------------------------------------------------------------------------------------- 25

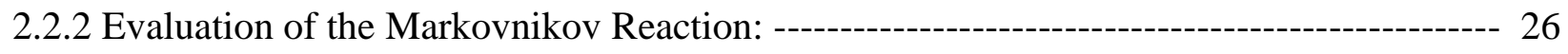

2.2.3 Synthesis and Characterization of (4-allyl-2-methoxyphenoxy)trimethylsilane, 24: ------ 29

2.2.4 Synthesis and Characterization of Compound 25: ----------------------------------------------- 32 
2.3 Preparation of Diols Suitable for Polymerization from Natural Phenolic Materials: --------- 36

2.3.1 Overview of Synthetic Diols: ----------------------------------------------------------------------- 36

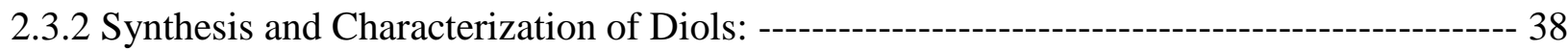

2.3.2.1 3-(4-allyl-2-methoxyphenoxy)propane-1,2-diol, 16: ------------------------------- 38

2.3.2.2 3-(2-methoxyphenoxy)propane-1,2-diol, 26: ------------------------------------------ 42

2.3.2.3 3-(2-methoxy-4-propylphenoxy)propane-1,2-diol, 29: ----------------------------- 45

2.3.2.4 4-(2,3-dihydroxypropoxy)-3-methoxybenzaldehyde, 31: -------------------------- 48

2.3.2.5 3-(2-isopropyl-5-methylphenoxy)propane-1,2-diol, 33, and 3-(5-isopropyl-2methyl phenoxy) propane-1,2-diol, 36: --------------------------------------------------- 51

2.3.2.6 4-(4-(2,3-dihydroxypropoxy)phenyl)butan-2-one, 39: --------------------------- 56

2.3.2.7 3-(4-methoxyphenoxy)propane-1,2-diol, 42, and 3-(p-tolyloxy)propane-1,2-

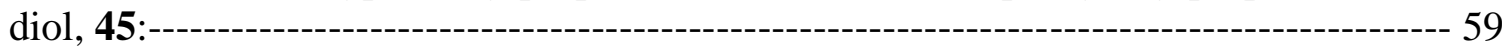

2.3.2.8 3-(4-(2-(2-methoxyphenoxy)ethyl)phenoxy)propane-1,2-diol 47: ---------------- 62

2.3.3 Efforts to Determine the Mechanism Leading to Di-substituted by-products: --------------- 66

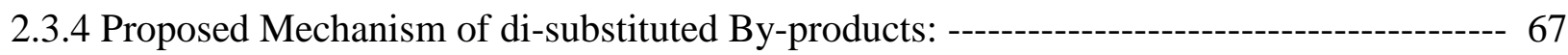

2.3.5 Unlikely Mechanism of Formation of Di-substituted By-products: ------------------------- 68

2.4 Polymerization of Bio-based Monomers: ---------------------------------------------------------- 70

2.4.1 Polymerization Overview; Monitoring and Evaluating Resulting Polymers: -----------------70

2.4.2 Polymerizations of $\mathbf{2 6}$ with Succinic, Isoterephathalic and Terephathalic Acids: -----------71

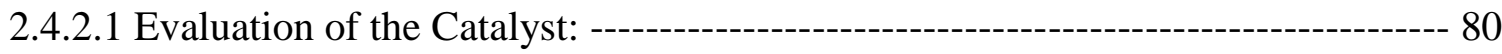

2.4.3 Polymerization of 3-(2-methoxy-4-propylphenoxy)propane-1,2-diol, 29, with Succinic Acid:-------------------------------------------------------------------------------------------------------- 80

2.4.4 Polymerization of 3-(4-allyl-2-methoxyphenoxy)propane-1,2-diol with, 16, Succinic

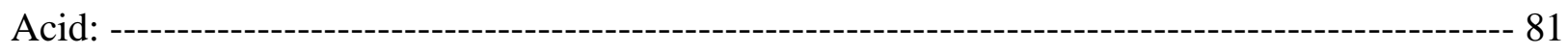

2.4.5 Self Condensing Polymerization of 4-(2,3-dihydroxypropoxy)-3-methoxybenz aldehyde,

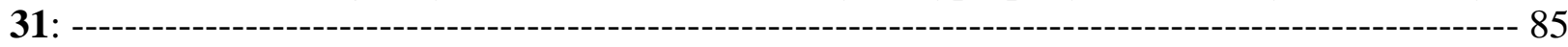

2.4.6 Attempted Polymerizations Using Crude Materials 33, 36 and 39 with Succinic Acid: --- 90

2.4.7 Depolymerization of Cross - Linked Materials: -------------------------------------------------- 91

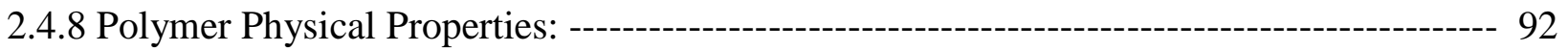


3.0 Conclusion:

4.0 Future work: --

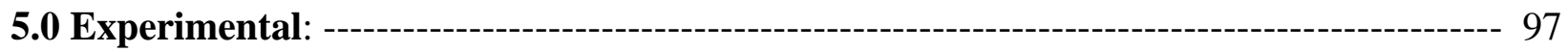

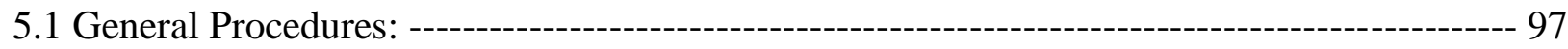

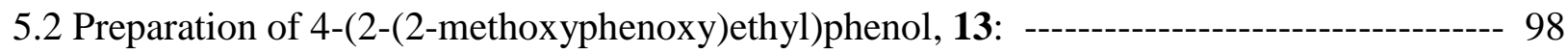

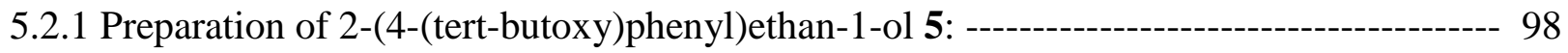

5.2.2 Preparation of 4-(tert-butoxy)phenethyl 4-methylbenzenesulfonate 8: ------------------ 99

5.2.3 Preparation of 1-(4-(tert-butoxy)phenethoxy)-2-methoxybenzene 11: ------------- 100

5.2.4 Preparation of 4-(2-(2-methoxyphenoxy)ethyl)phenol 13: ---

5.3 Preparation of 3-(2-methoxy-4-(2-(2-methoxyphenoxy)propyl)phenoxy) propane-1,2diol, 25: -----on 101

5.3.1 Evaluation of the Markovnikov Addition Reaction of a Phenol to a Double Bond: ------ 101

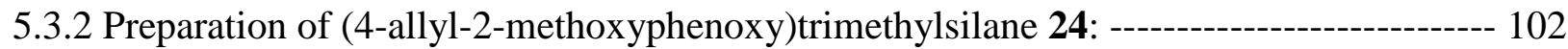

5.3.3 Preparation of 2-methoxy-4-(2-(2-methoxyphenoxy)propyl)phenol 25: ------a------ 103

5.4 Preparation of Diols Suitable for Polymerization from Natural Phenolic Materials: ------- 104

5.4.1 Preparation of 3-(4-allyl-2-methoxyphenoxy)propane-1,2-diol 16: ---------------------- 104

5.4.2 Preparation of 3-(2-methoxyphenoxy)propane-1,2-diol 26 and 3-(4-methox phenoxy)

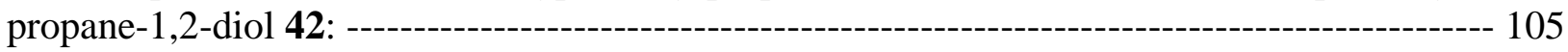

5.4.3 Preparation of 3-(2-methoxy-4-propylphenoxy)propane-1,2-diol 29: ------------------- 107

5.4.4 Preparation of 4-(2,3-dihydroxypropoxy)-3-methoxybenzaldehyde 31: ----------------- 108

5.4.5 Preparation of 3-(2-isopropyl-5-methylphenoxy)propane-1,2-diol 33 and 3-(5-iso propyl-2-methylphenoxy)propane-1,2-diol 36: ------------------------------ 109

5.4.6 Preparation of 4-(4-(2,3-dihydroxypropoxy)phenyl)butan-2-one 39: -------------------- 112

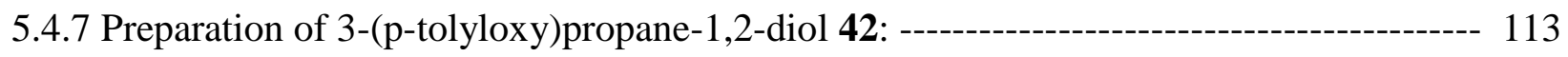

5.4.8 Preparation of 3-(4-(2-(2-methoxyphenoxy)ethyl)phenoxy)propane-1,2-diol 47: -------- 115

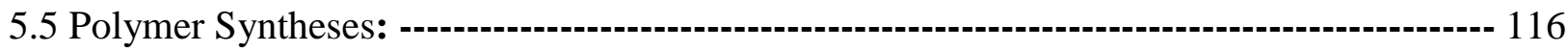

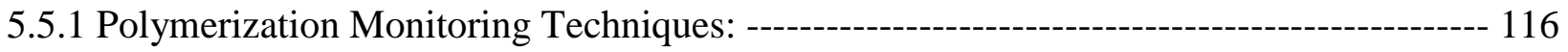

5.5.2 Polymerization of 3-(2-methoxyphenoxy)propane-1,2-diol 26 with Succinic,

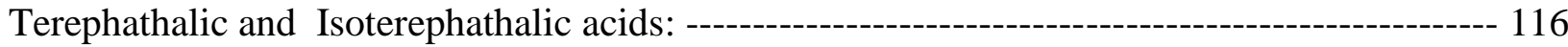


5.5.3 Polymerization of $\mathbf{2 6}$ with a Ti Catalyst 56:

5.5.4 Polymerization of 3-(2-methoxy-4-propylphenoxy)propane-1,2-diol 57 with Succinic Acid:

5.5.5 Polymerization of 3-(4-allyl-2-methoxyphenoxy)propane-1,2-diol 58 with Succinic acid:

5.5.6 De-polymerization of Cross-linked Materials: 121

5.5.7 Self-polymerization of Vanillin-based Material: 121

6.0 Appendices: 123

List of Appendix Figures:

7.0 References: 


\section{List of Figures}

Figure 1: Representation of a softwood lignin fragment highlighting the phenolic component. -- 2

Figure 2: Phenylpropanoid fragments in Canadian softwood. ----------------------------------------- 3

Figure 3: The $\beta-O-4$ linkage commonly observed in lignin. ----------------------------------------- 4

Figure 4: Naturally occurring phenols evaluated for polyester resin production. -------------------- 5

Figure 5: Several successfully generated bio-based resins. ------------------------------------------- 6

Figure 6: ${ }^{1} \mathrm{H}$ NMR $\left(\mathrm{CDCl}_{3}\right)$ spectrum of 5.

Figure 7: ${ }^{13} \mathrm{C}$ NMR $\left(\mathrm{CDCl}_{3}\right)$ spectrum of $\mathbf{5}$. --------------------------------------------------- 15

Figure 8: ${ }^{1} \mathrm{H}$ NMR $\left(\mathrm{CDCl}_{3}\right)$ spectrum of 8. ------------------------------------------------------------ 16

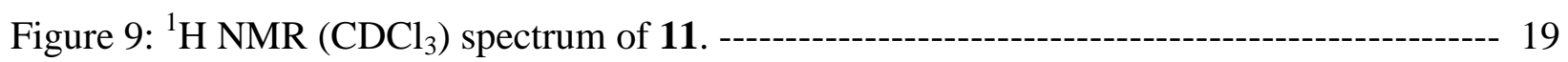

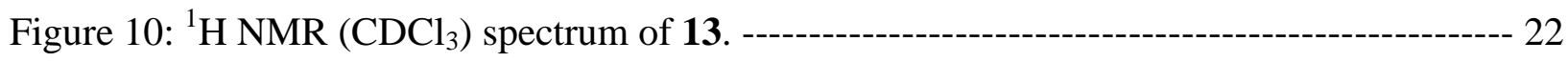

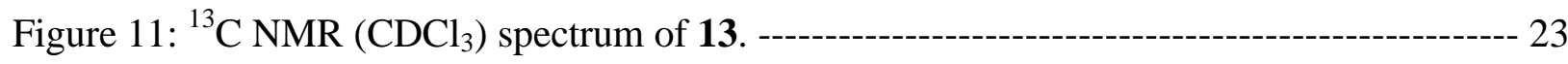

Figure 12: Ortep representation of the unit cell components of 13. ------------------------------ 24

Figure 13: PLATON representation of the unit cell components of $\mathbf{1 3}$ with CXA and CXB

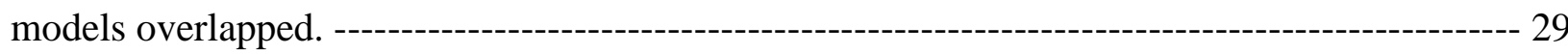

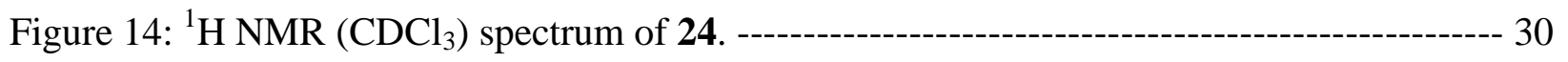

Figure 15: ${ }^{13} \mathrm{C} \mathrm{NMR}\left(\mathrm{CDCl}_{3}\right)$ spectrum of 24. -------------------------------------------------------- 31

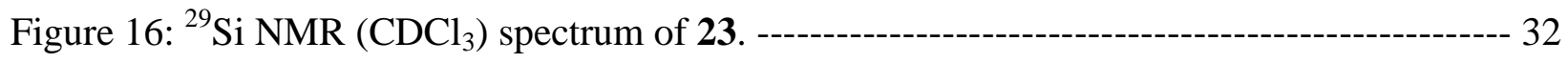

Figure 17: ${ }^{1} \mathrm{H}$ NMR $\left(\mathrm{CDCl}_{3}\right)$ spectrum of 25. -------------------------------------------------------- 33

Figure 18: ${ }^{13} \mathrm{C}$ NMR $\left(\mathrm{CDCl}_{3}\right)$ spectrum of 25. ----------------------------------------------------- 34

Figure 19: Various products reported by Truscello et al. --------------------------------------------- 37

Figure 20: Thin layer chromatography plate demonstrating column efficacy for diol

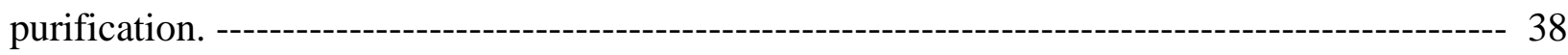

Figure 21: Compound 16 with reference to the newly added propyl diol chain. ------------------ 39

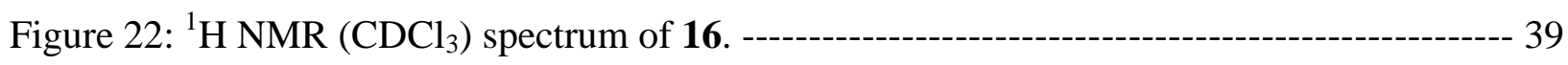

Figure 23: ${ }^{13} \mathrm{C} \mathrm{NMR}\left(\mathrm{CDCl}_{3}\right)$ spectrum 16. -------------------------------------------------------- 40

Figure 24: ORTEP representation of the unit cell components of 16. ---------------------------- 41 
Figure 25: Structure of compound 26 with reference to characteristic ${ }^{13} \mathrm{C}$ NMR resonances. --- 43 Figure 26: Structure of compound 27 with reference to characteristic ${ }^{1} \mathrm{H}$ NMR resonances. --- 43

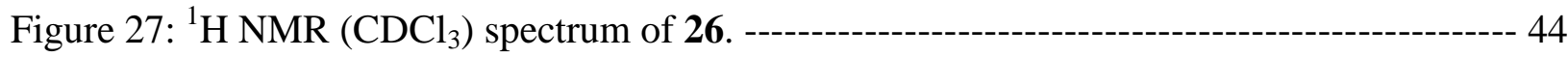

Figure 28: ${ }^{13} \mathrm{C}$ NMR $\left(\mathrm{CDCl}_{3}\right)$ spectrum of 26. ------------------------------------------------------ 45

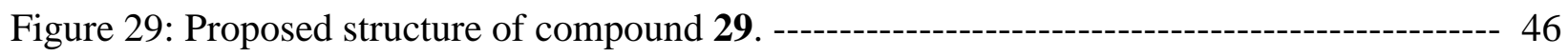

Figure 30: ${ }^{1} \mathrm{H}$ NMR $\left(\mathrm{CDCl}_{3}\right)$ spectrum of 29. ------------------------------------------------------ 46

Figure 31: ${ }^{13} \mathrm{C}$ NMR $\left(\mathrm{CDCl}_{3}\right)$ spectrum of 29. ------------------------------------------------------- 47

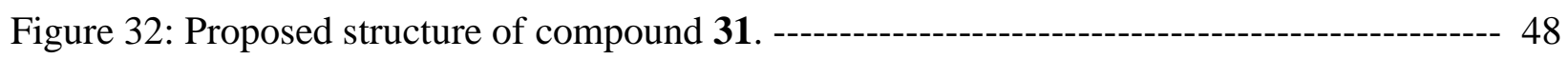

Figure 33: ${ }^{1} \mathrm{H}$ NMR $\left(\mathrm{CDCl}_{3}\right)$ spectrum of 31. -------------------------------------------------------- 49

Figure 34: ${ }^{13} \mathrm{C}$ NMR $\left(\mathrm{CDCl}_{3}\right)$ spectrum of 31. ------------------------------------------------------ 50

Figure 35: Proposed structure of compounds 33 and 36. ------------------------------------------- 51

Figure 36: ${ }^{1} \mathrm{H}$ NMR $\left(\mathrm{CDCl}_{3}\right)$ spectrum of 33. ------------------------------------------------------ 52

Figure 37: ${ }^{13} \mathrm{C}$ NMR $\left(\mathrm{CDCl}_{3}\right)$ spectrum of 33. -------------------------------------------------------- 53

Figure 38: ${ }^{1} \mathrm{H}$ NMR $\left(\mathrm{CDCl}_{3}\right)$ spectrum of 34. ------------------------------------------------------- 54

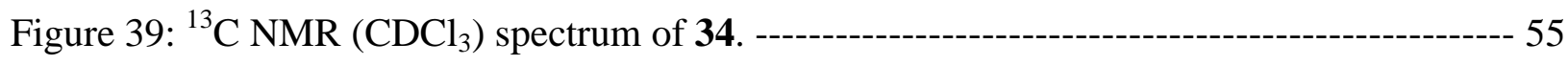

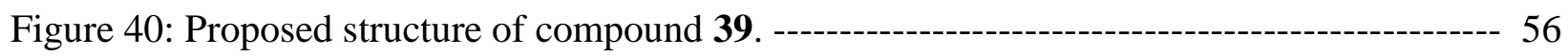

Figure 41: ${ }^{1} \mathrm{H}$ NMR $\left(\mathrm{CDCl}_{3}\right)$ spectrum of 39. --------------------------------------------------------- 57

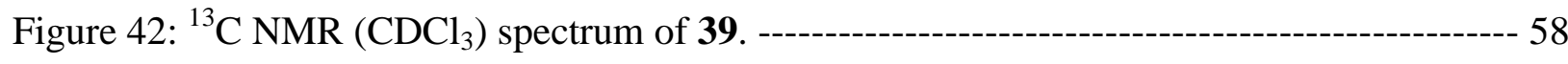

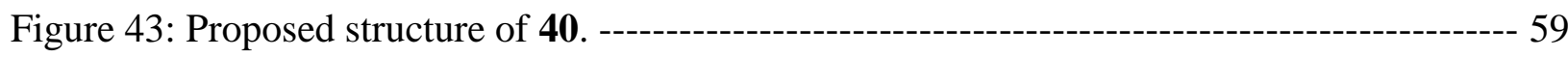

Figure 44: Structure of p-methoxy phenol, 41 and $p$-cresol 44. ------------------------------------- 60

Figure 45: Proposed structure of compound 42. ------------------------------------------------------- 60

Figure 46: Proposed structure of compound 43. --------------------------------------------------------- 61

Figure 47: Proposed structure of compound 45. -------------------------------------------------------- 61

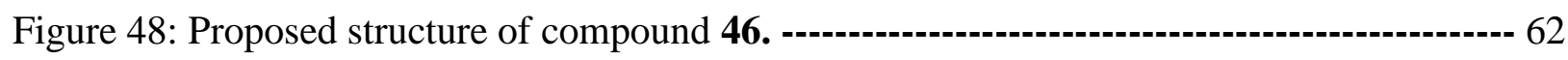

Figure 49: Proposed structure of compound 47. ---------------------------------------------------- 63

Figure 50: ${ }^{1} \mathrm{H}$ NMR spectrum $\left(\mathrm{CDCl}_{3}\right)$ of 47. ------------------------------------------------------ 63

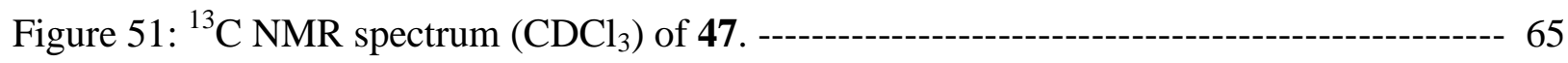


Figure 52: Characteristic fragment of $\mathbf{4 7}$ detected during high resolution mass spectrometry. - 66

Figure 53: Image of resin 51. ----------------------------------------------------------------------------- 72

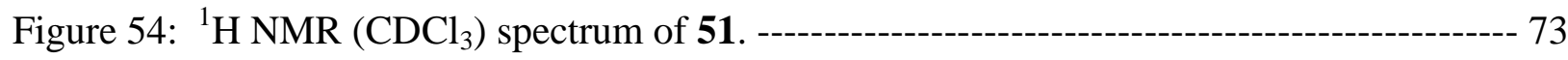

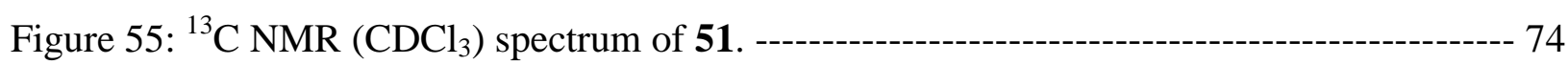

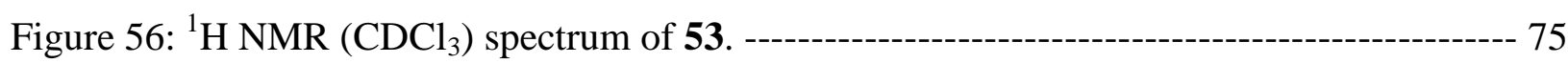

Figure 57: ${ }^{13} \mathrm{C}$ NMR $\left(\mathrm{CDCl}_{3}\right)$ spectrum of 53. ------------------------------------------------------ 76

Figure 58: ${ }^{1} \mathrm{H}$ NMR $\left(\mathrm{CDCl}_{3}\right)$ spectrum of $\mathbf{5 5}$. ---------------------------------------------------- 77

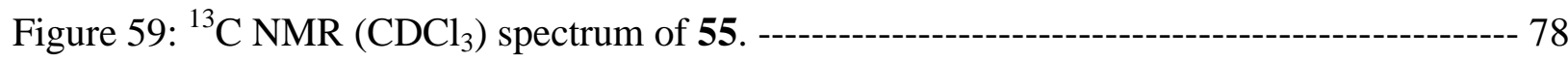

Figure 60: Proposed structure of resin 57. -------------------------------------------------------------- 81

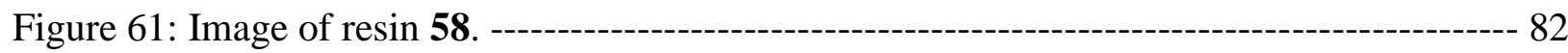

Figure 62: ${ }^{1} \mathrm{H}$ NMR $\left(\mathrm{CDCl}_{3}\right)$ spectrum of $\mathbf{5 8}$. --------------------------------------------------------- 83

Figure 63: ${ }^{13} \mathrm{C}$ NMR $\left(\mathrm{CDCl}_{3}\right)$ spectrum of 58. ----------------------------------------------------- 84

Figure 64: Unlikely structure of the polyether which underwent acetylation. ---------------------- 86

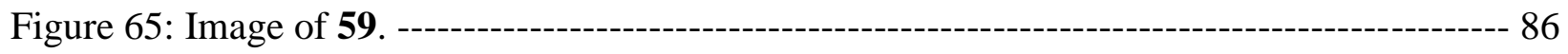

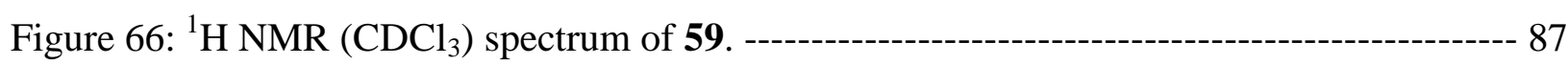

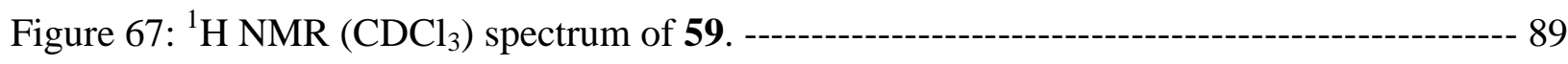

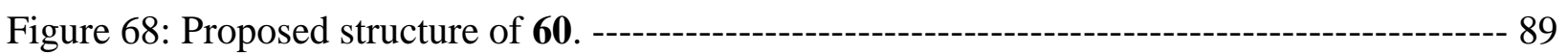




\section{List of Schemes}

Scheme 1: Polymerizations involving cyclic carbonates and diols. ----------------------------------- 8

Scheme 2: General transesterification scheme. ----------------------------------------------------------- 9

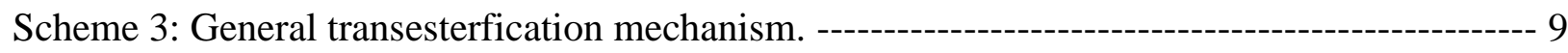

Scheme 4: General polymerization employed in this work. ------------------------------------------- 10

Scheme 5: Overview of generating polyesters from phenols in this work. ------------------------- 11

Scheme 6: Synthetic pathway to $\mathbf{1 3}$ developed by Nagy. ------------------------------------------ 12

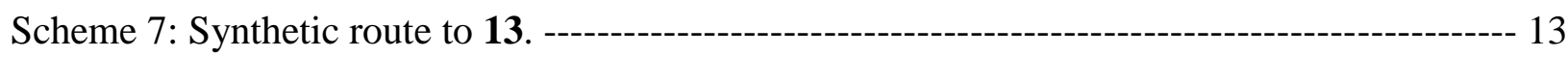

Scheme 8: Compound $\mathbf{8}$ undergoing transformation to the chlorinated by-product. -------------- 18

Scheme 9: Unsuccessful Markovnikov addition of 14 with 9 under acidic conditions. ---------- 26

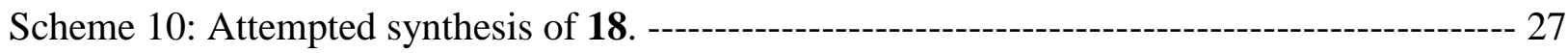

Scheme 11: Evaluation of the Markovnikov addition reported by Li et al. ------------------------ 28

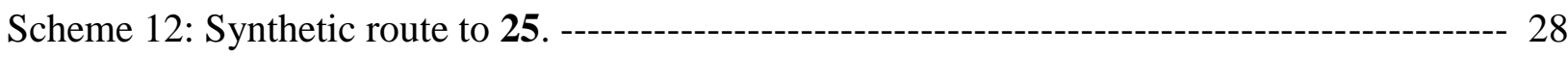

Scheme 13: Proposed synthetic routes to generate a diol from a phenol. ---------------------------- 36

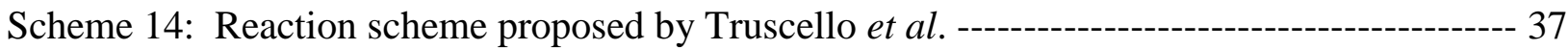

Scheme 15: Proposed mechanism for the formation of di-substituted by-products. -------------- 68

Scheme 16: Unlikely mechanism leading to the formation of di-substituted by-products. ------ 69

Scheme 17: Unsuccessful efforts to synthesize 27 in efforts to understand its formation. ------ 69

Scheme 18: Polymerizations of $\mathbf{2 6}$ with various organic acids. ----------------------------------- 71

Scheme 19: Evaluation of an environmentally friendly catalyst. ------------------------------------ 80

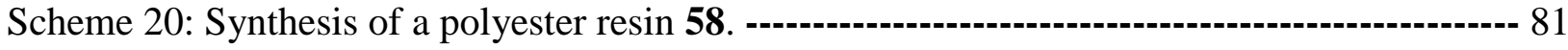

Scheme 21: Vanillin undergoing self condensation to yield a polyether, 59b. -------------------- 86

Scheme 22: Attempted polymerizations using crude materials. ------------------------------------- 91

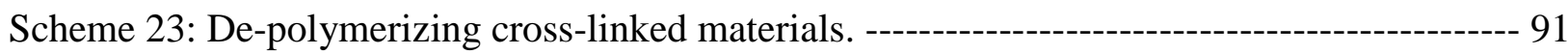




\section{List of Tables}

Table 1: Selected bond lengths $[\AA]$ and bond angles $\left[{ }^{\circ}\right]$ for 13.

Table 2: Selected bond lengths $\left[\AA ̊ 0\right.$ ] and bond angles $\left[{ }^{\circ}\right]$ for 16.

Table 3: Softening points $\left(\mathrm{T}_{\mathrm{s}}\right)$, DSC and GPC data of resulting polymeric resins. --------------- 92 


\subsection{Introduction}

\subsection{Lignin Overview}

The pulp and paper industry is one of Canada's largest industries providing over 300000 jobs and generating $\$ 34$ billion in exports. ${ }^{1}$ It is estimated that between 3-6 billion trees are cut down annually where about half of these are processed in order to extract cellulose, the main component of paper, from wood. ${ }^{2,3}$ Dry wood or lignocellulosic material is primarily composed of a variety of carbohydrates such as cellulose, hemicellulose and pectin along with an amorphous component known as lignin. In general cellulose, the most abundant naturally occurring polymer on earth, is a straight chain polymer composed of linked glucose units. Cellulose, along with the other carbohydrate based materials, account for approximately $65-75$ $\%$ of a tree by mass. Lignin on the other hand, although well studied, is still puzzling to researchers due to its random and amorphous nature. By mass, lignin accounts for approximately $18-35 \%$ of dry wood. The remaining mass of wood is comprised of minor extractives such as starch. ${ }^{4}$

Prior to paper production, cellulose needs to be separated from the other components in wood. Through a process known as pulping, cellulose can be efficiently separated from these other materials. There are several pulping methods which include sulfite, sulfate and the most dominant today is kraft pulping. In general, pulping involves breaking down wood under harsh conditions which include high temperatures and strong chemical reagents such as $\mathrm{NaOH}$ and NaS. This process, to a degree, can break down lignin, hemicellulose and pectin while leaving the cellulose intact. ${ }^{5}$ Through years of innovation, pulping facilities have been designed to efficiently recycle the harsh pulping chemicals within the facility itself; however other concerns associated with these processes still exist. One of the major environmental concerns is that the 
recovered lignocellulosic components result in a substantial amount of waste; although biobased, it is still waste that needs to be managed. Hemicellulose is a complex network of various polysaccharide units and when hydrolyzed during the pulping process, results in a relatively useless material. Pectin, similar to hemicellulose, is composed of varying polysaccharide units that when hydrolyzed also results in a low value product. The structure of lignin is even more complex than the previous two components. It is composed of a complex network of cross linked heteropolymers containing various types of aromatic species, including potentially valuable phenolic fragments. Due to its rigid and stable structure, lignin serves primarily as a structural support within the cell walls. ${ }^{6}$ Next to cellulose, lignin (Figure 1) is the most abundant biopolymer on Earth with approximately 50 million tons produced annually as waste. ${ }^{7}$

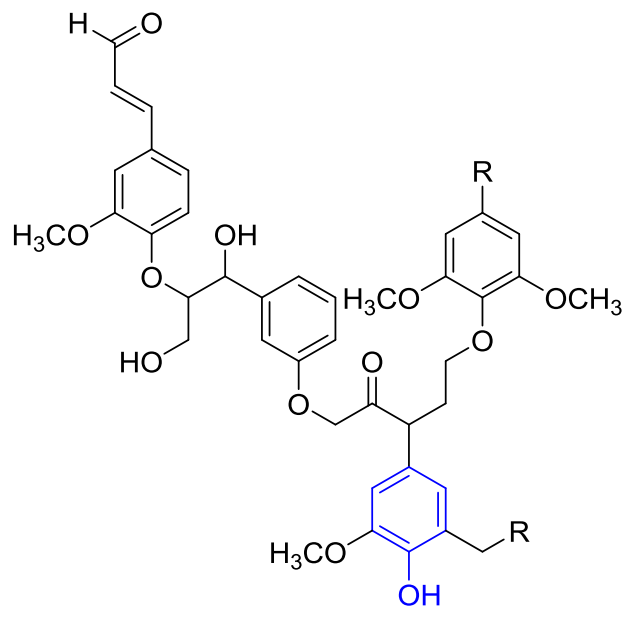

$\mathrm{R}=$ remaining lignin network<smiles>Oc1ccccc1</smiles>

Phenol

Figure 1: Representation of softwood lignin fragment highlighting the phenolic component.

The three lignocellulosic materials generated from pulping are normally burned somewhere within the pulping facility in an effort to try and recycle some of the energy used in the separation process. Other practical uses of lignin include filler in animal feed and as a composite additive in paving materials. ${ }^{8}$ Lignin is gaining tremendous attention as an important 
and potentially valuable renewable resource. In 2008, 40 million tons of lignin was produced by the pulp and paper industry of which $95 \%$ was burned. ${ }^{9}$ Conventionally sourced phenols are primarily derived from petroleum sources and its derivatives. As concerns continue to grow over petroleum extraction and environmental protection, coupled with the massive "green" push within society in general, naturally occurring and renewable sources of phenols are gaining more attention in industries as viable, cheap and environmentally friendly substitutes to traditionally sourced phenols. The aromatic components of lignin would have significant value and applications in industry. Due to its relatively low cost (8-25 cents $\mathrm{kg}^{-1}$ ), lignin (Figure 1) may serve as an economically feasible source for these valuable compounds.

Present in both softwood and hardwood tree species, lignin is also found in other types of vegetation including leaves and the stems of plants as well as in particular forms of algae. ${ }^{10}$ Lignin is a three dimensional amorphous biopolymer primarily consisting of three phenylpropanoid units of varying concentration throughout the polymeric network (Figure 2).

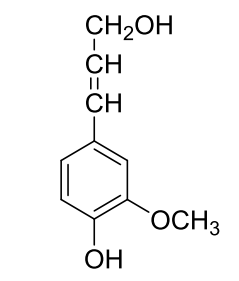

coniferyl alcohol

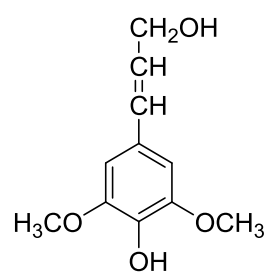

sinapyl alcohol

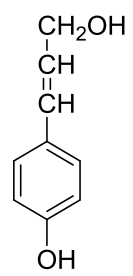

p-coumaryl alcohol

Figure 2: Phenylpropanoid fragments in Canadian softwood.

The type of wood (softwood versus hardwood) will dictate the phenylpropanoid ratios found within the lignin network. In Canadian softwood, the coniferyl fragment comprises approximately $95 \%$ of all phenylpropanoids possibilities. ${ }^{5}$ Nagy et al. reported that the primary 
linkage observed in softwood lignin was the $\beta-\mathrm{O}-4$, (Figure 3), which was approximated to account for $45 \%$ of all lignin linkages. ${ }^{11}$

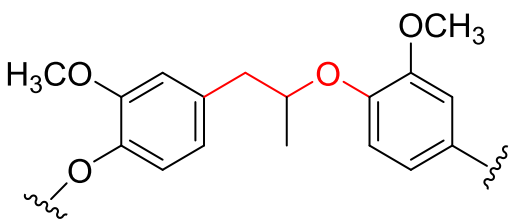

Figure 3: The $\beta-\mathrm{O}-4$ linkage commonly observed in lignin.

Presently, aromatic based compounds are being harvested from lignin; however current extraction technology has not made these processes cost effective or scalable to satisfy industrial demand. There have been numerous studies that involve the digestion of lignin through biological means such as the use of various types of rot fungus including white and brown rot fungi. ${ }^{12}$ Intensive studies have also examined the enzymatic breakdown of lignin produced by these fungi and others. ${ }^{13}$ Microwave digestion has shown promise of oxidizing and in turn hydrolyzing lignin in the presence $\mathrm{CuO}$ generate, among other chemical species, phenols which include guaiacol and propyl guaiacol. ${ }^{14}$ As the primary linkage found in softwood lignin, the $\beta$ O-4 linkage should be quite prevalent and the hydrolyzable site for phenolic species during lignin digestion.

\section{$\underline{1.2 \text { Natural Phenols }}$}

Initially this project was designed as a two stage project where the first part involved evaluating naturally occurring phenolics including the $\beta-\mathrm{O}-4$ linkage in polyester resin production. Along with two synthetically prepared compounds modelling the $\beta-\mathrm{O}-4$ linkage, other commercially available, bio-based phenolic compounds were also explored (Figure 4). In this context, bio-based refers to materials which can be sourced from naturally occurring 
materials. The second part, although later abandoned, was envisioned to involve the chemical degradation of lignin in an effort to harvest the resulting fragments to generate bio-based resins.<smiles>COc1ccccc1O</smiles>

guaiacol<smiles>CC(=O)CCc1ccc(O)cc1</smiles>

raspberry ketone<smiles>CCCc1ccc(O)c(OC)c1</smiles>

propyl guaiacol

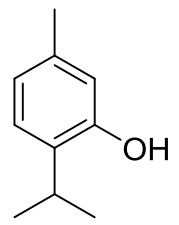

thymol<smiles>C=CCc1ccc(O)c(OC)c1</smiles>

eugenol

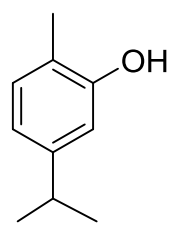

carvacrol<smiles>COc1cc(C=O)ccc1O</smiles>

vanillin

Figure 4: Naturally occurring phenols evaluated for polyester resin production.

Vanillin and eugenol can be derived from lignin. Vanillin (4-hydroxy-3methoxybenzaldehyde), a phenolic aldehyde, is primarily responsible for the sweet aroma and taste associated with vanilla. It was first isolated from vanilla extract and accounts for approximately $2 \%(\mathrm{w} / \mathrm{w})$ of the dried vanilla pod. ${ }^{15}$ Vanillin is commonly used in the food and beverage industry as a cheap substitute for vanilla extract. It is also used in the fragrance and pharmaceutical industries in various applications. The limited supply of vanilla extract, coupled with its tremendous demand, prompted the mass synthetic production of vanillin to meet industrial demands. Approximately $85 \%$ of the world's vanillin supply is synthetically produced from petroleum-based materials while the remaining $15 \%$ is produced primarily from lignin. ${ }^{16}$ Generally, lignin is oxidized to produce vanillin in yields of $3-7 \% .^{17}$

Eugenol (4-allyl-2-methoxyphenol), a phenylpropene is another naturally occurring phenol and is the main chemical component of cloves ( $80 \% \mathrm{wt})$. It can also be found, in smaller quantities, in other plant species including thyme and oregano leaves. ${ }^{18}$ It is harvested for many reasons including food flavouring, scents and for medicinal purposes. ${ }^{19}$ Eugenol can also be 
chemically modified to generate useful phenolic compounds such as iso-eugenol, a compound that can be readily oxidized to yield vanillin and other useful chemical compounds. ${ }^{15}$

Phenolic aldehyde resins have been in general use since the beginning of the $20^{\text {th }}$ century and have traditionally employed the use of a phenol in combination with formaldehyde to generate synthetic resins. ${ }^{20}$ Many different phenols have also been employed in the development of formaldehyde resins including various cresols, xylenols and bisphenol-A. ${ }^{21}$ Although formaldehyde is primarily utilized due to its relatively cheap cost and availability, other aldehydes such as furfural have also been used in resin production. ${ }^{22}$ Unlike the phenolic aldehyde resins which employ aldehyde and phenol groups on respective compounds, vanillin contains both a phenol and an aldehyde functionality. Vanillin based polymers have been utilized in a variety of applications which include polymerizations with Schiff bases, allowing for the chelation of metal ions. ${ }^{23}$ They have been utilized in the medical industry as therapeutic agents. ${ }^{24}$ In particular, vanillin oxalate based polymers have been designed by the pharmaceutical industry to, once administered, break down into various non toxic components allowing the body to take advantage of vanillin's well known anti-oxidant and inflammatory properties resulting in the relief of oxidative stress. Vanillin based resins have also been developed which involve the use of methacrylates to generate thermoset materials in a quick and efficient one pot synthesis. ${ }^{25}$ The thermal properties of these materials can in turn be improved and almost tailored with various curing agents.

Phenylpropenes, similar to ones observed in lignin have been employed in several synthetic polymerizations primarily as plasticisers. Eugenol based polymers have been evaluated in a variety of applications including polymerizations involving methacrylates or zinc oxide generating materials suitable to be used in orthopedics or as dental cement. ${ }^{26}$ Eugenol titanium 
based polymers have been developed utilizing electropolymerizations and assessed as a cysteine detector for use in clinical studies and pharmaceutical industries. ${ }^{27}$ Eugenol based polymers have also shown promise within the biomedical field as an anti-microbial material. ${ }^{28}$

Other phenols for investigation in this thesis include guaiacol, thymol, carvacol and raspberry ketone (Figure 4). Guaiacol, which is naturally extracted from flowering plant species, is also produced from the pyrolysis of lignin. ${ }^{29}$ Thymol and carvacol are naturally found in a variety of herbs but are typically collected from thyme and oregano oil while raspberry ketone, a phenolic ketone, is found in raspberries. ${ }^{30}$ Phenols derived from fossil fuels such as $p$-cresol and p-methoxy phenol were also evaluated for reasons other than polymerization purposes.

\subsection{Monomer and Polymer Overview}

Polyester resins are used in a wide variety of applications including toner. Toner can be generalized as very fine pieces of resin or plastic, typically $5-7 \mu \mathrm{m}$ in size and are fused with coloring agents. During xerography, or photocopying, toner is electrostatically deposited onto paper. The paper, along with the deposited toner, is then carefully sent through a heated press which melts or binds the toner to the paper which is why after xerography, the paper is warm to the touch. In order for this process to be successful, the physical properties of toner needed to be carefully addressed. In particular, the ability of the resin within the toner, when heated with a very specific amount of heat will transform from a solid to molten state and upon removal of heat, will solidify immediately. As this work was focused on producing bio-based materials suitable for toner production, polyester resins tailored with specific thermal properties such as specific softening point $\left(\mathrm{T}_{\mathrm{s}}\right)$ and glass transition temperatures $\left(\mathrm{T}_{\mathrm{g}}\right)$ were desired. 
A number of polyester polymerizations have employed propylene carbonate (Scheme 1). Propylene carbonate has been used in polymerization chemistries involving urethanes and other reactions resulting in, but not limited to, the production of adhesives, coatings and lubricants. ${ }^{31}$ When propylene carbonate and a phenol are heated in the presence of a base, a polyalkoxy diol is formed. ${ }^{32}$ These polyalkoxy diols are then presumed to undergo transesterification polymerizations in the presence of di-carboxylic acids and acid catalysts.

Step1<smiles>CC(O)COc1ccc(C(C)(C)c2ccc(OCC(C)O)cc2)cc1</smiles>

Step 2<smiles>CC(O)COc1ccc(C(C)(C)c2ccc(OCC(C)O)cc2)cc1</smiles>

$\mathrm{R}^{\prime}=$ any alkyl or aryl group

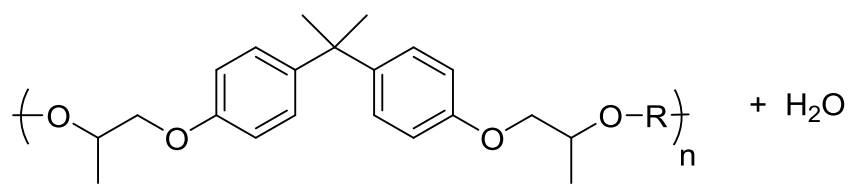

Scheme 1: Polymerizations involving cyclic carbonates and diols.

Traditional transesterfication reactions involve combining carboxylic acids and alcohols, in the presence of a strong acid such as sulfuric acid, yields esters (Scheme 2). 


$$
\mathrm{R}_{\mathrm{OH}}^{\mathrm{O}}+\mathrm{R}^{\prime} \mathrm{OH} \stackrel{\mathrm{H}^{+}}{\longrightarrow} \mathrm{R}_{\mathrm{O}^{-} \mathrm{R}^{\prime}}^{\mathrm{O}}+\mathrm{H}_{2} \mathrm{O}
$$

Scheme 2: General transesterification scheme.

In general, the carbonyl group is protonated by the acid. This generates a positive charge on the oxygen atom which is delocalized, generating a carbocation. The lone pair of the alcohol is then able to attack the carbocation followed by the elimination of water. The catalyst is then regenerated and the esterfication process is complete. This mechanism of the transesterfication process is presented below (Scheme 3).

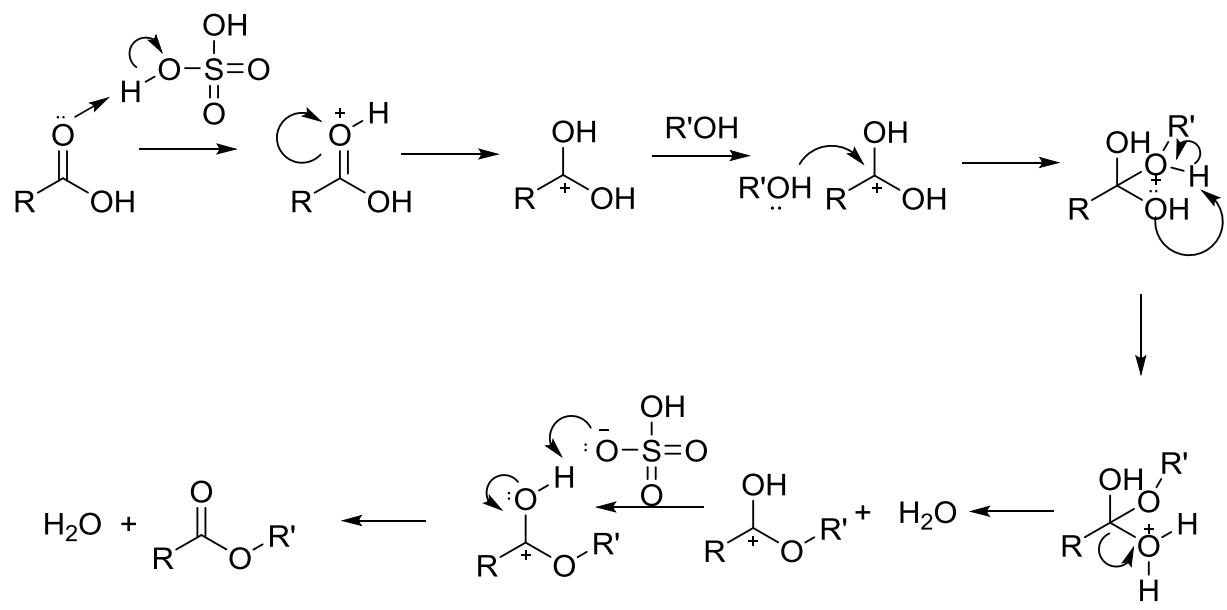

Scheme 3: General transesterfication mechanism.

In this work, a variety of propyl diols are reacted with suitable dicarboxylic acids in the presence of butylstannoic acid, also known as Fascat 4100, to generate polyester resins with varying properties. The generated polyalkoxy diols are heated in the presence of a di-acid and acid catalyst resulting in transesterfication polymerizations (Scheme 4). 

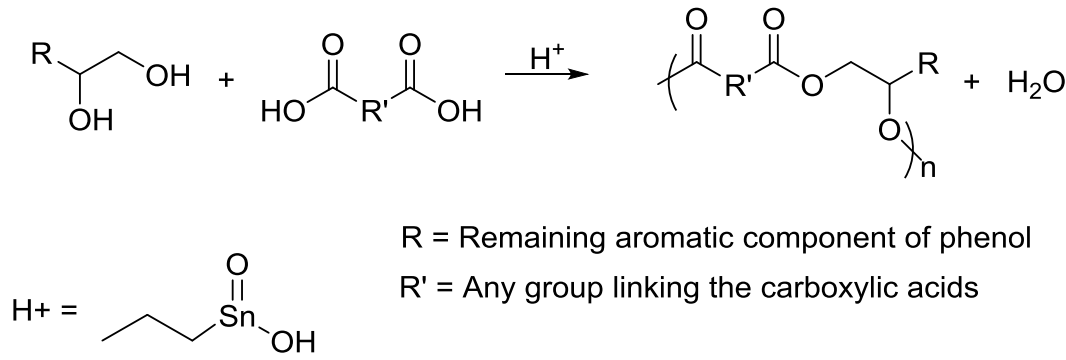

Scheme 4: General polymerization scheme employed in this work.

Although tin compounds are generally considered quite toxic, they are quite popular among manufacturers of polyester resins and were utilized throughout this work.

\section{$\underline{1.4 \text { Project Overview and Research Objectives }}$}

The primary objectives in this work are to explore and develop polyester resins suitable for industrial scale toner production in a two step process. Phenols are reacted with glycerine carbonate in efforts to develop functionalized monomers. Unlike reactions involving propylene carbonate, which require a compound containing two phenolic hydroxyl groups in order to generate a suitable monomer, glycerine carbonate requires only a single phenolic site to synthesize a diol suitable for polymerization. The second step, diols were polymerized employing a variety of di-carboxylic acids and the thermal properties of the resulting materials were to be tailored to meet specific thermal requirements. The vanillin based diol underwent self polymerizetion generating a suspected polyether .(Figure 5 and Scheme 5). ${ }^{33}$

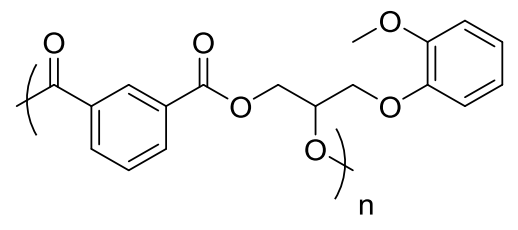

A

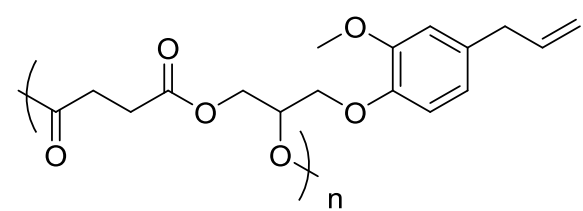

B<smiles>CCC(COc1ccc(C=O)cc1OC)OC(C)(C)C</smiles>

C

Figure 5: Several successfully generated bio-based resins. 
Step 1<smiles>O=C1OCC(CO)O1</smiles>

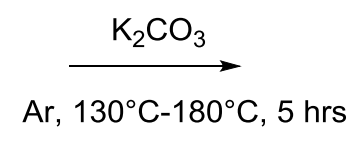<smiles>O=C([O-])C(O)COc1ccccc1</smiles>

Step 2

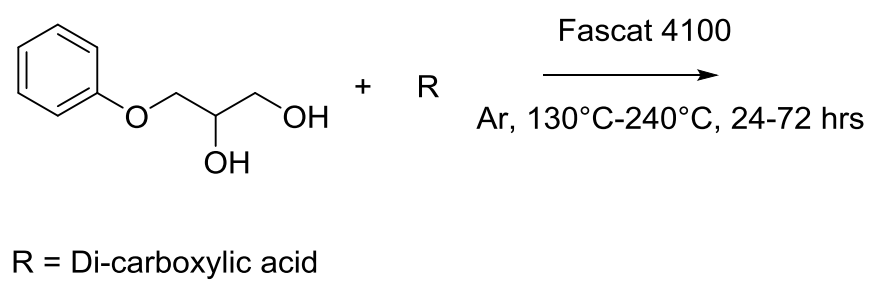<smiles></smiles>

Scheme 5: Overview of generating polyesters from phenols in this work.

\subsection{Results and Discussion}

\subsection{Modelling the $\beta$-O-4 Aryl Ether Linkage Found in Lignin}

\subsubsection{Overview of the Synthetic Strategy}

One of the initial scopes of research in this project was to hopefully attempt to breakdown lignin and utilize the resulting fragments to synthesize polyester resins suitable for toner production as well as for other consumable applications. The aryl ether $\beta-\mathrm{O}-4$ linkage in lignin by mass constitutes 45 - 50\% of all lignin fragments. An effort to synthesize a compound modelling this aryl ether linkage was undertaken (Scheme 6). It was assumed that during lignin digestion, phenolic fragments very similar to the model compound would be quite prevalent as resulting materials. Polymerizations involving these model compounds were to be carried out to assess the resulting materials and to see if suitable resins could be generated from lignin based materials. 


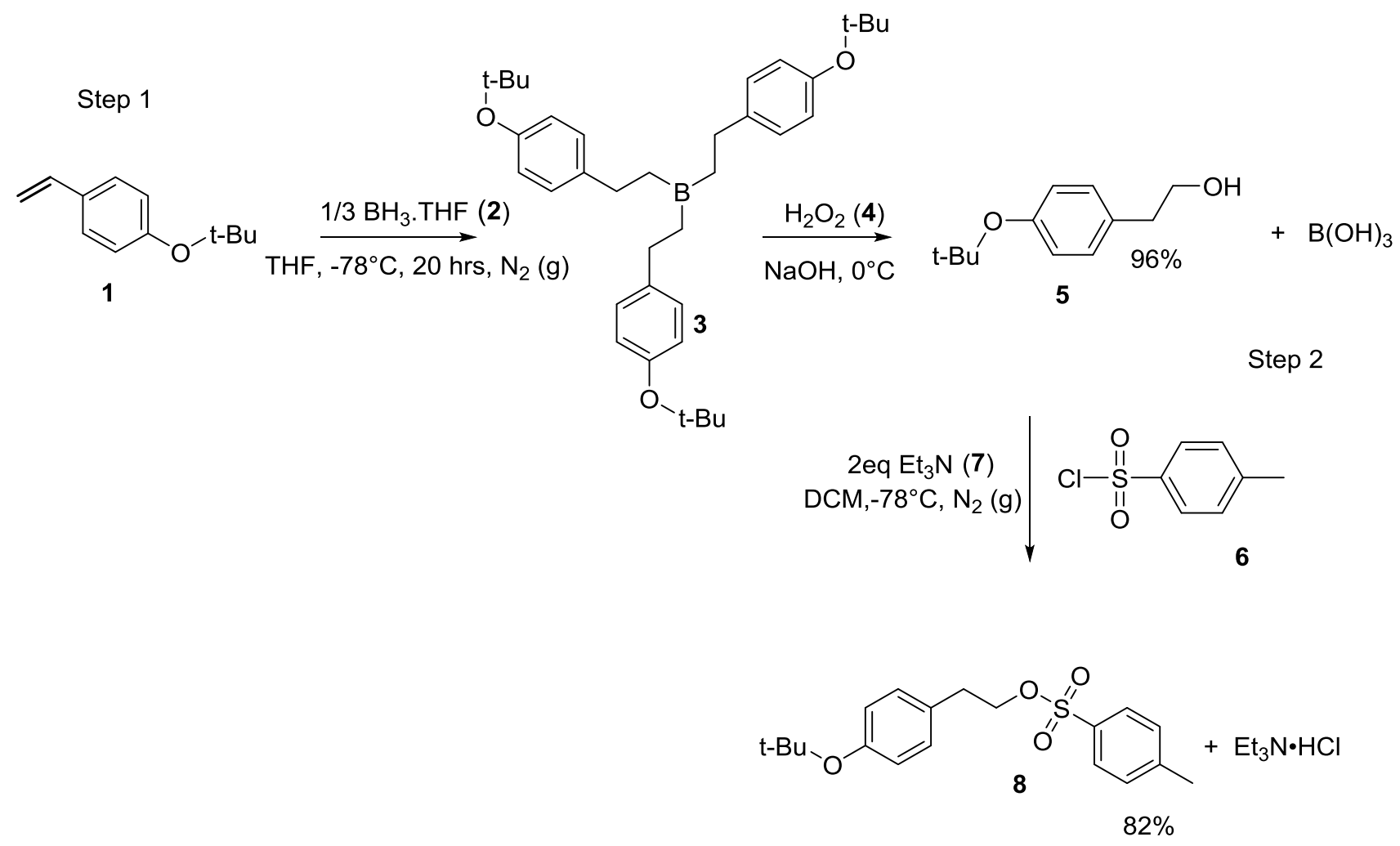

Step 3
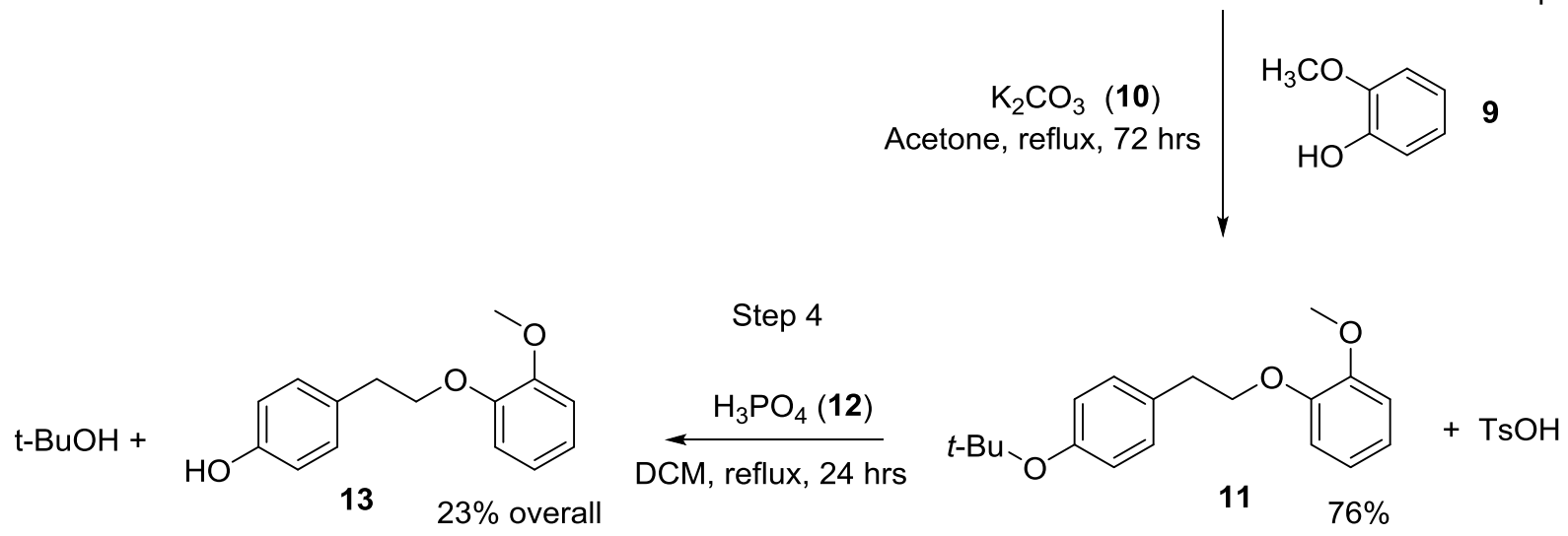

Scheme 6: Synthetic route to 13 .

This was done prior to lignin digestion experiments. If suitable polymeric materials could not be created with lignin based fragments, then proceeding with lignin digestion was not required. Although it is likely that other consumable materials could be produced from the resulting lignin fragments, this project was approached from a relatively specific industrial point 
of view. The use of lignin was aimed to be both a green and an inexpensive source of desirable phenolics for this process and as such, if resins with specific properties could not be manufactured from lignin sources, then industrially, this process is not plausible. All polymerizations were to be carried out on an industrial scale, requiring between $500-1000 \mathrm{~g}$ of material. As such, a cost effective and scalable synthetic route to $\mathbf{1 3}$ was developed.

The synthetic pathway to $\mathbf{1 3}$ was originally based on Nagy's approach (Scheme 7). ${ }^{11}$ Due to the relatively high cost of starting materials employed in his research, in particular the diol, as well as the considerable amount of $\mathbf{1 3}$ required for polymerizations, different starting materials were selected.<smiles>Cc1ccc(S(=O)(=O)OCCc2ccc(OS(=O)(=O)c3ccc(C)cc3)cc2)cc1</smiles><smiles>COc1ccccc1OCCc1ccc(OS(=O)(=O)c2ccc(C)cc2)cc1</smiles>

Scheme 7: Synthetic pathway to 13 developed by Nagy.

Beginning with the diol, the first step involved protecting both hydroxyl groups with a tosylate group. The next step involved the selective substitution of guaiacol onto the ethyl chain generating the ether and finally regenerating the hydroxyl to arrive at $\mathbf{1 3 .}$ 
In this work, 1-(tert-butoxy)-4-vinylbenzene, 1, was chosen as the starting material for two main reasons. First, the cost of this material is relatively low compared to the material used by Nagy. Second, the $t$-butyl group can already act as a protecting group on the phenolic hydroxyl which facilitated the conversion of the vinyl group to the desired ether linkage. In our hands, $\mathbf{1 3}$ was synthesized in four steps with an overall yield of $23 \%$.

\subsubsection{Synthesis of 2-(4-(tert-butoxy)phenyl)ethan-1-ol, $\mathbf{5}$}

The first step involved the hydroboration of $\mathbf{1}$, followed by the oxidation of the resulting intermediate, $\mathbf{3}$, in order to generate the aryl ether alcohol, $\mathbf{5}^{33}$ Compound $\mathbf{5}$ was isolated as a clear and colorless oil and confirmed using ${ }^{1} \mathrm{H}$ and ${ }^{13} \mathrm{C}$ NMR spectroscopy (Figures 6 and 7).

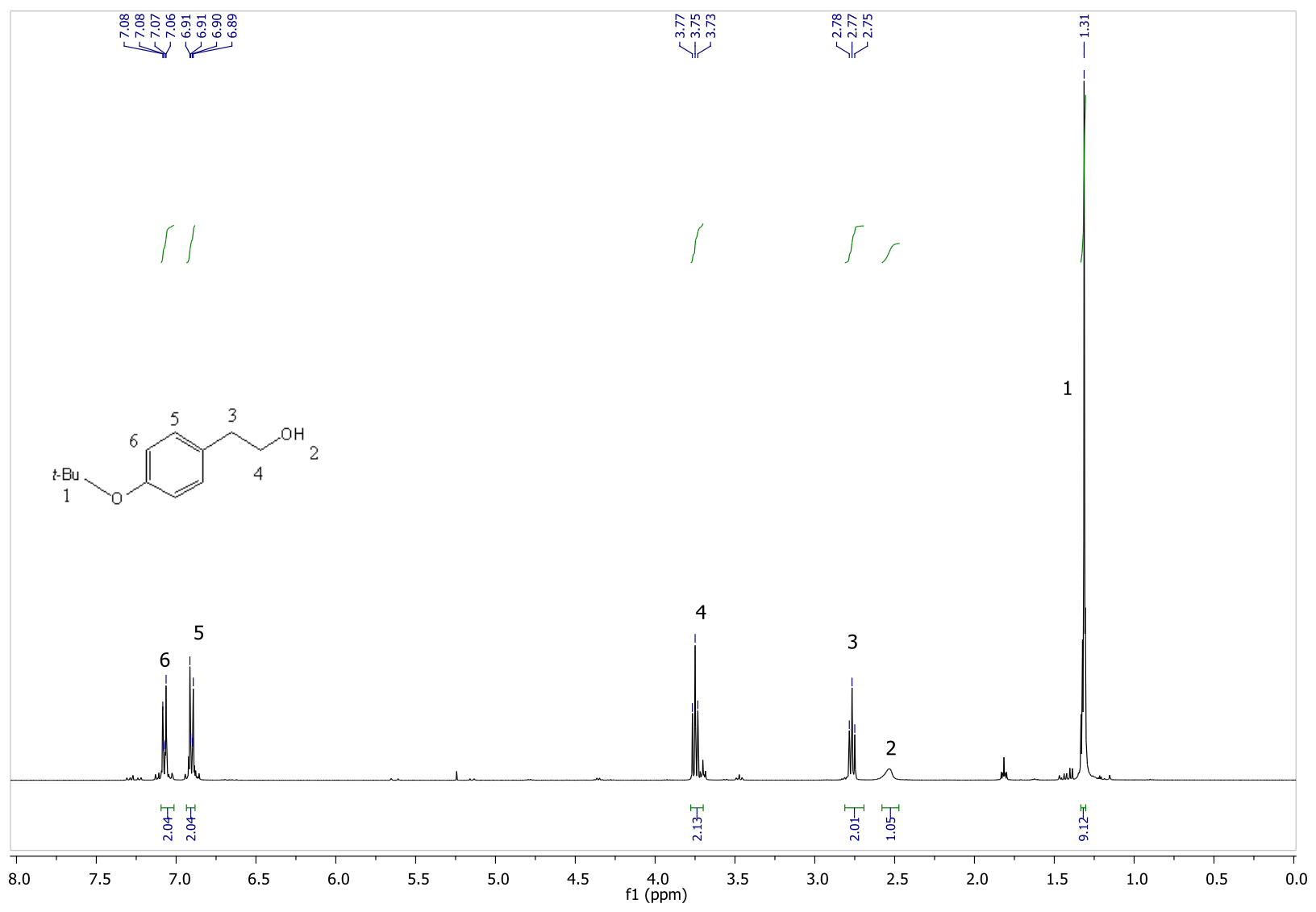

Figure 6: ${ }^{1} \mathrm{H} \mathrm{NMR}\left(\mathrm{CDCl}_{3}\right)$ spectrum of 5. 
The ${ }^{1} \mathrm{H}$ NMR spectrum of $\mathbf{5}$ shows a singlet resonance at $1.31 \mathrm{ppm}$ integrating for 9 protons which accounts for the $t$-butyl protons, H1. A small, broad resonance integrating for 1 proton is characteristic of the hydroxyl proton, H2. Two triplets observed at 2.77 and 3.75 ppm, each integrating for two protons with a ${ }^{3} J=6.8 \mathrm{~Hz}$ are characteristic resonances of the ethyl chain, H3 and H4. A pair of doublets observed in the aromatic region of the spectrum, integrating for two protons each with $\mathrm{a}^{3} J=8.6 \mathrm{~Hz}$ account for the four aromatic protons, H5 and H6. There is no indication that any starting material remains as the resonance signals associated with the vinyl protons of $\mathbf{1}$, which appeared in the $5.2-6.8 \mathrm{ppm}$ range, are no longer visible.

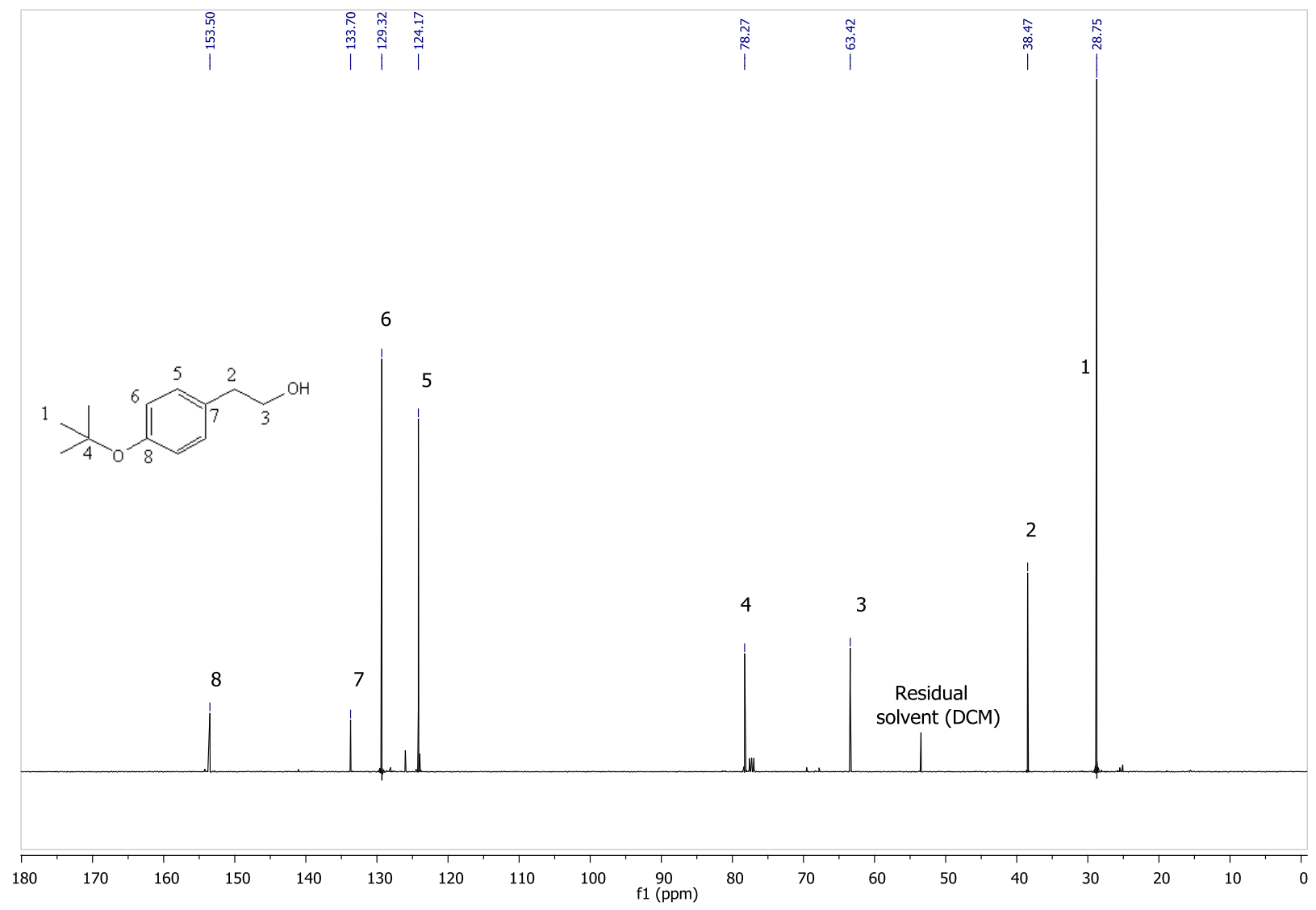

Figure 7: ${ }^{13} \mathrm{C} \mathrm{NMR}\left(\mathrm{CDCl}_{3}\right)$ spectrum of $\mathbf{5}$.

All expected ${ }^{13} \mathrm{C}$ NMR resonances for 5 were observed. The methyl groups associated with the $t$-butyl group, C1, were observed at $28.8 \mathrm{ppm}$. Resonances representing the ethyl chain, 
C2 and C3, were observed at 38.5 and $63.4 \mathrm{ppm}$, respectively. The resonance at $78.3 \mathrm{ppm}$ was assigned to the ipso carbon of the $t$-butyl group, C4. The four remaining resonances between 124.2 and 153.5 ppm are characteristic of a para substituted aromatic ring. Resonances at 124.2 and $129.3 \mathrm{ppm}$ account for two carbons each, C5 and C6. Resonances at 133.7 and 153.5 represent the ipso carbons of the aromatic ring, $\mathrm{C} 7$ and $\mathrm{C} 8$. .

\subsubsection{Synthesis of 4-(tert-butoxy)phenethyl 4-methylbenzene sulfonate, $\mathbf{8}$}

The next step involved the protection of $\mathbf{5}$ with $\mathbf{6}$ in the presence of $\mathbf{7}$ to afford (presumably) a better leaving group facilitating the addition of guaiacol, 9. ${ }^{34}$ The resulting product 8, was obtained as a yellow colored oil and confirmed using ${ }^{1} \mathrm{H}$ and ${ }^{13} \mathrm{C}$ NMR spectroscopy (Figure 8).

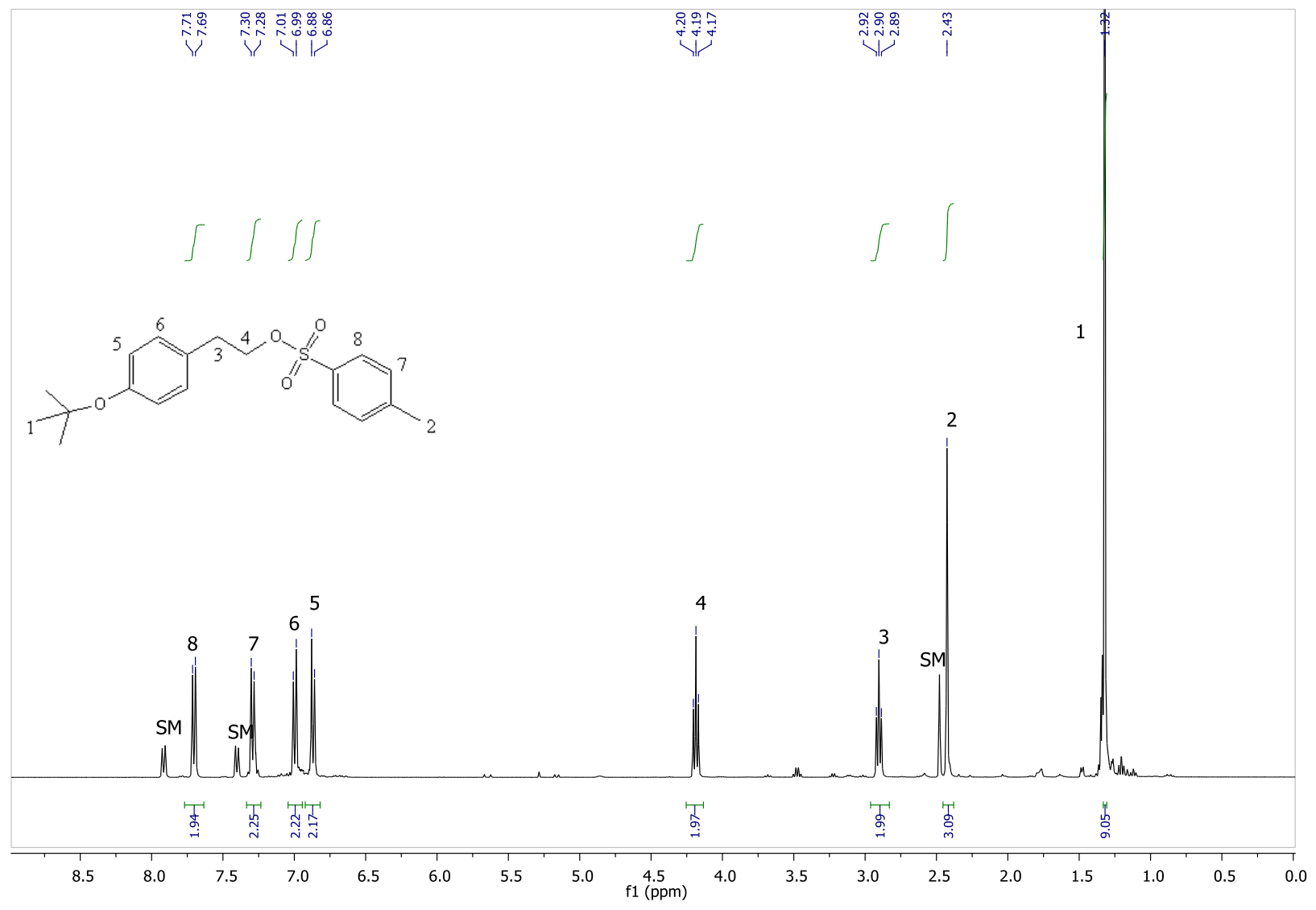

Figure 8: ${ }^{1} \mathrm{H} \mathrm{NMR}\left(\mathrm{CDCl}_{3}\right)$ spectrum of 8 . 
A strong singlet resonance at $1.32 \mathrm{ppm}$ integrating for nine protons is characteristic of the $t$-butyl group, H1. A second less intense singlet resonance at $2.43 \mathrm{ppm}$ integrating for 3 protons is indicative of the tosylate methyl group, H2. The two triplets at 2.90 and $4.19 \mathrm{ppm}$ integrating for two protons are assigned to the ethyl chain, H3 and H4. Two sets of doublets observed between 6.75 and $7.75 \mathrm{ppm}$ are characteristic of the two para substituted aromatic rings. Doublet resonances detected at 6.87 and $7.00 \mathrm{ppm}$ integrating for two protons with a ${ }^{3} \mathrm{~J}=6.8 \mathrm{~Hz}$ coupling associated with H5 and H6. Doublet resonances at 7.29 and $7.70 \mathrm{ppm}$ are characteristic of the aromatic tosylate protons, $\mathrm{H} 7$ and $\mathrm{H} 8$, with a coupling of ${ }^{3} J=7.9 \mathrm{~Hz}$. There is evidence of starting material $(\mathrm{SM})$ in the spectra. The expected by-product, $\mathrm{Et}_{3} \mathrm{~N} \cdot \mathrm{HCl}$, was observed as long colourless crystals and confirmed using ${ }^{1} \mathrm{H}$ NMR spectroscopy. There is evidence of residual starting material in the spectrum. Purification of $\mathbf{8}$ was attempted using recrystallization and distillation techniques, however all proved ineffective. Efforts to generate $\mathbf{1 1}$ directly through a Williamson ether synthesis involving $\mathbf{5}$ and $\mathbf{9}$ failed.

It was also observed that if the tosylate was added too rapidly to $\mathbf{5}$ or if the solution containing 5 was not cold enough, the reaction mixture would change from clear to brownish color. When assessed by ${ }^{1} \mathrm{H}$ NMR spectroscopy, the resulting brown liquid was nearly identical to the yellow liquid but also contained several additional minor resonances. In particular, a fourth set of doublets was observed which was attributed to the chlorinated by product instead of the desired tosylate as shown below (Scheme 8). This result was also previously reported by Ding et al. ${ }^{35}$ 
Step 1

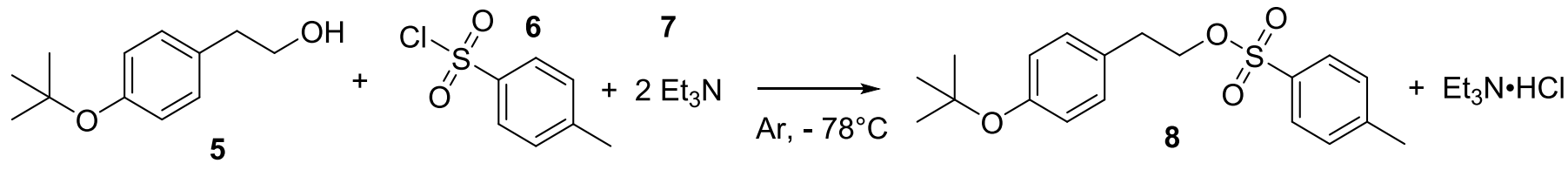

Step 2<smiles>Cc1ccc(S(=O)(=O)OCCc2ccc(OC(C)(C)C)cc2)cc1</smiles>

Scheme 8: Compound 8 undergoing transformation to the chlorinated by-product.

\subsubsection{Synthesis of 1-(4-(tert-butoxy)phenethoxy)-2-methoxybenzene, 11}

The synthesis of 11, a dark orange oil, was accomplished via substitution of the tosylate,

8, with guaiacol, 9. In the presence of $\mathrm{K}_{2} \mathrm{CO}_{3}, 9$ is deprotonated and nucleophilic attack of the $\alpha$ carbon relative to the tosyl species takes place generating the desired ether linkage. Compound 11 was characterized using both ${ }^{1} \mathrm{H}$ and ${ }^{13} \mathrm{C}$ NMR spectroscopy (Figure 9). ${ }^{11}$ 


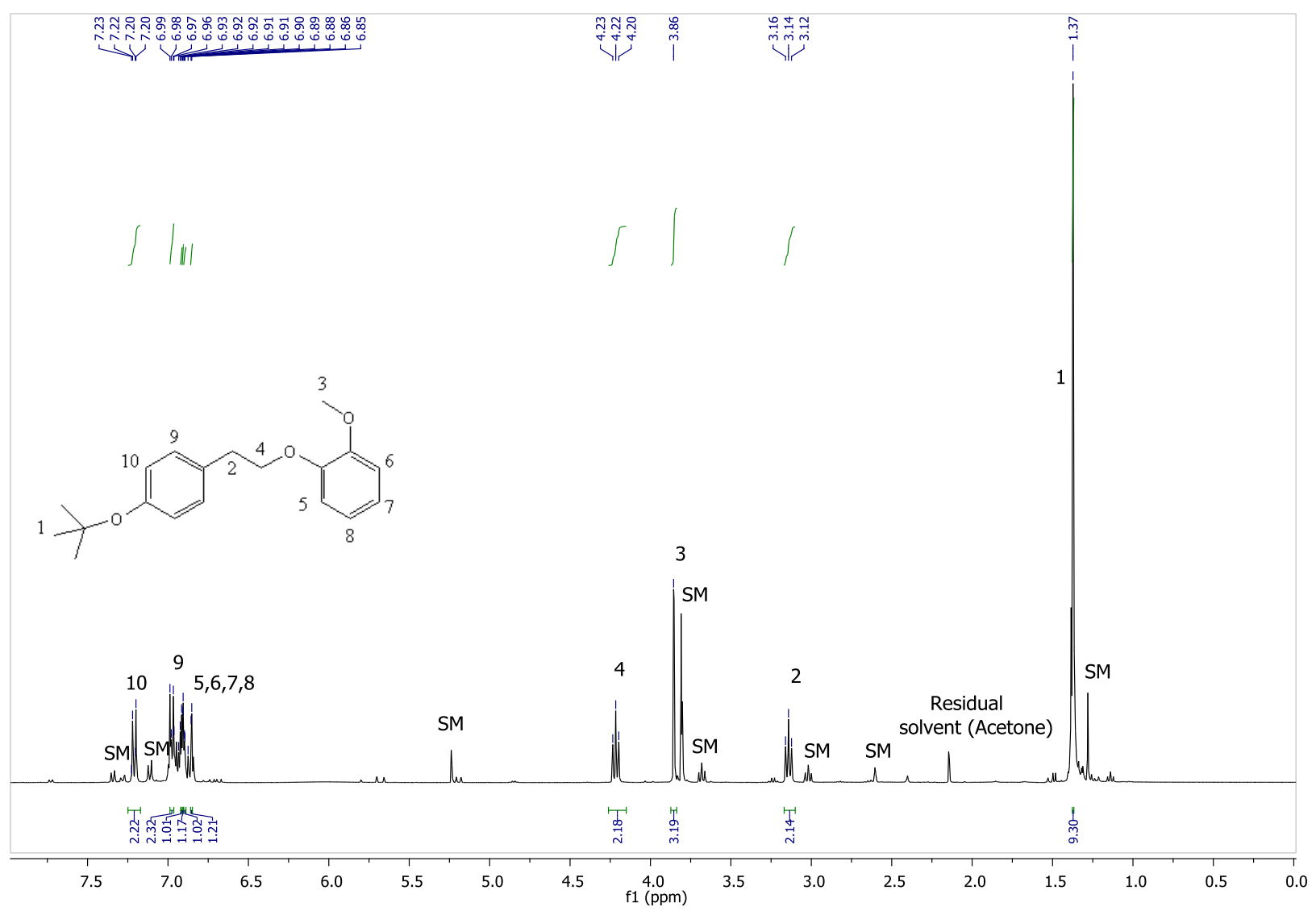

Figure 9: ${ }^{1} \mathrm{H} \mathrm{NMR}\left(\mathrm{CDCl}_{3}\right)$ spectrum of crude 11.

All expected ${ }^{1} \mathrm{H}$ NMR resonances for $\mathbf{1 1}$ were detected. A strong singlet resonance at $1.37 \mathrm{ppm}$ integrating for nine protons is characteristic of the $t$-butyl group, H1. Two sets of triplets at 3.14 and $4.22 \mathrm{ppm}$, each integrating for two protons with a coupling of ${ }^{3} \mathrm{~J}=7.5 \mathrm{~Hz}$, is characteristic of the ethyl protons, $\mathrm{H} 2$ and $\mathrm{H} 4$. A singlet resonance at $3.86 \mathrm{ppm}$ integrating for three protons is characteristic of methoxy group, H3. Eight protons detected between 6.75 and $7.5 \mathrm{ppm}$ reflect the aromatic components of 11. The multiplet resonance observed at $6.90 \mathrm{ppm}$, integrating for a total of 4 protons is the result of ortho substituted aromatic species. H5 - H8. A set of doublet resonances at 6.97 and $7.21 \mathrm{ppm}$, integrating for two protons each with a ${ }^{3} J=1.3$ $\mathrm{Hz}$ are due to the para substituted aromatic component. According to the ${ }^{1} \mathrm{H}$ NMR spectrum, there is evidence of starting materials, $\mathbf{8}$ and $\mathbf{9}$ still present in the resulting material. Purification 
attempts including distillation and acid-base extractions were unsuccessful. As such, the resulting material which contained $\mathbf{1 1 , 9}$ and $\mathbf{8}$ in an approximately 9:1:1 respective ratio, was used to generate $\mathbf{1 3}$.

\subsubsection{Synthesis of 4-[2-(2-methoxyphenoxy)ethyl] phenol, $\mathbf{1 3}$}

The hydroxyl group of $\mathbf{1 3}$ was regenerated using phosphoric acid (Scheme 2). ${ }^{36}$ Purification was accomplished using column chromatography with a 3:1 ratio of ethyl acetate and hexanes respectively. For the scaled up procedures, $\mathbf{1 3}$ was purified using an acid - base extraction using $\mathrm{NaOH}$ followed by diluted $\mathrm{HCl}$. This reaction was also successfully performed using trifluoroacetic acid (TFA) with similar yields, but due to the higher cost of TFA, phosphoric acid was used in scaled up procedures. Compound $\mathbf{1 3}$ was isolated as a white crystalline material. Both ${ }^{1} \mathrm{H}$ and ${ }^{13} \mathrm{C}$ NMR spectra are presented (Figures 10 and 11). 


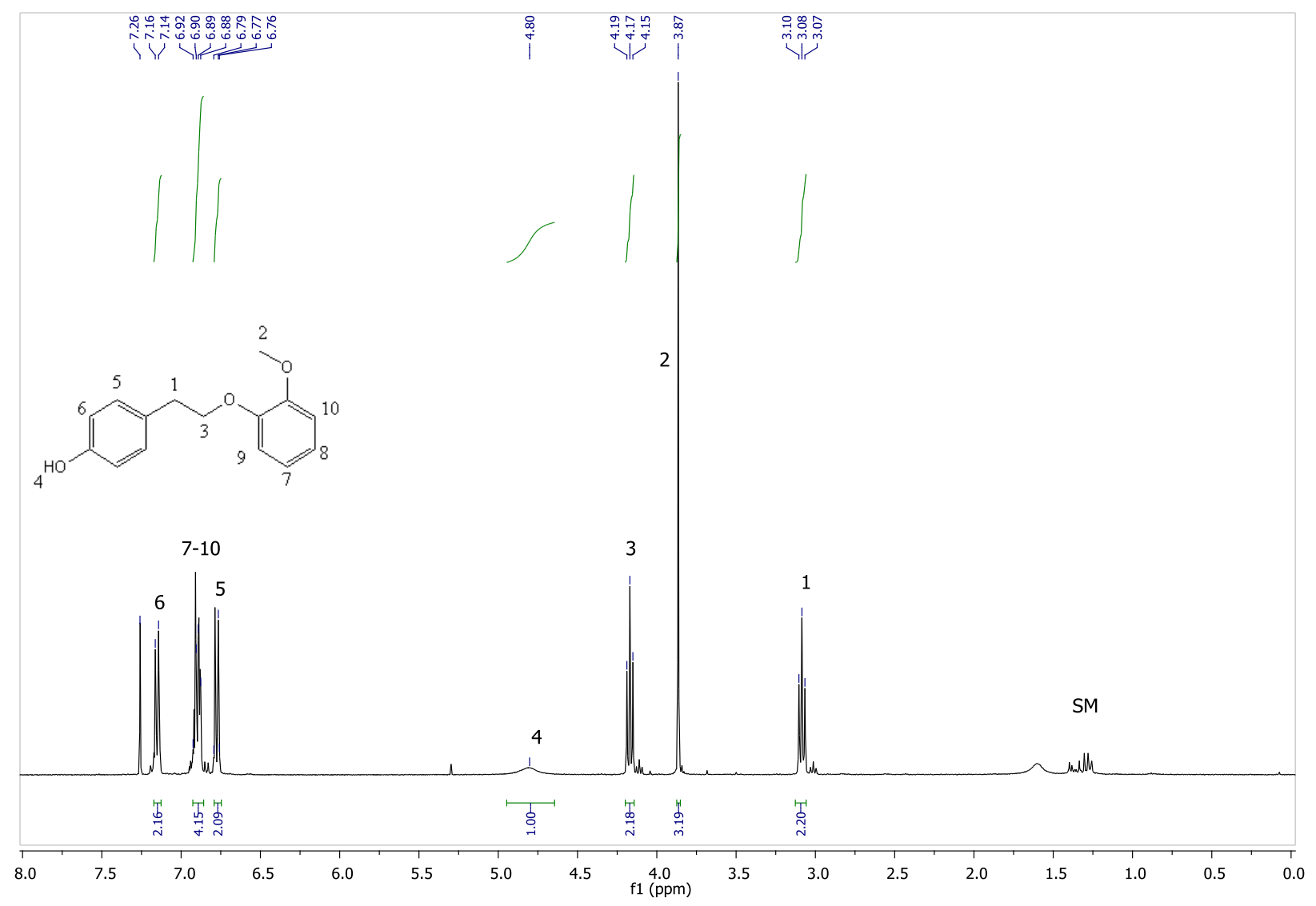

Figure 10: ${ }^{1} \mathrm{H} \mathrm{NMR}\left(\mathrm{CDCl}_{3}\right)$ spectrum of 13.

All expected resonances for $\mathbf{1 3}$ were observed. A set of triplet resonances at 3.08 and $4.17 \mathrm{ppm}$, each integrating for two protons with a coupling of ${ }^{3} J=7.6 \mathrm{~Hz}$ represent the ethyl protons, $\mathrm{H} 1$ and $\mathrm{H} 3$. A strong singlet resonance at $3.87 \mathrm{ppm}$ integrating for three protons is characteristic of the methoxy group, H2. A weak and broad resonance observed at $4.80 \mathrm{ppm}$ integrating for one proton is characteristic of the hydroxyl proton, H4. A set of doublet resonances at 6.78 and $7.14 \mathrm{ppm}$, each integrating for two protons, with a ${ }^{3} J=8.3 \mathrm{~Hz}$ coupling representing the aromatic protons of the para substituted aromatic group, H5 and H6. A multiplet resonance at $6.90 \mathrm{ppm}$ integrating for 4 protons is characteristic of the ortho substituted aromatic species, H7 - H10. Several minor resonances characteristic of residual $\mathbf{1 1}$ were also detected. 


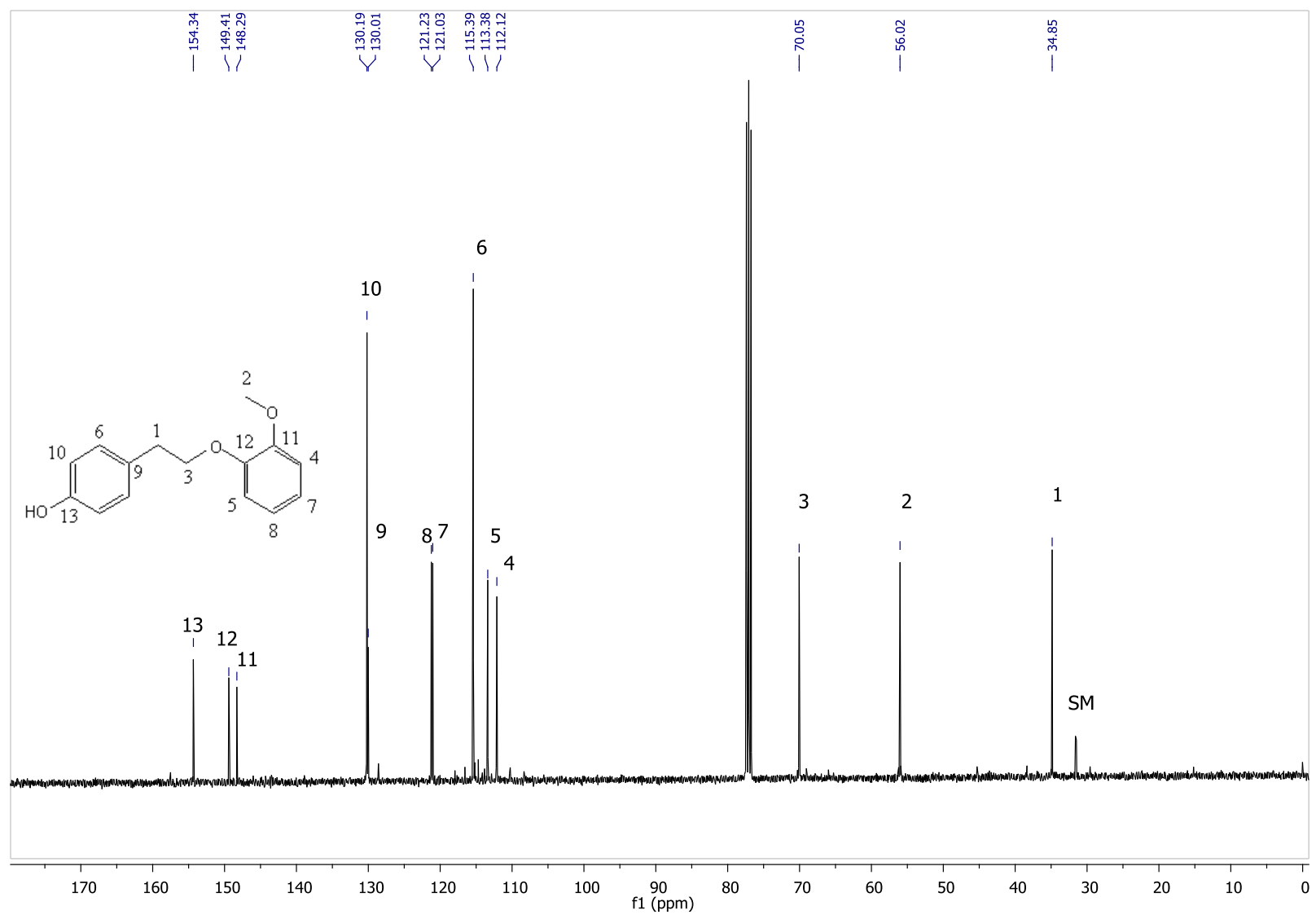

Figure 11: ${ }^{13} \mathrm{C} \mathrm{NMR}\left(\mathrm{CDCl}_{3}\right)$ spectrum of 13.

All expected ${ }^{13} \mathrm{C}$ NMR resonance signals of $\mathbf{1 3}$ were detected. Resonances at 34.9 and $70.1 \mathrm{ppm}$ are characteristic of the aliphatic ethyl carbons, $\mathrm{C} 1$ and $\mathrm{C} 3$. The methoxy carbon, C2, was observed at $56.0 \mathrm{ppm}$. All ten aromatic carbon signals were observed between $130-160$ ppm, C4 - C13. Although there are twelve aromatic carbons, one of the six membered aromatic rings is para substituted and as such, only two resonances were detected for the ortho and meta carbons, C6 and C10. Similar to the ${ }^{1} \mathrm{H}$ NMR spectrum of 13, several minor resonances attributed to 11 were also detected.

Time of flight, high resolution mass spectrometry, detected signals at $241.1 \mathrm{~m} / \mathrm{z}$ and $262.1 \mathrm{~m} / \mathrm{z}$ represent $\mathbf{1 3}$ as the $\left[\mathrm{M}^{+}\right]$and $\left[\mathrm{M}^{+}+\mathrm{NH}_{4}\right]$ respectively. A minor signal at $297.2 \mathrm{~m} / \mathrm{z}$ is characteristic of $11\left[\mathrm{M}^{+}\right]$. A melting point of $83.76^{\circ} \mathrm{C}$ for $\mathbf{1 3}$ was determined using DSC. 


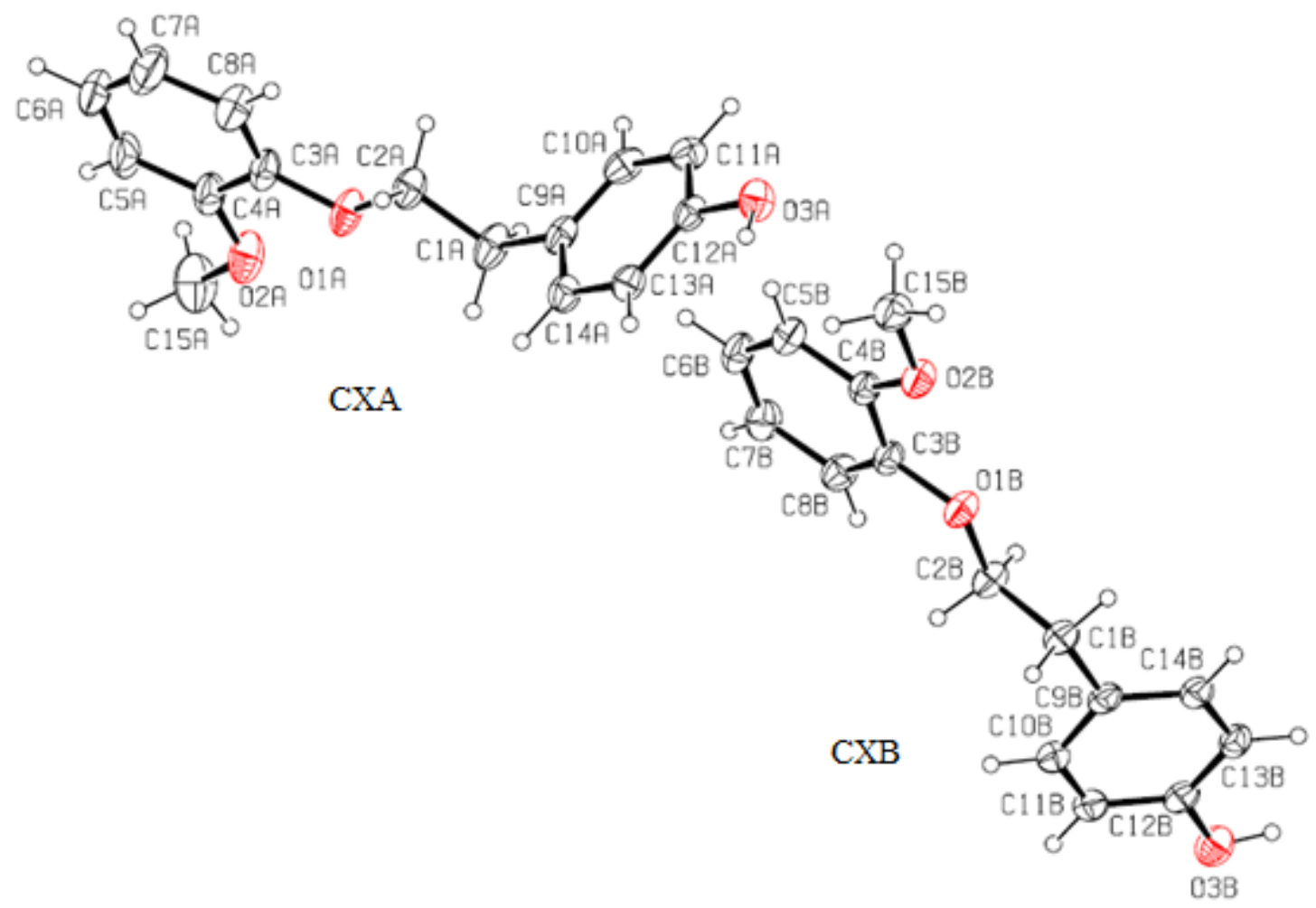

Figure 12: ORTEP representation of the unit cell components of $\mathbf{1 3 .}$

Crystals of $\mathbf{1 3}$ were grown from a solution in a DCM/hexane mixture. Crude $\mathbf{1 3}$ was dissolved in DCM and an equal layer of hexanes were slowly added on top. The layered solution was then left to slowly evaporate at room temperature resulting in crystals suitable for $\mathrm{x}$-ray crystallography. In the unit cell of $\mathbf{1 3}$ there are two independent molecules with slightly different molecular conformations (Figure 12). The major difference is the orientation of the para substituted aromatic component of $\mathbf{1 3}$. With respect $\mathrm{CXB}$, all the components of $\mathbf{1 3}$ and in particular $\mathrm{C} 9 \mathrm{~B}-\mathrm{C} 14 \mathrm{~B}$ are all relatively within the plane. With respect to CXA, the bond of the para substituted component is rotated approximately $90^{\circ}$ (Figure 13). 


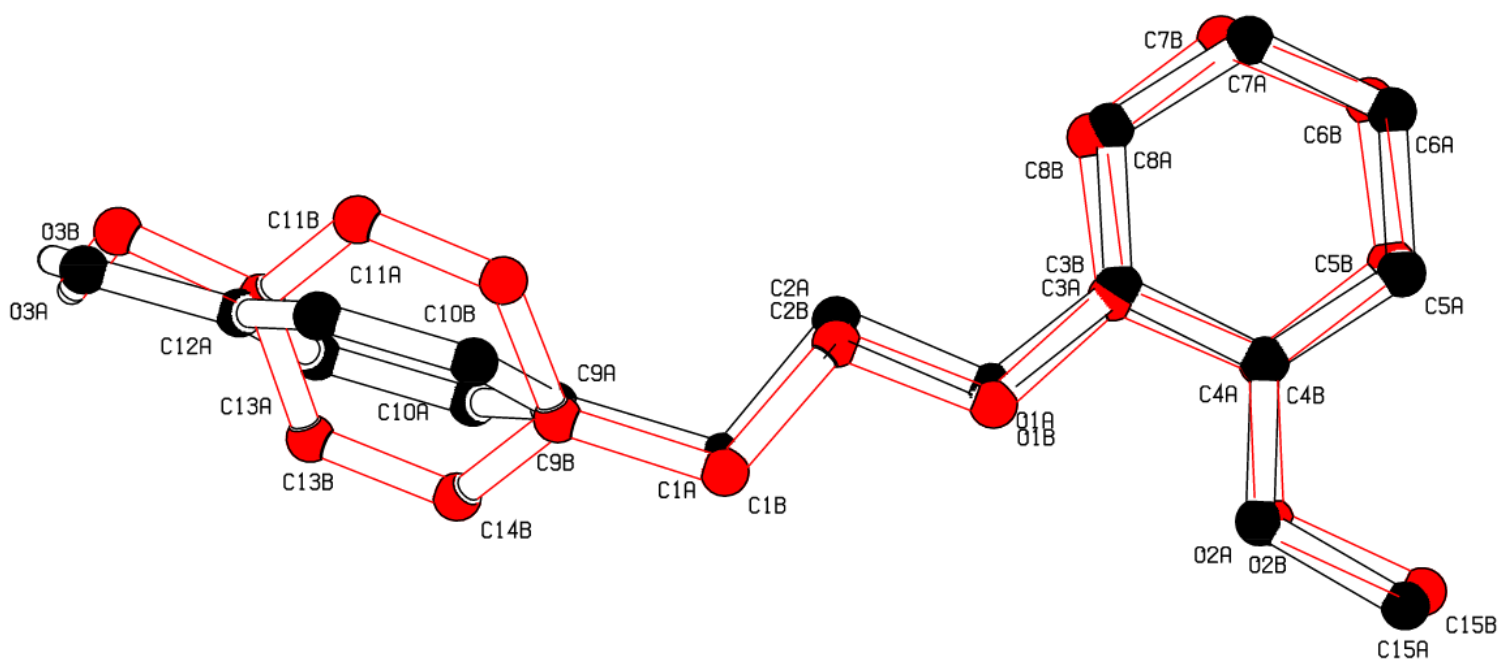

Figure 13: PLATON representation of the unit cell components of 13 with CXA and CXB models overlapped

The bond lengths and angles of both structures are quite similar. Other than the rotated aromatic component and small variations of bond angles and bond distances, CXB and CXA are relatively the same (Table 1).

\begin{tabular}{|c|c|c|c|}
\hline Bond & Length $[\AA]$ & Bond & Angle $\left.{ }^{\circ}\right]$ \\
\hline $\mathrm{O}(3 \mathrm{~A})-\mathrm{C}(12 \mathrm{~A})$ & $1.3714(17)$ & $\mathrm{O}(3 \mathrm{~A})-\mathrm{C}(12 \mathrm{~A})-\mathrm{C}(13 \mathrm{~A})$ & $122.57(13)$ \\
\hline $\mathrm{O}(1 \mathrm{~A})-\mathrm{C}(3 \mathrm{~A})$ & $1.3699(18)$ & $\mathrm{C}(3 \mathrm{~A})-\mathrm{C}(8 \mathrm{~A})-\mathrm{C}(7 \mathrm{~A})$ & $119.1(2)$ \\
\hline $\mathrm{O}(1 \mathrm{~A})-\mathrm{C}(2 \mathrm{~A})$ & $1.4396(18)$ & $\mathrm{O}(1 \mathrm{~A})-\mathrm{C}(3 \mathrm{~A})-\mathrm{C}(8 \mathrm{~A})$ & $125.51(15)$ \\
\hline $\mathrm{O}(2 \mathrm{~A})-\mathrm{C}(15 \mathrm{~A})$ & $1.430(2)$ & $\mathrm{O}(3 \mathrm{~A})-\mathrm{C}(12 \mathrm{~A})-\mathrm{C}(11 \mathrm{~A})$ & $117.27(14)$ \\
\hline $\mathrm{C}(3 \mathrm{~A})-\mathrm{C}(4 \mathrm{~A})$ & $1.396(2)$ & $\mathrm{O}(1 \mathrm{~A})-\mathrm{C}(2 \mathrm{~A})-\mathrm{C}(1 \mathrm{~A})$ & $106.29(13)$ \\
\hline $\mathrm{C}(6 \mathrm{~A})-\mathrm{C}(7 \mathrm{~A})$ & $1.356(3)$ & $\mathrm{C}(12 \mathrm{~A})-\mathrm{O}(3 \mathrm{~A})-\mathrm{H}(3 \mathrm{OA})$ & $108.6(16)$ \\
\hline
\end{tabular}

Table 1: Selected bond lengths $[\AA]$ and bond angles $\left[{ }^{\circ}\right]$ for $\mathbf{1 3}$.

Based on the ${ }^{1} \mathrm{H},{ }^{13} \mathrm{C}$ NMR and mass spectrometry, it appears that compound $\mathbf{1 1}$ is still present in crude $\mathbf{1 3}$ as an impurity after the acid - base extraction. The extraction was not completely effective in separating the hydroxyl bearing compounds from the rest of the material 
present in the crude. It is therefore assumed that a small fraction of $\mathbf{1 1}$ prevailed through the various phase extractions. This does not cause concern as the amount of $\mathbf{1 1}$ present is minimal $(<1 \%)$ and that the following reaction, where $\mathbf{1 3}$ is converted into a diol, is performed under basic conditions. This reaction should not affect the $t$-butyl group, leaving $\mathbf{1 1}$ relatively inert. Purification processes which were used to purify diols in later experiments were able to fully remove $\mathbf{1 1}$ prior to polymerization efforts.

The overall procedure was scaled up in efforts to produce $500 \mathrm{~g}$ of $\mathbf{1 3}$. Unfortunately after large scale reactions were completed, only $150 \mathrm{~g}$ of $\mathbf{1 3}$ was recovered. To carry out industrial size polymerizations with $\mathbf{1 3}$, more than $500 \mathrm{~g}$ was required. Instead of synthesizing more 13, the challenge of synthesizing a second, more accurate model of the aryl ether $\beta-\mathrm{O}-4$ linkage was undertaken.

\subsection{Preparation of a Second Compound Modelling the Aryl Ether $\beta$-O-4 Linkage}

2.2.1 Attempted Synthesis of 3-(2-methoxy-4-(2-(2-methoxyphenoxy)propyl)phenoxy)propane$\underline{1,2 \text {-diol } 18}$

The synthesis of a second compound modelling the $\beta-\mathrm{O}-4$ linkage was attempted using eugenol, 14, and 9 through a Markovnikov reaction. It was predicted that a protecting group would be required to suppress the reactivity of the hydroxyl group of $\mathbf{1 4}$. The idea of protecting and then deprotecting the hydroxyl of $\mathbf{1 4}$ was considered however this presented the fact that two additional steps in the synthetic route may have been required. The idea of synthesizing $\mathbf{1 6}$ and using the diol component as a protecting group was attempted in efforts to generate $\mathbf{1 8}$ in a two step process (Scheme 9). Compound 16 was successfully synthesized; (Section 2.3.2.1)

however, the reaction to transform $\mathbf{1 6}$ into $\mathbf{1 8}$ was not successful. According to ${ }^{1} \mathrm{H}$ NMR 
spectroscopy, no predicted resonances of $\mathbf{1 8}$ were observed. Compound $\mathbf{1 6}$ will be fully characterized in Section 2.3.
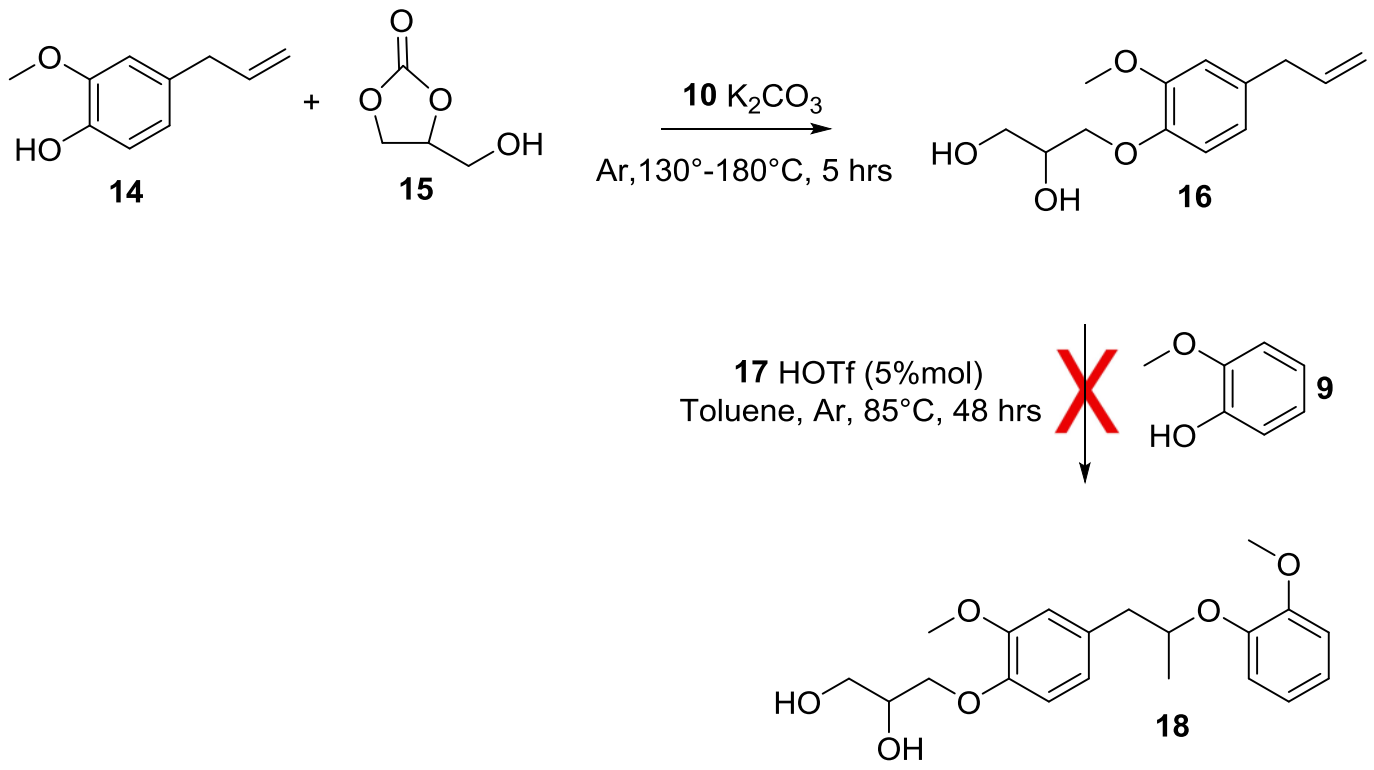

Scheme 9: Attempted synthesis of $\mathbf{1 8 .}$

\subsubsection{Evaluation of the Markovnikov Reaction}

The Markovnikov addition of a phenol across a double reported by Li et al. was based on software simulations and was not physically carried out in a laboratory setting. ${ }^{37}$ Additionally, only para substituted compounds were reported in his work. Since the Markovnikov reaction in Scheme 18 was not successful, the feasibility of this reaction was assessed. An evaluation of the reaction was carried out involving cyclohexene, 19, and both ortho and para substituted compounds, 9 and $\mathbf{2 0}$ (Scheme 11). In respective reaction vessels, the reactions were left to stir at room temperature over 3 days. Monitoring the reaction by TLC, no reaction was observed. The materials were then heated to $65^{\circ} \mathrm{C}$ over a 2 day period and still no reaction was observed. The temperature was then increased to $75^{\circ} \mathrm{C}$ and after a 2 day period, a new but faint TLC spot was observed in both cases. The reaction was redone with the temperature set to $85^{\circ} \mathrm{C}$ and 
allowed to run for 2 days, after which the spots had become much more pronounced. Based on this result, it is believed that a reaction had occurred for both the meta and para substituted compounds. NMR spectroscopy was not performed to confirm that either $\mathbf{2 1}$ or $\mathbf{2 2}$ had formed.<smiles>C1=CCCCC1</smiles>

19<smiles>COc1ccccc1O</smiles>

20

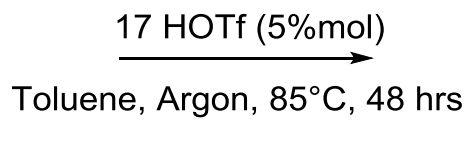

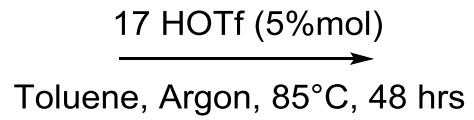
Toluene, Argon, $85^{\circ} \mathrm{C}, 48 \mathrm{hrs}$<smiles>COc1ccc(OC2CCCCC2)cc1</smiles><smiles>COc1ccccc1OC1CCCCC1</smiles>

22

Scheme 10: Evaluation of the Markovnikov addition reported by Li et al. ${ }^{38}$

2.2.3 Overview of the Synthetic Strategy to Synthesize 2-methoxy-4-(2-(2-methoxyphenoxy) propyl) phenol, 25

The reaction between 19 and the two phenols suggested that the Markovnikov reaction using 9 would work; which it did (Scheme 11). By protecting with chlorotrimethyl silane, (23), compound $\mathbf{2 4}$ was generated which in turn was successfully employed the Markovnikov addition to generate $\mathbf{2 5}$. 

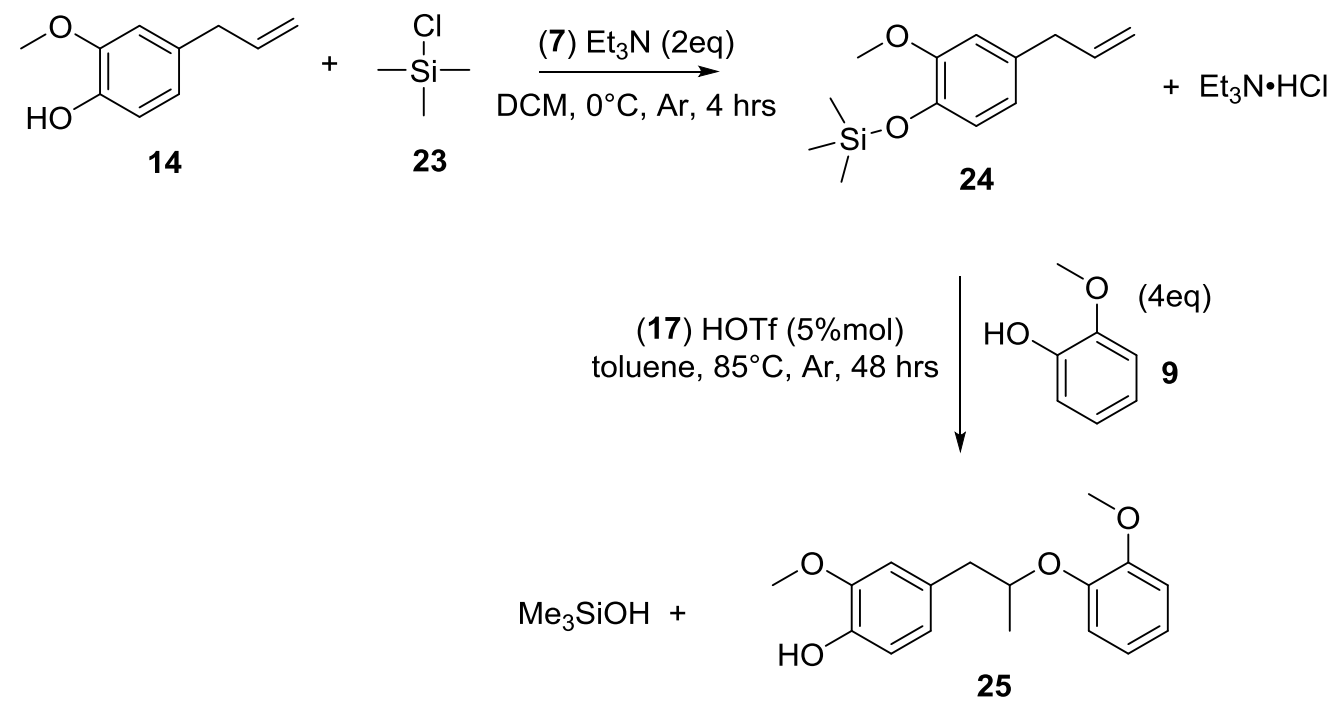

Scheme 11: Synthetic route to 25.

Ideally, 25 would have been synthesized through a Markovnikov reaction involving $\mathbf{1 4}$ and 9 in the presence of an acid; however this proved to be unsuccessful (Scheme 12).

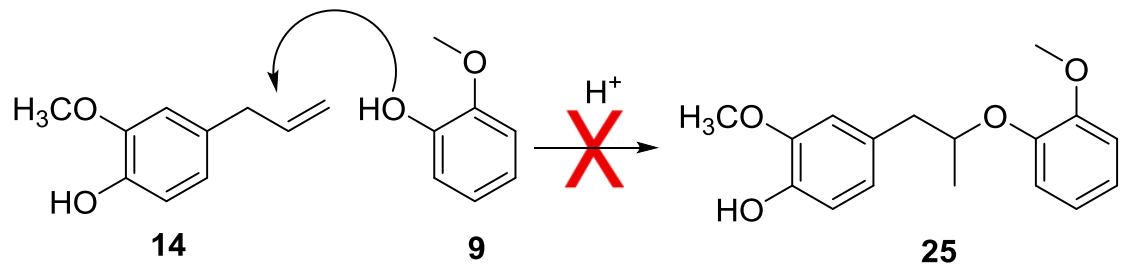

Scheme 12: Unsuccessful Markovnikov addition of 14 with 9 under acidic conditions.

After attempting the reaction displayed in Scheme 12 and the reaction involving 16 and 9, other protecting groups were examined.

The hydroxyl group of $\mathbf{1 4}$ was protected with $\mathbf{2 3}$ to generate $\mathbf{2 4}$. The Markovnikov addition involving $\mathbf{2 4}$ and $\mathbf{9}$ was carried out which in turn successfully generated compound $\mathbf{2 5}$, albeit in a low yield (8\%), in a two step process. 
2.2.4 Synthesis of (4-allyl-2-methoxyphenoxy)trimethylsilane, $\mathbf{2 4}$

The use of $\mathbf{2 3}$ as an appropriate protecting group was questioned as the Markovnikov addition requires the use of a strong acid. Strong acids, as previously observed, are capable of cleaving protecting groups and most available protecting groups are susceptible to such acids. As such, the idea that $\mathbf{2 3}$ would be cleaved during the synthesis of $\mathbf{2 5}$ resulting in unwanted byproducts was a possibility. One advantage of using $\mathbf{2 3}$ was that, unlike the tosyl protecting group, residual $\mathbf{2 3}$ is quite volatile and thus easily removed during solvent removal. Compound 24 was isolated as a yellow liquid and characterized using ${ }^{1} \mathrm{H},{ }^{13} \mathrm{C}$ and ${ }^{29} \mathrm{Si}$ NMR spectroscopy (Figures 14, 15 and 16).

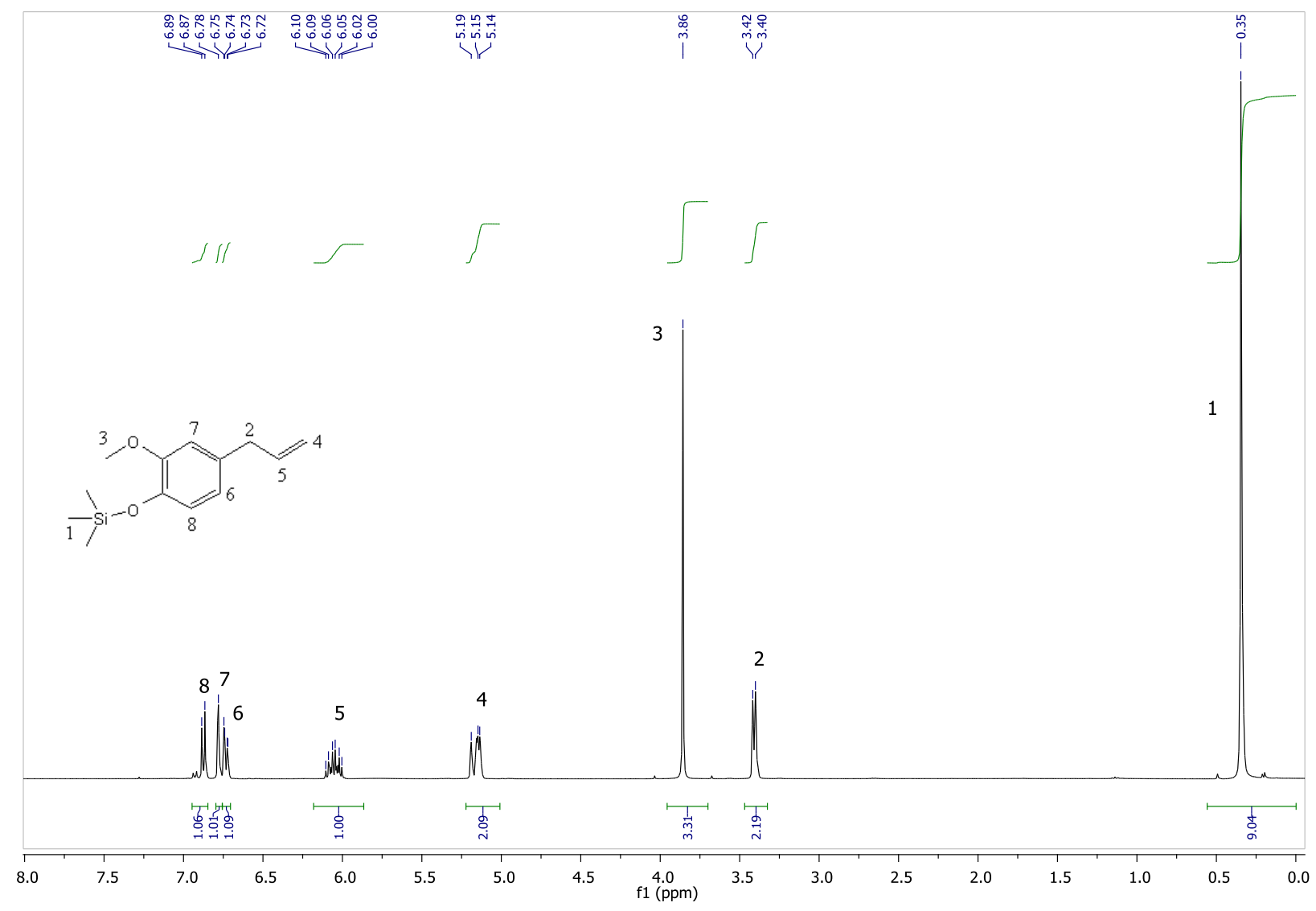

Figure 14: ${ }^{1} \mathrm{H}$ NMR $\left(\mathrm{CDCl}_{3}\right)$ spectrum of 24. 
All expected ${ }^{1} \mathrm{H}$ NMR resonances for $\mathbf{2 4}$ were observed. A singlet resonance at $0.35 \mathrm{ppm}$ integrating for nine protons is characteristic of the methyl protons of the silyl group, H1. A doublet resonance at $3.41 \mathrm{ppm}$ integrating for two protons represents the protons of the $\mathrm{CH}_{2}$ group, H2. A singlet resonance at $3.86 \mathrm{ppm}$ integrating for three protons is characteristic of the methoxy group, H3. Multiplets at 5.15 and $6.05 \mathrm{ppm}$, integrating for two and one protons respectively, are characteristic of the protons associated with terminal double bond, H4 and H5. Three aromatic protons were detected between $6.70-6.90 \mathrm{ppm}$. A pair of doublet resonances, each integrating for a proton with a ${ }^{3} J=8.2 \mathrm{~Hz}$ coupling represent $\mathrm{H} 6$ and $\mathrm{H} 8$. A singlet resonance at $6.78 \mathrm{ppm}$ integrating for one proton was assigned to $\mathrm{H} 7$.

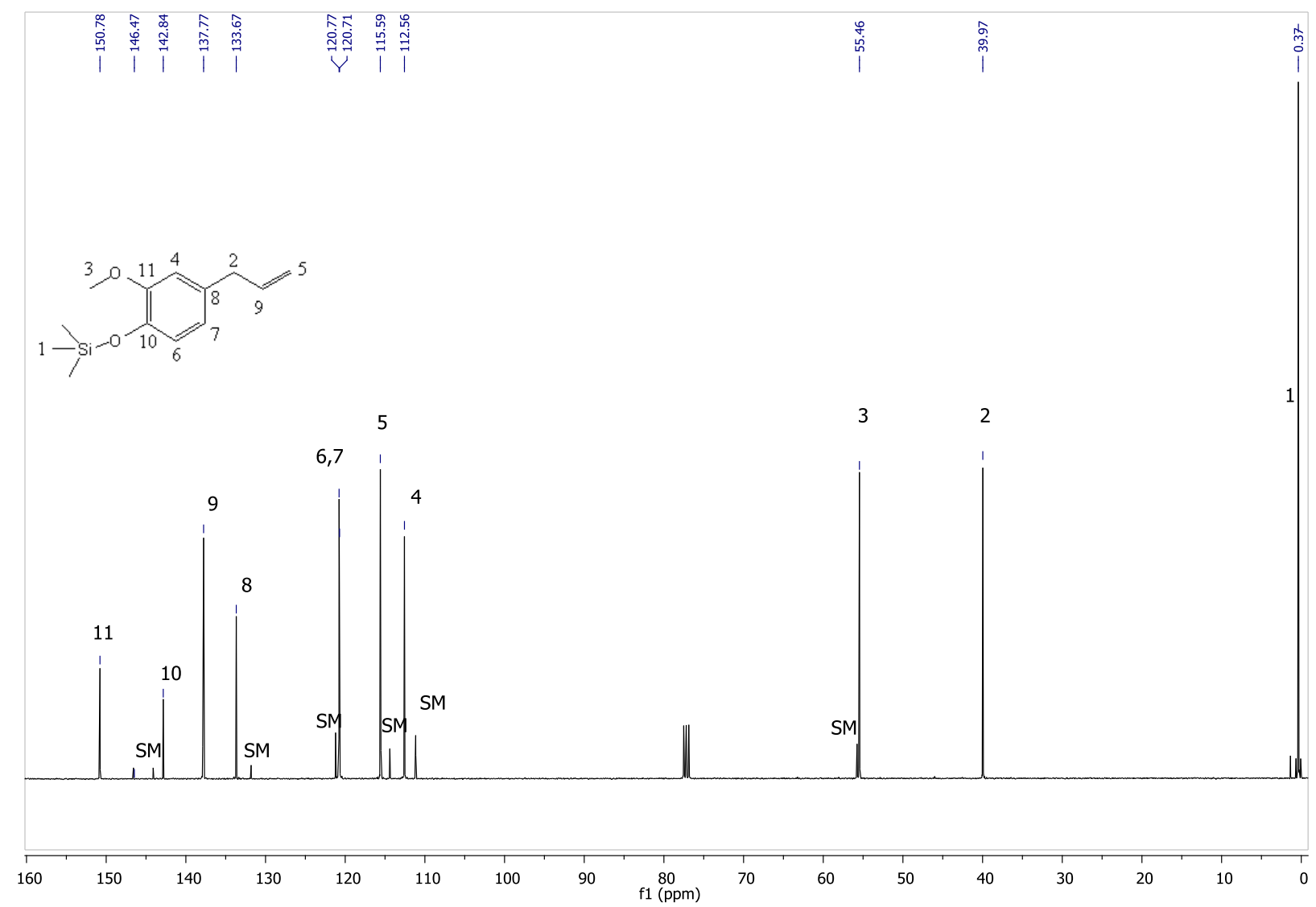

Figure 15: ${ }^{13} \mathrm{C} \mathrm{NMR}\left(\mathrm{CDCl}_{3}\right)$ spectrum of 24. 
All expected ${ }^{13} \mathrm{C}$ NMR resonances for 24 were observed. A strong resonance at -0.37 ppm is characteristic of protecting group carbon atoms, C1. The methoxy carbon, C3, is detected at $55.5 \mathrm{ppm}$. Resonances observed at 40.0, 115.6 and $137.8 \mathrm{ppm}$ represent the allyl chain, C2, C5 and C9 respectively. The six aromatic carbons, C4, C6 - C8, C10 and C11 are all observed between 110 - $155 \mathrm{ppm}$. There are sev6eral minor resonances visible throughout the spectrum which are characteristic of starting material, in particular 14.

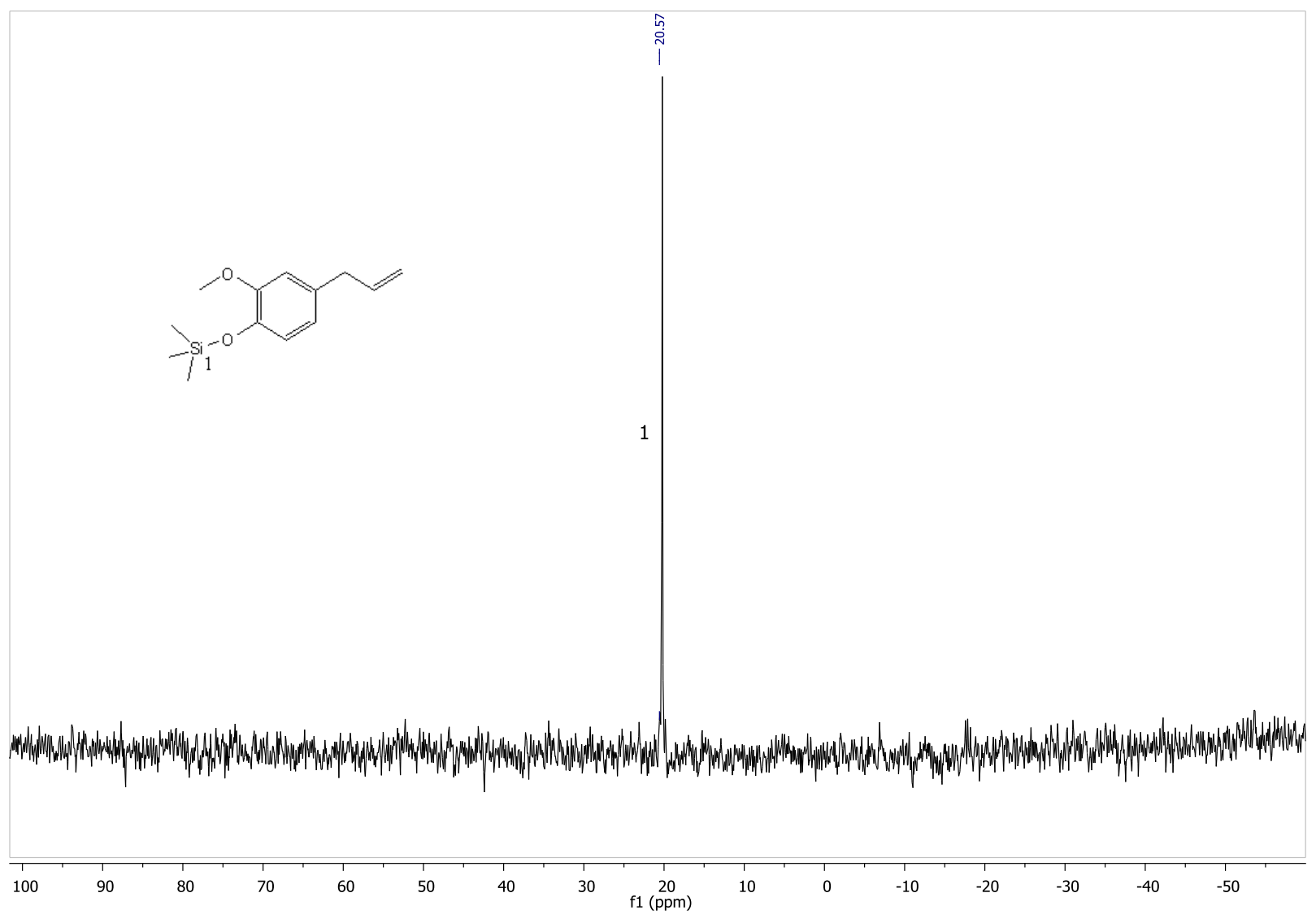

Figure 16: ${ }^{29} \mathrm{Si} \mathrm{NMR}\left(\mathrm{CDCl}_{3}\right)$ spectrum of 23.

The presence of the silyl protecting group was confirmed using ${ }^{29} \mathrm{Si}$ NMR spectroscopy as the only silicon resonance, as expected, was observed at $\delta=20.6 \mathrm{ppm}$. $^{38}$ 


\section{$\underline{2.2 .5 \text { Synthesis of Compound } \mathbf{2 5}}$}

Compound 25 was synthesized employing a Markovnikov addition involving 9 and 24. Compound 9, according to $\mathrm{Li}$ et al., was to be added in excess which made later product purification much more difficult. Upon completion of the reaction and work up, the isolated materials were identified as a mixture of $\mathbf{9}, \mathbf{1 4}$ and $\mathbf{2 5}$ along with unidentified impurities. Compound 25 was separated from the remaining compounds using column chromatography and was isolated as a yellow solid. Characterization was accomplished using ${ }^{1} \mathrm{H}$ and ${ }^{13} \mathrm{C}$ NMR spectroscopy (Figures 17 and 18) and mass spectrometry. Recrystallization techniques were also attempted, but did not result in improved purity of $\mathbf{2 5}$.

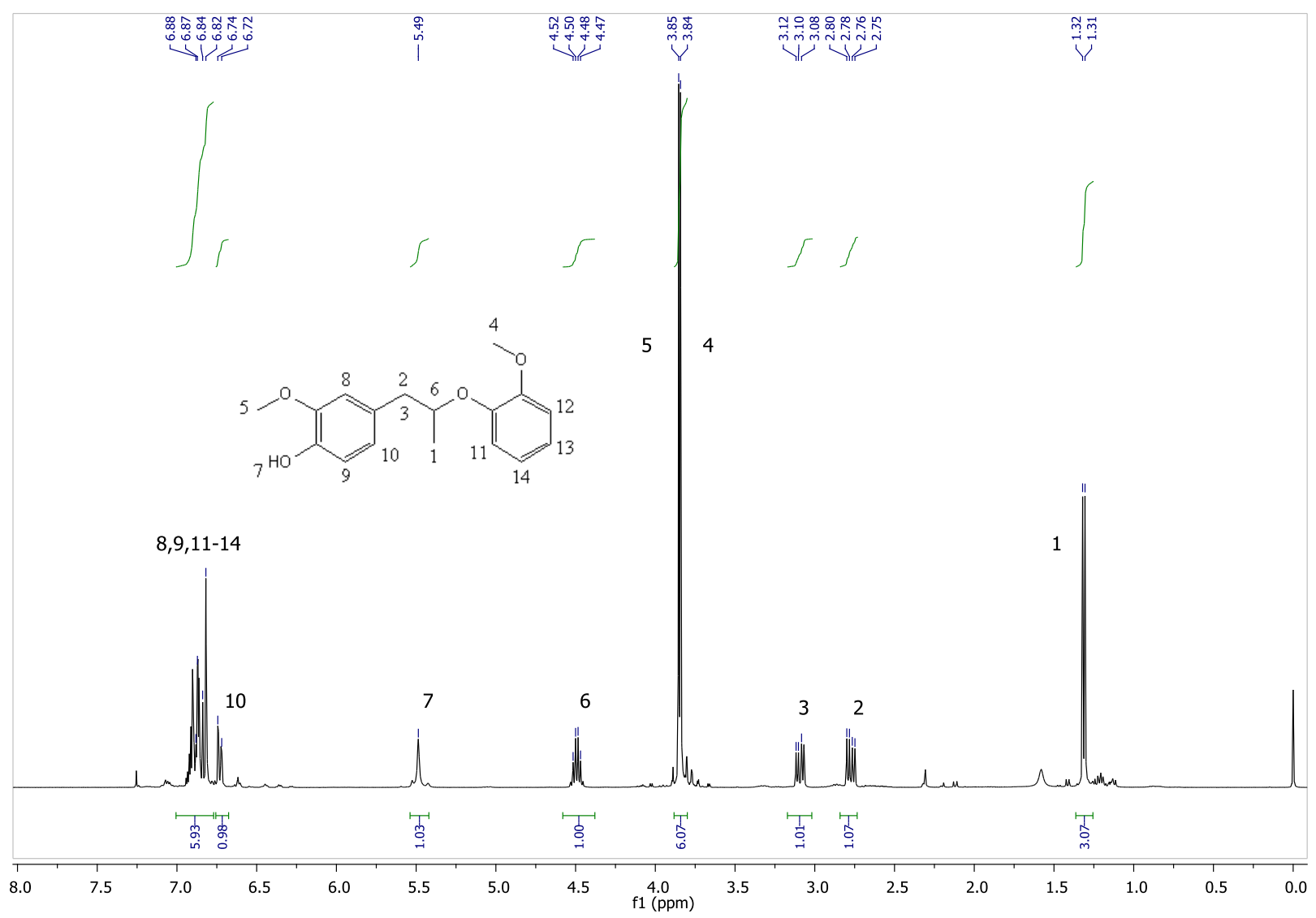

Figure 17: ${ }^{1} \mathrm{H} \mathrm{NMR}\left(\mathrm{CDCl}_{3}\right)$ spectrum of $\mathbf{2 5}$. 
All expected resonances for $\mathbf{2 5}$ were detected. A doublet resonance detected at $1.32 \mathrm{ppm}$ integrating for three protons with $\mathrm{a}^{3} J=6.2 \mathrm{~Hz}$ coupling represents H1. Resonances at 2.76 and $3.10 \mathrm{ppm}$, each integrating for one proton with a coupling of $6.8 \mathrm{~Hz}$ are characteristic of $\mathrm{H} 2$ and H3. Two singlet resonances at 3.84 and $3.85 \mathrm{ppm}$, each integrating for 3 protons, represent both methoxy groups, $\mathrm{H} 4$ and $\mathrm{H} 5$. A quartet at $4.49 \mathrm{ppm}$ integrating for one proton with a ${ }^{3} \mathrm{~J}=6.2 \mathrm{~Hz}$ coupling is characteristic of H6. A broad singlet at $5.49 \mathrm{ppm}$ integrating for one proton is characteristic of the hydroxyl proton, H7. Two resonances associated with the seven aromatic protons, $\mathrm{H} 8-\mathrm{H} 14$ were observed between 6.60 and $7.25 \mathrm{ppm}$. A multiplet resonance at 6.85 ppm integrating for a total of 6 protons, H8, H10, H11 - H14 and a single doublet resonance, H10, integrating for a proton account for all seven aromatic protons. There are several minor resonances detected in the $1-2.5 \mathrm{ppm}$ range which are characteristic of solvents, in particular acetone and water. 


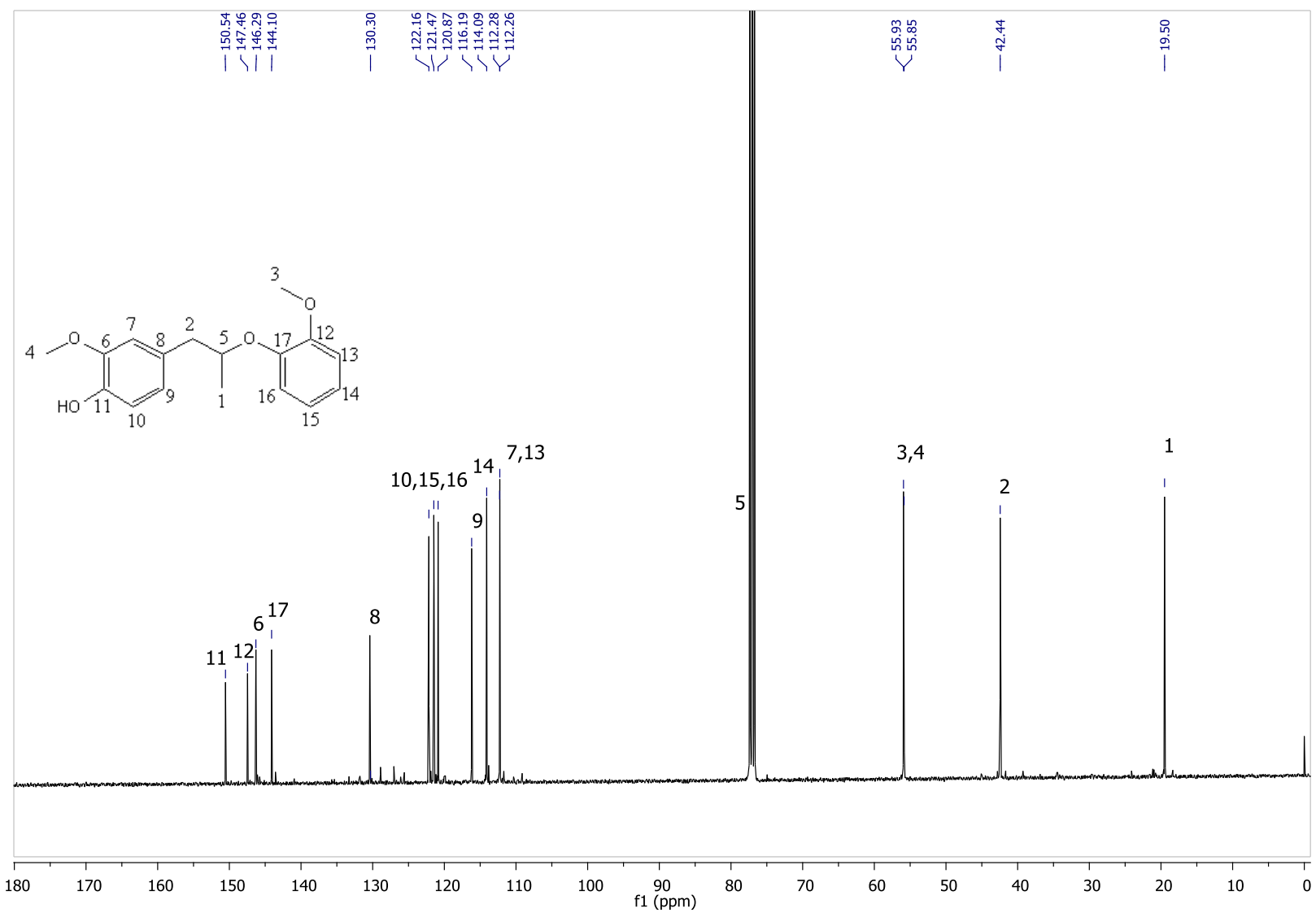

Figure 18: ${ }^{13} \mathrm{C} \mathrm{NMR}\left(\mathrm{CDCl}_{3}\right)$ spectrum of 25 .

All expected ${ }^{13} \mathrm{C}$ NMR resonances were detected. The three methyl peaks, $\mathrm{C} 1, \mathrm{C} 3$ and C4 were observed respectively at 19.5, 55.9 and $55.9 \mathrm{ppm}$. Carbon 5 was observed at $76.8 \mathrm{ppm}$ which is overlapped by the solvent peak. The aromatic carbon signals, C6 - C17 were all observed between $110-155 \mathrm{ppm}$. There are several minor resonances, particularly in the aromatic region, which are characteristic of starting material 24.

Examining the mass spectrometry data of $\mathbf{2 5}$, the protonated product $(288.1 \mathrm{~m} / \mathrm{z})$ was observed in a minor quantity relative to all other signals. The ammoniated product $(306.2 \mathrm{~m} / \mathrm{z})$ was the major ion. Similar to $\mathbf{1 3}$, the ether linkage of $\mathbf{2 5}$ was broken as a signal at $165.2 \mathrm{~m} / \mathrm{z}$ represents this cleaved portion. This was confirmed to not be $\mathbf{1 4}$ as it was expected to have had a signal of $164.2 \mathrm{~m} / \mathrm{z}$. A signal at $329.2 \mathrm{~m} / \mathrm{z}$ was observed but this was not further investigated. 
Upon addition of triflic acid (17), to the reaction vessel containing 25 (toluene), it appeared that the triflic acid was not soluble. Upon the addition of $\mathbf{1 7}$, a fraction of the reaction solution adhered to the side of the reaction vessel for the duration of the reaction. It was presumed that this was $\mathbf{1 7}$ and as a result, its effectiveness as a catalyst was assumed to be limited at best. This could help to justify the low yield. Other solvents were not explored. It may be possible to dramatically improve the yield by using a catalyst that is soluble in the organic solvents or using a different solvent altogether. Another option could be the use of a phase transfer catalyst. ${ }^{39}$ These options were not investigated due to time constraints as well as the fact that other lignin based materials were evaluated as potential monomers. Another possible yield limiting factor was that the protecting silyl group of $\mathbf{2 4}$ was cleaved in the presence of acid and the exposure to high temperature over several days. Lastly, an actual deprotection procedure was not performed on the reaction material as it was assumed that the silyl group was cleaved in the presence of triflic acid. This was suggested by the detection of $\mathbf{2 5}$ in the reaction mixture of the Markovnikov addition reaction. In the event that $\mathbf{1 7}$ was a poor deprotecting agent, a substantial amount of material was potentially left protected. Since purification was accomplished using an acid - base extraction, if the protecting silyl group remained intact, the acid - base extraction may have washed away a substantial amount of protected 25. Efforts to optimize this reaction may prove valuable as it is a two step reaction route to synthesize the $\beta$-O-4 linkage which may be useful in further studies. 


\subsection{Preparation of Diols Suitable for Polymerization from Natural Phenolic Materials}

\subsubsection{Overview of Synthetic Diols}

Phenolic materials were transformed into diols prior to their testing in polymerization reactions. Lignin degradation studies have shown that commonly available phenols such as guaiacol (9), eugenol (14) and vanillin (31) are readily recovered from lignin through various thermo-chemical degradation processes. ${ }^{31}$ It was assumed that during the proposed degradation processes for this work, similar, if not identical fragments would be derived from lignin. As such, these materials along with $\mathbf{1 3}$ and other naturally occurring bio-based phenols, that can be obtained from raspberries and various herbs, were evaluated for their polymeric potential.

Various methods of generating diols have been reported with $90 \%^{40}, 82 \%^{41}$ and $75 \%^{42}$ yields, (Scheme 13: product yields in parentheses).

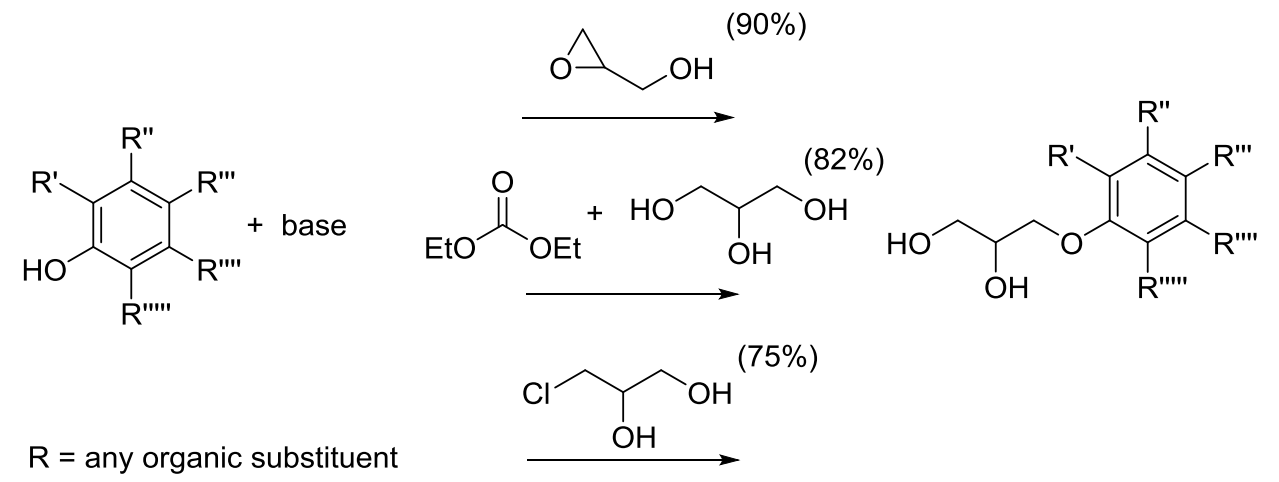

Scheme 13: Proposed synthetic routes to generate a diol from a phenol.

The reaction scheme proposed below by Truscello et al. was the selected route for synthesizing diols in this work (Scheme 14). ${ }^{43}$ 
(1.03eq)
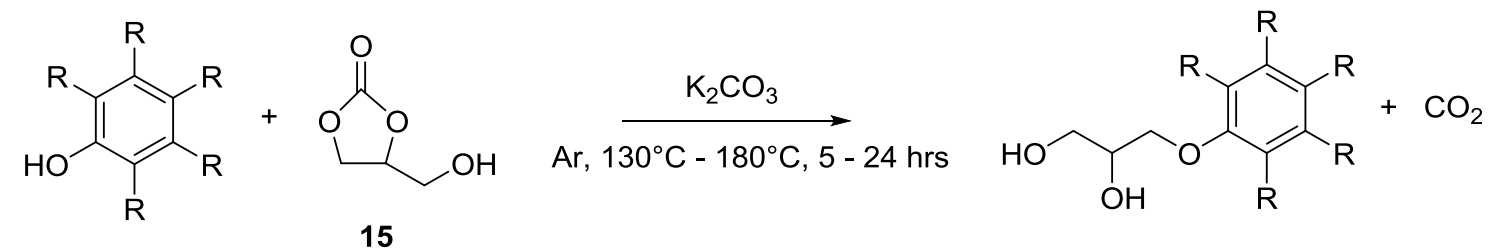

Scheme 14: Reaction scheme used by Truscello et al. ${ }^{44}$

Truscello et al. reported a yield of $44 \%$ and also reported various by-products; compounds $\mathbf{B}$ through $\mathbf{D}$ (Figure 19). In this work, only the desired diol $\mathbf{A}$ and the di-substituted by-product $\mathbf{C}$ were observed. Along with the desired diols, di-substituted compounds were characterized and efforts were made to understand their mechanism of formation.

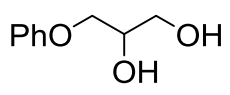

A

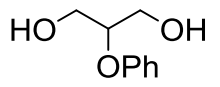

B

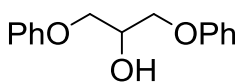

C

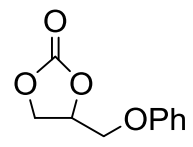

D

Figure 19: Various products reported by Truscello et al. ${ }^{44}$

Purification of resulting materials was accomplished using recrystallization in cold $\mathrm{Et}_{2} \mathrm{O}$. In the event that recrystallization was not possible, as was observed with several materials, column chromatography was utilized to obtain pure samples for characterization. On an industrial scale, due to the substantial amount of material required, standard columns were not economical. Using a 3:1 solvent mixture of ethyl acetate and hexane, any remaining starting materials along with di-substituted by-products could be easily and efficiently separated from desired diol type compounds. Under the conditions mentioned above, once starting material and by-products were eluted, the solvent composition was increased to 95\% ethyl acetate, 5\% hexanes and diols were collected shortly after. The TLC plate below is a representation of efficacy of the separation (Figure 20). 


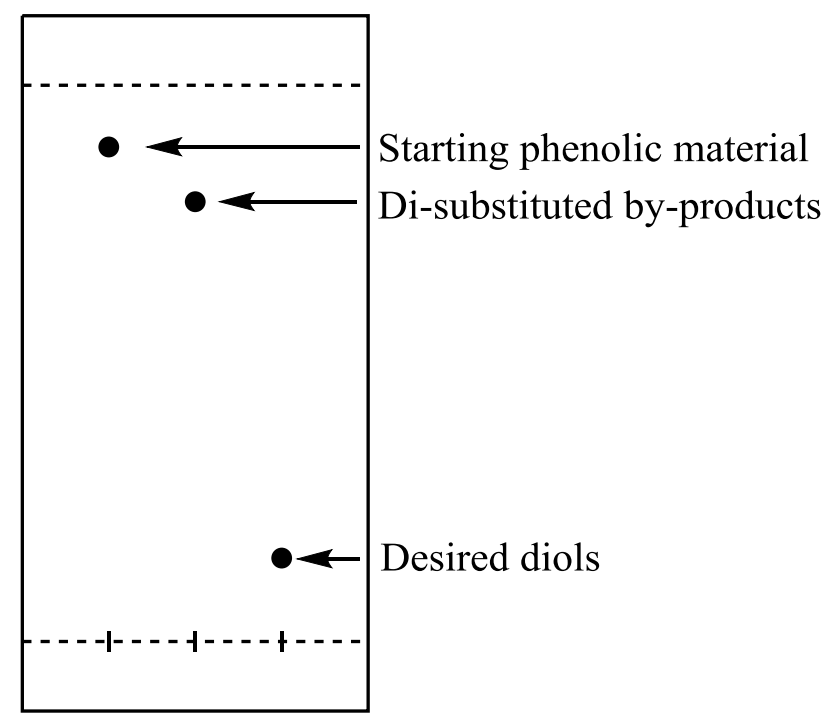

Figure 20: Thin layer chromatography plate demonstrating column efficacy for diol purification.

The glycerin carbonate (15) that was used in this work was obtained from Jeffsol Inc. which contained approximately $3 \%$ glycerol, the precursor to $\mathbf{1 5}$. Glycerol is not highly soluble in any typical solvent except for water and as such is removed along with excess $\mathrm{K}_{2} \mathrm{CO}_{3}$ during the water wash that is performed prior to recrystallization or chromatographic purification techniques.

\subsubsection{Synthetically Generated Diols}

\subsubsection{Characterization of 3-(4-allyl-2-methoxyphenoxy)propane-1,2-diol, 16}

Eugenol (14) was the first of many phenols successfully transformed into a diol as it was generated in efforts to synthesize 18. The resulting diol, 16, was isolated as an orange crystalline material and was confirmed using NMR spectroscopy, high resolution mass spectrometry and Xray crystallography (Figures 22,23 and 24$).{ }^{13} \mathrm{C}$ NMR spectroscopy clearly identifies the added propyl chain carbon resonances (C3, C4 and C5) which are labeled in Figure 21. 


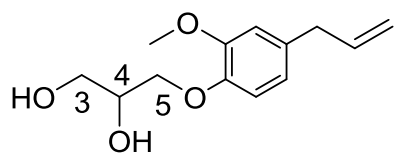

Figure 21: Compound 16 with reference to the newly added propyl diol chain.

This resonance pattern was used to confirm other new diols prior to mass spectrometry analysis. In contrast, ${ }^{1} \mathrm{H}$ NMR spectroscopy was relatively unresolved with respect to the propyl chain (Figure 22). Di-substituted by-products were not detected in this reaction.

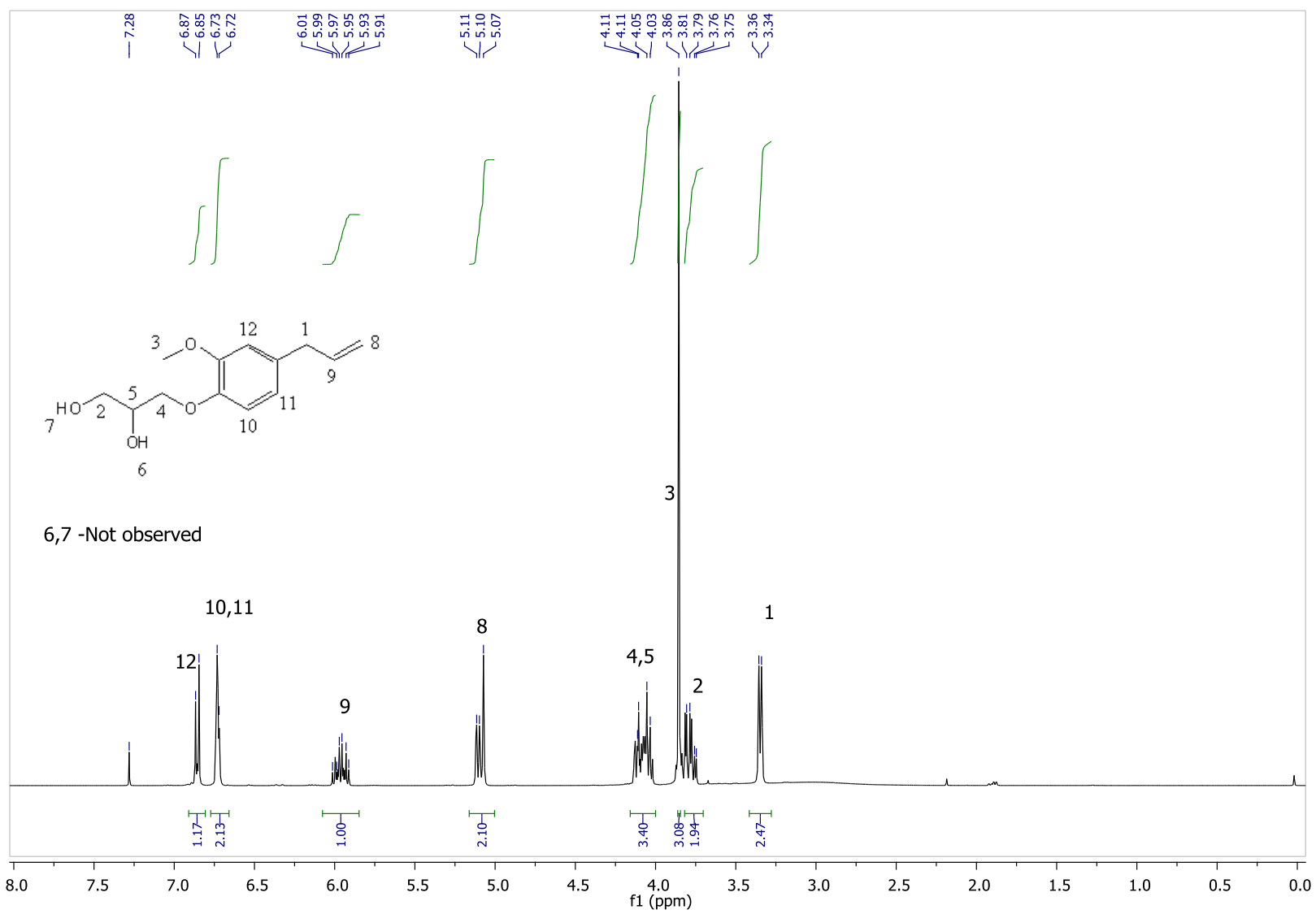

Figure 22: ${ }^{1} \mathrm{H}$ NMR $\left(\mathrm{CDCl}_{3}\right)$ spectrum of $\mathbf{1 6}$.

The ${ }^{1} \mathrm{H}$ NMR spectrum displays resonances at 6.73 and $6.85 \mathrm{ppm}$ that account for the three aromatic protons $\mathrm{H} 10-\mathrm{H} 12$. Three unique resonances observed at 3.36, 5.10 and 5.96 ppm are assigned to protons $\mathrm{H} 1, \mathrm{H} 8$ and $\mathrm{H} 9$ which are characteristic of the allyl chain. Protons, $\mathrm{H} 2, \mathrm{H} 4$ and $\mathrm{H} 5$ are associated with the propyl chain and were detected as various multiplets 
between $4.15-3.75 \mathrm{ppm}$. Both hydroxyl protons, H6 and $\mathrm{H} 7$ were not detected. A strong singlet resonance at $5.86 \mathrm{ppm}$ is characteristic of the methoxy group.

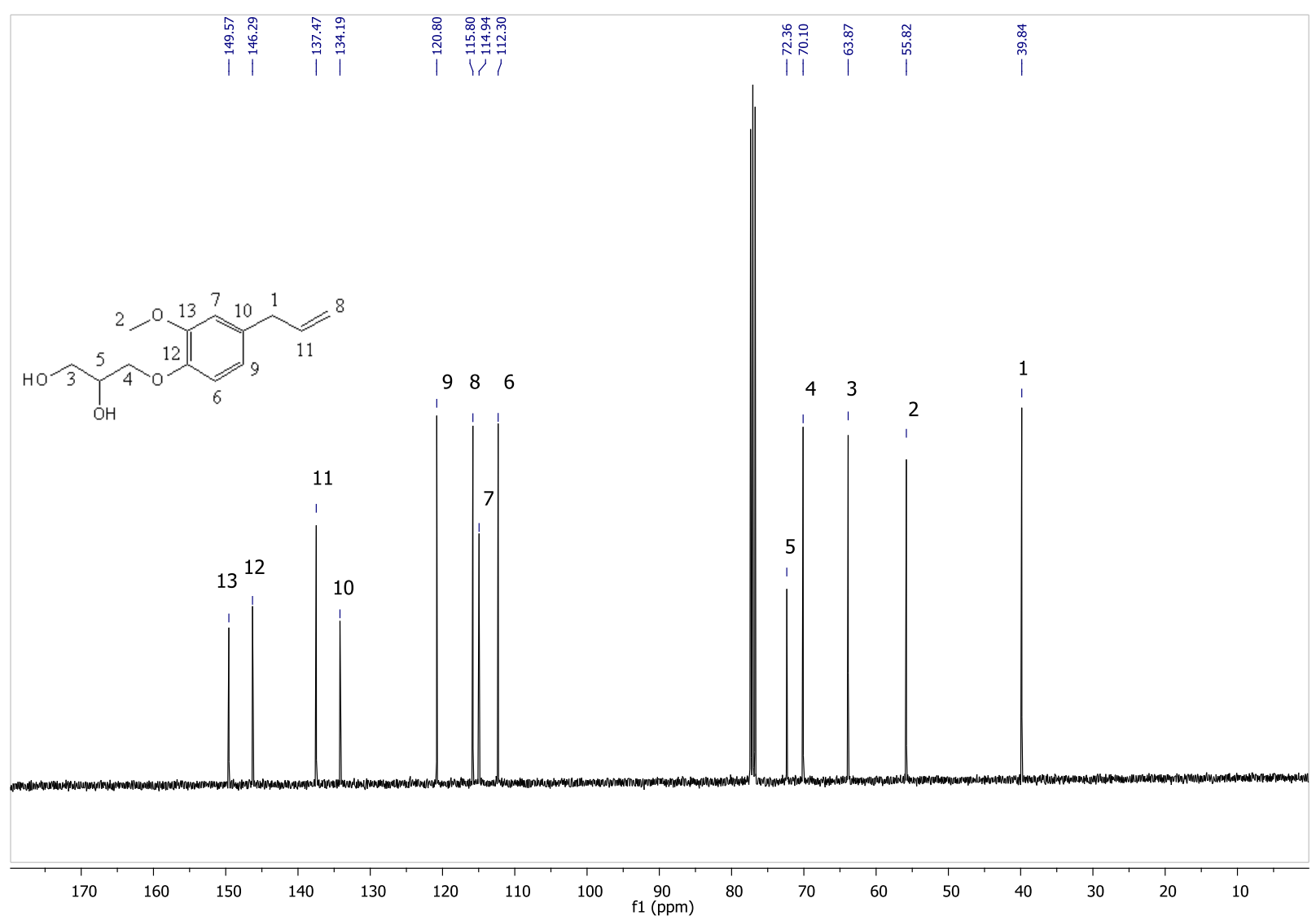

Figure 23: ${ }^{13} \mathrm{C}$ NMR $\left(\mathrm{CDCl}_{3}\right)$ spectrum 16.

The ${ }^{13} \mathrm{C}$ NMR spectrum of $\mathbf{1 6}$ shows all 13 expected carbon resonances. All six aromatic (C6, C7, C9, C10, C12 and C13), three allyl (C1, C8 and C11) and the methoxy carbon (C2) resonances, all characteristic of eugenol, were readily observed. Three new carbon resonances (C3 - C5) were observed between $80-60 \mathrm{ppm}$ and are characteristic of the newly formed propyl chain. No downfield resonances indicative of residual glycerin carbonate were observed.

Examination of the time of flight mass spectrum associated with this material revealed signals at $239.1 \mathrm{~m} / \mathrm{z}$ and $256.2 \mathrm{~m} / \mathrm{z}$ which represent the $\left[\mathrm{M}^{+}\right]$and $\left[\mathrm{M}^{+}+\mathrm{NH}_{4}\right]$. 
When initially isolated, 16 was a viscous orange coloured oil. Left exposed to air over a couple days, the material solidified into a waxy solid. Successful recrystallization efforts were achieved only after $\mathbf{1 6}$ had solidified. All efforts to recrystallize $\mathbf{1 6}$ from its oil, including attempts with $\mathrm{Et}_{2} \mathrm{O}$, failed. Crystals of $\mathbf{1 6}$ suitable for X-ray crystallography were obtained by recrystallization from a solvent system of hexanes and ethyl acetate. Compound $\mathbf{1 6}$ was dissolved at room temperature in ethyl acetate. An equal amount of hexanes was slowly layered on top. The vial was then carefully transferred to a freezer and left undisturbed until crystals formed and were ready to be removed. This was accomplished over several days.

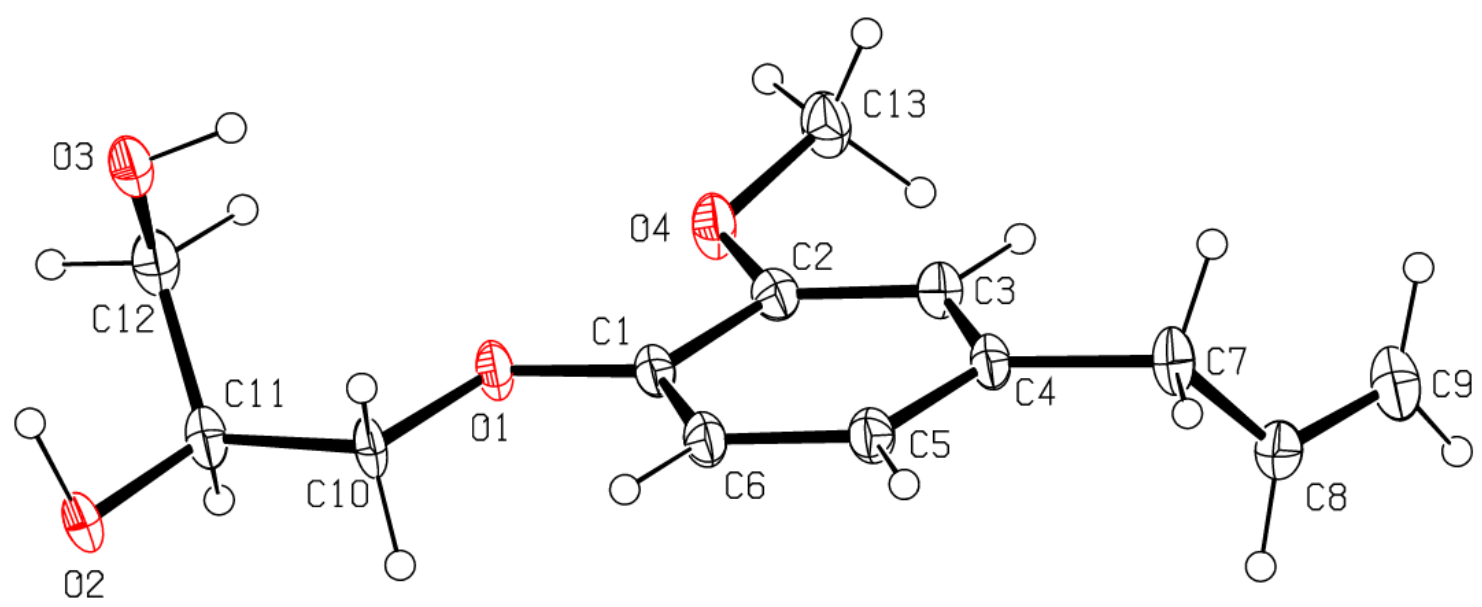

Figure 24: ORTEP representation of the unit cell components of $\mathbf{1 6 .}$

The data generated by X-ray crystallography was similar to other similar organic compounds. ${ }^{44}$ There was concern that under these reaction conditions the terminal double bond would be susceptible to attack. However, this was not the case as the allyl chain remained intact (Figure 24). The bond distance of $1.314 \AA$ between $\mathrm{C}(8)$ and $\mathrm{C}(9)$, is characteristic of other known carbon-carbon double bonds. ${ }^{46}$ The bond lengths between $\mathrm{C}(7)-\mathrm{C}(8), 1.477 \AA$ and $\mathrm{C}(4)$ - C(7), $1.516 \AA$ are characteristic of the remaining components allyl chain. Allyl containing crystallized compounds such as $\mathrm{N}$-(2-allyl-4-chloro- $\mathrm{H}$-indazol-5-yl)-4-methoxybenzene- 
sulfonamide hemihydrate have comparable structural data to that of $\mathbf{1 6} .^{45}$ All reported bond angles are reasonable within the compound.

\begin{tabular}{|c|c|c|c|}
\hline Bond & Length $[\AA]$ & Bond & Angle $\left[{ }^{\circ}\right]$ \\
\hline $\mathrm{O}(1)-\mathrm{C}(1)$ & $1.369(6)$ & $\mathrm{C}(1)-\mathrm{O}(1)-\mathrm{C}(10)$ & $116.8(4)$ \\
\hline $\mathrm{O}(1)-\mathrm{C}(10)$ & $1.439(6)$ & $\mathrm{C}(8)-\mathrm{C}(7)-\mathrm{C}(4)$ & $113.0(5)$ \\
\hline $\mathrm{O}(2)-\mathrm{C}(11)$ & $1.447(7)$ & $\mathrm{C}(9)-\mathrm{C}(8)-\mathrm{C}(7)$ & $126.2(7)$ \\
\hline $\mathrm{O}(3)-\mathrm{C}(12)$ & $1.412(8)$ & $\mathrm{O}(1)-\mathrm{C}(10)-\mathrm{C}(11)$ & $106.9(5)$ \\
\hline $\mathrm{C}(11)-\mathrm{C}(12)$ & $1.499(9)$ & $\mathrm{O}(2)-\mathrm{C}(11)-\mathrm{C}(12)$ & $111.9(5)$ \\
\hline $\mathrm{C}(4)-\mathrm{C}(7)$ & $1.516(7)$ & $\mathrm{O}(2)-\mathrm{C}(11)-\mathrm{C}(10)$ & $107.1(5)$ \\
\hline $\mathrm{C}(7)-\mathrm{C}(8)$ & $1.477(9)$ & $\mathrm{C}(12)-\mathrm{C}(11)-\mathrm{C}(10)$ & $113.19(5)$ \\
\hline $\mathrm{C}(8)-\mathrm{C}(9)$ & $1.314(9)$ & $\mathrm{O}(3)-\mathrm{C}(12)-\mathrm{C}(11)$ & $111.8(5)$ \\
\hline
\end{tabular}

Table 2: Selected bond lengths $[\AA]$ and bond angles $\left[^{\circ}\right]$ for $\mathbf{1 6}$.

2.3.2.2 Purification and Characterization of 3-(2-methoxyphenoxy)propane-1,2-diol, 26

Compound 26 was synthesized from the reaction of 9 and $\mathbf{1 5}$. The resulting material was isolated as a white powder. Among other uses, 26, also known as guaifenesin, is a well known pharmaceutical. Compound $\mathbf{2 7}$ was also detected in the resulting material by characteristic resonances using both ${ }^{1} \mathrm{H}$ and ${ }^{13} \mathrm{C}$ NMR spectroscopy; but never isolated. In particular, these characteristic resonances of $\mathbf{2 7}$ can be associated with the absence of the resonance of the $\alpha$ carbon $\left(\mathbf{C}_{\mathbf{1}}\right)$ and the pattern displayed in the ${ }^{1} \mathrm{H}$ NMR spectra with respect to $\mathbf{H}_{1}$, and $\mathbf{H}_{\mathbf{2}}$ (Figures 25 and 26). This was the first time that a di-substituted by-product was detected. 


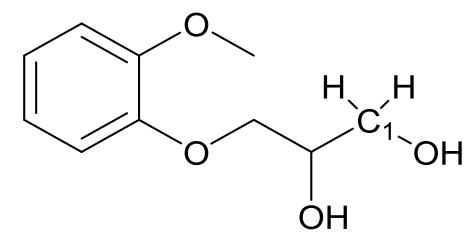

Figure 25: Structure of compound 26 with reference to characteristic ${ }^{13} \mathrm{C}$ NMR resonances.

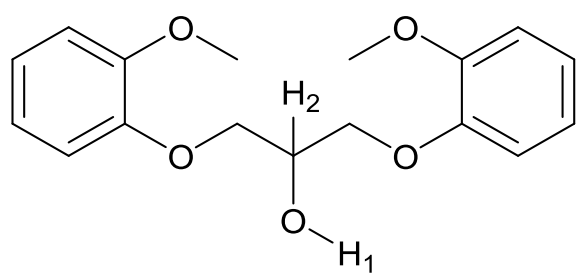

Figure 26: Structure of compound 27 with reference to characteristic ${ }^{1} \mathrm{H}$ NMR resonances.

In the ${ }^{1} \mathrm{H}$ NMR spectrum of $\mathbf{2 7}$, a doublet resonance along with a multiplet resonance are characteristic $\mathbf{H}_{1}$ and $\mathbf{H}_{2}$ protons respectively. With respect to ${ }^{13} \mathrm{C}$ NMR spectroscopy, the ${ }^{13} \mathrm{C}$ NMR spectrum of $\mathbf{2 7}$ does not contain a ${ }^{13} \mathrm{C}$ resonance, similar $\mathbf{C}_{\mathbf{1}}$ of $\mathbf{2 6}$. These characteristic ${ }^{1} \mathrm{H}$ and ${ }^{13} \mathrm{C}$ NMR resonances will be used to identify other resulting by-products.

The resulting material from the reaction generating $\mathbf{2 6}$ was a clear liquid with a yellowish tint. After washing and solvent removal, the liquid, if left exposed to air, would generate a waxy yellowish precipitate. Purification of $\mathbf{2 6}$ was performed via recrystallization with $\mathrm{Et}_{2} \mathrm{O}$. In order for recrystallizations to be successful, the initial material needs to be in solid form. All attempts to recrystallize $\mathbf{2 6}$ from the liquid form failed. Similar results were found for all other diols in this study. The ${ }^{1} \mathrm{H}$ and ${ }^{13} \mathrm{C}$ NMR spectra of $\mathbf{2 6}$ are displayed below (Figures 27 and 28). 


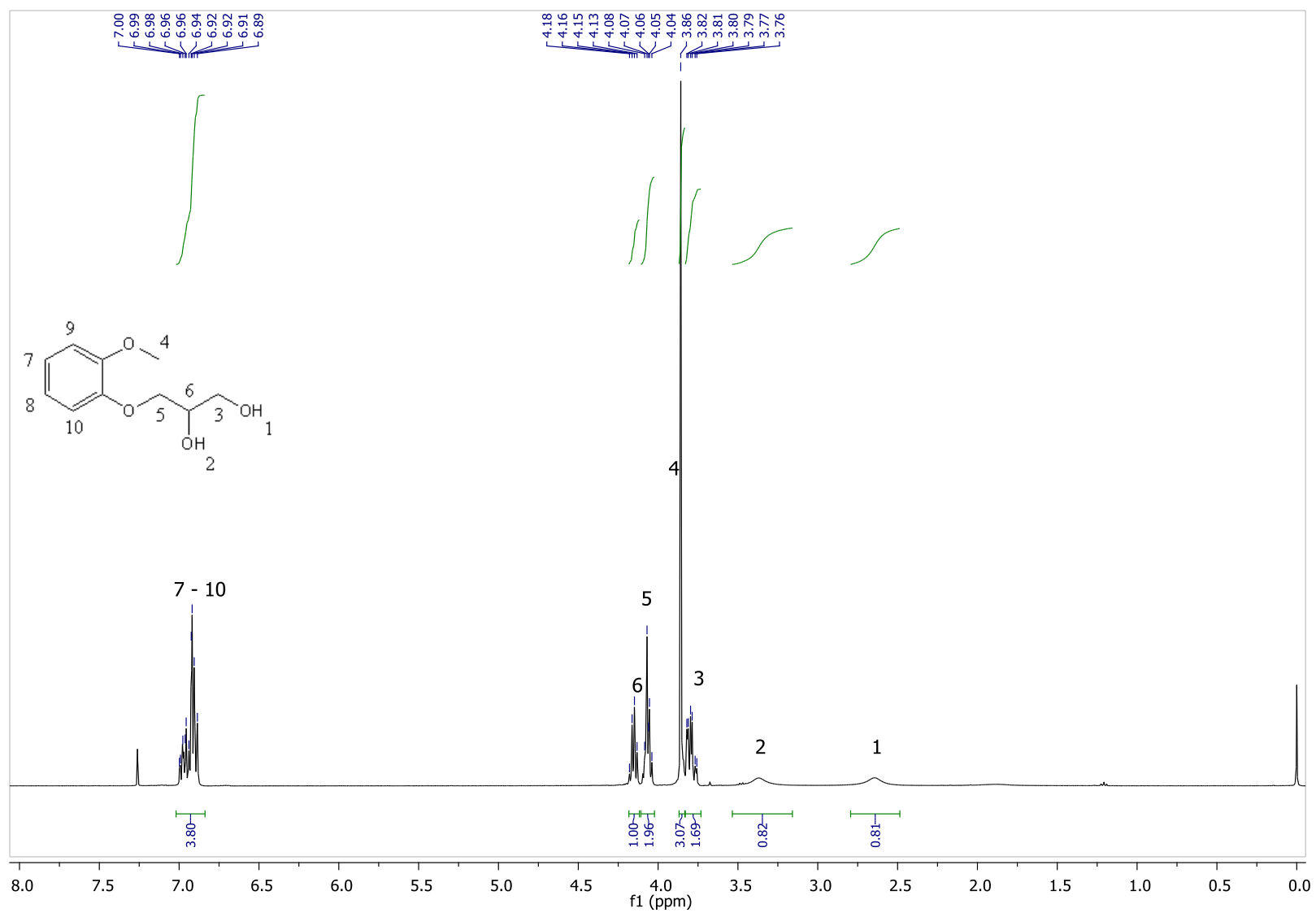

Figure 27: ${ }^{1} \mathrm{H} \mathrm{NMR}\left(\mathrm{CDCl}_{3}\right)$ spectrum of $\mathbf{2 6}$.

The ${ }^{1} \mathrm{H}$ NMR spectrum of $\mathbf{2 6}$ displayed all expected resonances. The resonances associated with the hydroxyl protons, $\mathrm{H} 1$ and $\mathrm{H} 2$, were detected as weak, broad resonances at approximately 2.6 and $3.4 \mathrm{ppm}$ each integrating for a single proton. The five protons, H3, H5 and H6, were observed as various multiplets at 3.78, 4.05 and $4.15 \mathrm{ppm}$, integrating for two, two and one protons respectively. A singlet integrating for three protons at $3.86 \mathrm{ppm}$ is characteristic of the methoxy protons, H2. A multiplet detected at $6.91 \mathrm{ppm}$, integrating for four protons is characteristic of the aromatic protons, H7 - H10 (Figure 27). 


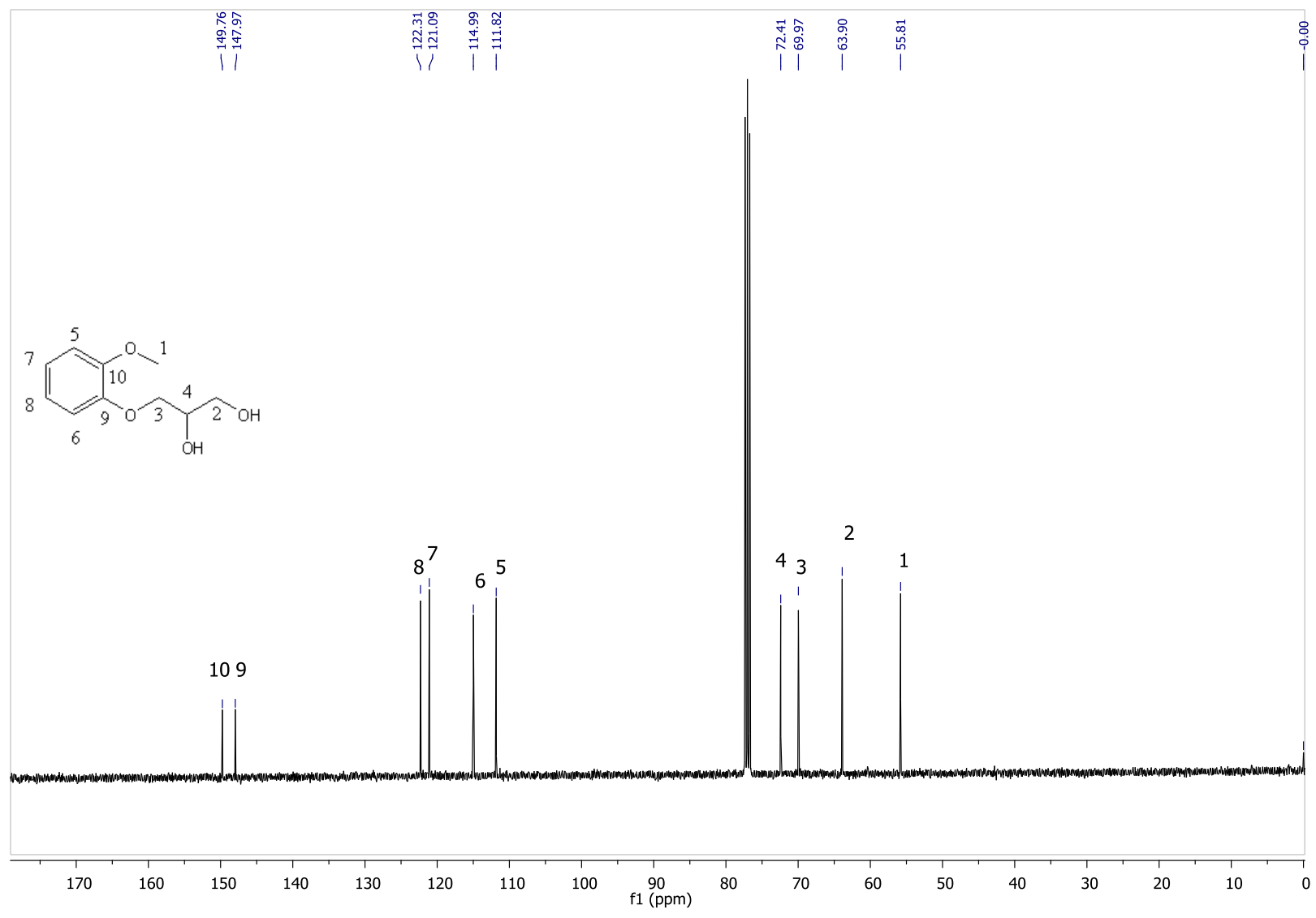

Figure 28: ${ }^{13} \mathrm{C} \mathrm{NMR}\left(\mathrm{CDCl}_{3}\right)$ spectrum of $\mathbf{2 6}$.

All the expected ${ }^{13} \mathrm{C}$ NMR resonances for $\mathbf{2 6}$ were observed. A resonance detected at $55.8 \mathrm{ppm}$ was assigned to the methoxy carbon, $\mathrm{C} 1$. Three resonances detected at $63.9,70.0$ and 72.4 ppm are characteristic of the propyl chain carbons. Six resonances detected between $110-$ $155 \mathrm{ppm}$ are characteristic of the six aromatic protons. Both ${ }^{1} \mathrm{H}$ and ${ }^{13} \mathrm{C}$ NMR assignments were in good agreement with reported data for $26^{46}$

\subsubsection{Purification and Characterization of 3-(2-methoxy-4-propylphenoxy)propane-1,2-diol, 29}

Compound 29 was synthesized from 28 and 15 and was investigated as a potential monomer in the preparation of various polymers (Figure 29). The difference in physical properties between polymers synthesized with and without the additional propyl chain, compounds $\mathbf{2 6}$ and 29, was also questioned. 


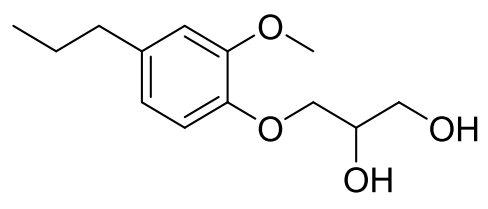

Figure 29: Proposed structure of compound 29.

The reaction synthesizing $\mathbf{2 9}$ carried out under both an air and argon atmospheres. The only difference was that under an air atmosphere the resulting material is a brown liquid as opposed to a yellow liquid under an argon atmosphere. After washing, solvent removal and left exposed to air, a waxy precipitate formed in both cases. Recrystallizations involving cold $\mathrm{Et}_{2} \mathrm{O}$ successfully purified 29, generating a white crystalline solid. Compound 29 was characterized using ${ }^{1} \mathrm{H}$ and ${ }^{13} \mathrm{C}$ NMR and mass spectrometry (Figures 30 and 31).

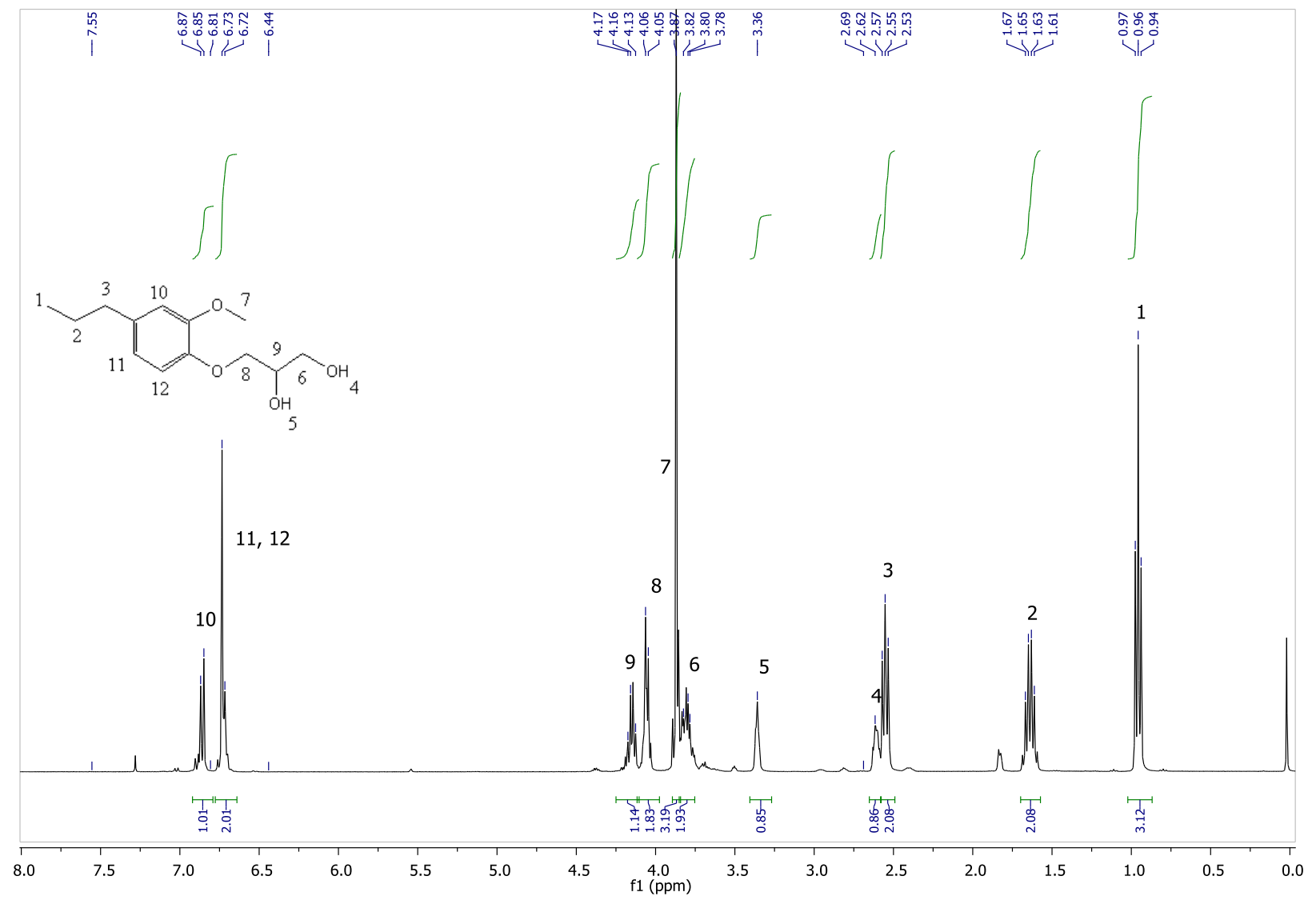

Figure 30: ${ }^{1} \mathrm{H}$ NMR $\left(\mathrm{CDCl}_{3}\right)$ spectrum of 29. 
All expected ${ }^{1} \mathrm{H}$ NMR resonances for 29 were observed. Resonances in the forms of a triplet, quartet and triplet observed at $0.96,1.64$ and $2.55 \mathrm{ppm}$ respectively and integrating for a total of seven protons is characteristic of the saturated propel chain, H1 - H3. Two weak and broad resonances detected at 2.60 and $3.36 \mathrm{ppm}$, each integrating for a single proton are characteristic of the hydroxyl protons, $\mathrm{H} 4$ and H5. A singlet resonance at 3.87 ppm integrating for three protons is characteristic of the methoxy protons, H5. Resonances associated with the protons of the newly formed propel chain were observed as a multiple at $3.81 \mathrm{ppm}$ integrating for two protons, a doublet at $4.06 \mathrm{ppm}$ integrating for two protons and a quartet at $4.16 \mathrm{ppm}$ integrating for one proton, $\mathrm{H} 4, \mathrm{H} 6$ and $\mathrm{H} 9$ respectively. Two resonances detected at 6.72 and $6.86 \mathrm{ppm}$, integrating for a total of three protons represents the aromatic protons.

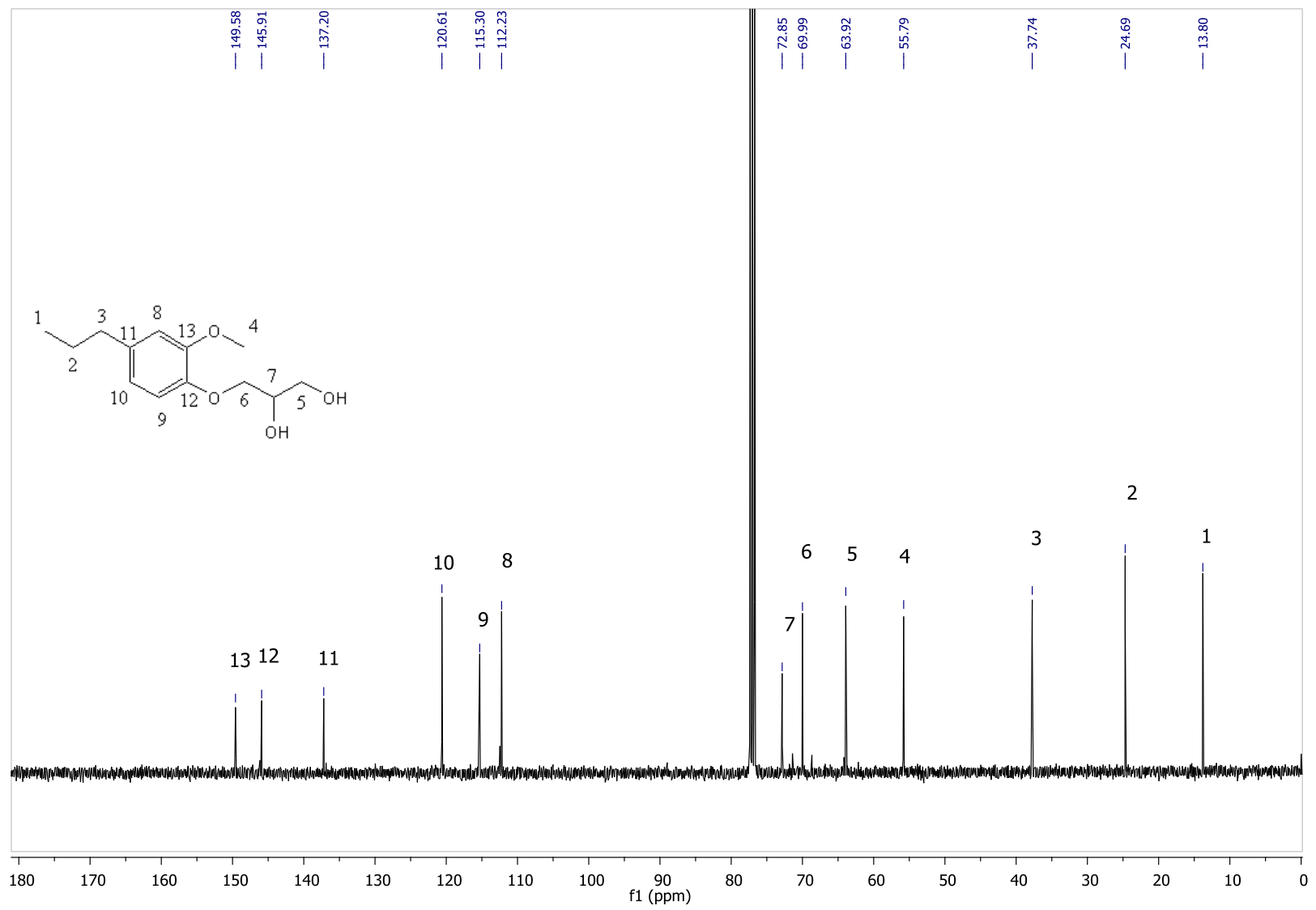

Figure 31: ${ }^{13} \mathrm{C} \mathrm{NMR}\left(\mathrm{CDCl}_{3}\right)$ spectrum of 29.

47 
All expected ${ }^{13} \mathrm{C}$ NMR resonances were observed. Resonances at 13.8, 24.7 and 37.7 ppm are characteristic of the saturated propyl chain, $\mathrm{C} 1-\mathrm{C} 3$ and the resonance at $55.8 \mathrm{ppm}$ was assigned to the methoxy carbon. Resonances detected at 63.9, 70.0 and $77.9 \mathrm{ppm}$ are characteristic of the newly formed propyl chain, C5-C7. Six resonances observed between 110 $-150 \mathrm{ppm}$ are characteristic of the six aromatic ring carbons, C8 - C13. High resolution mass spectrometry was performed and signals at $241.1 \mathrm{~m} / \mathrm{z}$ and $256.2 \mathrm{~m} / \mathrm{z}$ representing $\left[\mathrm{M}^{+}\right]$and $\left[\mathrm{M}^{+}+\mathrm{NH}_{4}\right]$ were detected. No by-products were observed.

2.3.2.4 Purification and Characterization of 4-(2,3-dihydroxypropoxy)-3-methoxybenzaldehyde,

\section{$\underline{31}$}

Vanillin (30), a compound readily derived from lignin, was also explored for its polymeric potential. In the presence of $\mathbf{1 5}$ and $\mathrm{K}_{2} \mathrm{CO}_{3}, \mathbf{3 0}$ was transformed into $\mathbf{3 1}$ (Figure 32). During the attempted synthesis of $\mathbf{3 1}$, the reaction material underwent a self polymerization generating, what is suspected to be an interesting, bio-based polyether.

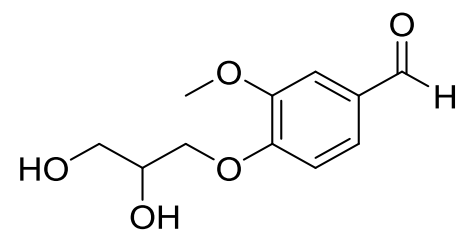

Figure 32: Proposed structure of compound 31.

In efforts to determine the structure of the resulting polymer, the mechanism of the reaction was investigated. It was determined that prior to polymerization, $\mathbf{3 1}$ can be detected. The resulting polymer is discussed in Section 3.4. 
Compound 31, a reddish-orange viscous liquid, was isolated with methanol and confirmed using ${ }^{1} \mathrm{H}$ and ${ }^{13} \mathrm{C}$ NMR spectroscopy and high resolution mass spectrometry (Figures 33 and 34).

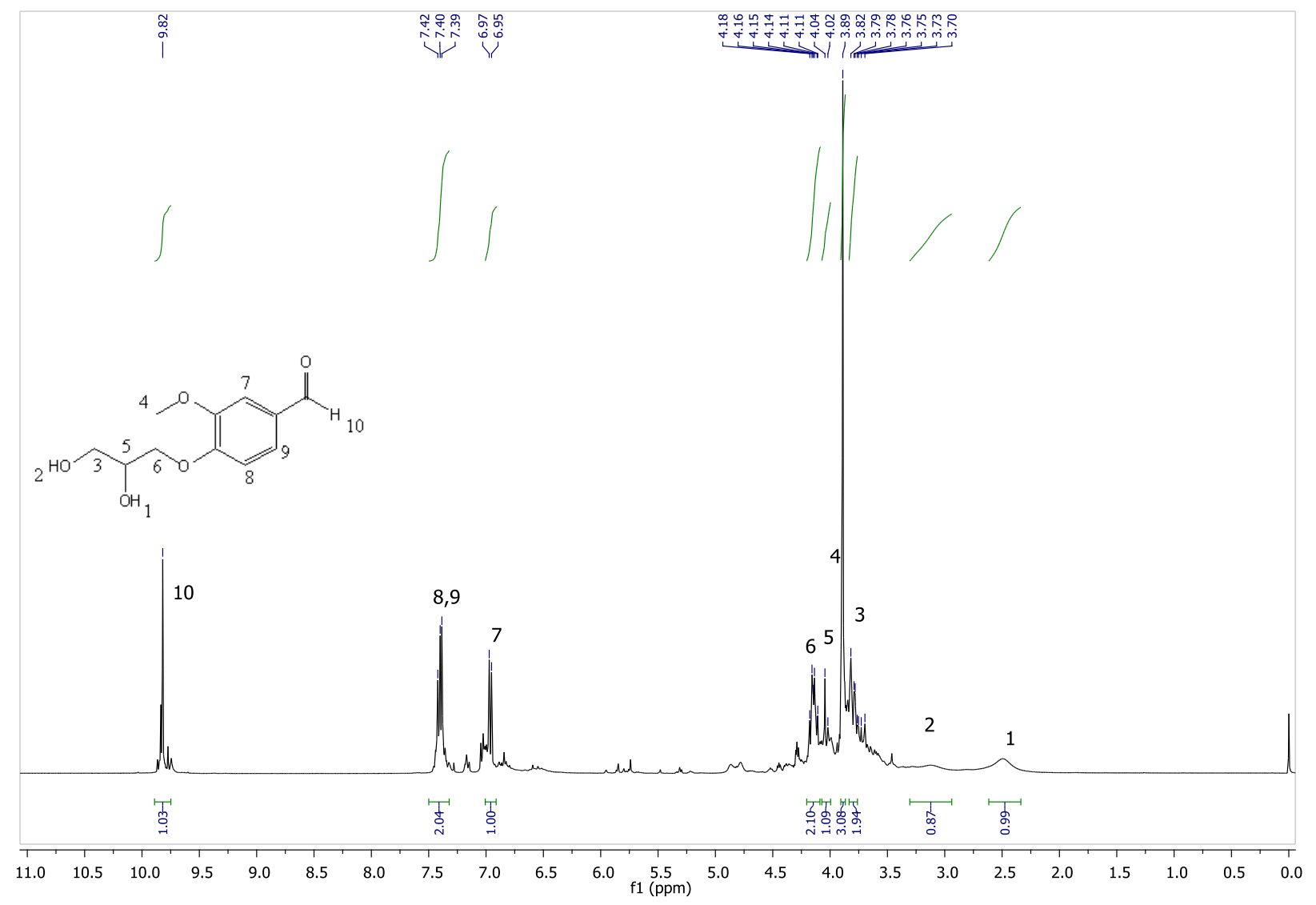

Figure 33: ${ }^{1} \mathrm{H}$ NMR $\left(\mathrm{CDCl}_{3}\right)$ spectrum of 31.

A strong singlet resonance at $9.82 \mathrm{ppm}$ integrating for one proton confirms the presence of the aldehyde proton, H10. All 3 aromatic protons were identified by the doublet and singlet resonances observed at 7.40 and $6.96 \mathrm{ppm}$ respectively, H7 - H9. A strong singlet resonance at $3.90 \mathrm{ppm}$, integrating for three protons is characteristic of the methoxy group, H4. Resonances at $4.15,4.03,3.82$ and $3.76 \mathrm{ppm}$, integrating for a total of five protons are characteristic of the propyl chain, H3, H5 and H6. Resonances detected at 2.48 and $3.12 \mathrm{ppm}$ is characteristic alcohol protons, $\mathrm{H} 1$ and $\mathrm{H} 2$. 


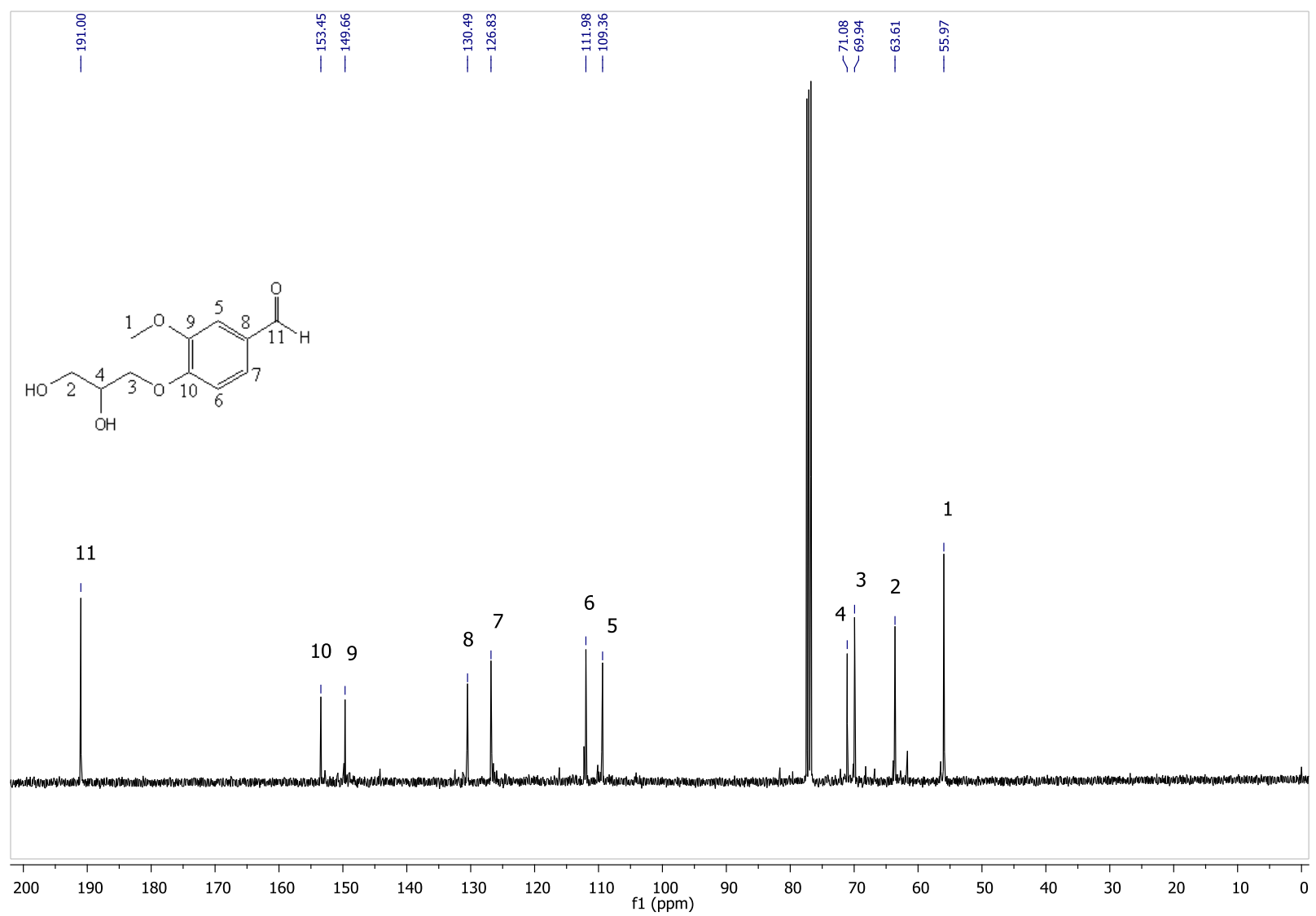

Figure 34: ${ }^{13} \mathrm{C} \mathrm{NMR}\left(\mathrm{CDCl}_{3}\right)$ spectrum of 31 .

All expected ${ }^{13} \mathrm{C}$ resonances were observed. A resonance detected at $191.0 \mathrm{ppm}$ is characteristic of the carbonyl carbon, C11. Six resonances detected between $105-155$ ppm represent the six aromatic carbons, C5 - C10. Resonances observed at 71.1, 69.9 and 61.6 ppm, are characteristic of the newly formed propyl chain, $\mathrm{C} 2-\mathrm{C} 4$. Last but not least, a resonance at $56.0 \mathrm{ppm}$ is characteristic of the methoxy carbon, $\mathrm{C} 1$.

High resolution mass spectrometry detected signals $227.1 \mathrm{~m} / \mathrm{z}$ and $244.1 \mathrm{~m} / \mathrm{z}$ which correspond the $\left[\mathrm{M}^{+}\right]$of $\mathbf{3 1}$ along with the ammoniated product of $\mathbf{3 1}$ i.e., $\left[\mathrm{M}^{+}+\mathrm{NH}_{4}\right]$ respectively. Examining the mass spectrum of $\mathbf{3 1}$, signals pertaining to $\mathbf{3 0}$, both the $\left[\mathrm{M}^{+}\right]$and $\left[\mathrm{M}^{+}+\mathrm{NH}_{4}\right]$ were also detected. Although starting material is still present, the data pertaining to this sample was 
taken as an aliquot to confirm the intermediate species. All efforts to recrystallize $\mathbf{3 1}$ including ethyl acetate and hexane mixtures $\left(\mathrm{Et}_{2} \mathrm{O}, \mathrm{MeOH}\right.$ and $\left.\mathrm{EtOH}\right)$ failed.

2.3.2.5 Purification and Characterization of 3-(2-isopropyl-5-methylphenoxy)propane-1,2-diol,

$\underline{\text { 33, and 3-(5-isopropyl-2-methylphenoxy)propane-1,2-diol, } 36}$

Although not lignin based materials, thymol (32) and carvacol (35) (Figure 4) were also evaluated as potential polymeric materials due to their low cost and large natural abundance. Hence, these materials were converted into $\mathbf{3 3}$ and $\mathbf{3 6}$ for such study (Figure 35).

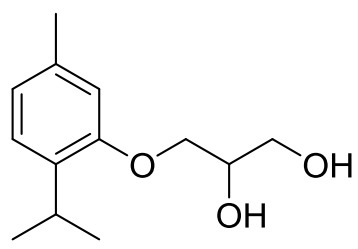

33

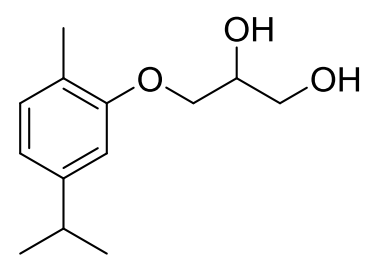

36

Figure 35: Proposed tructure of compounds 33 and 36.

After reacting compounds 32 and 35 with 15 in the presence of $\mathrm{K}_{2} \mathrm{CO}_{3}$ in respective reaction vessels, the resulting compounds, $\mathbf{3 3}$ and $\mathbf{3 6}$, were isolated as white solids via column chromatography. Compounds 34 and 37, the di-substituted by-products, were also isolated as white solids (Figure 38). The reaction material containing 33 was a yellowish-orange color where as the reaction material containing 36 was brown. Unlike the previous resulting diols which solidified when left exposed to air, neither 33 nor 36 precipitated out. As such, recrystallization efforts were not successful. Resulting compounds were characterized using ${ }^{1} \mathrm{H}$, ${ }^{13} \mathrm{C}$ NMR spectroscopy and high resolution mass spectrometry (Figure $36-39$ ). 


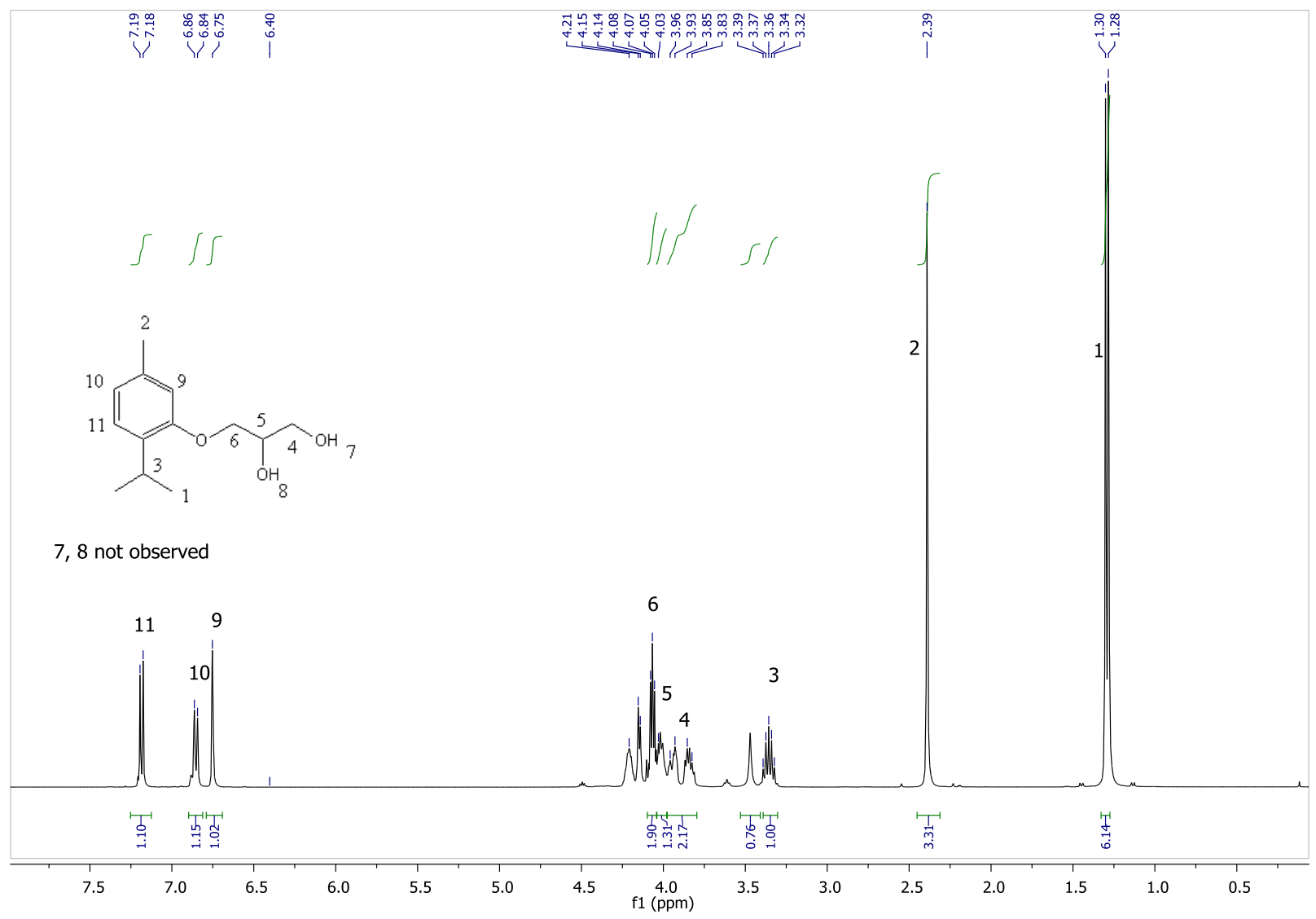

Figure 36: ${ }^{1} \mathrm{H}$ NMR $\left(\mathrm{CDCl}_{3}\right)$ spectrum of 33.

All expected ${ }^{1} \mathrm{H}$ NMR resonances for 33 were observed as expected. Resonances characteristic of the methyl groups, $\mathrm{H} 1$ and $\mathrm{H} 2$ were detected at 1.29 and $2.39 \mathrm{ppm}$ as doublet and singlet, integrating for six and three protons respectively. A quintet resonance observed at $3.16 \mathrm{ppm}$ is characteristic of H3. Five protons associated with the 1,2-propyl diol group, H4 H6 readily observed between $3.75-4.25 \mathrm{ppm}$. Both hydroxyl protons, $\mathrm{H} 7$ and $\mathrm{H} 8$, were not detected. Resonances associated with the three aromatic protons were observed between $6.75-$ $7.25 \mathrm{ppm}$ as a set of doublets and a singlet integrating for a total of three protons. 


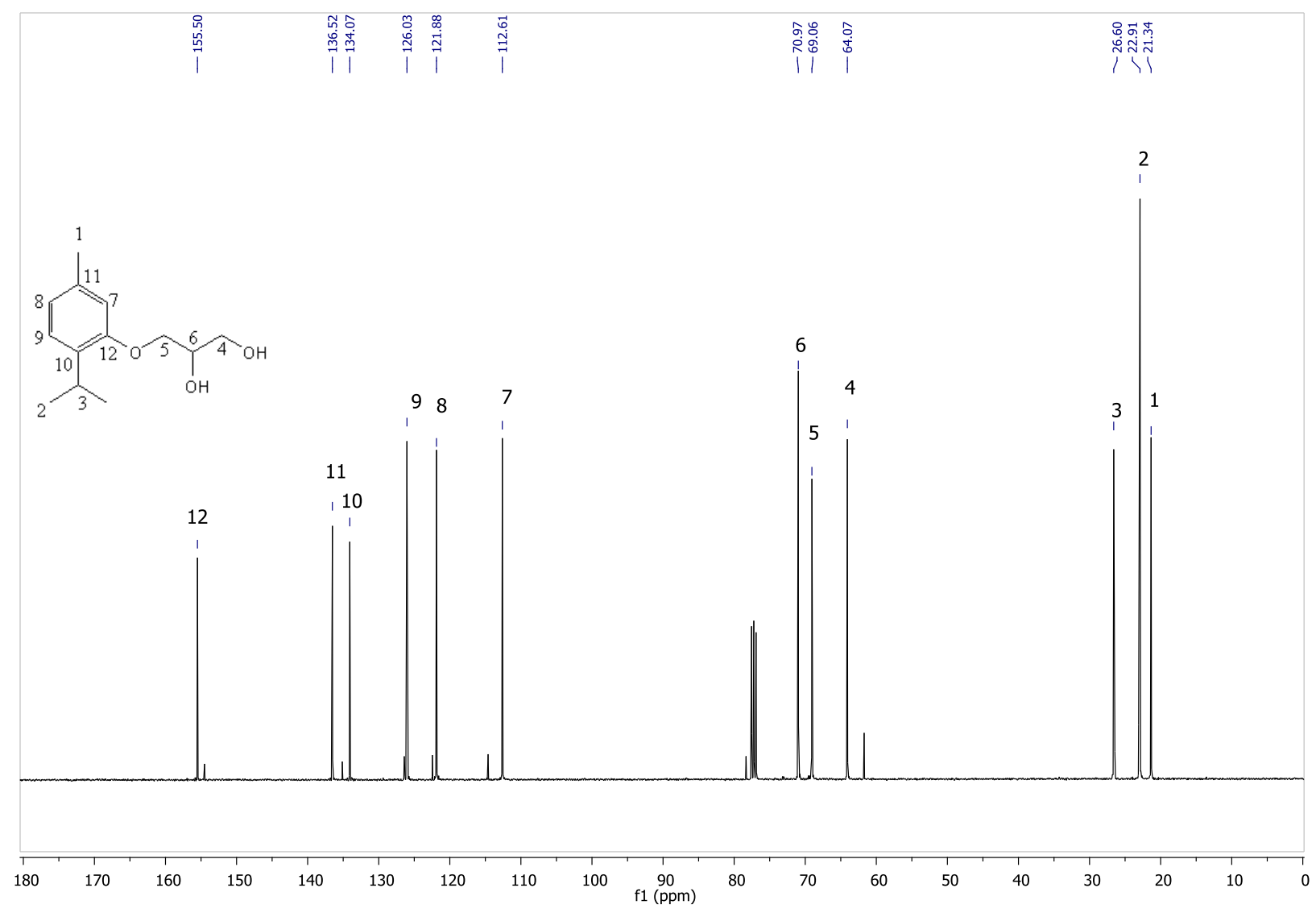

Figure 37: ${ }^{13} \mathrm{C} \mathrm{NMR}\left(\mathrm{CDCl}_{3}\right)$ spectrum of 33 .

All expected ${ }^{13} \mathrm{C}$ NMR resonances for $\mathbf{3 3}$ were readily observed. The alkyl substituent's, $\mathrm{C} 1$ - C3, were observed between 20 and $30 \mathrm{ppm}$. The three characteristic resonances associated with the newly added propyl chain were detected at 64.1, 69.0 and 71.0 ppm. Six resonances detected between $110-160$ ppm are characteristic of the six aromatic carbons.

The mass of the proposed compound was confirmed using high resolution mass spectrometry. The protonated product was detected at $225.1[\mathrm{M}]^{+}$, while the ammoniated product was detected at 242.2 ; i.e., $\left[\mathrm{M}+\mathrm{NH}_{4}\right]^{+}$. 


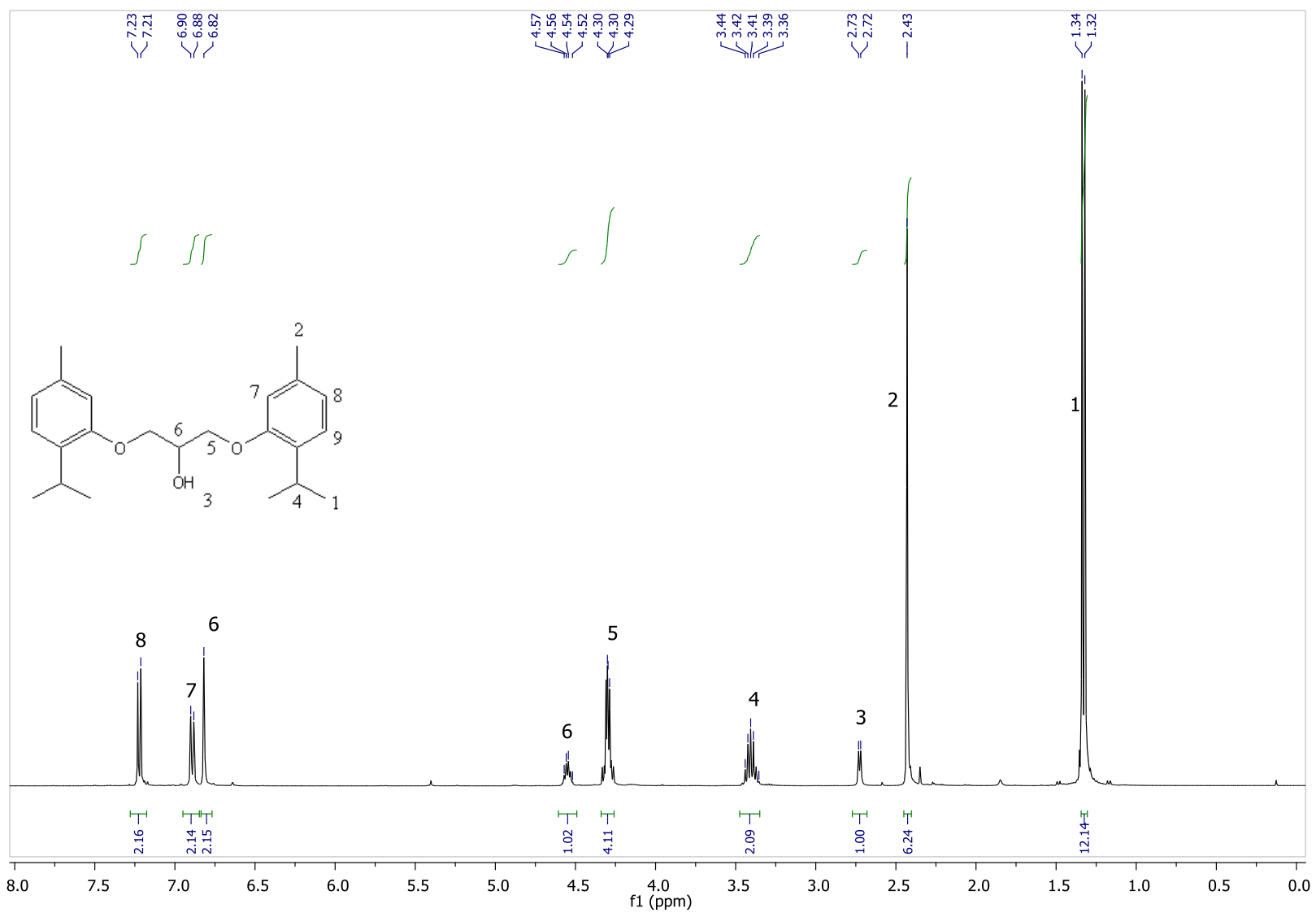

Figure 38: ${ }^{1} \mathrm{H} \mathrm{NMR}\left(\mathrm{CDCl}_{3}\right)$ spectrum of 34 .

All expected ${ }^{1} \mathrm{H}$ NMR resonances for $\mathbf{3 4}$ were detected. Resonances associated with thymol, H1, H2, H4 and H6 - H8, were observed as expected. Distinctive resonances expected from 34 were detected at 2.72, 4.30 and $4.54 \mathrm{ppm}, \mathrm{H} 3, \mathrm{H} 6$ and H6. These resonances were observed as a doublet, multiplet and multiplet integrating for a total of six protons; one, four and one protons representing $\mathrm{H} 3, \mathrm{H} 5$ and $\mathrm{H} 6$ respectively. Coupling constants of $\mathrm{H} 3$ and $\mathrm{H} 6$ are both ${ }^{3} J=5.3 \mathrm{~Hz}$. 


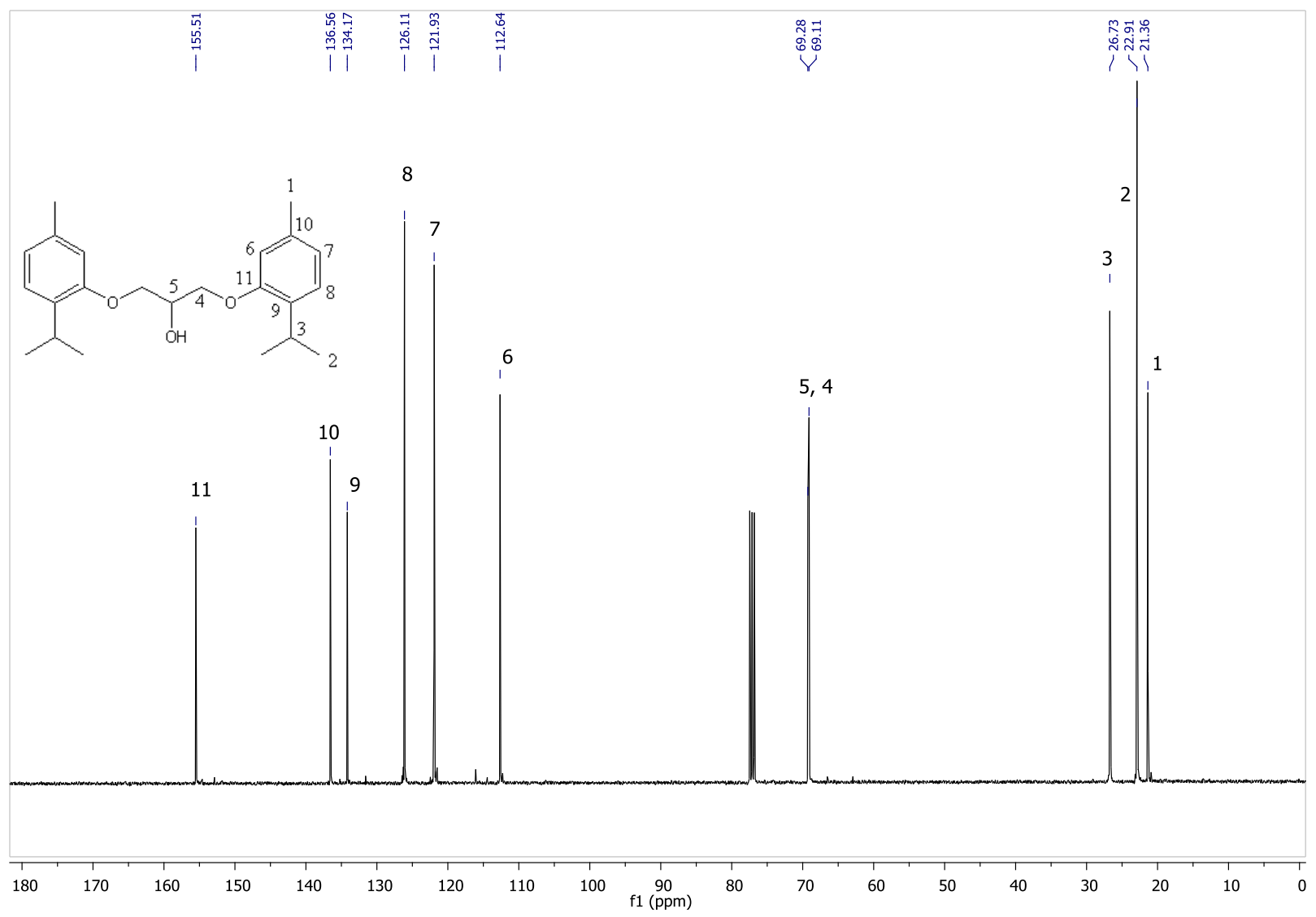

Figure 39: ${ }^{13} \mathrm{C} \mathrm{NMR}\left(\mathrm{CDCl}_{3}\right)$ spectrum of 34 .

All expected ${ }^{13} \mathrm{C}$ NMR resonances associated with $\mathbf{3 4}$ were detected. Resonances associated with thymol were detected as expected, C1 - C3 and C6 - C11. Characteristic resonances of $\mathbf{3 4}$ were detected at 69.1 and $69.3 \mathrm{ppm}$ were assigned to C4 and C5.

The mass of the proposed compound was confirmed using high resolution mass spectrometry. The protonated product was detected at $356.2[\mathrm{M}]^{+}$, while the ammoniated product was detected at 374.3 ; i.e., $\left[\mathrm{M}+\mathrm{NH}_{4}\right]^{+}$.

The NMR spectra associated with compounds 36 and 37 displayed all the expected resonances. As the resonances associated with $\mathbf{3 6}$ and $\mathbf{3 7}$ are almost identical to those of compounds $\mathbf{3 3}$ and 34, they were not presented in detail. Fully assigned spectra pertaining to 36 
and 37 are available in Appendix 1. Compound 36 was further characterized using mass spectrometry; with $\mathrm{m} / \mathrm{z}=225.1$ representing $\left[\mathrm{M}^{+}\right]$.

\subsubsection{Preparation and Characterization of 4-(4-(2,3-dihydroxypropoxy)phenyl)butan-2-one, 39}

The third natural phenol evaluated was raspberry ketone (38: Figure 4), which was reacted with glycerine carbonate, $\mathbf{1 5}$, to generate 39 (Figure 40). This particular material was explored to assess the functionality of the ketone and to evaluate its potential in polymerization.

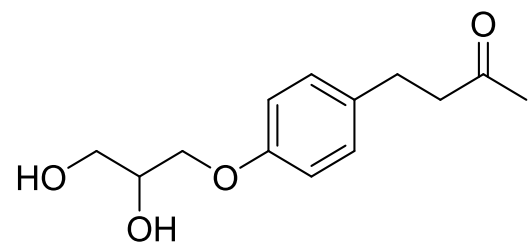

Figure 40: Proposed structure of compound 39.

As was observed with both thymol and carvacrol, after purification and exposure to air, 39 did not solidify. Purification through recrystallization was also not successful. Compound 39 was isolated as a viscous yellow oil using column chromatography. Of all the synthesized diols, 39 was the only diol isolated as a liquid. In the reaction involving $\mathbf{3 1}$ which underwent selfpolymerization (Scheme 21), it was questioned if the ketone group would have a similar effect and result in another self-polymerized material. However, 39 did not undergo selfpolymerization. 


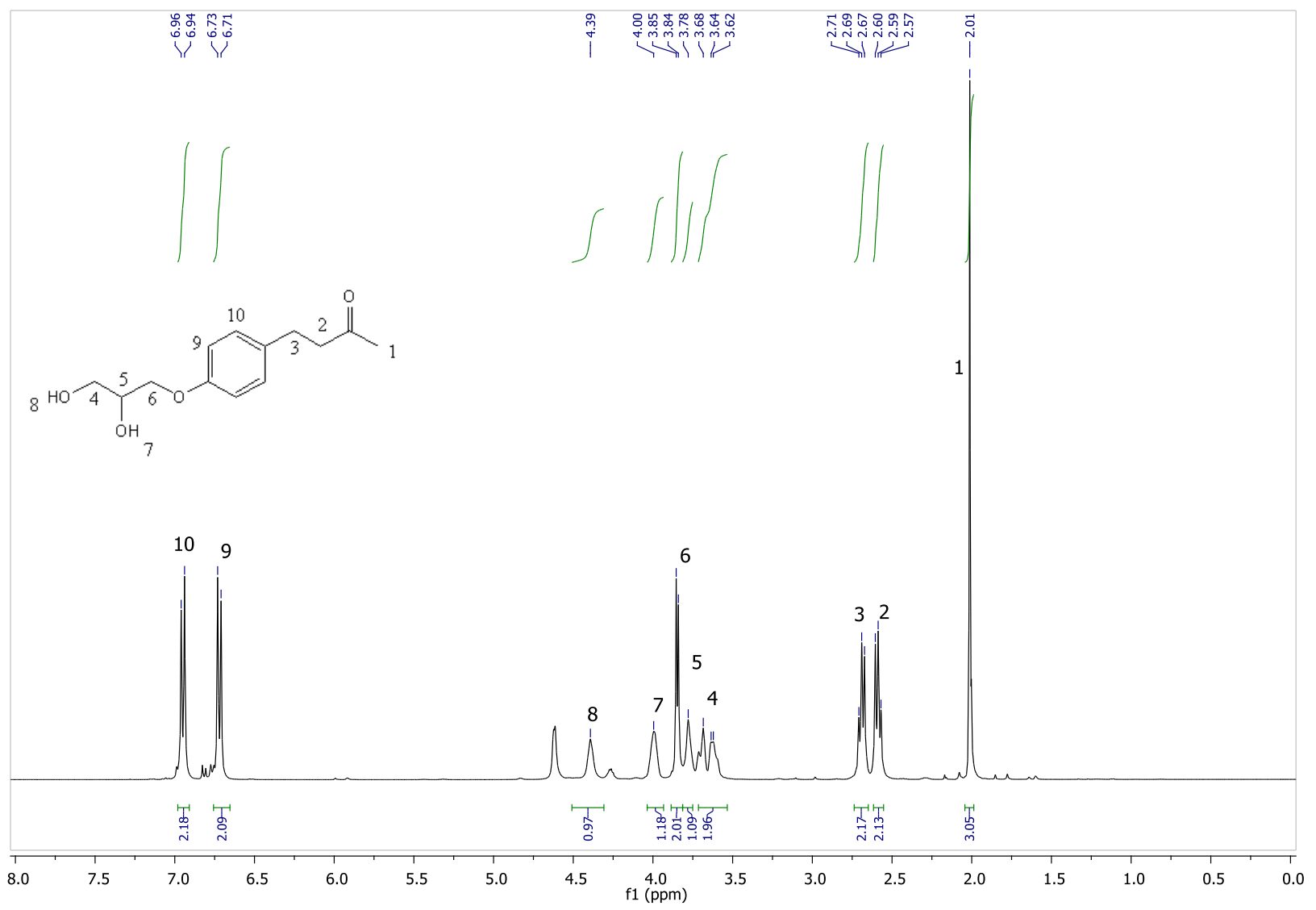

Figure 41: ${ }^{1} \mathrm{H} \mathrm{NMR}\left(\mathrm{CDCl}_{3}\right)$ spectrum of 39.

All expected ${ }^{1} \mathrm{H}$ NMR resonances for 39 were observed (Figure 41). The methyl protons, $\mathrm{H} 1$, were detected as a singlet resonance, integrating for three protons at $2.01 \mathrm{ppm}$. Two triplet resonances at 2.59 and $2.69 \mathrm{ppm}$, each integrating for two protons with a coupling constant of ${ }^{3} J$ $=7.2 \mathrm{~Hz}$ are characteristic of $\mathrm{H} 2$ and $\mathrm{H} 3$. Six resonances integrating for a total of seven protons detected between 3.5 and $4.5 \mathrm{ppm}$ is representative of the 1,2-propyl diol protons, $\mathrm{H} 4-\mathrm{H} 8$. A pair of doublet resonances detected at 6.73 and $6.94 \mathrm{ppm}$, each integrating for a total of two protons with a ${ }^{3} J=9.4 \mathrm{~Hz}$ are characteristic of the aromatic protons, $\mathrm{H} 9$ and $\mathrm{H} 10$. 


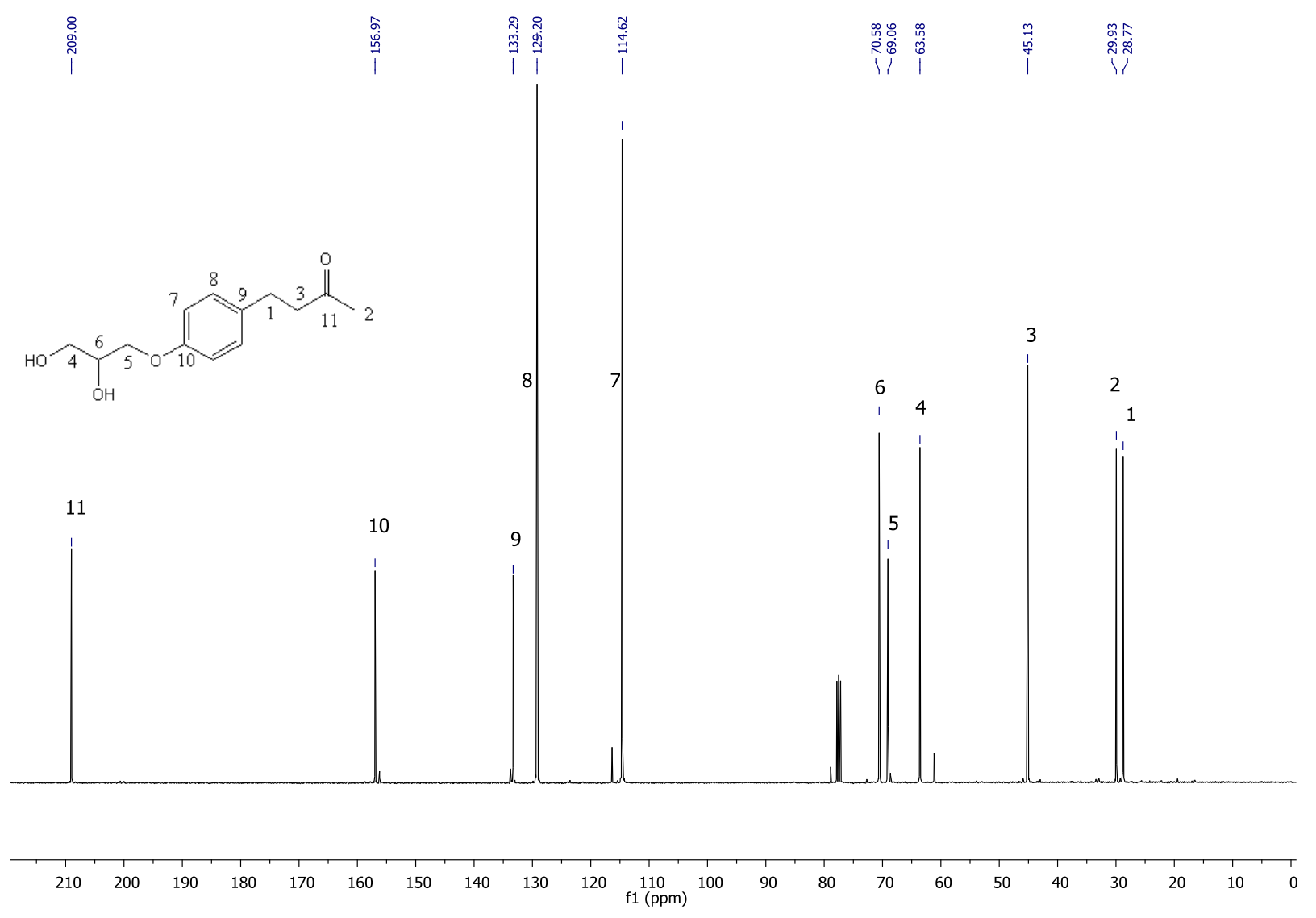

Figure 42: ${ }^{13} \mathrm{C} \mathrm{NMR}\left(\mathrm{CDCl}_{3}\right)$ spectrum of 39 .

All expected ${ }^{13} \mathrm{C}$ NMR resonances for 39 were detected (Figure 42). With respect to the butyl chain containing the carbonyl group, the four distinct carbons were observed at 28.8, 29.9, 45.1 and 209.0, C1 - C3 and C11. Three resonances at 63.4, 69.0 and 70.6 are characteristic of the newly added 1,2-propyl diol chain, C4 - C6. Two relatively large resonances at 114.6 and $129.2 \mathrm{ppm}$, each representing two carbons, represent the protonated aromatic carbon atoms, C7 and $\mathrm{C} 8$. The ispo carbons, $\mathrm{C} 9$ and $\mathrm{C} 10$, are detected at 133.3 and $156.0 \mathrm{ppm}$ respectively.

High resolution mass spectrometry was used to confirm the mass of 39. Signals were detected at $238.1 \mathrm{~m} / \mathrm{z}\left[\mathrm{M}^{+}\right]$and $256.2 \mathrm{~m} / \mathrm{z}\left[\mathrm{M}+\mathrm{NH}_{4}\right]^{+}$. 
Compound 40, the di-substituted product was isolated as a yellow colored oil and characterized using ${ }^{1} \mathrm{H}$ and ${ }^{13} \mathrm{C}$ spectroscopy.

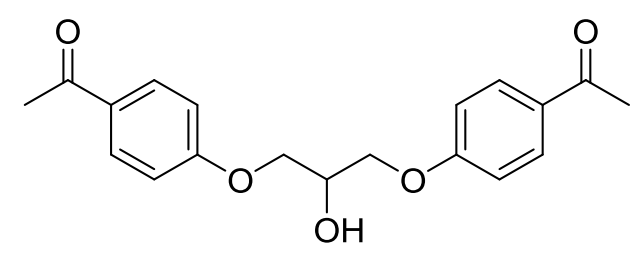

Figure 43: Proposed structure of 40.

Both spectra can be found in Appendix 1. Compound 40 was not confirmed using high resolution mass spectrometry as it is a by-product and of little interest.

The three natural phenols explored above, all have a similar issue; they do not solidify if exposed to air. This eliminates the possibility of recrystallization. Polymerizations involving the resulting crude material from the reactions above were attempted but did not prove successful (see Section 2.4.6.) As this work was to be targeted for an industrial process, materials requiring chromatography for separation were not suitable and as such polymerization efforts were not undertaken with the three diols described above.

2.3.2.7 Preparation and Characterization of 3-(4-methoxyphenoxy)propane-1,2-diol, 42, and 3(p-tolyloxy)propane-1,2-diol, 45

With respect to the natural compounds explored above, none of them contained a methoxy group. This was the only noticeable difference with respect to the lignin based materials which all readily solidified. The position of the methoxy group also plays a role in determining the state of the material. Guaiacol (9) has a methoxy group ortho to the hydroxyl group and, at room temperature, is a liquid. $P$-methoxy phenol (20) has a methoxy group para to 
the hydroxyl group and at room temperature exists as a solid. Materials suitable for polymerizations required recrystallization and as such, rapidly solidifying materials allowing for rapid recrystallization, were ideal. The following reactions involved phenols $\mathbf{4 1}$ and $\mathbf{4 4}$ that were not explored for polymeric purposes but rather, were carried out to evaluate the effect of the position of the methoxy group relative to the hydroxyl group in resulting materials (Figure 44). Lignin fragments, for the most part, often contain a methoxy group. As such, determining the ideal position, as well as if the methoxy group is required for quick solidification, would be useful information.

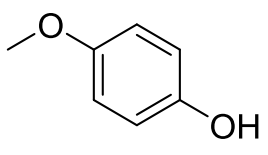

41

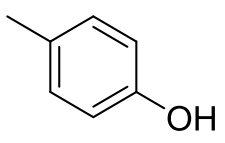

44

Figure 44: Structure of $p$-methoxy phenol, 41 and $p$-cresol 44.

Since purification required the solidified materials, the position of the methoxy group was examined to see if would make any difference in the solidification process. The resulting material from a reaction involving 41, 15 and $\mathrm{K}_{2} \mathrm{CO}_{3}$ yielded 42 and the di-substituted by-product 43 (Figure 45 and 46). Both compounds were isolated as white powders and characterized using NMR spectroscopy. NMR spectra of the isolated compounds can be found in Appendix 1.

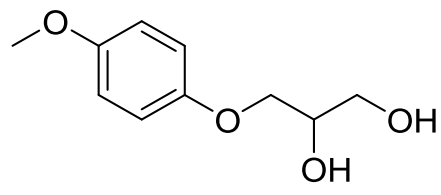

Figure 45: Proposed structure of compound 42. 


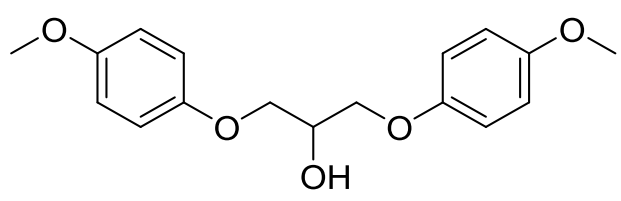

Figure 46: Proposed structure of compound 43.

When 26 (Figure 25) was synthesized, it took several days for the material to completely solidify where as the diol synthesized from $p$-methoxy phenol (42), solidified almost immediately. Relative to the solidification of $\mathbf{2 6 , 4 2}$ solidified much faster. As such, a general assumption can be made that phenols with a methoxy group in the para position would be preferred for diol production.

$P$-cresol (44) was also reacted with glycerine carbonate to examine if the resulting material would produce a solid. This was done to determine whether or not a methoxy group was required for the resulting material to readily solidify. This question was asked because when diol synthesis was attempted from thymol, carvacol and raspberry ketone, unlike all other diols, their resulting reaction materials did not solidify. When isolated, 39 was an oil and as such, solids were not expected however $\mathbf{3 3}$ and $\mathbf{3 6}$ were in fact isolated as solids. As solid materials were required for recrystallization, it was questioned as to why these two materials did not precipitate from the reaction mixture. The primary difference in these materials was the absence of the methoxy group and as such $\mathbf{4 4}$ was further explored.

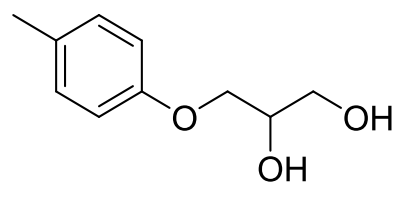

Figure 47: Proposed structure of compound 45. 
Compound 45 was isolated as yellow solid and characterized using ${ }^{1} \mathrm{H}$ and ${ }^{13} \mathrm{C}$ NMR spectroscopy and high resolution mass spectrometry (Figure 47).

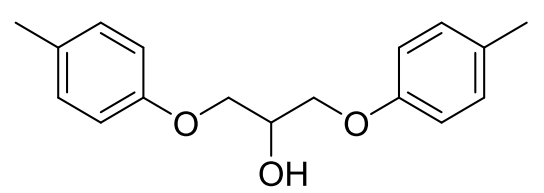

Figure 48: Proposed structure of compound 46.

Compound 46 was also isolated and characterized (Figure 48). The resulting reaction material had an extremely foul odor. The resulting material solidified within several hours after the reaction was completed. As such, the presence of a methoxy group was not required for solidification. Further evaluation other than characterization of this material was not performed.

In these materials, the di-substituted by-product was much more evident than in reactions involving the lignin based phenols such eugenol, propyl guiaicol or vanillin. The NMR spectra of 45 and 46 are available in Appendix 1.

2.3.2.8 Preparation and Characterization of 3-(4-(2-(2-methoxyphenoxy)ethyl)phenoxy)propane-

\section{$\underline{1,2-\operatorname{diol} 47}$}

The final synthetically generated diol was based on the $\beta-\mathrm{O}-4$ linkage which was modelled using 13. In the presence of glycerine carbonate and $\mathrm{K}_{2} \mathrm{CO}_{3}, 13$ was transformed into 47 (Figure 49). The resulting reaction material was a reddish-brown colored oil. Recrystallization efforts were attempted with various solvents. The only solvent to recrystallize any of the material was $\mathrm{Et}_{2} \mathrm{O}$ and even then, only a fraction of the material was successfully recrystallized. 
<smiles>COc1ccccc1OCCc1ccc(OCC(O)CO)cc1</smiles>

Figure 49: Proposed structure of compound 47.

Compound $\mathbf{4 7}$ was isolated as a white solid using column chromatography and characterized using ${ }^{1} \mathrm{H},{ }^{13} \mathrm{C}$ NMR spectroscopy and high resolution mass spectrometry (Figure 50 and 51).

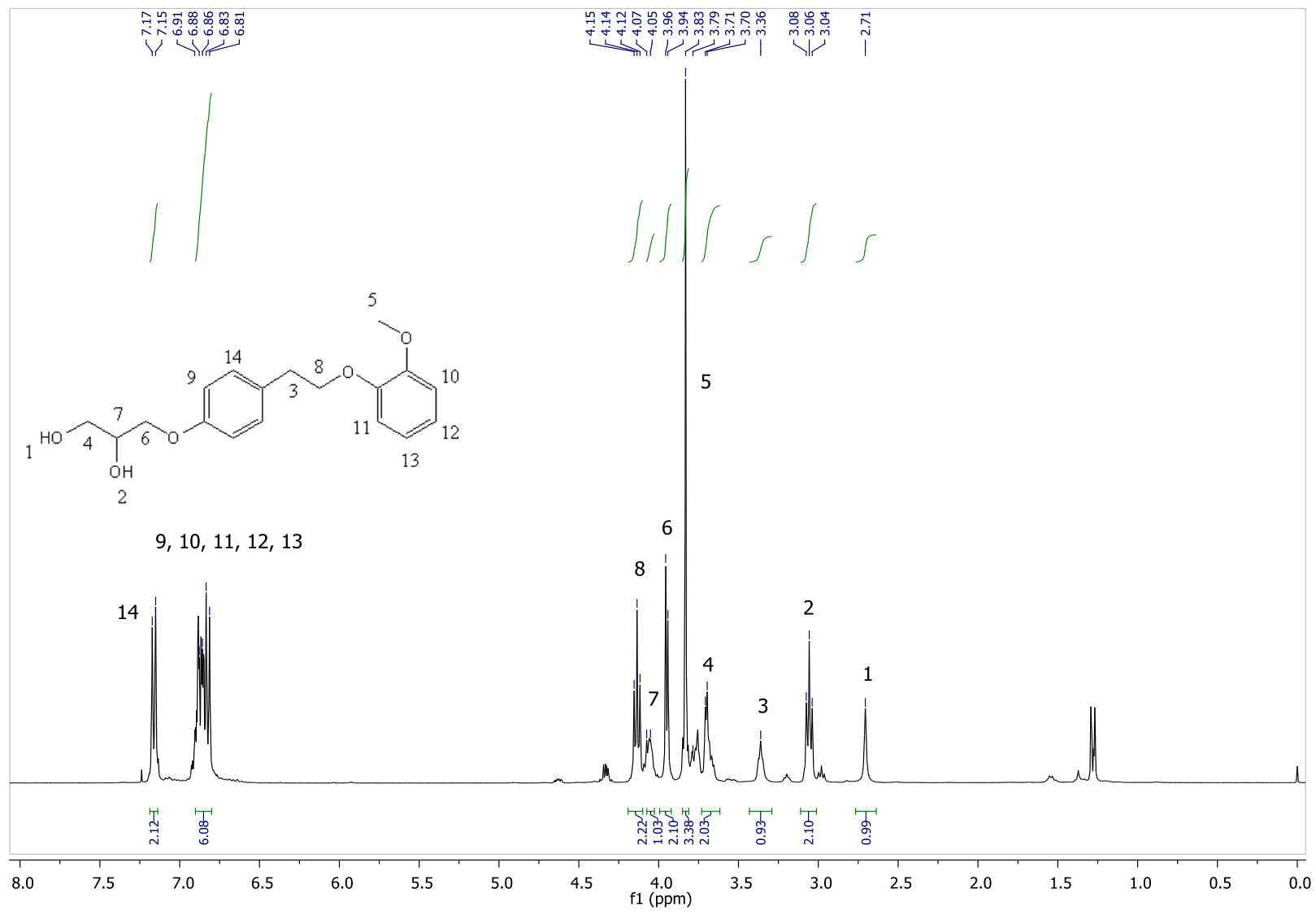

Figure 50: ${ }^{1} \mathrm{H}$ NMR spectrum $\left(\mathrm{CDCl}_{3}\right)$ of 47.

All expected ${ }^{1} \mathrm{H}$ NMR resonances associated with $\mathbf{4 7}$ were observed. A set of triplet resonances detected at 3.06 and $4.14 \mathrm{ppm}$, each integrating for two protons with a coupling constant of ${ }^{3} \mathrm{~J}=7.3 \mathrm{~Hz}$ are characteristic of $\mathrm{H} 2$ and $\mathrm{H} 8$. Both hydroxyl protons are observed at 
2.71 and $3.36 \mathrm{ppm}$. A strong singlet resonance at $3.89 \mathrm{ppm}$, integrating for three protons is characertistic of the methoxy group. Resonances resulting from the 1,2-propyldiol group can be observed between $3.5-4.5 \mathrm{ppm}, \mathrm{H} 4$, H6 and H7. Proton H4 is detected as a multiplet, integrating for two protons. A doublet observed at $3.94 \mathrm{ppm}$ integrating for two protons is characteristic of $\mathrm{H6}$ and multiplet integrating for one proton is characteristic of H7. All six aromatic protons were detected between $6.5-7.5 \mathrm{ppm}$. As is expected with para substituted aromatic species, a set of doublets is usually observed. In this spectrum, only a doublet is evidently visible. The second set is hidden under the multiplet at $\delta=6.85 \mathrm{ppm}$. As a result, the multiplet is integrating for six protons. The hidden doublet is actually at $6.82 \mathrm{ppm}$ which was confirmed as the coupling constant for the doublet which was ${ }^{3} J=8.6 \mathrm{~Hz}$, this matches the coupling constant of the doublet at $7.16 \mathrm{ppm}$. 


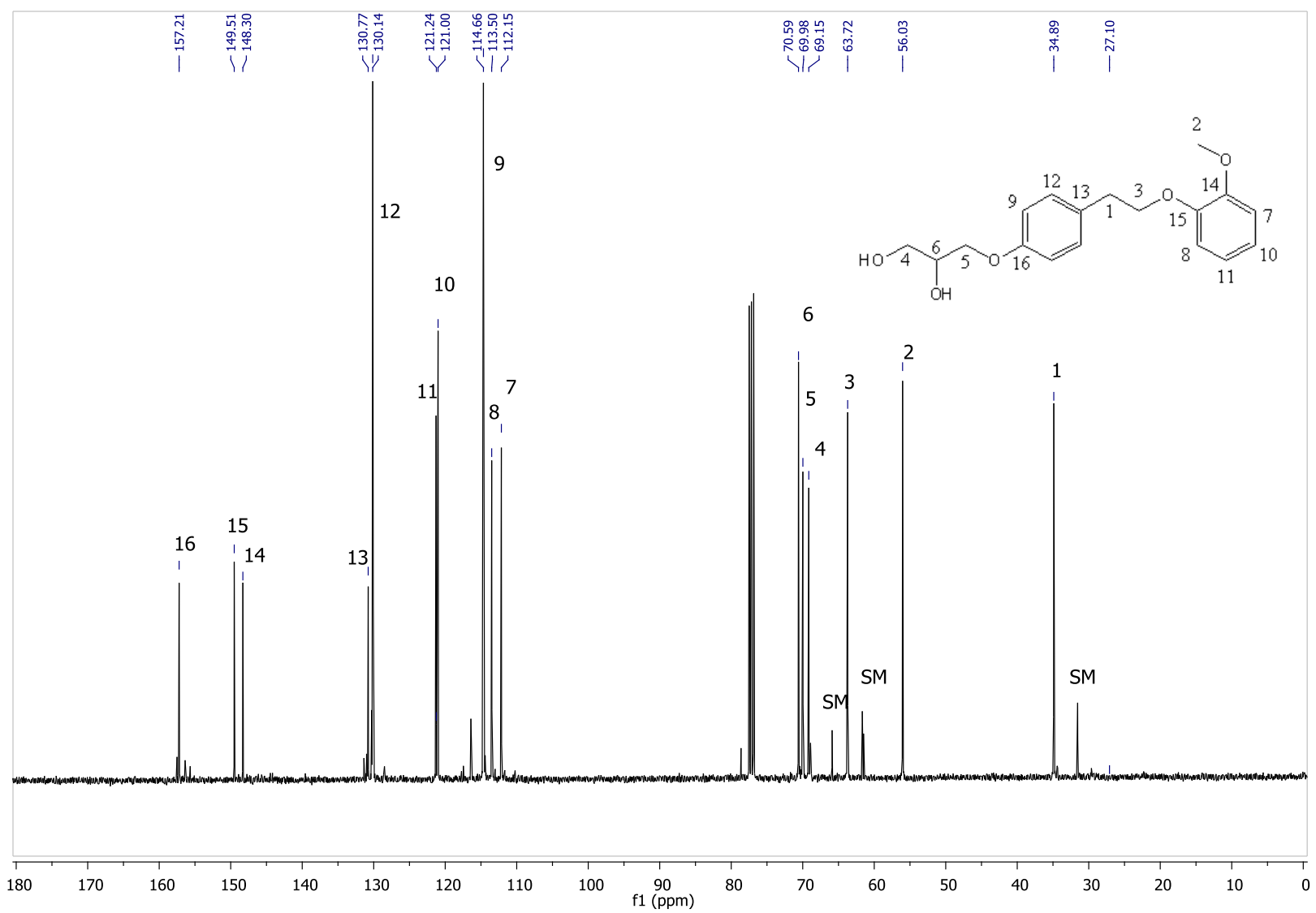

Figure 51: ${ }^{13} \mathrm{C}$ NMR spectrum $\left(\mathrm{CDCl}_{3}\right)$ of 47 .

All expected ${ }^{13} \mathrm{C}$ NMR resonances were detected. The ethyl ether linking carbons, $\mathrm{C} 1$ and C3, were detected at 34.9 and $63.7 \mathrm{ppm}$. The methoxy carbon, C2, was observed at 58.0 ppm. The three propyl carbons were detected at 69.2, 70.0 and $70.6 \mathrm{ppm}$. All twelve aromatic carbon species were accounted for in the $110-160 \mathrm{ppm}$ range. Although, only ten resonances are visible, the resonances observed at 114.7 and $130.1 \mathrm{ppm}$ are due to the para substituted aromatic species and hence, account for two carbon atoms each.

The resulting sample was analyzed using high resolution mass spectrometry. Both 319.16 [M $\left.{ }^{+}\right]$ and $336.2 \mathrm{~m} / \mathrm{z}\left[\mathrm{M}^{+}+\mathrm{NH}_{4}\right]$ were detected. As was seen with 13, the ethyl ether link was broken and a signal at $195.1 \mathrm{~m} / \mathrm{z}$ was detected which is characteristic of the fragment presented below (Figure 52). 


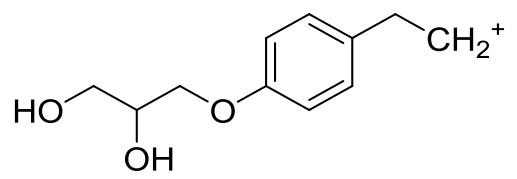

Figure 52: Fragment of $\mathbf{4 7}$ detected during high resolution mass spectrometry.

Even though the resulting material from $\mathbf{4 7}$ was recrystallized, multiple species were found in this material which was confirmed using NMR, mass spectrometry and simple thin layer chromatography. These excess species were assumed to come from minor by-products associated with the synthesis of precursor 13. The assumption was made that, as the scale-up procedure for $\mathbf{1 3}$ was performed on a large scale, it was more than likely that impurities made it through the initial purification process. Efforts were undertaken to further purify this material including acid washes, acid - base extractions and various solvent extractions. However, no successful results were noted. With respect to the material containing $\mathbf{4 7}$, based on NMR, it was approximated that about $10-20 \mathrm{wt} \%$ of the crude was impurities and as such, polymerizations were not attempted with the resulting material.

\subsubsection{Efforts to Determine the Mechanism Meading to Di-substituted By-products}

Efforts were undertaken to try and understand the mechanism during which the disubstituted product forms as well as to try and minimize its occurrence. If the by - product production could be eliminated during diol production, purifications would no longer be required which would allow for a continuous process during resin production. The following reactions were monitored using TLC and resulting products were evaluated against confirmed reference materials. Experiments were carried out using guaiacol (9) and commercially acquired 26. Reference TLC materials were $\mathbf{9 , 2 6}$ and $\mathbf{2 7}$. One method by Truscello et al. proposed to reduce the formation of by-products by using a higher ratio of glycerin carbonate (15) to phenol. 
According to Truscello et al., this greatly reduced the yield of the by-product. However, employing those ratios would still require a further purification step therefore eliminating the possibility of a continuous process.

A weak base, Triethylamine hydroiodide $\left[\mathrm{C}_{6} \mathrm{H}_{16} \mathrm{NI}\right.$, was explored to see if the use of a weaker base would reduce the yield of by-products. All reaction conditions, including reagent ratios and heating patterns were kept as close to the original reaction conditions, yielding $\mathbf{2 6}$, as possible. Using $\mathrm{K}_{2} \mathrm{CO}_{3}(\mathbf{1 0})$ a reaction was observed at approximately $140^{\circ} \mathrm{C}$. Both bubbling, assumed to be the release of $\mathrm{CO}_{2}$, and the appearance of two new spots on the TLC plate were observed at this temperature. In the presence of $\left[\mathrm{C}_{6} \mathrm{H}_{16} \mathrm{NI}\right]$, bubbling and new spots were observed after approximately two hours of reaction time and after reaching a temperature of $170^{\circ} \mathrm{C}$. The reaction was allowed to run to completion and only the two expected products, along with a very faint spot of the starting material 9 was observed. As such, it was concluded that using this base did not stop the formation of the by - product. The ratio of resulting products was not determined.

The reaction was then performed in the absence of a base. Bubbling and additional spots were observed after heating to around $170^{\circ} \mathrm{C}$. The two expected products, along with a very faint spot of starting material 9 , was observed. Based on this observation, $\left[\mathrm{C}_{6} \mathrm{H}_{16} \mathrm{NI}\right]$ may have been ineffective. Regardless, the current experimental parameters involving temperature and reagent ratios will result in the formation of di-substituted by-products.

\subsubsection{Proposed Mechanism of Formation of Di-substituted By-products}

Unlike the formation of the desired diol which occurs in one step, it is presumed that the formation of the di-substituted by-products requires a two-step process involving a presumed 
intermediate compound, by-product $\mathbf{D}$, as discussed in Figure 19. The formation of intermediate D is presumed to be the cause of the formation of the di-substituted by-products (Scheme 15).
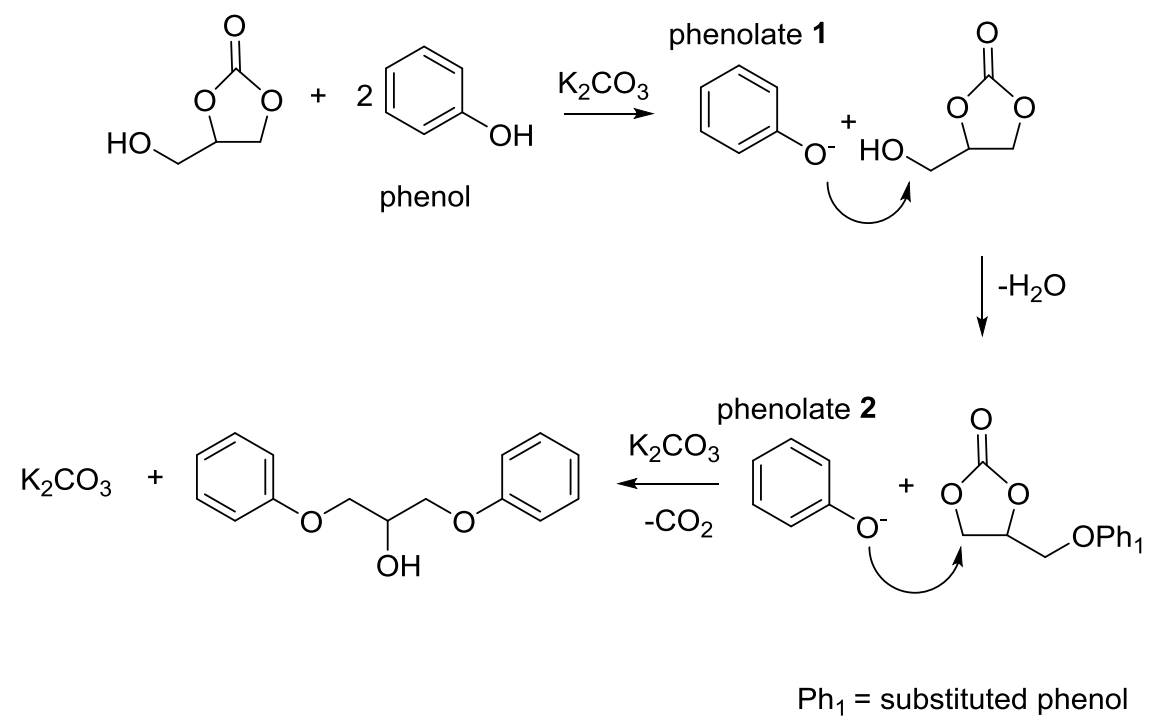

Scheme 15: Proposed general mechanism for the formation of di-substituted by-products.

In this mechanism, a phenol is deprotonated which then attacks the $\alpha$ carbon generating $\mathbf{D}$ and water. Compound $\mathbf{D}$ is then susceptible to attack by a second phenolate present in the reaction mixture, phenol $\mathbf{B}$, which generates the di-substituted by-product and $\mathrm{CO}_{2}$.

\subsubsection{Unlikely Mechanism of Formation of Di-substituted By-products}

The possibility of the desired diol forming first followed by nucleophilic attack of a second phenol on the $\alpha$ carbon of diol to generate the di-substituted by-product was explored. If the hydroxyl group found on glycerine carbonate acts as a leaving group during the nucleophilic attack of the phenol, then the question of whether or not it would be possible for the 1,2-propyl diol based compound to have formed followed by the nucleophilic attack of a second phenol onto the $\alpha$ carbon, as shown below (Scheme 16). 


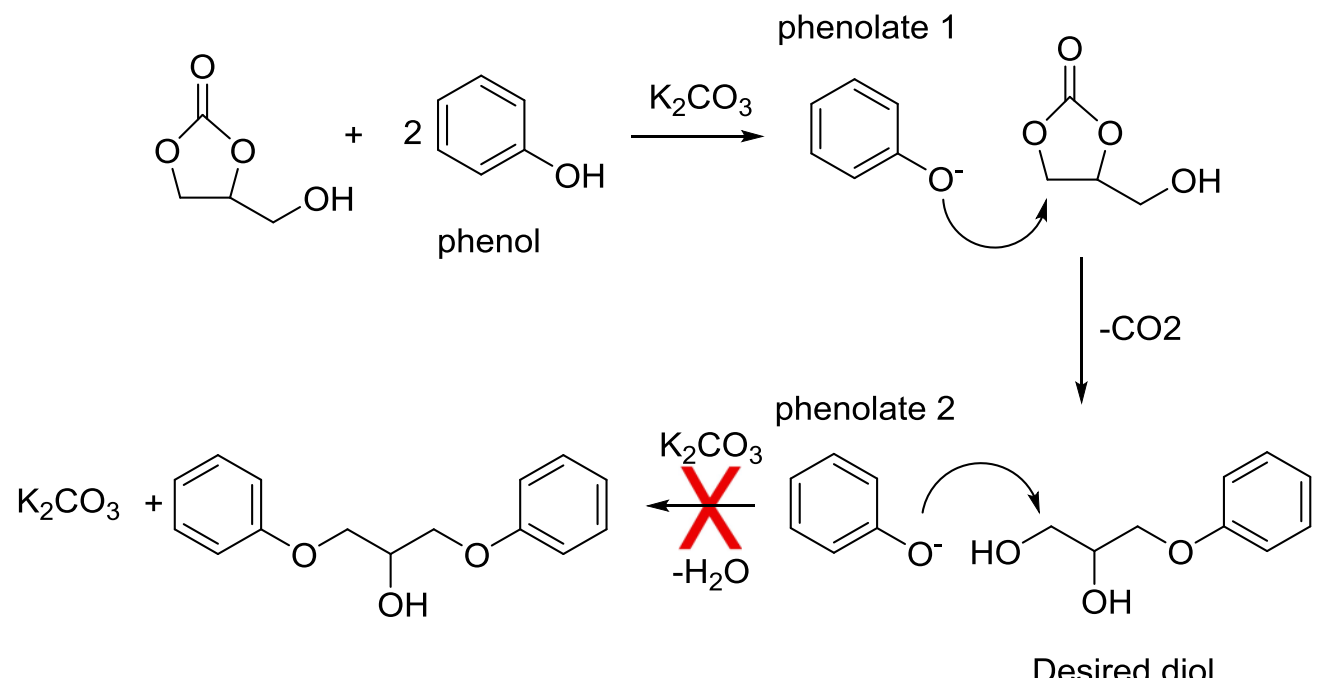

Scheme 16: Unlikely mechanism leading to the formation of di-substituted by-products.

This is not believed to be case for several reasons. Compound $\mathbf{9}$ and commercially acquired 26 were heated in the presence of 10. In a separate reaction, compound 9 and glycerol, 48, were heated in the presence of 10. The heating regiment applied and reagent ratios were identical to previous experiments. No reaction was observed. Reagent ratios were then altered to $1: 1.5,1: 0.5$ of phenol to diol respectively. Evaluated using TLC, the expected di-substituted by-product was not observed in either reaction (Scheme 17).<smiles>COc1ccccc1OCC(O)CO</smiles>

26<smiles>OCC(O)CO</smiles>

48<smiles>COc1ccccc1O</smiles>

9<smiles>COc1ccccc1OCC(O)COc1ccccc1OC</smiles>

27<smiles>COc1ccccc1OCC(O)COc1ccccc1OC</smiles>

27

Scheme 17: Unsuccessful efforts to synthesize di-substituted compounds in efforts to understand its formation. 
In these reactions, $\mathbf{2 7}$ was not detected. The noticeable difference between the reactions presented in scheme 17 and other reactions which yielded di-substituted by-products was the absence of the carbonyl group of $\mathbf{1 5}$.

From a processing or manufacturing point of view, synthetically generated diols need to be relatively pure (>95\%) for successful polymerization processes which will be discussed in the following section. None the less, more efforts are needed to generate diols in a relatively pure manner if these processes are to be successful in generating resins suitable for commercial use.

\subsection{Polymerization of Bio-based Monomers}

\subsubsection{Polymerization Overview; Monitoring and Evaluating Resulting Polymers}

Monitoring the polymerization to determine the level of completion of the reaction was accomplished using acid values (A.V.'s) and softening points $\left(T_{s}\right)$. A.V.'s are a measure of the remaining carboxylic acid groups in the system while the $T_{\mathrm{s}}$ is a property measured to determine at what temperature a material softens to a specific point. A.V. were obtained by removing a small amount of molten material, usually between $0.25 \mathrm{~g}-0.5 \mathrm{~g}$. The exact mass was recorded. The molten material, which solidified almost immediately upon removal from the reaction vessel, was dissolved in THF. Two drops of phenophathalene were added to the solution. The solution was titrated with $0.1 \mathrm{~N} \mathrm{KOH}$. The required volume of $\mathrm{KOH}$ was then multiplied by 5.611 which is the mass, in grams, of $\mathrm{KOH}$ per litre of a $0.1 \mathrm{~N}$ solution. This value was then divided by the mass of the dissolved material to generate the current acid value of the system. Polymerizations were considered complete once the A.V. of the material was between $15-20$. With previously explored polyester resins, the reaction was considered complete when the calculated A.V. value was between $15-20$. The A.V. is a representation of the remaining acidic 
protons of the organic acids employed in the polymerization. These acidic protons could be attributed to either end groups or to free acid compounds within the material. Softening points were determined using a Mettler-Toledo instrument. The instrument was set at an initial temperature of $100^{\circ} \mathrm{C}$ and once engaged would increase at a rate of $1^{\circ} \mathrm{C}$ per min. All other default settings were kept. Molten material was removed from the reaction vessel and placed into the circular holder. Once the resulting sample had cooled, it was then inserted into the instrument. Softening points below $100^{\circ} \mathrm{C}$ were simply recorded as such. Softening points greater than $100^{\circ} \mathrm{C}$ were recorded to the exact value. The ideal ratio of diol to acid was determined using 26 and 49 . Initially, 26 was polymerized with an equal ratio of diol to acid. The reaction was allowed to proceed however the A.V of the system would level off well above a value of 20. It was determined that a starting reagent ratio of 1.15:1.00, diol to acid, would yield the desired A.V. This ratio was used and validated for further polymerizations.

\subsubsection{Polymerizations of $\mathbf{2 6}$ with Succinic (SA), Isoterephathalic (IA) and Terephathalic (TA)} $\underline{\text { acids }}$

Polymerizations involving $\mathbf{2 6}$ and $\mathbf{5 0 , 5 2}$, and $\mathbf{5 4}$ were successfully carried out (Scheme 18). An image of material $\mathbf{5 1}$ is presented below (Figure 53).<smiles>COc1ccccc1OCC(O)C[OH2+]</smiles> 


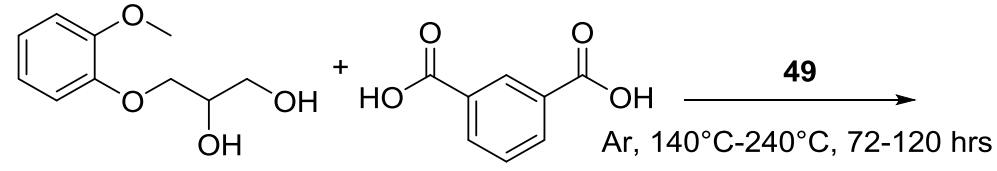

26<smiles>COC1=C(OCC(COC(=O)c2cccc(C(C)=O)c2)OC(C)(C)C)C=[C+]CO1</smiles><smiles></smiles>

Scheme 18: Polymerizations of $\mathbf{2 6}$ with various organic acids.

Materials 51, 53 and $\mathbf{5 5}$ were isolated as yellow colored solids and characterized using ${ }^{1} \mathrm{H},{ }^{13} \mathrm{C}$ NMR spectroscopy and elemental analysis.

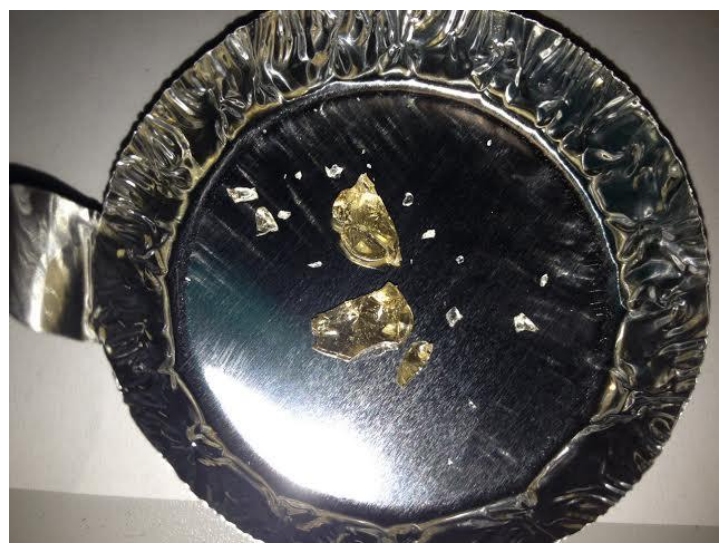

Figure 53: Image of resin 51.

Purification was attempting using toluene and methanol mixtures however these procedures proved ineffective. Elemental analyses were initially performed on some polymers however this was considered inaccurate and hence are not reported. This was because polymerizations were carried out with other ratios other than 1:1. Since purification was ineffective, the elemental analysis would be skewed as there is excess reagent and would not be reflective of the polymer alone. The resulting spectra are of crude polymeric materials. 


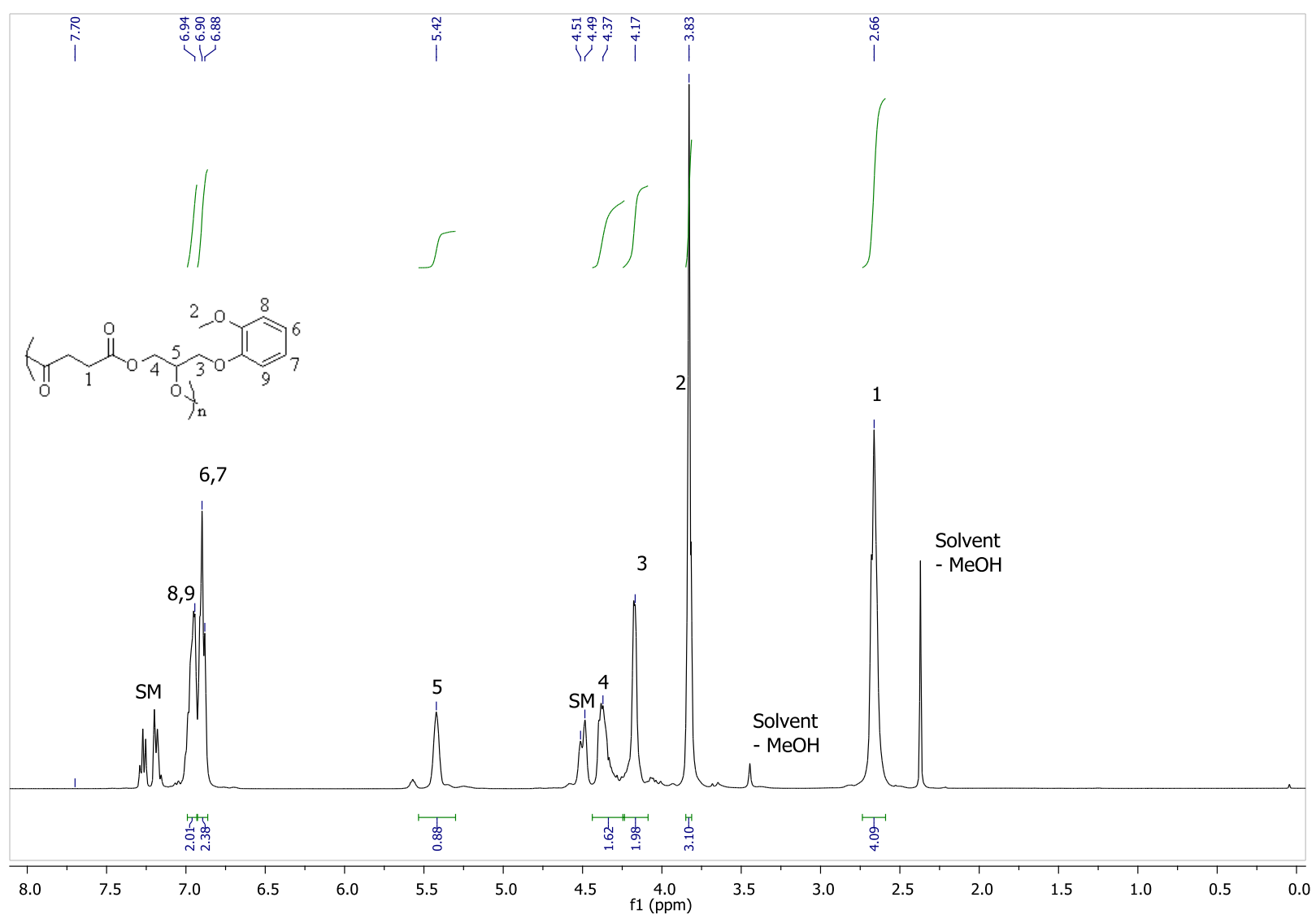

Figure 54: ${ }^{1} \mathrm{H} \mathrm{NMR}\left(\mathrm{CDCl}_{3}\right)$ spectrum of 51.

All ${ }^{1} \mathrm{H}$ NMR resonances for $\mathbf{5 1}$ were detected (Figure 54). A singlet resonance at 2.66 ppm integrating for four protons is characteristic the two saturated carbons of succinic acid, H1. Due to the nature of the polymer, all four ethyl protons of succinct are equivalent, as such, only a singlet resonance was observed. Although the resonance is quite broad, broad resonances are typically associated with polymers due to their nature. The propyl chain protons, $\mathrm{H} 3-\mathrm{H} 5$, were observed between 4.0 and $5.5 \mathrm{ppm}$ as four resonances integrating for a total of five protons. The four aromatic protons, $\mathrm{H} 6$ - H9, were observed as a two multiplets integrating for four protons at $6.90 \mathrm{ppm}$. There is evidence of starting material in the sample; most evidently, resonances associated with the aromatic region of $\mathbf{2 6}$ were detected at approximately $7.25 \mathrm{ppm}$. This is not surprising as one of the issues with this reaction was that due to the high temperatures employed, 
SA would sublime to various parts of the reaction vessel however there is no evidence of unreacted SA. This is because when the reaction was complete, the reaction vessel was carefully opened and sublimed SA was carefully removed leaving only an excess of $\mathbf{2 6}$ in the resulting material.

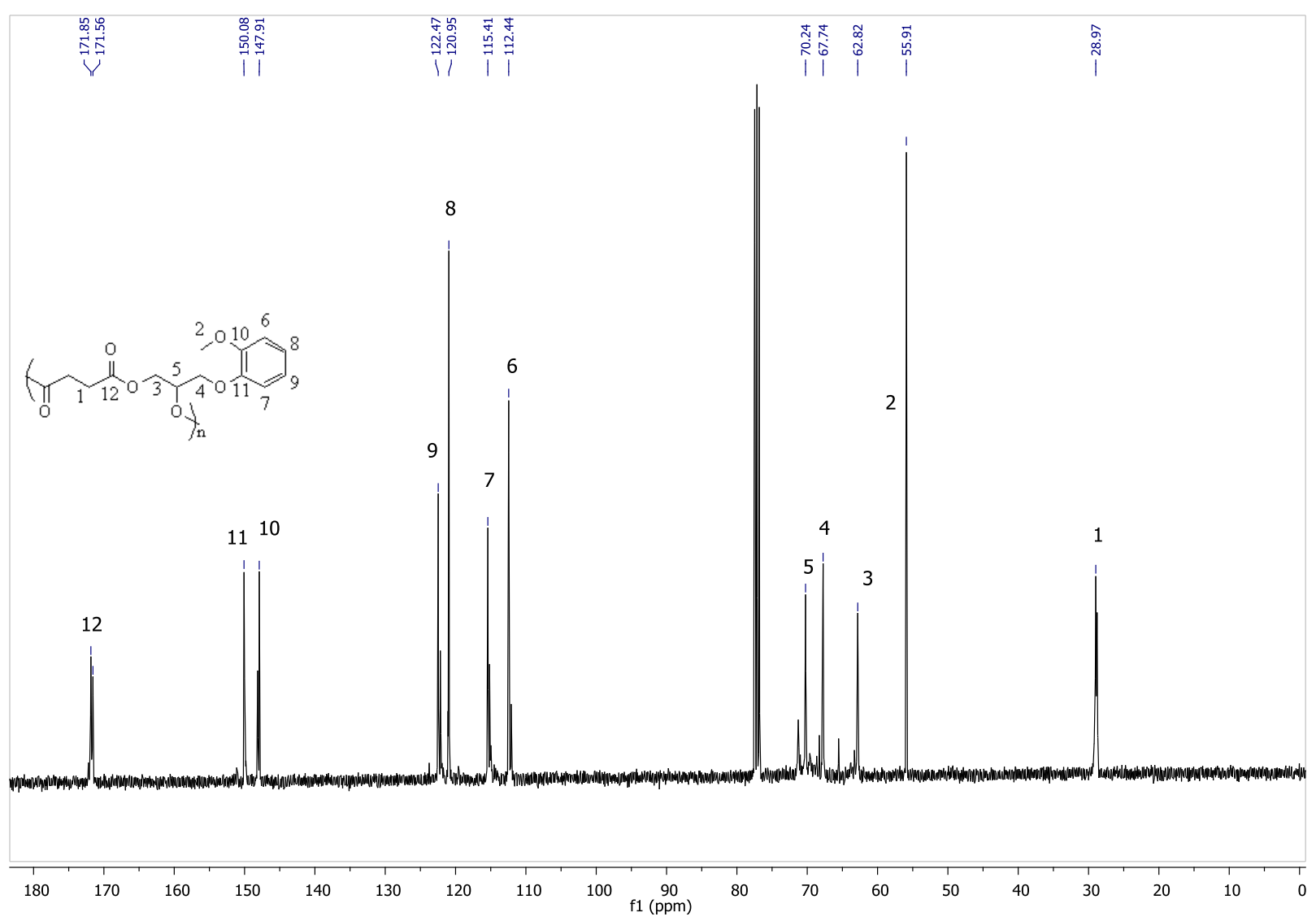

Figure 55: ${ }^{13} \mathrm{C}$ NMR $\left(\mathrm{CDCl}_{3}\right)$ spectrum of 51 .

All expected ${ }^{13} \mathrm{C}$ NMR resonances for $\mathbf{5 1}$ were detected (Figure 55). The resonance pertaining to the ethyl chain of succinic acid, C1, was detected at $30.0 \mathrm{ppm}$. The carbonyl resonance, $\mathrm{C} 12$, was observed down field at $171.9 \mathrm{ppm}$. The remaining carbon resonances, $\mathrm{C} 2-$ C11 were observed in similar fashion to 26. The methoxy carbon, C2, was observed at 55.9 ppm. The three propyl carbon atoms, C3-C5, were observed at 62.8, 67.7 and $70.2 \mathrm{ppm}$ and all six aromatic carbon signals were detected between $110-160 \mathrm{ppm}$. 


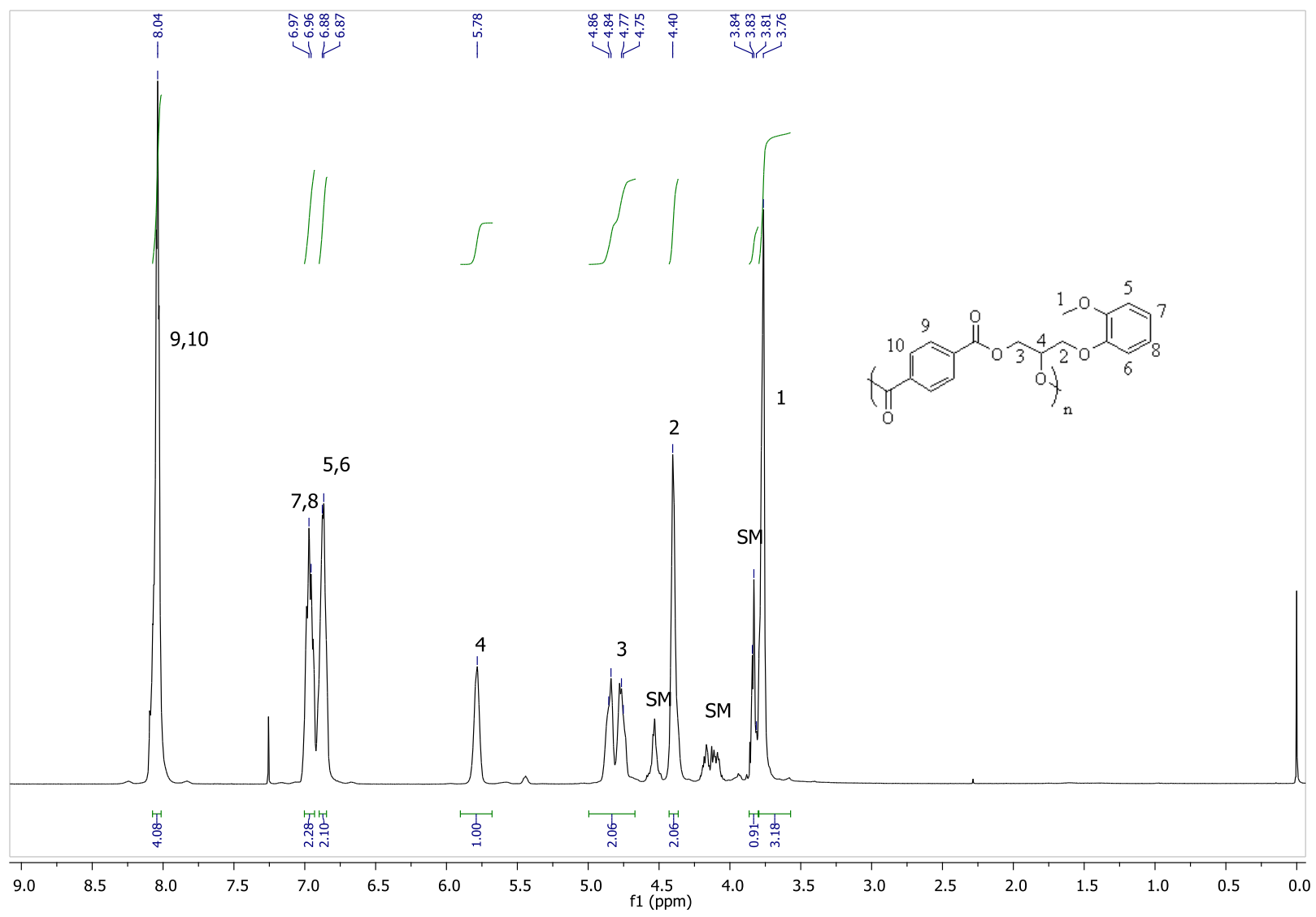

Figure 56: ${ }^{1} \mathrm{H} \mathrm{NMR}\left(\mathrm{CDCl}_{3}\right)$ spectrum of 53.

All expected ${ }^{1} \mathrm{H}$ NMR resonances for $\mathbf{5 3}$ were observed (Figure 56). The isoterephathalic aromatic protons, $\mathrm{H} 9$ and $\mathrm{H} 10$, were observed at $8.04 \mathrm{ppm}$ as a singlet resonance integrating for four protons. The methoxy protons, $\mathrm{H} 1$, were observed at $3.76 \mathrm{ppm}$. The propyl chain protons, $\mathrm{H} 2$ - H4 were observed between 4.00 and $5.00 \mathrm{ppm}$, integrating for a total of five protons. The four protons bonded to the ortho substituted aromatic ring were observed at $6.90 \mathrm{ppm}$ as a set of multiplets integrating for a total of four protons. There is evidence of $\mathbf{2 6}$ in the sample, this result was not due to sublimation but rather the excess use of $\mathbf{2 6}$ to achieve desired A.V. as discussed above. 


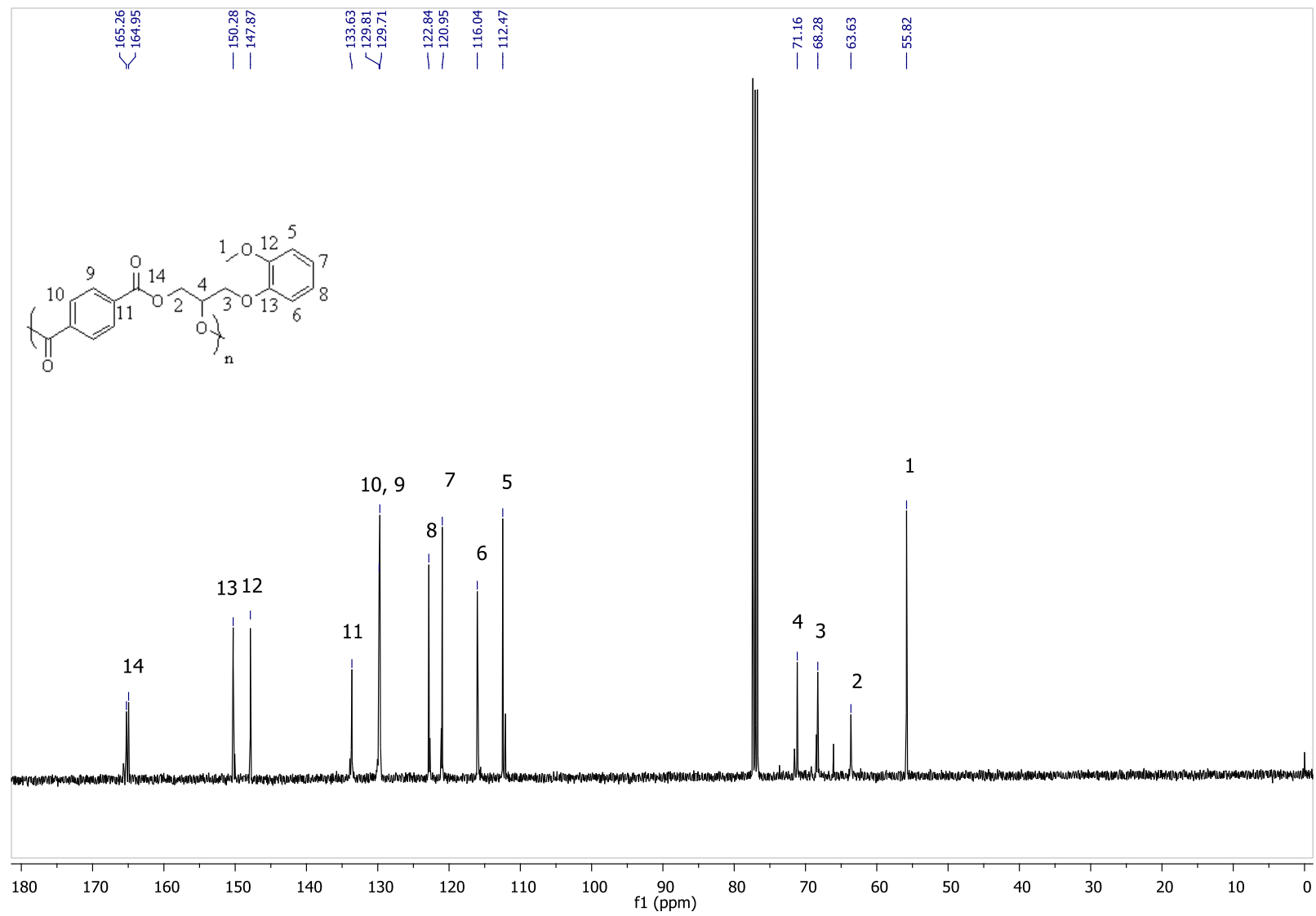

Figure 57: ${ }^{13} \mathrm{C} \mathrm{NMR}\left(\mathrm{CDCl}_{3}\right)$ spectrum of 53.

All ${ }^{13} \mathrm{C}$ NMR resonances were observed as expected (Figure 57). The isoterephathalic carbon resonances C9 - C11 and C14 were detected between 125 - 170 ppm. The aromatic carbon atoms, C9 - C11, were detected at 129.7, 129. 8 and 133.6 ppm while the carbonyl carbon, C14, at $165.1 \mathrm{ppm}$. All other resonances due to $\mathbf{2 6}$ were detected in a very similar fashion to those already described above. The aliphatic carbon atoms, $\mathrm{C} 1-\mathrm{C} 4$ were detected between 50 - 80 ppm and the remaining aromatic carbon species were detected between $110-$ $160 \mathrm{ppm}$. 


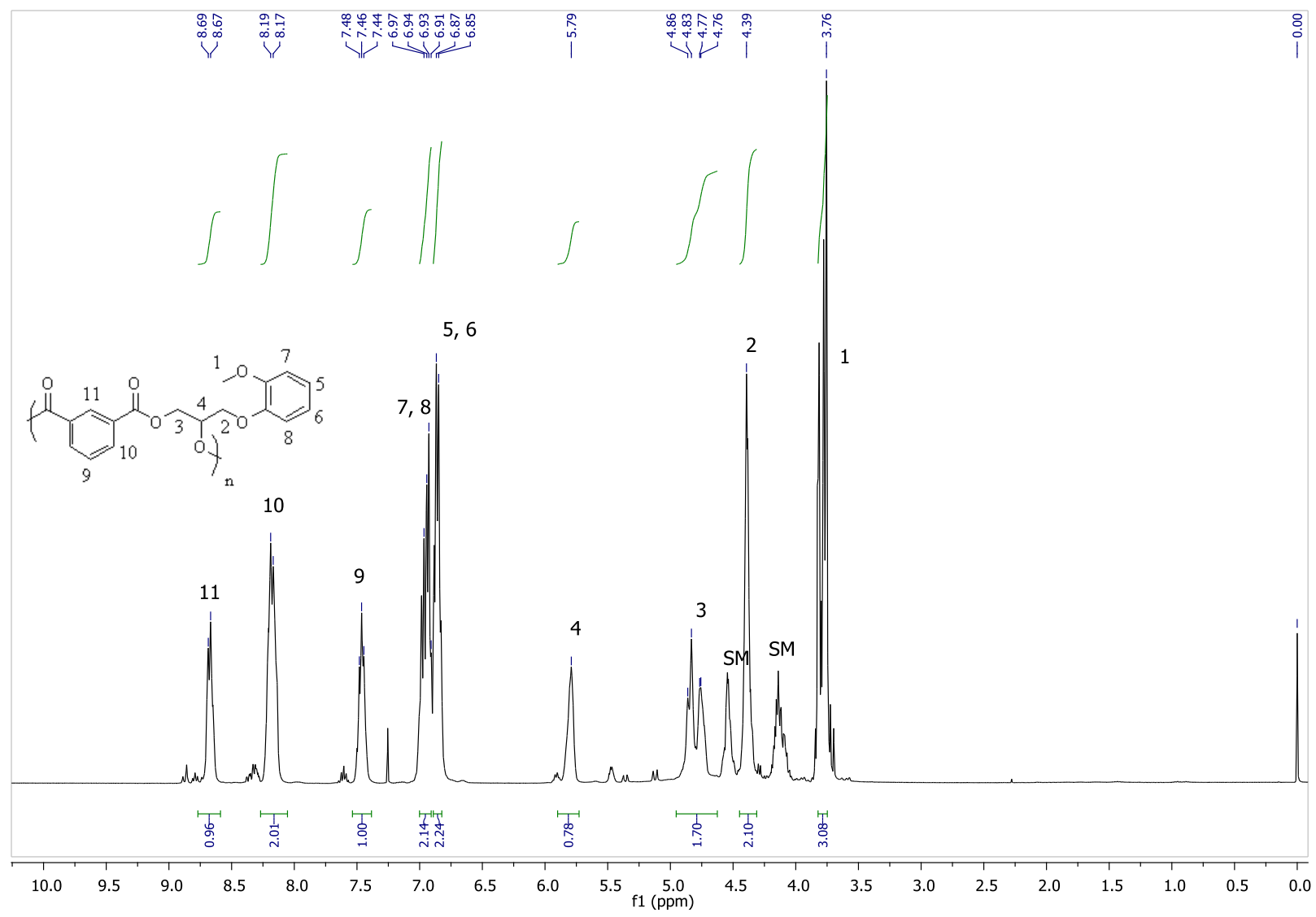

Figure 58: ${ }^{1} \mathrm{H} \mathrm{NMR}\left(\mathrm{CDCl}_{3}\right)$ spectrum of 55.

All expected ${ }^{1} \mathrm{H}$ NMR resonances for 55 were detected (Figure 58). The terephathalic aromatic protons, $\mathrm{H} 9$ - H11 were observed as three multiplets at 7.46, 8.18 and $8.68 \mathrm{ppm}$ respectively. The multiplet at 8.18 integrated for two protons while the other two multiplets integrated for only a single proton each. The aliphatic protons, H1 - H4 were detected between $3.50-6.00 \mathrm{ppm}$. Four protons associated with the aromatic component of $\mathbf{2 6}$ were detected as a set of multiplets at $6.90 \mathrm{ppm}$, each integrating for two protons. As observed with the other samples, starting material is present. 


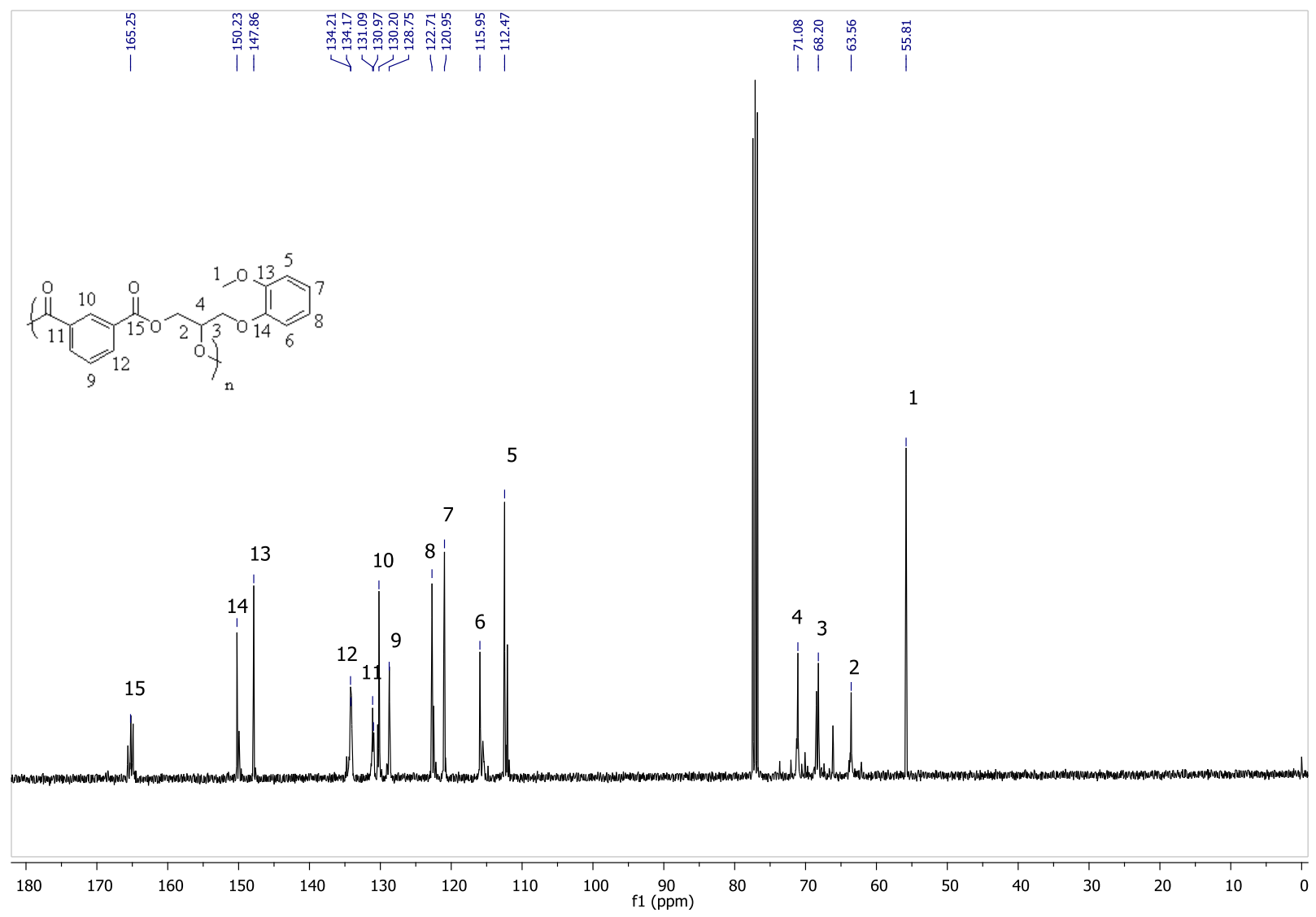

Figure 59: ${ }^{13} \mathrm{C} \mathrm{NMR}\left(\mathrm{CDCl}_{3}\right)$ spectrum of 55.

All expected ${ }^{13} \mathrm{C}$ resonances were detected (Figure 59). The methoxy and propyl chain carbons, C1 - C4, displayed resonance between $50-80 \mathrm{ppm}$. The terephathalic acid carbon species, in particular, the four aromatic carbons, C9 - C12, were detected between $125-135$ ppm. The carbonyl carbon, C15, was detected at 165.3 ppm. Carbon atoms, C5 - C8, were observed between 110 - 125 ppm and the ipso carbon atoms, C13 and C14, were detected at 147.9 and $149.2 \mathrm{ppm}$ respectively.

Producing purified 26 took several days to accomplish due to the required extensive drying and recrystallization steps. Compound $\mathbf{2 6}$ was commercially available and quite cheap and as such, was acquired to explore polymerizations with the various acids mentioned above on an industrial scale. Commercially acquired 26 was polymerized with 50, 52 and 54 with 
successful results. These results are discussed in Section 3.4.3 physical properties. The resulting materials behaved like true thermoplastics melting when heated and solidifying when cooled. These materials were heated for upwards of $120 \mathrm{hrs}$ without noticeable degradation. The resulting materials were also very glossy.

When a sufficient amount of $\mathbf{2 6}$ had been synthesized, polymerizations were attempted again using this material. The resulting polymer properties were quite poor relative to using commercially acquired $\mathbf{2 6}$. The major difference between the synthetic and commercial material is that when the synthetically generated diol was used, the reaction material would cross link and precipitated out after several days of reacting. This was not only observed in polymerizations involving 26 but polymerizations also involving 16 and 29 . Once cross linked, the resulting material was useless as it would not melt nor would dissolve in any solvent. Polymers synthesized using commercially acquired $\mathbf{2 6}$ would not produce this result. The only difference in reaction conditions was the use of a motorized stirring rod. The commercial polymerizations involved the use of a mechanical stirring arm. Due to uncontrollable circumstances, the mechanical stirring device was no longer available after the polymerizations involving commercial products were completed. All other polymerizations which involved only synthetically generated diols, involved the use of a magnetic stirring bar. Examining the commercially acquire material of $\mathbf{2 6}$ against the synthetically prepared material, no differences were observed. NMR spectra and TLC plates of commercial $\mathbf{2 6}$ versus synthetic $\mathbf{2 6}$ are identical. One explanation for the material crashing out is that as the polymerization progresses, the reaction material becomes more viscous. As this occurs, the magnetic stirring bar is not strong enough to thoroughly mix the material and as such, it slowly solidifies or cross links due to the 
concentrated heat being directly applied to uneven portion of the material. This occurs until all the material is rendered useless.

\subsubsection{Evaluation of the Catalyst}

The reaction synthesizing $\mathbf{2 6}$ was successfully repeated in the presence of a titanium catalyst (56), in particular tetraalkyl titanates instead of a tin catalyst (Scheme 19). ${ }^{47}$ This was carried out to evaluate other options instead of using a tin based catalyst as tin species are known to have detrimental environmental effects.
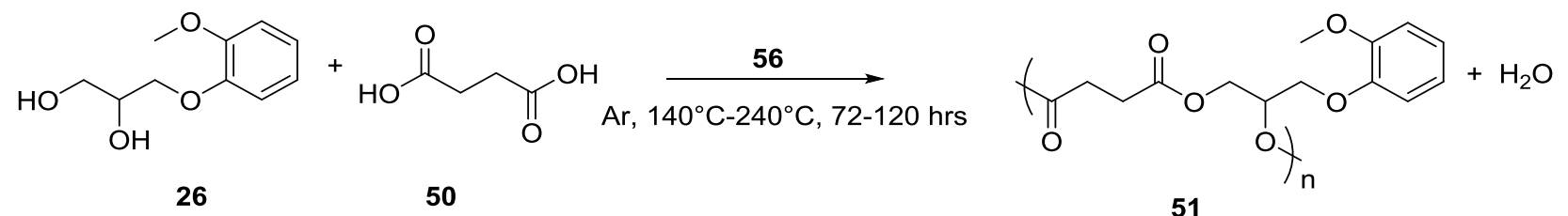

Scheme 19: Evaluation of an environmentally friendly catalyst.

Although the reaction was successful, titanium catalysts are susceptible to water which is the by - product of this reaction. Although $\mathbf{5 6}$ was successful at co-polymerizing $\mathbf{2 6}$ and 50, if and when monomers requiring higher and longer reaction times such as $\mathbf{5 2}$ and $\mathbf{5 4}$ are employed, the titanium catalyst may degrade and in these circumstances the tin catalyst will continue to be used.

\subsubsection{Polymerization of Propyl Guaiacol}

Compound 29 was reacted with all three of the organic acids (50, 52 and 54). Only succinic acid was successful in generating a resin (57: Figure 60). The heating requirements are likely too intense when employing isoterephathalic (52) or terephathalic (54) acids as monomers. The resulting material cross links before any useful material is generated. The obtained polymer (57) was soft in texture and with a yellowish tint ofcolor. 


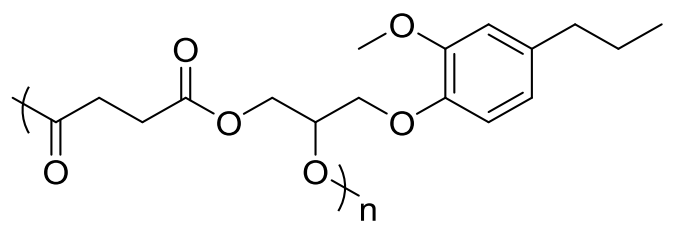

Figure 60: Proposed structure of resin 57.

Both ${ }^{1} \mathrm{H}$ and ${ }^{13} \mathrm{C}$ NMR spectroscopy analyses were performed however the resulting spectra are currently unavailable. It was assumed that the elemental analysis would not be purely reflective of the polymer due to excess diol coupled with the lack of purification. ICP elemental analysis was performed to determine the tin concentration as it posed a potential hazard since tin is considered quite toxic. The tin content was $149 \mathrm{ppm}$ in the resulting polymer. Although this concentration is relatively high, it is likely that larger amounts of reagents could be polymerized with the same amount of catalyst than what was done in this work therefore reducing this value. Physical properties are discussed below.

\subsubsection{Polymerization and Characterization of 3-(4-allyl-2-methoxyphenoxy)propane-1,2-diol}

Polymerizations involving 16 where attempted using 50, 52 and 54. Only polymerizations involving succinic acid (50) were successful (Scheme 20). An image of material $\mathbf{5 8}$ is presented below (Figure 61).<smiles>C=CCc1ccc(OCC(O)CO)c(OC)c1</smiles>

Scheme 20: Synthesis of a polyester resin $\mathbf{5 8 .}$ 


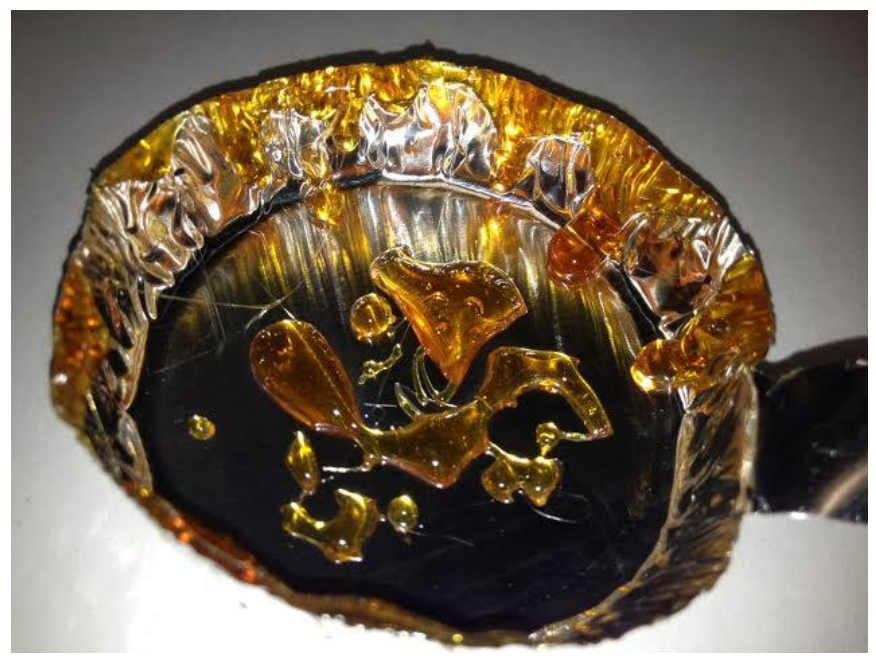

Figure 61: Image of resin 58.

Compounds 16, 50 and 49 were solids and, upon the application of heat, melt and produce a viscous orange melt. The longer the reaction proceeded, the greater the viscosity of the melt would become until it would eventually solidify. Once the material solidified, it would no longer melt nor be soluble in any solvent and resembled "rock candy". This was assumed to be due to excessive cross-linking. Prior to solidification, the resulting material, if isolated, could be melted and solidified as desired. After 72 hours, the resulting material was a clear, orange, soft and sticky solid. Spectral data, including ${ }^{1} \mathrm{H}$ and ${ }^{13} \mathrm{C}$ NMR spectra, of compound $\mathbf{5 7}$ were obtained prior to the material cross linking (Figures 62 and 63). 


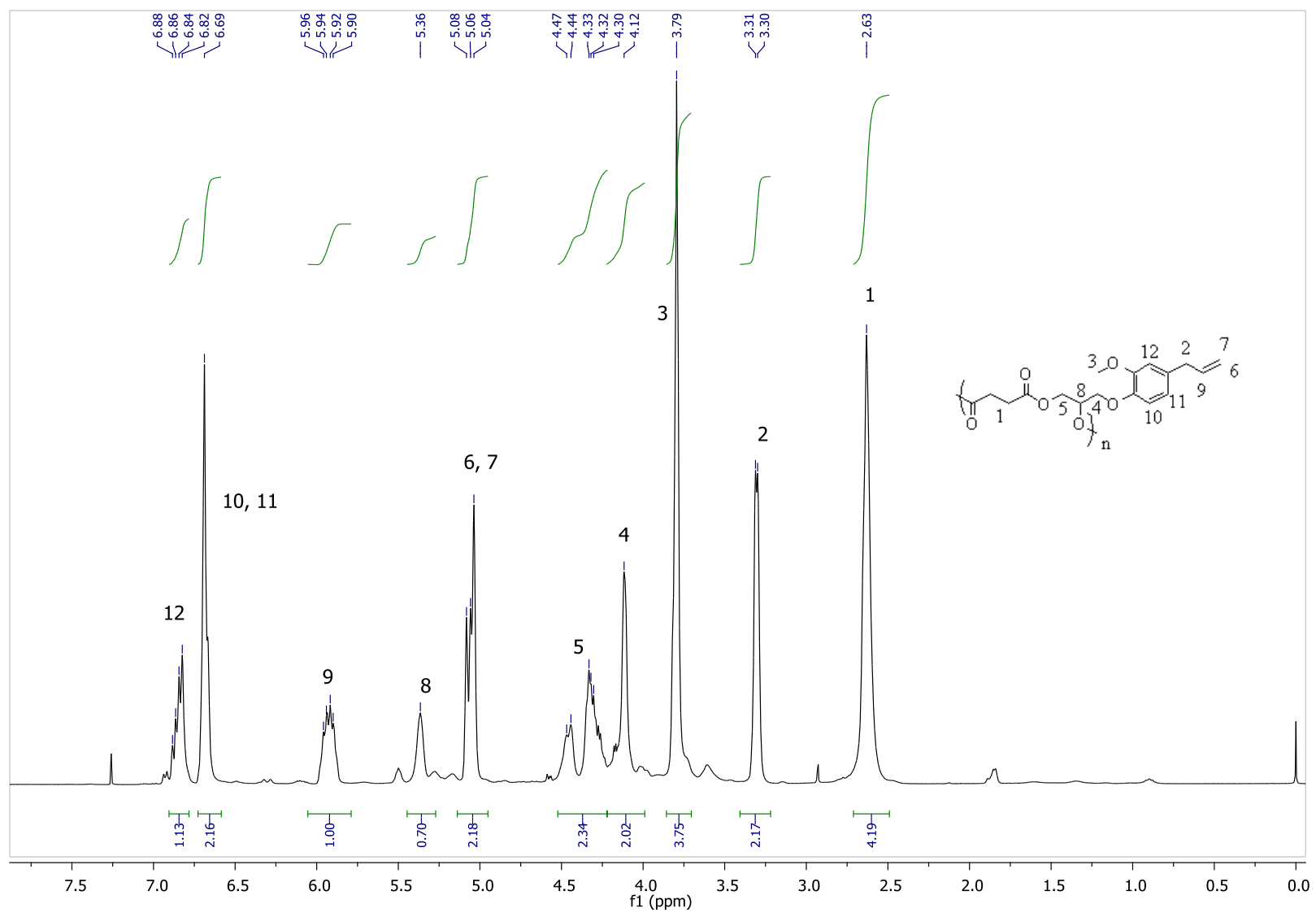

Figure 62: ${ }^{1} \mathrm{H} \mathrm{NMR}\left(\mathrm{CDCl}_{3}\right)$ spectrum of $\mathbf{5 8}$.

All ${ }^{1} \mathrm{H}$ NMR expected resonances were detected. A resonance at $2.63 \mathrm{ppm}$ integrating for four protons is characteristic of the aliphatic protons of succinic acid, H1. Resonances at 3.30, 5.93 and 5.06 ppm integrating for two, one and two protons are assigned to $\mathrm{H} 2, \mathrm{H} 6, \mathrm{H} 7$ and H10, respectively are characteristic the allyl chain. The three aromatic protons, protons H10 H13, integrating for a total of three protons are observed as a set of multiplets at approximately 6.70 and $6.80 \mathrm{ppm}$ The three methoxy protons, $\mathrm{H} 3$, and the five protons associated with the propyl chain, protons $\mathrm{H} 4, \mathrm{H} 5$ and $\mathrm{H} 8$ were all detected between 3.5 and 4.5 ppm. 


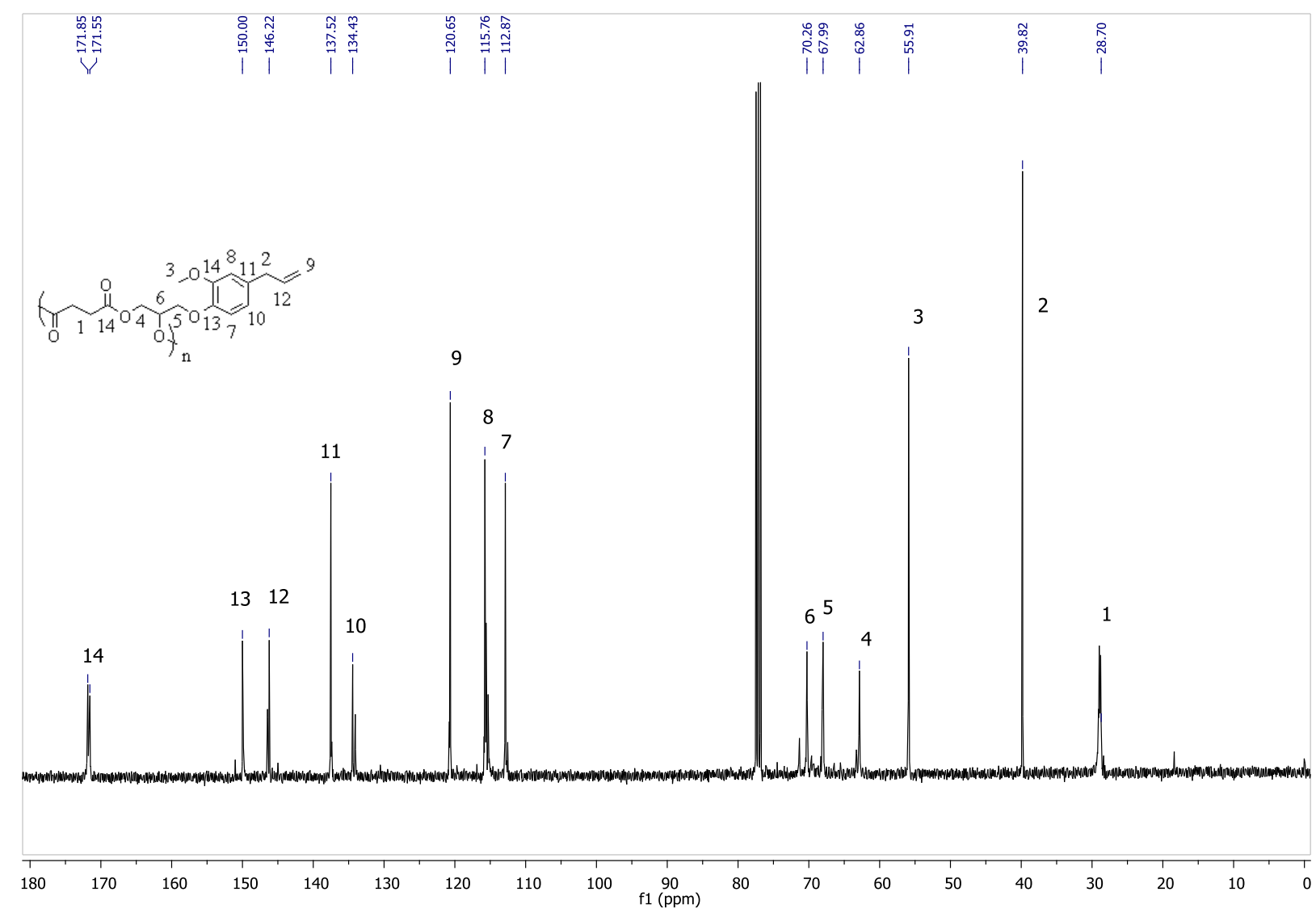

Figure 63: ${ }^{13} \mathrm{C} \mathrm{NMR}\left(\mathrm{CDCl}_{3}\right)$ spectrum of $\mathbf{5 8}$.

All ${ }^{13} \mathrm{C}$ NMR resonances were observed as expected. The carbonyl carbon resonance characteristic of succinic acid was observed $171.5 \mathrm{ppm}, \mathrm{C} 14$. All six aromatic carbon atoms were accounted for with resonances observed between $150-110$ ppm, C7, C8, C10, C11, C12 and $\mathrm{C} 13$. The three resonances associated with the allyl chain, $\mathrm{C} 2$, C9 and $\mathrm{C} 12$, the proyl chain, C4 - C6 and the methoxy carbon, C3, were detected as expected between $25-75$ ppm.

Polymerizations involving $\mathbf{1 6}$ and $\mathbf{5 2}$ or $\mathbf{5 4}$ were not successful. This is suspected to be caused by the synthetic diols as they solidify via cross-linking after several days of attempted copolymerization. This result was also observed in polymerizations involving succinic acid (50) however succinic based polymerizations required shorter reaction times and as such, would yield useful materials prior to undesirable cross-linking. Terephathalic (52) and isoterephathalic (54) 
acids require higher reaction temperatures and longer reaction times and as such, do not yield any useful materials because of related cross-linking. The terminal double bond of the allyl group is not believed to be responsible for this result. As well, the presence of the allyl chain is clearly detected in both ${ }^{1} \mathrm{H}$ and ${ }^{13} \mathrm{C}$ NMR polymer spectra after $50 \mathrm{hrs}$ of reaction time.

Polymerizations involving commercially acquired 26 did not solidify during polymerization reactions. The materials were left to react for up to seven days at temperatures reaching $245^{\circ} \mathrm{C}$. Polymerizations using commercially acquired diols and the aromatic based diacids were also successful. During reaction involving commercial 26 and 52 and 54, the reaction material was mixed with a mechanical stirring arm which could stir very viscous materials. Polymerizations involving synthetically generated diols were mixed with a magnetic stirring rod. It is possible that the cross-linking was the result of the material not being mixed properly.

\subsubsection{Self Condensing Polymerization of 4-(2,3-dihydroxypropoxy)-3-methoxybenzaldehyde, $\mathbf{3 1}$}

Unlike the eugenol-based polymer which was transformed into a polyester resin using a di-acid, the vanillin-based material underwent a self-condensing polymerization resulting in what is believed to be a polyether (59). However, the exact structure of the polymeric material has yet to be conclusively determined. Two suspected possibilities are presented below (Scheme 21). Compound $\mathbf{6 0}$ is believed to be likely outcome through the formation of a hemi-acetal followed by the formation of an acetal due to the instability of hemi-acetal (Figure 64). Although this is a likely possibility, there is little NMR data to support this claim. Compound $\mathbf{5 9}$ is believed to have formed through a condensation reaction of the alcohol groups and although less likely, is supported by both ${ }^{1} \mathrm{H}$ and ${ }^{13} \mathrm{C}$ NMR spectroscopy. 
<smiles>COc1cc(C=O)ccc1O</smiles>

30<smiles>O=C1OCC(CO)O1</smiles>

15<smiles>COc1cc(C=O)ccc1OCC(O)CO</smiles>

31

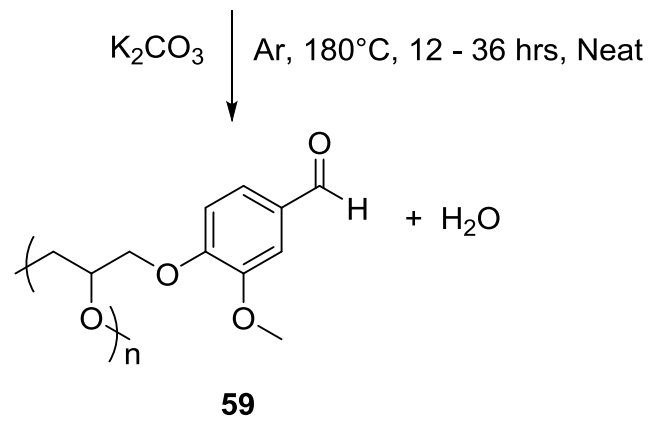

Scheme 21: Vanillin undergoing self condensation to yield a polyether (59).<smiles>COc1cc(C(C)(C)C)ccc1OCC1COC2(C)CC12</smiles>

Figure 64: Unlikely structure of the polyether which underwent acetylation.

The resulting resin was a reddish brown solid (Figure 65).

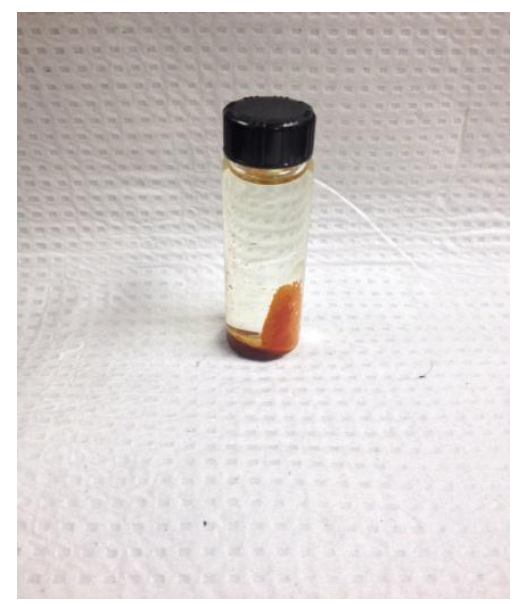

Figure 65: Image of suspected self condensing polyether. 
Elemental analysis of crude polymeric material was $63.04 \%$ Carbon, 5.48\% Hydrogen and $30.62 \%$ Oxygen: values which are consistent with a material having an empirical formula of $\mathrm{C}_{11} \mathrm{H}_{12} \mathrm{O}_{4}$. This formula is reflective of both $\mathbf{5 9}$ and $\mathbf{6 0}$. During the course of the reaction, after approximately $24 \mathrm{hrs}$, compounds 30 and $\mathbf{3 1}$ were also present in the material. After 48 hrs, neither $\mathbf{3 0}$ nor $\mathbf{3 1}$ were detected. Also, it is interesting to note that $\mathbf{5 9}$ isolated after $24 \mathrm{hrs}$, (sample 59a) had dramatically different physical properties from sample obtained after 48 hrs (sample 59b). This will be discussed in the Section 2.4.8. The resulting material after $48 \mathrm{hrs}$ was characterized using both ${ }^{1} \mathrm{H}$ and ${ }^{13} \mathrm{C}$ NMR.

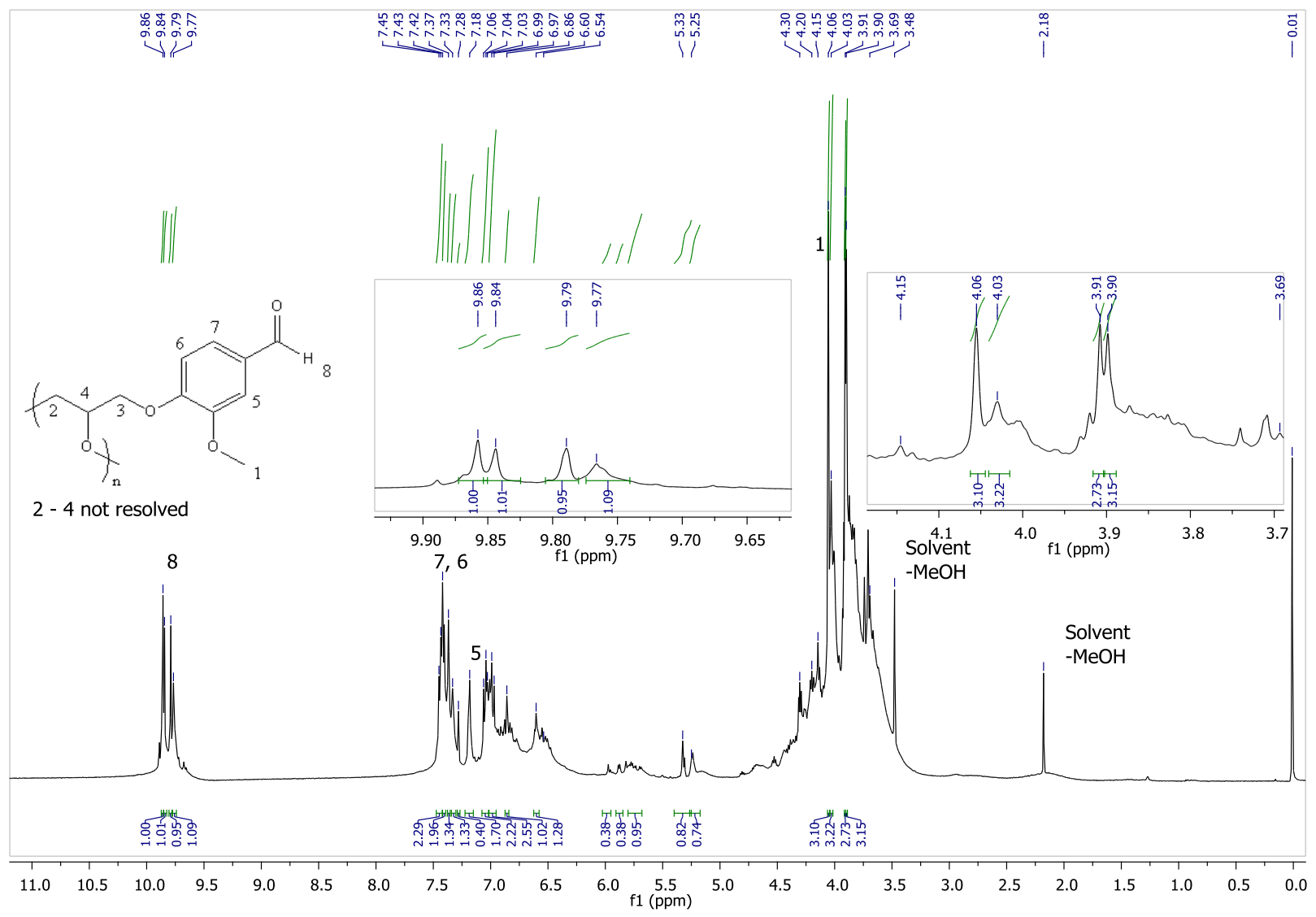

Figure 66: ${ }^{1} \mathrm{H} \mathrm{NMR}\left(\mathrm{CDCl}_{3}\right)$ spectrum of 59.

With respect to the ${ }^{1} \mathrm{H}$ NMR spectroscopy, all the resonances appear in at least duplicate and as such, is presumed that multiple or a combination of different structural conformations of 
the proposed polyether exist (Figure 66). The most notable resonances to suggest this idea of multiple conformations are detected between $9.5-10.0 \mathrm{ppm}$ and $3.5-4.5 \mathrm{ppm}$. These resonances are usually assigned to protons associated with an aldehyede and methoxy groups, respectively. Resonances assigned to aldehyde and methoxy protons are typically singlets. As such, if only one chemical conformation is present then only one resonance should be detected in each respective region. However, there are the four resonances in each respective ppm range mentioned above. The resonances detected at 9.77, 9.79, 9.84 and $9.86 \mathrm{ppm}$ all integrate for one proton each while resonances detected at 3.90, 3.91, 4.03 and 4.06 ppm each integrate for three protons. It is also important to note the pattern of the resonances; in both regions three of the four resonances are relatively the same size while one resonance is noticeably smaller. The spacing of resonances in respective region is also similar; they appear almost as sets of doublets. Detecting four resonances, all integrating for the same value, observed in two different regions while following the same pattern is suggesting that, in fact, four conformations may be present in the material. The aromatic resonances are not resolved enough to assign four various sets of resonances. At least two different sets of aromatic resonances were resolved. Two sets of doublets at 7.40 and $7.00 \mathrm{ppm}$ and two singlets at $6.88 \mathrm{ppm}$ and $6.55 \mathrm{ppm}$, integrating for two and a proton respectively were detected. The propyl peaks, expected between 4.5 ppm and 3.5 ppm, cannot be observed due to poor resolution. There is evidence to suggest that the disubstituted product has formed. In particular, a doublet resonance at $5.25 \mathrm{ppm}$ is characteristic of these products (61: Figure 67). 
<smiles>COc1cc(C=O)ccc1OCC(O)COc1ccc(C=O)cc1OC</smiles>

Figure 67: Proposed structure of 61.

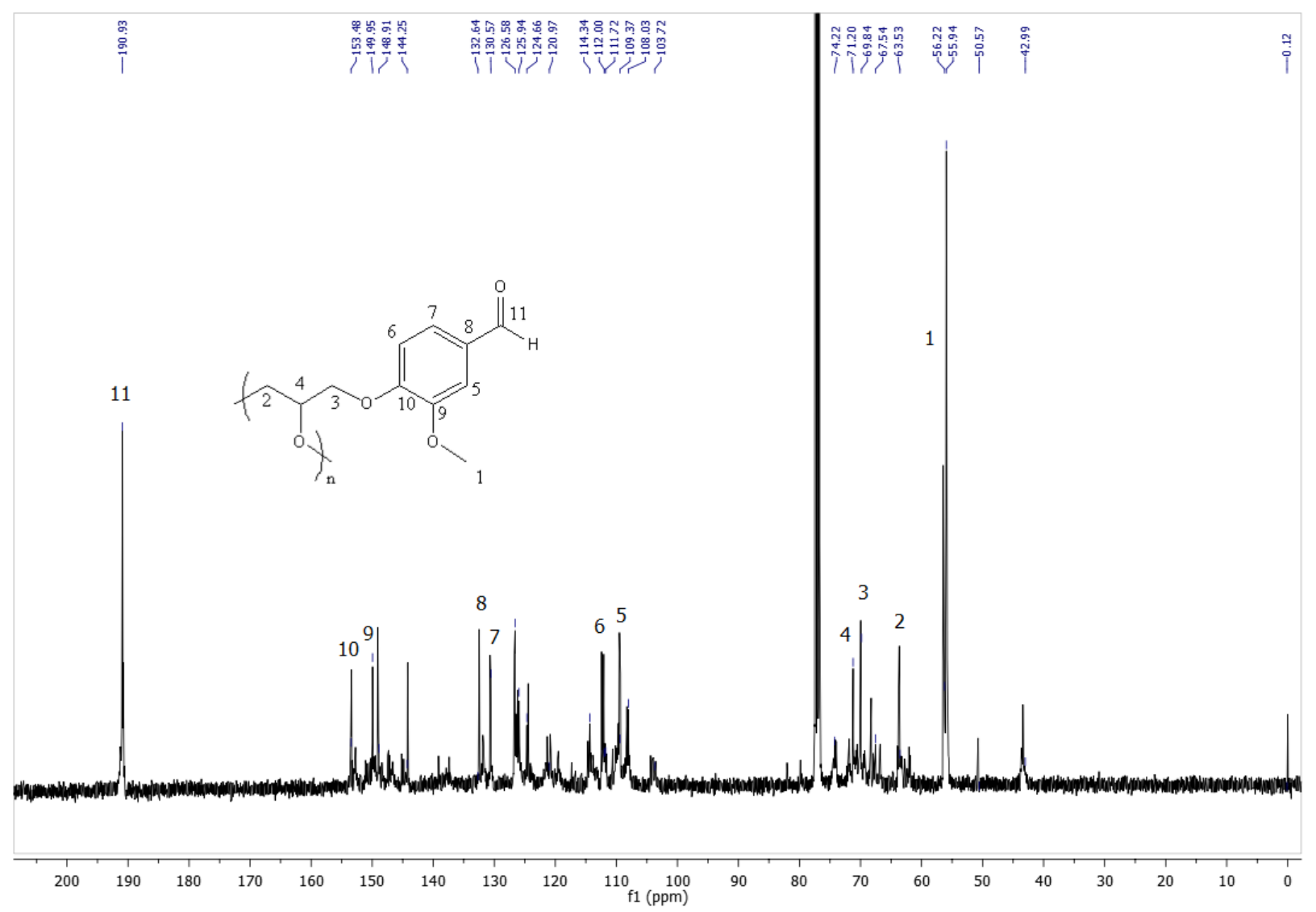

Figure 68: ${ }^{1} \mathrm{H} \mathrm{NMR}\left(\mathrm{CDCl}_{3}\right)$ spectrum of 59.

Examining the ${ }^{13} \mathrm{C}$ NMR spectrum, a similar pattern to the ${ }^{1} \mathrm{H}$ NMR spectrum is observed (Figure 65). Multiple resonances were detected in regions where only one resonance was expected. Although polymers generally do produce less resolved spectra, the resonances observed in both the proton and carbon spectra of $\mathbf{5 9}$ appear to be resonances associated with 
different structures or conformations and not due to typical polymer properties. Several peaks observed at approximately $190 \mathrm{ppm}$ are characteristic of the carbonyl carbons in different chemical environments. Resonances between 165 - 105 ppm are characteristic of a sixmembered aromatic group and resonances detected between $75-60 \mathrm{ppm}$ appear as two sets of three which are characteristic of the propyl chain. Resonances detected at approximately $56 \mathrm{ppm}$ are characteristic of methoxy groups. There is also evidence of the di-substituted product, in particular the signal detected at approximately $68 \mathrm{ppm}$. The NMR data, in general, presents multiple resonances for each expected resonance and the resonance patterns suggest that two distinct chemical environments are present, two structures, each with a slightly different conformation. However, as there was evidence to support $\mathbf{5 9}$, it is also possible, based on the analytical data, that various conformations exist within the material. As is well known with polymers, the linking of monomer units can happen in several ways. Compound $\mathbf{5 9}$ may have various conformations depending on its polymerization. The possible conformations of $\mathbf{5 9}$ could include head to head, head to tail, tail to tail and the di-substituted product. These four conformations may account of the various resonances observed in the NMR spectra.

\subsubsection{Attempted Polymerizations Using Crude Material}

Polymerizations were attempted using crude diols to assess purification requirements. 


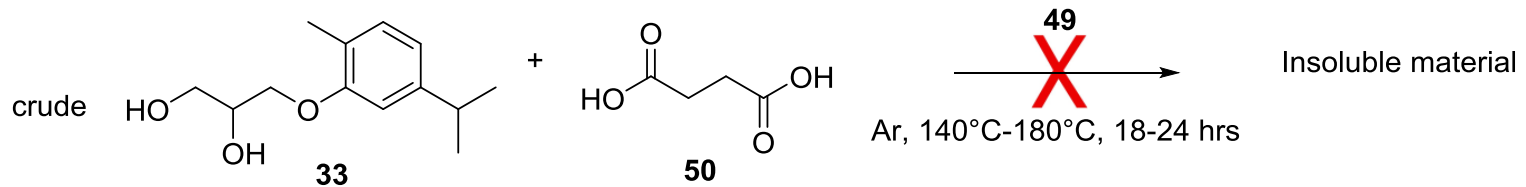<smiles>Cc1ccc(C(C)C)c(OCC(O)CO)c1</smiles><smiles>CC(=O)CCc1ccc(OCC(O)CO)cc1</smiles>

Scheme 22: Attempted polymerizations using crude materials.

After $24 \mathrm{hrs,}$ the resulting materials had degraded. Unfortunately, until some improvements are made during diol production, purification prior to polymerization will be required.

\subsubsection{Depolymerization of Cross - linked Materials}

Cross-linked materials that were insoluble were dealt with in two ways. The first was refluxing the material in methanol for several days. This returns the cross-linked material to a flowing state. In order to remove cross-linked polymers from the reaction vessels rapidly, glycol (62) was utilized. The process shown below (Scheme 23) depolymerises the insoluble materials in several hours.

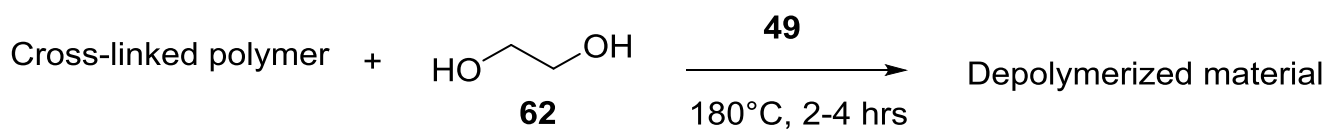

Scheme 23: Depolymerizing cross-linked materials. 


\subsubsection{Physical Polymer Properties}

Resulting polymeric resins were evaluated for their physical properties which are presented in the table below (Table 3).

\begin{tabular}{|c|c|c|c|c|c|c|}
\hline & $\mathrm{T}_{\mathrm{s}}\left({ }^{\circ} \mathrm{C}\right)$ & $\mathrm{T}_{\mathrm{g}}\left({ }^{\circ} \mathrm{C}\right)$ & $\mathrm{M}_{\mathrm{w}}(\mathrm{Da})$ & $\mathrm{M}_{\mathrm{n}}(\mathrm{Da})$ & $\mathrm{M}_{\mathrm{p}}(\mathrm{Da})$ & $\mathrm{PDI}$ \\
\hline $\mathbf{5 1}$ & $100.1^{\circ} \mathrm{C}$ & $17.66^{\circ} \mathrm{C}$ & $26.44 \times 10^{3}$ & $3.73 \times 10^{3}$ & $3.79 \times 10^{3}$ & 7.01 \\
\hline $\mathbf{5 3}$ & $102.9^{\circ} \mathrm{C}$ & $41.82^{\circ} \mathrm{C}$ & $3.90 \times 10^{3}$ & $2.79 \times 10^{3}$ & $2.71 \times 10^{3}$ & 1.39 \\
\hline $\mathbf{5 5}$ & $104.1^{\circ} \mathrm{C}$ & $49.52^{\circ} \mathrm{C}$ & $5.07 \times 10^{3}$ & $2.53 \times 10^{3}$ & $4.15 \times 10^{3}$ & 2.00 \\
\hline $\mathbf{5 7}$ & Below $100^{\circ} \mathrm{C}$ & $20.09^{\circ} \mathrm{C}$ & $94.50 \times 10^{3}$ & $2.84 \times 10^{3}$ & $3.63 \times 10^{3}$ & 33.25 \\
\hline $\mathbf{5 8}$ & Below $100^{\circ} \mathrm{C}$ & $29.93^{\circ} \mathrm{C}$ & $132.90 \times 10^{3}$ & $1.85 \times 10^{3}$ & $1.65 \times 10^{3}$ & 71.94 \\
\hline $\mathbf{5 9 a}$ & $116^{\circ} \mathrm{C}$ & $69^{\circ} \mathrm{C}$ & $1.33 \times 10^{3}$ & $0.93 \times 10^{3}$ & $1.23 \times 10^{3}$ & 1.44 \\
\hline $\mathbf{5 9 b}$ & $121^{\circ} \mathrm{C}$ & $43^{\circ} \mathrm{C}$ & $1.45 \times 10^{3}$ & $0.75 \times 10^{3}$ & $0.55 \times 10^{3}$ & 1.936 \\
\hline
\end{tabular}

Table 3: (Ts), DSC and GPC data of resulting polymeric resins.

Compounds 51, 53 and 55, all polymerized from 26, displayed similar softening points. The glass transition temperatures on the other hand were quite different. Compounds $\mathbf{5 3}$ and $\mathbf{5 5}$ are similar in nature relative to $\mathbf{5 1}$. The difference in $\mathrm{T}_{\mathrm{g}}$ between either $\mathbf{5 3}$ or $\mathbf{5 5}$ and $\mathbf{5 1}$ is almost $30^{\circ} \mathrm{C}$. This can be attributed to the "flexibility" of the organic acids. Compound $\mathbf{5 1}$ has flexibility due mainly to the ethyl chain, it has the ability to bend and rotate. Compounds $\mathbf{5 3}$ or 55 are much more rigid due to the aromatic species and as such, require higher energy inputs relative to $\mathbf{5 1}$ to initiate intramolecular rotation.

Resin 57 produced interesting results. The $\mathrm{M}_{\mathrm{w}}$ and PDI of this polymer were quite high. Unfortunately, this resin does not solidify and is very sticky which will limit its applications. 
The very high molecular weight of the polymer may indicate that, as the polymer reaction conditions are intensified, the polymer chains grow to the point where they can no longer remain as a melt and precipitates. This may explain why the material solidifies after several days of growth. However this is unlikely as the commercial acquired material was able to grow and grow without solidifying. Relative to previously synthesized polyester resins with propylene carbonate which have, in general, $\mathrm{M}_{\mathrm{w}}$ values of $2000-3000 \mathrm{Da}$, this process generates polymers with much higher $\mathrm{M}_{\mathrm{w}}$ values. Due to its low glass transition temperature and liquid state at room temperature, this polyester resin is not suitable for toner production.

The resulting vanillin based material, while hot, had a very low viscosity. It was brownish red in color and hardened almost immediately after removal from the reaction vessel. The application of heat returned the hardened material back into a molten state. After 24 hours of reaction time, monomer was still observed, but after 48 hours, no monomer remained. After $24 \mathrm{hrs}$ of reaction time, $\mathbf{5 9}$ was purified using a methanol wash and analyzed, 59a. After $48 \mathrm{hrs}$ of reaction time, crude $\mathbf{5 9}$ was analyzed without purification as no starting material was visible, 59b. The difference in physical properties, in particular the $T_{g}$ values, were 59a had a $T_{g}$ of $69^{\circ} \mathrm{C}$ while 59b had a $\mathrm{T}_{\mathrm{g}}$ of $43^{\circ} \mathrm{C}$ (Table 3).

Crude material was analyzed using thermal gravimetric experiments, an initial decomposition temperature of $127.59^{\circ} \mathrm{C}$ was observed. Due to the initial decomposition temperature, it was concluded that the polymer is likely decomposing during the reaction and as such, thermal properties such as $T_{g}$ are decreased and the PDI values increased. Manufacturers require resins with different glass transition temperatures to produce various products. This biobased resin has shown a glass transition temperature range of almost $30^{\circ} \mathrm{C}$ within the same material and under very similar reaction conditions. This material could potentially be tailored to 
meet manufacturer requirements to be used in variety of products with varying thermal requirements as a bio-based and bio-sourced resin. From an industrial processing point of view, this process was successful in generating a bio-based thermoplastic in a one step, one pot synthesis.

Stress strain analyses were attempted on all polymers other than 58. Adequate samples for analyses could not be produced due to the nature of the polymeric materials. Two main issues arose. The material was easily molded however would adhere to the molds and chip or break when being removed. The other issue was that air bubbles often get trapped in molten material and need to be removed. This was accomplished in a vacuum oven by heating the material to a molten state then slowly turning on the vacuum. During this time, the material would bubble or leak producing samples unfit for analyses. Due to these hardships, stress strain analyses were abandoned.

\subsection{Conclusion}

Overall, many of the starting objectives were accomplished in this work. Two new synthetic routes were developed to compounds modelling the aryl ether $\beta-\mathrm{O}-4$ linkage found in lignin. Although 13 was prepared before by Nagy, the synthetic pathway was different and this was the first time the crystal structure of 13 was obtained. Compound 25, although only synthesized and not experimented with, was synthesized in two steps. Compound $\mathbf{2 5}$ is a more

accurate representation of the fragments expected in lignin relative to $\mathbf{1 3}$. Since $\mathbf{2 5}$ can be synthesized in only two steps, this work can provide future lignin researchers with an easily produced and accurate model of the $\beta-\mathrm{O}-4$ linkage found in hardwood-based lignins. 
All explored phenols, including $\mathbf{1 3}$ were successfully transformed into diols. Most importantly, 13 was transformed into 47 which demonstrated that the $\beta-O-4$ linkage is stable under the harsh reaction conditions described above. Phenols with additional functionality such as allyl, ketone, aldehyde as well as aliphatic groups all appeared to be stable during reactions and the only by-product observed throughout these reactions were the di-substituted products. In the event that purification was required for bulk material, recrystallization using ether was proven to be a quick and successful process with the majority of the diols. The eugenol based diol, 16, was isolated as crystals. This was the first time that the crystal structure of this compound was determined.

Several diols (16, 26 and 29) were successfully transformed into polyester-based resins. The most interesting result was that the vanillin-based diol, 31, which underwent selfpolymerization during polyalkoxydiol synthesis resulting in what is believed to be a polyetherbased resin, 59. This one step one pot synthesis generates an almost completely bio-based thermo plastic with desirable thermal properties which was generated without the use of a di-carboxylic acid or a tin catalyst. It is also worth noting that there is quite a wide range of the glass transition temperature associated with this material depending on the reaction conditions which can result in the tailoring of resins to meet manufacturer's requirements. The eugenol-based diol (16) was also successfully polymerized and both ${ }^{1} \mathrm{H}$ and ${ }^{13} \mathrm{C}$ NMR spectroscopic data demonstrated that the terminal double bond was still intact and, in turn, stable throughout the reaction. Compound 26 was successfully polymerized using a variety of di-carboxylic acids. Employing various dicarboxylic acids can alter the thermal properties of the resulting resins. Depending on the desired thermal properties, resins can be tailored by using the proper di-carboxylic acid. 
Materials with lower desired thermal properties would likely employ $\mathbf{5 0}$ where as if higher thermal properties were desired than either $\mathbf{5 2}$ or $\mathbf{5 4}$ would likely be employed.

All reactions should be carried out using a mechanical stirring arm as magnetic stir bars are not strong enough to mix the material as the viscosity increases. Without proper mixing, the material solidifies presumably due to cross-linking and is rendered useless. It was also determined that thermal properties could be slightly increased by pushing the polymerization to more extreme conditions such as an increase in temperature or through a reduction of pressure. However, there is a maximum that the material can be pushed to where the thermal properties no longer continue to increase and where the risk of cross linking is possible. The use of an inert gas is not required however materials in the presence of one remained yellow, red or orange in color. Polymerizations in the absence of an inert gas produced very dark colored material.

Overall, the primary objectives of this research were achieved. Several novel, bio-based resins were produced from bio-based materials. These materials displayed a range of thermal properties, in particular, glass transition temperatures. Although these materials did not meet the specifications for toner production at this time, they have the potential to be tailored to meet these specifications as well as a variety of other industrial applications.

\subsection{Future Work}

Bio-based resins from lignin-based materials appear to be plausible and as such, the next step would be to breakdown lignin. If successfully accomplished, isolating the available fragments and using the information provided above to produce a variety of bio-based resins would be a good direction to continue this work. Upon resin production, efforts tailoring these 
materials to produce cost effective, bio-based resins suitable for toner may be undertaken. Outside of toner applications, other industrial applications may also be explored.

Exploring a variety of environmentally friendly or bio-based catalysts in efforts to replace the tin-based catalyst could potentially make these resins $100 \%$ bio-based and may be worth pursuing. Improving the yield of $\mathbf{2 5}$ may also be worth the effort as many researchers continue to model and employ variations of the $\beta-\mathrm{O}-4$ linkage.

Once work with phenolic species is concluded, efforts should continue exploring other bio-based materials that could potentially replace conventional materials sourced from nonrenewable sources. It is only a matter of time until these sources, such as crude oil, disappear and society will have nothing left but bio-based materials to rely on. Efforts should focus not only designing bio-based polyester resins but all types of industrially applicable materials.

\subsection{Experimental Procedures}

\section{$\underline{5.1 \text { General Procedures }}$}

All procedures were carried out under $\mathrm{N}_{2}$ or Argon atmospheres and performed using standard Schlenk techniques unless otherwise stated. Compounds 1, 2, 4, 6, 7, 9, 11, 13, 16, 18, 19, 22, 29, 31, 34, 37, 40 and 56 were purchased from Sigma-Aldrich. Compound 15 was purchased from Huntsman. Compound 50 was obtained from BioAmber. Compounds 45, 49, 51 and 55 were produced on site within the pilot plant at Xerox Research Centre of Canada (XRCC). Compound $\mathbf{4 7}$ was purchased from Arkema. Nuclear magnetic resonance (NMR) experiments were recorded on a $400 \mathrm{MHz}$ Bruker Avance II Spectrometer (Ryerson University and XRCC) using deuterated chloroform $\left(\mathrm{CDCl}_{3}\right)$ as the solvent unless otherwise indicated. ${ }^{1} \mathrm{H}$ 
and ${ }^{13} \mathrm{C}$ NMR spectra were referenced to the residual $\mathrm{CDCl}_{3}(\delta=7.26 \mathrm{ppm}$ and $\delta=77.0 \mathrm{ppm})$ solvent signal while ${ }^{29} \mathrm{Si}$ spectrum were referenced externally to Tetramethylsilane ( $\left.\delta=0 \mathrm{ppm}\right)$. Proton and carbon chemical shift assignments are given in $\delta(\mathrm{ppm})$ and couplings between nuclei measured in Hertz $(\mathrm{Hz})$. High resolution mass spectra (HRMS) were recorded by direct analysis in real time by DART-TOF or by electrospray time-of-flight (ESI-TOF) at the Advanced Instrumentation for Molecular Structure (AIMS) laboratory at the University of Toronto. X-ray crystal structure analysis was performed with a Bruker-Nonius Kappa-CCD diffractometer at the University of Toronto X-ray facilities. Thin Layer Chromatography (TLC) was carried out on Silica gel 60 glass backed plates and visualized with a UV lamp or stained with $\left(\mathrm{KMnO}_{4}\right.$ or ninhydrin). Melting points were measured using a Fischer Scientific melting point apparatus. All prepared intermediates and compounds were stored in glass vials at RT. Thermogravimetric analyses (TGA), differential scanning calorimeter (DSC) and elemental analyses (EA) of newly synthesized polymers were performed by the analytical staff at XRCC. All reactions are carried out in a 1:1 ratio unless otherwise stated.

\subsection{Preparation of 4-(2-(2-methoxyphenoxy)ethyl)phenol}

\subsubsection{Preparation of 2-(4-(tert-butoxy)phenyl)ethan-1-ol 5}

To $350 \mathrm{~mL}$ of dried THF under $\mathrm{N}_{2}$ atmosphere and constant stirring, 1 (17.61 g, $0.10 \mathrm{~mol}$ ) was added drop wise. The solution was cooled to $-78^{\circ} \mathrm{C}$ using a dry ice and acetone bath. To the cooled solution 2 (2.80 g of a $1 \mathrm{M}$ soln., $0.033 \mathrm{~mol})$ was added drop wise. After $4 \mathrm{hrs}$, the ice bath was removed and the solution left to stir for $20 \mathrm{hrs}$ at RT. The reaction flask was then exposed to air and once again cooled using an ice bath. To the solution, $1 \mathrm{M} \mathrm{NaOH}_{(\mathrm{aq})}(15 \mathrm{~mL}$, $0.015 \mathrm{~mol})$ was added via graduated cylinder followed by the drop wise addition of 4 (90 $\mathrm{mL}$, $1.00 \mathrm{~mol}$ ). After $6 \mathrm{hrs}$, a white emulsion formed. The solution was decanted and the organic 
layer removed using a rotary evaporator. The product was washed $(3 \times 50 \mathrm{~mL})$ with water, the organic layer extracted with DCM $(100 \mathrm{~mL})$ and solvent removed by rotary evaporation. The resulting product (5) was isolated as a clear viscous oil.
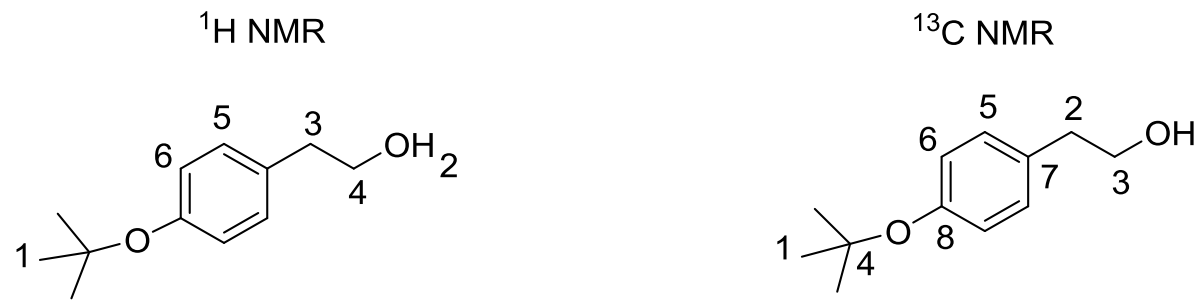

Yield: $96 \%$ (18.63g). ${ }^{\mathbf{1}} \mathbf{H}$ NMR (400 MHz, $\left.\mathrm{CDCl}_{3}, \delta\right): 7.10\left(\mathrm{~d},{ }^{3} J=8.6 \mathrm{~Hz}, 2 \mathrm{H}, \mathrm{H1}\right), 6.92\left(\mathrm{~d},{ }^{3} J\right.$ $=8.6 \mathrm{~Hz}, 2 \mathrm{H}, \mathrm{H} 2), 5.28(\mathrm{~s}, 1 \mathrm{H}, \mathrm{H} 3), 3.79\left(\mathrm{t},{ }^{3} J=6.8 \mathrm{~Hz}, 2 \mathrm{H}, \mathrm{H} 4\right), 3.96\left(\mathrm{t},{ }^{3} J=6.8 \mathrm{~Hz}, 2 \mathrm{H}, \mathrm{H} 5\right)$, 1.35 (s, 9H, H6) ppm. ${ }^{13} \mathrm{C}$ NMR (100 MHz, $\left.\mathrm{CDCl}_{3}, \delta\right):(\mathrm{C} 10)$ 153.50, (C9) 133.70, (C5 and C6) 124.17, (C7 and C8) 129.39, (C4) 78.27, (C3) 63.42, (C2) 38.47 (C1) 28.75 ppm. (See appendices A.1.1 and A.1.2)

\subsubsection{Preparation of 4-(tert-butoxy)phenethyl 4-methylbenzenesulfonate $\mathbf{8}$}

Under a $\mathrm{N}_{2}$ atmosphere, $5(1.94 \mathrm{~g}, 0.01 \mathrm{~mol})$ was dissolved in $30 \mathrm{~mL}$ of DCM and cooled to $0^{\circ} \mathrm{C}$. To the cooled flask, triethylamine $7(2.02 \mathrm{~g}, 0.02 \mathrm{~mol})$ was added via syringe. In a dropper funnel under $\mathrm{N}_{2}$, tosyl cholirde $6(1.90 \mathrm{~g}, 0.01 \mathrm{~mol})$ was dissolved in $60 \mathrm{~mL}$ of DCM then added drop wise to the cooled solution. Once the solution containing 6 was added, the ice bath was removed and the solution was left to stir for a total of $20 \mathrm{hrs}$ after which, a white precipitate had formed. The solution was decanted and solvent removal was performed using a rotary evaporator. Once solvent removal was complete, more of white precipitate was visible. The mixture was filtered, washed $(2 \times 50 \mathrm{~mL})$ with water and the organic layer was extracted using DCM (100 mL). The resulting material, 8 was a viscous yellow oil. 
${ }^{1} \mathrm{H}$ NMR

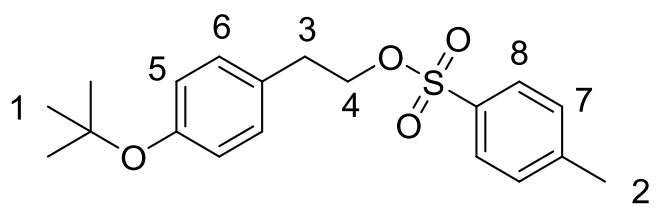

Yield: $82 \%$ (2.73 g). ${ }^{1} \mathbf{H}$ NMR (400 MHz, $\left.\mathrm{CDCl}_{3}, \delta\right): 7.70\left(\mathrm{~d},{ }^{3} J=7.9 \mathrm{~Hz}, 2 \mathrm{H}, \mathrm{H} 8\right), 7.29\left(\mathrm{~d},{ }^{3} J=\right.$ $7.9 \mathrm{~Hz}, 2 \mathrm{H}, \mathrm{H} 7), 6.99\left(\mathrm{~d},{ }^{3} \mathrm{~J}=8.3 \mathrm{~Hz}, 2 \mathrm{H}, \mathrm{H} 6\right), 6.88\left(\mathrm{~d},{ }^{3} J=8.3 \mathrm{~Hz}, 2 \mathrm{H}, \mathrm{H} 5\right), 4.19$ (t, ${ }^{3} J=7.1$ $\mathrm{Hz}, 2 \mathrm{H}, \mathrm{H} 4), 2.91\left(\mathrm{t},{ }^{3} \mathrm{~J}=7.1 \mathrm{~Hz}, 2 \mathrm{H}, \mathrm{H} 3\right), 2.43$ (s, 3H, H2) 1.33 (s, 9H, H1) ppm. ${ }^{13} \mathbf{C}$ NMR Not recorded. (See appendix A.2.1)

\subsubsection{Preparation of 1-(4-(tert-butoxy)phenethoxy)-2-methoxybenzene 11}

Exposed to air, $8(10.34 \mathrm{~g}, 29.7 \mathrm{mmol}), 9(3.68 \mathrm{~g}, 29.7 \mathrm{mmol})$ and $\mathrm{K}_{2} \mathrm{CO}_{3}(8.20 \mathrm{~g}, 59.4 \mathrm{mmol})$ were dissolved in $50 \mathrm{~mL}$ of acetone. Under constant mixing and reflux, the reaction was allowed to run for $72 \mathrm{hrs}$. The resulting solution was filtered and solvent removal was performed using rotary evaporation. The solution was then washed $(2 \times 50 \mathrm{~mL})$ with water and extracted with DCM $(100 \mathrm{~mL})$.

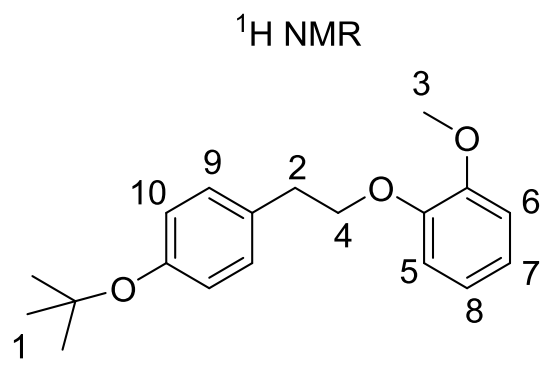

Yield: $76 \%$ (6.94 g). ${ }^{1} \mathbf{H}$ NMR (400 MHz, $\left.\mathrm{CDCl}_{3}, \delta\right): 7.30\left(\mathrm{~d},{ }^{3} J=1.3 \mathrm{~Hz}, 2 \mathrm{H}, \mathrm{H} 10\right), 7.19\left(\mathrm{~d},{ }^{3} J\right.$ $=1.3 \mathrm{~Hz}, 2 \mathrm{H}, \mathrm{H} 9), 6.96(\mathrm{~m}, 4 \mathrm{H}, \mathrm{H} 8-\mathrm{H} 5), 4.22\left(\mathrm{t},{ }^{3} J=7.5 \mathrm{~Hz}, 2 \mathrm{H}, \mathrm{H} 4\right), 3.87$ (s, 3H, H3), $3.13(\mathrm{t}$, ${ }^{3} J=7.5 \mathrm{~Hz}, 2 \mathrm{H}, \mathrm{H} 2$ ), 1.35 (s, 9H, H1) ppm. ${ }^{13} \mathbf{C}$ NMR - Not recorded. (See appendix A.3.1) 


\section{$\underline{\text { 5.2.4 Preparation of 4-(2-(2-methoxyphenoxy)ethyl)phenol } \mathbf{1 3}}$}

Under standard conditions 11 (1.00 g, $0.003 \mathrm{~mol})$ was dissolved in $2 \mathrm{~mL}$ of DCM. To this solution, phosphoric acid $12(2 \mathrm{~mL}$ of $85 \%)$ was added drop wise then refluxed for $24 \mathrm{hrs}^{48}$ The resulting solution was then washed $(2 \times 25 \mathrm{~mL})$ with water and the organic layer was extracted with DCM $(50 \mathrm{~mL})$. Purification was accomplished using column chromatography with a solvent composition of 3:1 ethyl acetate/hexane. Compound $\mathbf{1 3}$ was recrystallized using DCM and hexanes.
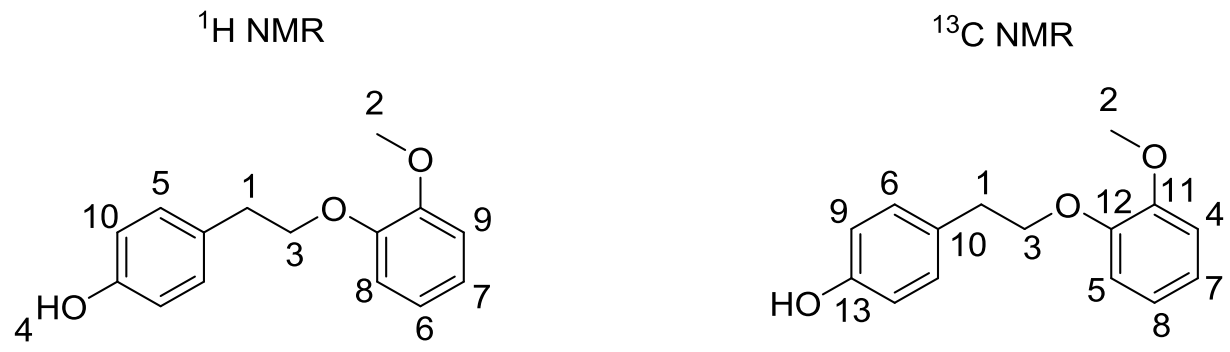

Yield: $51 \%(0.35 \mathrm{~g}) .{ }^{1} \mathbf{H}$ NMR (400 MHz, $\left.\mathrm{CDCl}_{3}, \delta\right): 7.17\left(\mathrm{~d},{ }^{3} \mathrm{~J}=8.3 \mathrm{~Hz}, 2 \mathrm{H}, \mathrm{H} 10\right), 6.91(\mathrm{~m}$, 4H, H9-H6), 6.86 (d, $\left.{ }^{3} J=8.3 \mathrm{~Hz}, 2 \mathrm{H}, \mathrm{H} 5\right), 5.30$ (s, 1H, H4), 4.17 (t, ${ }^{3} J=7.6 \mathrm{~Hz}, 2 \mathrm{H}, \mathrm{H} 3$ ), 3.88 (s, 3H, H2), 3.10 (t, $\left.{ }^{3} J=7.6 \mathrm{~Hz}, 2 \mathrm{H}, \mathrm{H} 1\right)$ ppm. ${ }^{13} \mathbf{C} \mathbf{N M R}\left(100 \mathrm{MHz}, \mathrm{CDCl}_{3}, \delta\right)$ : (C15) 154.32, (C14) 149.38, (C13) 148.27, (C12 and C11) 130.17, (C10) 129.99, (C9) 121.18, (C8) 120.96, (C7 and C6) 115.37, (C5) 113.36, (C4) 112.09, (C3) 70.03, (C2) 56.00, (C1) 34.83 ppm. (See appendices A.4.1 and A.4.2)

MS-Dart analysis (m/z): $121.1\left[\mathrm{HOCC}_{4} \mathrm{H}_{4} \mathrm{CCH}_{2} \mathrm{CH}_{2} \mathrm{O}\right]^{+}, 241.1[\mathrm{M}]^{+}$and $262.1\left[\mathrm{M}+\mathrm{NH}_{4}\right]^{+}$. (See appendix A.4.3)

X-Ray crystallography results available. (See appendix B.1) 
5.3 Preparation of 3-(2-methoxy-4-(2-(2-methoxyphenoxy)propyl)phenoxy) propane-1,2-diol, 25

5.3.1 Preparation of 1-(cyclohexyloxy)-4-methoxybenzene 21 and 1-(cyclohexyloxy)-2-methoxy benzene 22

In respective $500 \mathrm{~mL}$ Schlenk flasks, p-methoxy phenol 20 and 9 (7.69 g, $0.062 \mathrm{~mol})$, cyclohexene 19 (22.33 g, $0.27 \mathrm{~mol})$ and triflic acid 17 ( $2 \mathrm{~mL}, 0.023 \mathrm{~mol})$ were dissolved in 100 $\mathrm{mL}$ of toluene. The reaction was heated to $85^{\circ} \mathrm{C}$ for $48 \mathrm{hrs}$. This reaction was monitored using TLC with a solvent system composed of 9:1 ethyl acetate/hexane. The reaction mixture was washed $(1 \times 100 \mathrm{~mL})$ with water and the organic layer was extracted with ethyl acetate $(200$ $\mathrm{mL}$ ). Solvent and excess reagent removal was performed using rotary evaporation. Neither compound was isolated. No NMR data was obtained.

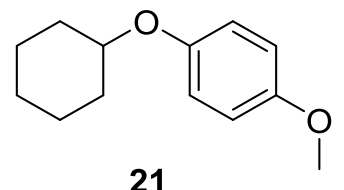

21

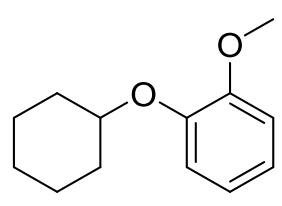

22

\subsubsection{Preparation of (4-allyl-2-methoxyphenoxy)trimethylsilane $\mathbf{2 4}$}

In a $500 \mathrm{~mL}$ round bottom flask, $14(10.00 \mathrm{~g}, 0.06 \mathrm{~mol})$ along with $7(9.35 \mathrm{~mL}, 0.12 \mathrm{~mol})$ were dissolved in $60 \mathrm{~mL}$ of DCM and cooled to $0^{\circ} \mathrm{C}$. In a separate dropping funnel, $23(6.74 \mathrm{~g}, 0.06$ mol) was dissolved in $40 \mathrm{~mL}$ of DCM. Under an argon atmosphere, the solution containing 23 was added drop wise to the round bottom flask. Upon the addition of the final drop, the ice bath was removed and reaction was allowed to run for an additional $2 \mathrm{hrs}$. The solution is then filtered, washed $(1 \times 100 \mathrm{~mL})$ with water and solvent removal plus excess reagent removal was performed using rotary evaporation. Once solvent removal was complete, a white precipitate 
plus an oily material were visible. The material was filtered and the resulting material, compound 24, was isolated as a clear yellow oil.
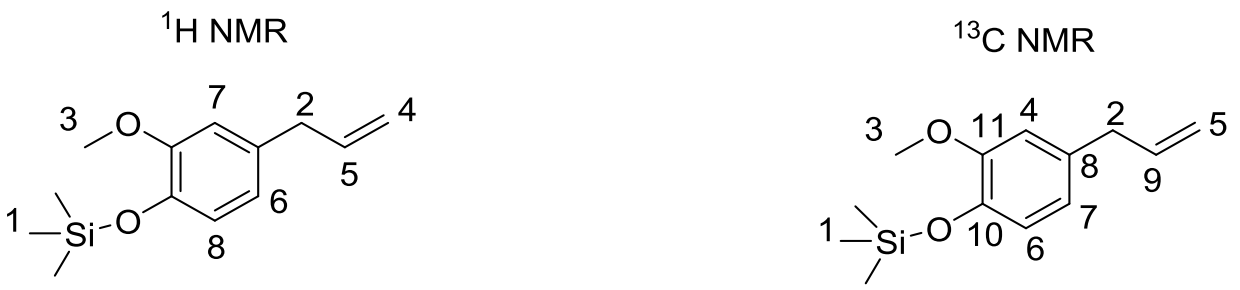

Yield 91\% (12.76 g). ${ }^{1} \mathbf{H}$ NMR (400 MHz, $\left.\mathrm{CDCl}_{3}, \delta\right): 6.88\left(\mathrm{~d},{ }^{3} \mathrm{~J}=8.2 \mathrm{~Hz}, 1 \mathrm{H}, \mathrm{H} 8\right), 6.78(\mathrm{~s}, 1 \mathrm{H}$, H7), 6.73(d, $\left.{ }^{3} J=8.2 \mathrm{~Hz}, 1 \mathrm{H}, \mathrm{H} 6\right), 6.05(\mathrm{~m}, 1 \mathrm{H}, \mathrm{H} 5), 5.16(\mathrm{~m}, 2 \mathrm{H}, \mathrm{H} 4), 3.86(\mathrm{~s}, 3 \mathrm{H}, \mathrm{H} 3), 3.41\left(\mathrm{~d},{ }^{3} J\right.$ $=6.6 \mathrm{~Hz}, 2 \mathrm{H}, \mathrm{H} 2), 0.35(\mathrm{~s}, 9 \mathrm{H}, \mathrm{H} 1) \mathrm{ppm} .{ }^{13} \mathbf{C} \mathbf{N M R}\left(100 \mathrm{MHz}, \mathrm{CDCl}_{3}, \delta\right):(\mathrm{C} 11) 150.78,(\mathrm{C} 10)$ 142.84, (C9) 137.77, (C8) 113.67, (C7) 120.77, (C6) 120.71, (C5) 115.59, (C4) 112.56, (C3) 55.46, (C2) 39.97, (C1) 0.37 ppm. ${ }^{29} \mathrm{Si}$ NMR (79.5 MHz, $\mathrm{CDCl}_{3}, \delta$ ): (Si1) $20.57 \mathrm{ppm}$ (See appendices A.6.1, A.6.2 and A. 6.3)

5.3.3 Preparation of 2-methoxy-4-(2-(2-methoxyphenoxy)propyl)phenol, the $\beta$-O-4 linkage 25 In a 500 mL Schlenk flask, $24(10.17 \mathrm{~g}, 0.043 \mathrm{~mol}), 9(21.35 \mathrm{~g}, 0.172 \mathrm{~mol})$ and $17(0.19 \mathrm{~mL}$, $0.02 \mathrm{~mol}$ ) were dissolved in $200 \mathrm{~mL}$ of toluene. Under an argon atmosphere, the reaction ran for $48 \mathrm{hrs}$ at $85^{\circ} \mathrm{C}$. The reaction changes from a clear to a dark purple color during the course of the reaction. The resulting solution was washed $(1 \times 200 \mathrm{~mL})$ with water and the solvent was removed using a rotary evaporator. The resulting material, a reddish orange oily liquid, was washed $(1 \times 200 \mathrm{~mL})$ with a $0.5 \mathrm{M}$ solution of $\mathrm{NaOH}_{(\mathrm{aq})}$ and extracted $(2 \times 200 \mathrm{~mL})$ with ethyl acetate. Purification was accomplished HPLC with a solvent system comprised of 1:3 ethyl acetate/hexanes. Compound $\mathbf{2 5}$ was isolated as a yellow-colored solid. 

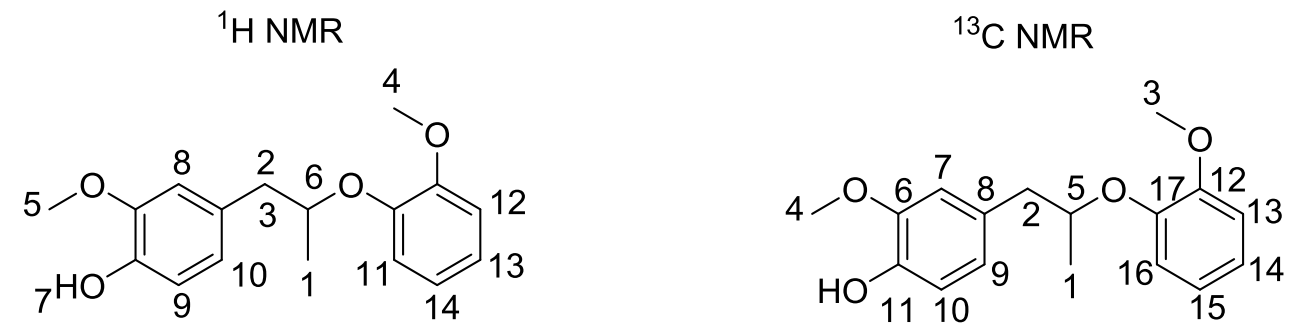

Yield: $8 \%\left(0.99\right.$ g). ${ }^{1} \mathbf{H}$ NMR (400 MHz, $\left.\mathrm{CDCl}_{3}, \delta\right): 6.84(\mathrm{M}, 6 \mathrm{H}, \mathrm{H} 8, \mathrm{H} 9, \mathrm{H} 11, \mathrm{H} 12, \mathrm{H} 13$ and H14), $6.59\left(\mathrm{~d},{ }^{3} J=9.8 \mathrm{~Hz}, 1 \mathrm{H}, \mathrm{H} 8\right), 5.49(\mathrm{~S}, 1 \mathrm{H}, \mathrm{H} 7), 4.48\left(\mathrm{q},{ }^{3} J=6.2 \mathrm{~Hz}, 1 \mathrm{H}, \mathrm{H} 6\right)$, ), 3.85(S, 3H, H5), $3.84(\mathrm{~S}, 3 \mathrm{H}, \mathrm{H} 4) 3.10\left(\mathrm{dd},{ }^{3} J=6.8 \mathrm{~Hz}, 1 \mathrm{H}, \mathrm{H} 3\right), 2.77\left(\mathrm{dd},{ }^{3} J=6.8 \mathrm{~Hz}, 1 \mathrm{H}, \mathrm{H} 2\right), 3.31\left(\mathrm{~d},{ }^{3} J=\right.$ 6.1Hz, 3H, H1) ppm. ${ }^{13} \mathrm{C}$ NMR (100 MHz, $\left.\mathrm{CDCl}_{3}, \delta\right):(\mathrm{C} 17)$ 150.54, (C16) 147.46, (C15) 146.29, (C14) 144.30, (C13) 130.30, (C12) 122.16, (C11) 121.47, (C10) 120.87, (C9) 116.19, (C8) 114.09, (C7)112.28, (C6)112.26, (C5) not observed, (C4) 55.93, (C3) 55.85, (C2) 42.44, (C1) 19.50 ppm. (See appendices A.7.1 and A.7.2)

MS-Dart analysis (m/z): $165.1\left[\mathrm{OHOCH}_{3} \mathrm{ArCH}_{2} \mathrm{CHCH}_{3}\right]^{+}, 306.2\left[\mathrm{M}+\mathrm{NH}_{4}\right]^{+}$(See appendix A.7.3)

5.4 Preparation of diols suitable for polymerization from natural phenolic materials

\subsubsection{Preparation of 3-(4-allyl-2-methoxyphenoxy)propane-1,2-diol 16}

In a $500 \mathrm{~mL} 3$ neck flask under an argon blanket $14(50.00 \mathrm{~g}, 0.30 \mathrm{~mol})$ along with glycerine carbonate $15(37.05 \mathrm{~g}, 0.31 \mathrm{~mol})$ and $10(0.25 \mathrm{~g}, 0.002 \mathrm{~mol})$ were heated to $130^{\circ} \mathrm{C}$ for $30 \mathrm{~min}$. The reaction temperature was increased by $10^{\circ} \mathrm{C}$ every $30 \mathrm{~min}$. until a temperature of $180^{\circ} \mathrm{C}$ was achieved. Bubbling was observed when the reaction reached approximately $150^{\circ} \mathrm{C}$. The reaction was allowed to run for an additional $2 \mathrm{hrs}$ after a temperature of $180^{\circ} \mathrm{C}$ was reached. The resulting material was then washed $(1 \times 600 \mathrm{~mL})$ with water and extracted $(1000 \mathrm{~mL})$ with ethyl acetate. Solvent removal was performed using rotary evaporation. The resulting material was isolated as a viscous orange oil. The material was left exposed to air and solidified soon after. 
When solidified, the resulting material was orange in color and waxy in appearance. Recrystallization was performed using ethyl acetate and hexanes. Compound $\mathbf{1 6}$ was isolated as an orange crystalline material.
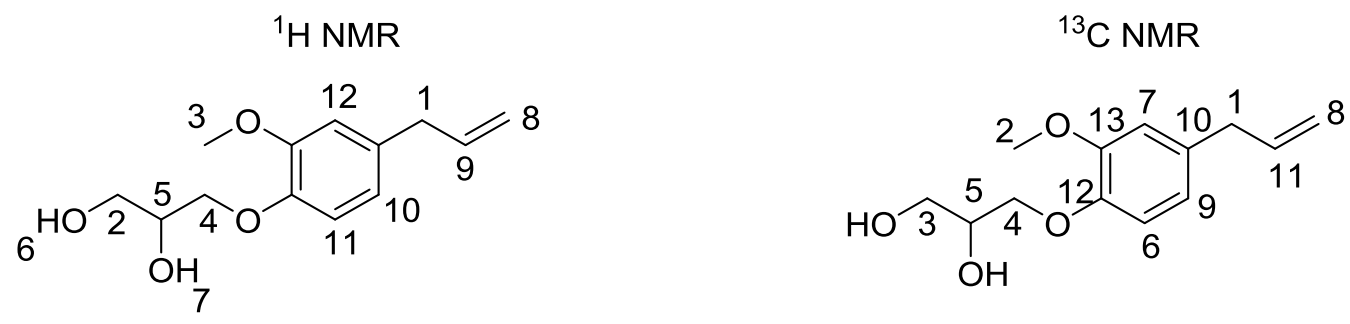

Yield: $72 \%(51.43 \mathrm{~g}) .{ }^{\mathbf{1}} \mathbf{H}$ NMR $\left(400 \mathrm{MHz}, \mathrm{CDCl}_{3}, \delta\right): 6.86\left(\mathrm{~d},{ }^{3} J=8.6 \mathrm{~Hz}, 1 \mathrm{H}, \mathrm{H} 12\right), 6.72\left(\mathrm{~d},{ }^{3} J\right.$ $=4.8 \mathrm{~Hz}, 2 \mathrm{H}, \mathrm{H} 11$ and H10), $5.96(\mathrm{~m}, 1 \mathrm{H}, \mathrm{H} 9), 5.10(\mathrm{~m}, 2 \mathrm{H}, \mathrm{H} 8),(\mathrm{H} 7$ not observed $), 4.09(\mathrm{~m}$, 4H, H4, H5 and H6), 3.86 (s, 1H, H3), $3.78\left(\mathrm{td},{ }^{3} \mathrm{~J}=3.7 \mathrm{~Hz}, 2 \mathrm{H}, \mathrm{H} 2\right), 3.35\left(\mathrm{~d},{ }^{3} \mathrm{~J}=6.7 \mathrm{~Hz}, 2 \mathrm{H}\right.$, H1) ppm. ${ }^{13} \mathbf{C}$ NMR (400 MHz, $\left.\mathrm{CDCl}_{3}, \delta \mathrm{ppm}\right):(\mathrm{C} 13)$ 149.57, (C12) 146.29, (C11) 137.47, (C10) 134.19, (C9) 120.80, (C8) 115.80, (C7) 114.94, (C6) 112.3, (C5) 72.36, (C4) 70.10, (C3) 63.87, (C2) 55.82, (C1) 39.84 ppm. (See appendices A.5.1 and A.5.2)

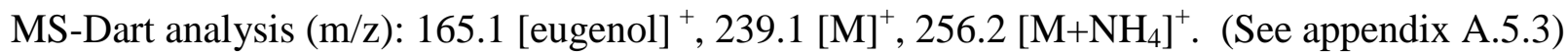

X-Ray crystallography results available. (See appendix B.2)

5.4.2 Preparation of 3-(2-methoxyphenoxy)propane-1,2-diol 26 and 3-(4-methoxyphenoxy) propane-1,2-diol 42

Under an argon blanket, in respective 500 mL 3 neck flasks, 9 and 41 (50.00 g, 0.40 mol) were added. Into each flask, glycerine carbonate 15 (48.69 g, $0.41 \mathrm{~mol})$ and 10 (0.25 g, $0.002 \mathrm{~mol})$ were added, mixed with a magnetic stir bar and heated to $130^{\circ} \mathrm{C}$. At a temperature of $130^{\circ} \mathrm{C}$, the reaction ran for $30 \mathrm{~min}$. The temperature was increased by $10^{\circ} \mathrm{C}$ every $30 \mathrm{~min}$ until a temperature of $180^{\circ} \mathrm{C}$ was reached. The reaction then ran for an additional $2.5 \mathrm{hrs}$. The resulting 
material was washed $(1 \times 200 \mathrm{~mL})$ with water and extracted $(1 \times 500 \mathrm{~mL})$ with ethyl acetate. Solvent removal was performed using rotary evaporation. The resulting materials were clear, viscous oils. The material was left exposed to air and solidified. The resulting waxy material was recrystallized with cold $\mathrm{Et}_{2} \mathrm{O}$. The final products $\mathbf{2 6}$ and $\mathbf{2 8}$ were isolated as fluffy white powders. Compounds $\mathbf{2 7}$ and $\mathbf{2 9}$, by products, were isolated as white powders. The resulting materials were characterized by ${ }^{1} \mathrm{H}$ and ${ }^{13} \mathrm{C}$ NMR. Compound 27 was only observed using TLC.

\section{Compound 26}
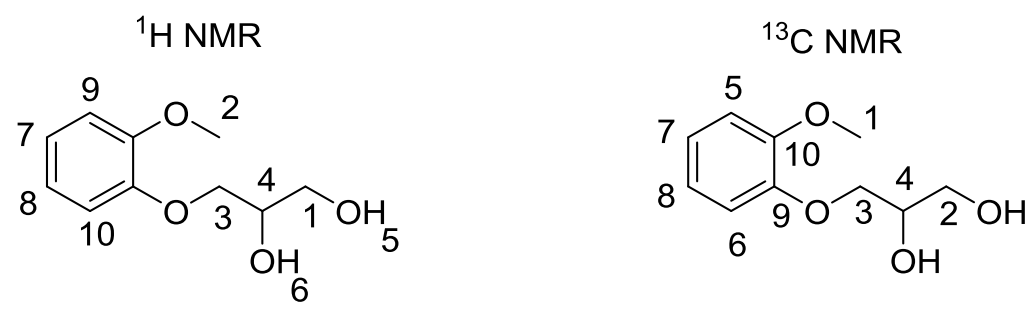

Yield: 74\% (58.67 g). ${ }^{1} \mathbf{H}$ NMR (400 MHz, $\left.\mathrm{CDCl}_{3}, \delta\right):$ 6.95(m, 4H, H5, H6, H7 and H8), 4.16(q, $\left.{ }^{3} J=6.5 \mathrm{~Hz}, 1 \mathrm{H}, \mathrm{H} 4\right), 4.06(\mathrm{~m}, 2 \mathrm{H}, \mathrm{H} 3), 3.86(\mathrm{~m}, 2 \mathrm{H}, \mathrm{H} 2), 3.76(\mathrm{~s}, 3 \mathrm{H}, \mathrm{H} 1) \mathrm{ppm} .{ }^{13} \mathbf{C}$ NMR $(100$ $\left.\mathrm{MHz}, \mathrm{CDCl}_{3}, \delta\right):(\mathrm{C} 10)$ 149.76, (C9) 147.97, (C8) 122.31, (C7) 121.09, (C6) 114.99, (C5) 111.82, (C4) 72.41, (C3) 69.97, (C2) 63.90, (C1) 55.81 ppm. (See appendices A.8.1 and A.8.2)

\section{Compound 42}

${ }^{1} \mathrm{H}$ NMR -Not available

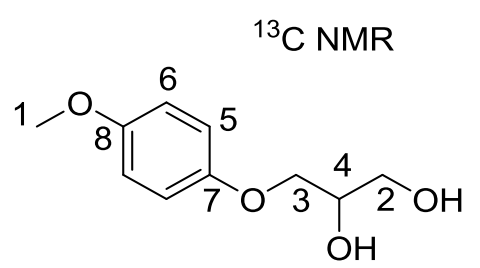

Yield: $69 \%$ (54.71g). ${ }^{\mathbf{1}} \mathbf{H}$ NMR (Not available); ${ }^{13} \mathbf{C}$ NMR (100 MHz, $\mathrm{CDCl}_{3} \delta$ ): (C8) 154.24, (C7) 152.57, (C6) 115.58, (C5) 114.74, (C4) 70.51, (C3) 69.97, (C2) 63.72, (C1) 55.74 ppm. (See appendix A.17.1) 


\section{Compound 43}
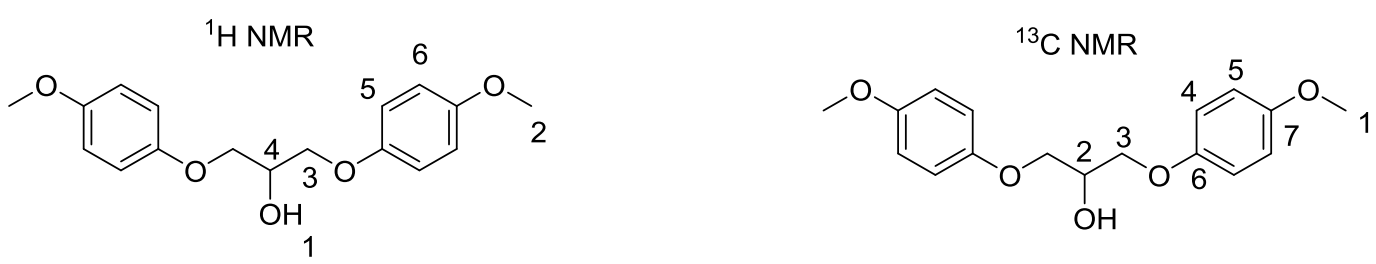

Yield: $18 \%(21.91 \mathrm{~g}) .{ }^{1} \mathbf{H}$ NMR $\left(400 \mathrm{MHz}, \mathrm{CDCl}_{3}, \delta\right): 6.88\left(\mathrm{dd},{ }^{3} \mathrm{~J}=2.7 \mathrm{~Hz}, 8 \mathrm{H}, \mathrm{H} 5\right.$ and $\left.\mathrm{H} 6\right)$, $4.37\left(\mathrm{q},{ }^{3} J=5.1 \mathrm{~Hz}, 1 \mathrm{H}, \mathrm{H} 4\right), 4.12\left(\mathrm{quin},{ }^{3} J=5.8 \mathrm{~Hz}, 4 \mathrm{H}, \mathrm{H} 3\right), 3.79(\mathrm{~s}, 3 \mathrm{H}, \mathrm{H} 2), 3.03\left(\mathrm{~d},{ }^{3} J=5.0\right.$ Hz, 1H, H1) ppm. ${ }^{13}$ C NMR (100 MHz, $\mathrm{CDCl}_{3,}$ ) : (C7) 154.16, (C6) 152.69, (C5) 115.65, (C4) 114.57, (C3) 69.39, (C2) 68.97, (C1) 55.74 ppm. (See appendices A.18.1 and A.18.2)

\subsubsection{Preparation of 3-(2-methoxy-4-propylphenoxy)propane-1,2-diol 29}

In a $500 \mathrm{~mL} 3$ neck flask, $28(50.00 \mathrm{~g}, 0.30 \mathrm{~mol})$ along with $\mathbf{1 5}(36.49 \mathrm{~g}, 0.31 \mathrm{~mol})$ and $\mathbf{1 0}(0.25$ g, $0.002 \mathrm{~mol}$ ) were added. Under an argon blanket and constant mixing, the temperature was increased to $130^{\circ} \mathrm{C}$ for $30 \mathrm{~min}$. After the 30 min mark, the temperature was increased periodically by $10^{\circ} \mathrm{C}$ every 30 min until a temperature of $180^{\circ} \mathrm{C}$ was reached. The reaction was allowed to continue for another $2.5 \mathrm{hrs}$. The color of the material went from a clear to yellow colored solution. The material was washed $(1 \times 200 \mathrm{~mL})$ with water and extracted $(1 \times 500 \mathrm{~mL})$ with ethyl acetate. Solvent removal was performed by rotary evaporation. The material was exposed to air until a white precipitated had formed which was then recrystallized using cold $\mathrm{Et}_{2} \mathrm{O}$.

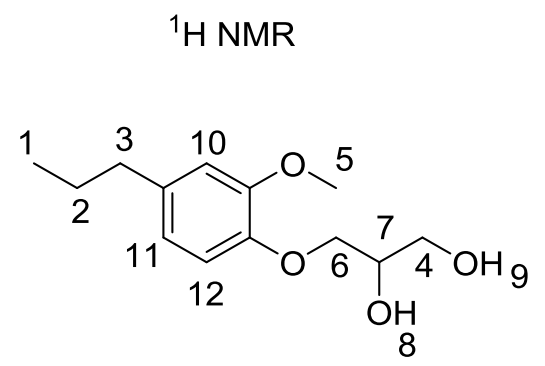

${ }^{13} \mathrm{C} N M R$

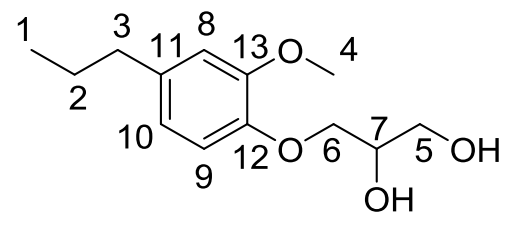


Yield: $71 \%(51.18 \mathrm{~g}) .{ }^{1} \mathbf{H}$ NMR $\left(400 \mathrm{MHz}, \mathrm{CDCl}_{3}, \delta\right): 6.84\left(\mathrm{~d},{ }^{3} J=8.2 \mathrm{~Hz}, 1 \mathrm{H}\right), 6.71(\mathrm{~m}, 2 \mathrm{H})$, $4.15(\mathrm{q}, 6.8 \mathrm{~Hz}, 1 \mathrm{H}), 4.04\left(\mathrm{~d},{ }^{3} J=7.0 \mathrm{~Hz}, 2 \mathrm{H}\right), 3.85(\mathrm{~s}, 3 \mathrm{H}), 3.78(\mathrm{~m}, 2 \mathrm{H}), 2.53\left(\mathrm{t},{ }^{3} J=7.6 \mathrm{~Hz}, 2 \mathrm{H}\right)$, $1.62\left(\mathrm{q},{ }^{3} J=7.5 \mathrm{~Hz}, 2 \mathrm{H}\right), 0.94\left(\mathrm{t},{ }^{3} J=7.3 \mathrm{~Hz}, 3 \mathrm{H}\right) \mathrm{ppm} .{ }^{13} \mathbf{C} \mathbf{N M R}\left(100 \mathrm{MHz}, \mathrm{CDCl}_{3}, \delta\right):(\mathrm{C} 13)$ 145.98, (C12) 145.91, (C11) 137.20, (C10) 120.61, (C9) 115.30, (C8) 112.23, (C7) 72.85, (C6) 69.99, (C5) 63.92, (C4) 55.79, (C3) 33.74, (C2) 24.69, (C1) 13.80 ppm. (See appendices A.9.1 and A.9.2)

MS-DART analysis: $241.1[\mathrm{M}]^{+}, 258.2\left[\mathrm{M}+\mathrm{NH}_{4}\right]^{+}$. (See appendix A.11.3)

\subsubsection{Preparation of 4-(2,3-dihydroxypropoxy)-3-methoxybenzaldehyde 31}

In a $500 \mathrm{~mL} 3$ neck flask, $\mathbf{3 0}(50.00 \mathrm{~g}, 0.33 \mathrm{~mol})$ along with $\mathbf{1 5}(40.14 \mathrm{~g}, 0.34 \mathrm{~mol})$ and $\mathbf{1 0}(0.25$ g, $0.002 \mathrm{~mol}$ ) were added. Under an argon blanket, the temperature was increased to $130^{\circ} \mathrm{C}$ for 30 min. After the 30 min mark, the temperature was increased periodically by $10^{\circ} \mathrm{C}$ every 30 min until a temperature of $180^{\circ} \mathrm{C}$ was reached. The reaction was allowed to run for another 2 hours. The material had a reddish-brown colour. An aliquot was taken and analyzed directly as a crude sample.

\section{Compound $\mathbf{3 1}$}
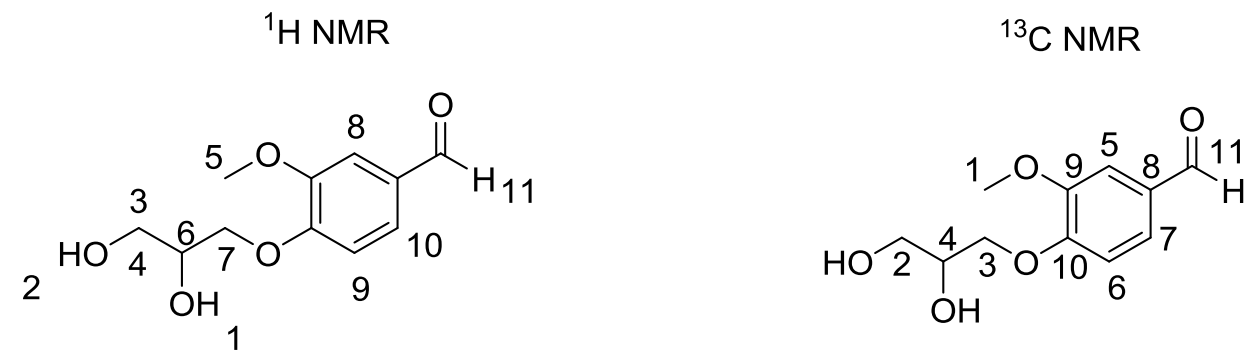

Yield: N/A. ${ }^{1} \mathbf{H}$ NMR (400 MHz, $\mathrm{CDCl}_{3}, \delta$ ): 9.82(s, 1H, H11), 7.40(m, 2H, H9-H10), 6.96(d, 1H, H8), 4.15(m, 2H, H7), 4.11(m, 1H, H6), 3.89(s, 3H, H5), 3.79(m, 1H, H4), 3.70(m, 1H, H3), 3.15(s, 1H, H2), 2.50(s, 1H, H1) ppm. ${ }^{13} \mathbf{C}$ NMR (100 MHz, $\left.\mathrm{CDCl}_{3}, \delta\right):(\mathrm{C} 11)$ 191.00, (C10) 
153.45, (C9) 149.66, (C8) 130.49, (C7) 126.83, (C6) 111.98, (C5) 109.36, (C4) 71.08, (C3)

69.94, (C2) 63.61, (C1) 55.97 ppm. (See appendices A.10.1 and A10.2)

MS-Dart analysis: $227.1[\mathrm{M}]^{+}, 244.1\left[\mathrm{M}+\mathrm{NH}_{4}\right]^{+}$. (See appendix A.10.3)

5.4.5 Preparation of 3-(2-isopropyl-5-methylphenoxy)propane-1,2-diol 33 and 3-(5-isopropyl-2methylphenoxy)propane-1,2-diol 36

Compounds 32 and 35 (50.00 g, $0.33 \mathrm{~mol}$ ) respectively thymol and carvacol, were each placed in respective $500 \mathrm{~mL}, 3$ neck flasks. To each flask, 15 (40.51 g, $0.34 \mathrm{~mol})$ was added along with $\mathbf{1 0}$ $(0.25 \mathrm{~g}, 0.002 \mathrm{~mol})$. Under an argon blanket, the temperature was increased to $130^{\circ} \mathrm{C}$ for $30 \mathrm{~min}$. After the $30 \mathrm{~min}$, the temperature was increased $10^{\circ} \mathrm{C}$ every 30 min until a temperature of $180^{\circ} \mathrm{C}$ was reached. The reaction was allowed to continue for another $2.5 \mathrm{hrs}$. The color of the reaction involving 32 went from yellow to orange in color. The color of the reaction involving $\mathbf{3 5}$ went from a clear solution to a brownish black color. The material was washed $(1 \times 200 \mathrm{~mL})$ with water and extracted $(1 \times 500 \mathrm{~mL})$ with ethyl acetate. Solvent removal was performed by rotary evaporation. The resulting material was left exposed to air but no precipitate was observed in either material. The resulting material from both reactions was separated using HPLC, solvent conditions were 3:1 ethyl actetate/hexane. Compounds $\mathbf{3 4}$ and $\mathbf{3 6}$ were obtained as by-products from the reaction. All four compounds were isolated as white solids.

\section{Compound $\mathbf{3 3}$}
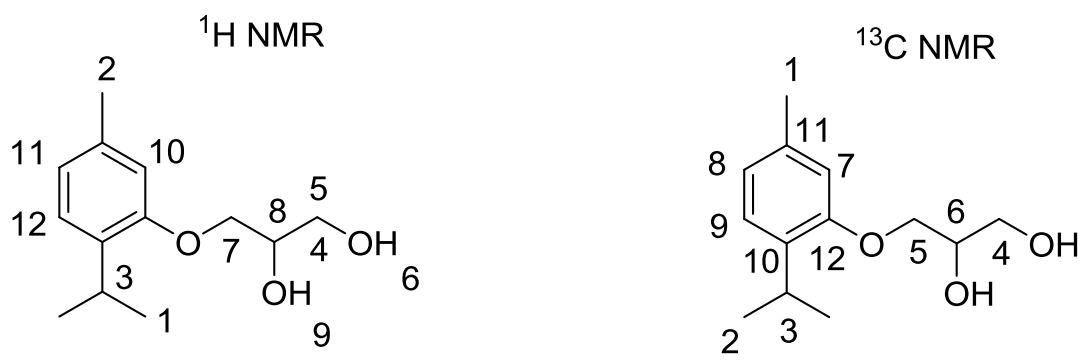
Yield: $63 \%$ (46.60g). ${ }^{1} \mathbf{H}$ NMR (400 MHz, $\left.\mathrm{CDCl}_{3}, \delta\right): 7.14\left(\mathrm{~d},{ }^{3} J=6.4 \mathrm{~Hz}, 1 \mathrm{H}, \mathrm{H} 12\right), 6.85\left(\mathrm{~d},{ }^{3} J=\right.$ $6.4 \mathrm{~Hz}, 1 \mathrm{H}, \mathrm{H} 11), 6.79(\mathrm{~s}, 1 \mathrm{H}, \mathrm{H} 10), 4.21(\mathrm{~m}, 1 \mathrm{H}, \mathrm{H} 9), 4.06\left(\mathrm{t},{ }^{3} J=6.4 \mathrm{~Hz}, 1 \mathrm{H}, \mathrm{H} 8\right), 4.03(\mathrm{~m}, 3 \mathrm{H}$, $\mathrm{H} 7$ and $\mathrm{H} 8), 3.95(\mathrm{~m}, 1 \mathrm{H}, \mathrm{H} 6), 3.84(\mathrm{~m}, 2 \mathrm{H}, \mathrm{H} 4$ and $\mathrm{H} 5), 3.36\left(\mathrm{~m},{ }^{3} \mathrm{~J}=7.1 \mathrm{~Hz}, 1 \mathrm{H}, \mathrm{H} 3\right), 2.39(\mathrm{~s}$, $3 \mathrm{H}, \mathrm{H} 2), 1.29\left(\mathrm{~d},{ }^{3} J=7.1 \mathrm{~Hz}, 6 \mathrm{H}, \mathrm{H} 1\right) \mathrm{ppm} .{ }^{13} \mathbf{C} \mathbf{~ N M R}\left(100 \mathrm{MHz}, \mathrm{CDCl}_{3}, \delta\right):(\mathrm{C} 12) 155.50$, (C11) 136.52, (C10) 134.07, (C9) 126.03, (C8) 121.88, (C7) 112.61, (C6) 70.97, (C5) 69.06, (C4) 64.07, (C3) 26.60, (C2) 22.91, (C1) 29.34 ppm. (See appendices A.11.1 and A.11.2)

MS-DART analysis: $225.1[\mathrm{M}]^{+}, 242.2[\mathrm{M}]^{+}$. (See appendix A.11.3)

\section{Compound 34}

${ }^{1} \mathrm{H}$ NMR

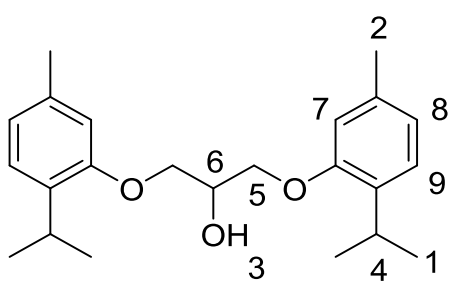

${ }^{13} \mathrm{C}$ NMR

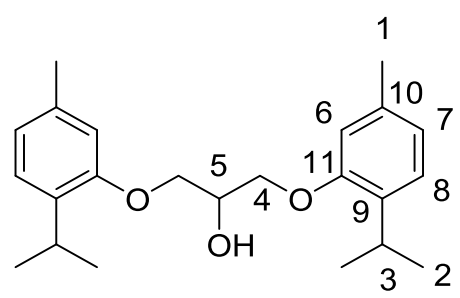

Yield: $27 \%$ (31.77 g). ${ }^{1} \mathbf{H}$ NMR (400 MHz, $\left.\mathrm{CDCl}_{3}, \delta\right): 7.22\left(\mathrm{~d},{ }^{3} J=7.7 \mathrm{~Hz}, 2 \mathrm{H}, \mathrm{H} 9\right), 6.89\left(\mathrm{~d},{ }^{3} J=\right.$ $7.7 \mathrm{~Hz}, 2 \mathrm{H}, \mathrm{H} 8), 6.82(\mathrm{~s}, 2 \mathrm{H}, \mathrm{H} 7), 4.56\left(\mathrm{~m},{ }^{3} J=5.1 \mathrm{~Hz}, 1 \mathrm{H}, \mathrm{H} 6\right), 4.30\left(\mathrm{~m},{ }^{3} J=5.0 \mathrm{~Hz}, 4 \mathrm{H}, \mathrm{H} 5\right)$, $3.41\left(\mathrm{~m},{ }^{3} J=7.1 \mathrm{~Hz}, 2 \mathrm{H}, \mathrm{H} 4\right), 2.73\left(\mathrm{~d},{ }^{3} J=5.3 \mathrm{~Hz}, 1 \mathrm{H}, \mathrm{H} 3\right) 2.43(\mathrm{~s}, 6 \mathrm{H}, \mathrm{H} 2), 1.33\left(\mathrm{~d},{ }^{3} J=7.0 \mathrm{~Hz}\right.$, 12H, H1) ppm. ${ }^{13}$ C NMR (100 MHz, $\mathrm{CDCl}_{3}, \delta$ ): (C11) 155.51, (C10) 136.56, (C9) 134.17, (C8) 126.11, (C7) 121.93, (C6) 112.64, (C5) 69.28, (C4) 69.11, (C3) 26.73, (C2) 22.91, (C1) 21.36 ppm. (See appendices A.12.1 and A.12.2)

MS-DART analysis: $356.2[\mathrm{M}]^{+}, 374.3[\mathrm{M}]^{+}$. (See appendix A.12.3) 


\section{Compound 36}

${ }^{1} \mathrm{H}$ NMR

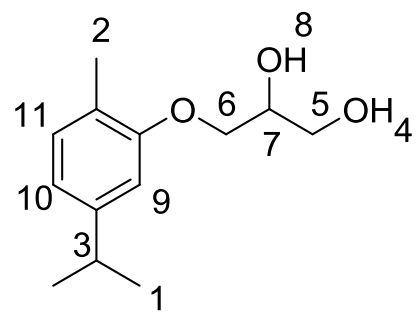

${ }^{13} \mathrm{C}$ NMR

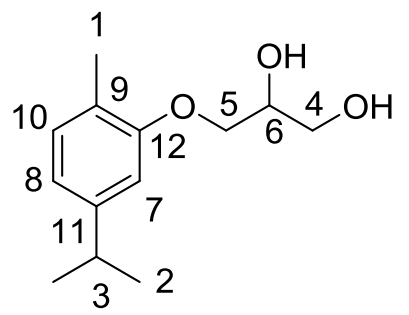

Yield: $71 \%$ (52.55 g). ${ }^{1} \mathbf{H}$ NMR (400 MHz, $\left.\mathrm{CDCl}_{3} .8\right): 7.13\left(\mathrm{~d},{ }^{3} J=7.6 \mathrm{~Hz}, 1 \mathrm{H}, \mathrm{H} 11\right), 6.85\left(\mathrm{~d},{ }^{3} J=\right.$ $7.6 \mathrm{~Hz}, 1 \mathrm{H}, \mathrm{H} 10), 6.79(\mathrm{~s}, 1 \mathrm{H}, \mathrm{H} 9), 4.20(\mathrm{~m}, 1 \mathrm{H}, \mathrm{H} 8), 4.13(\mathrm{~m}, 1 \mathrm{H}, \mathrm{H} 7), 4.10\left(\mathrm{t},{ }^{3} J=4.4 \mathrm{~Hz}, 2 \mathrm{H}\right.$, H6), 3.93(m, 2H, H5), 3.86(m, 1H, H4), 2.94(m, $\left.{ }^{3} J=6.9 \mathrm{~Hz}, 1 \mathrm{H}, \mathrm{H} 3\right), 2.28(\mathrm{~s}, 3 \mathrm{H}, \mathrm{H} 2), 1.33(\mathrm{~d}$, $\left.{ }^{3} J=7.0 \mathrm{~Hz}, 6 \mathrm{H}, \mathrm{H1}\right) \mathrm{ppm} .{ }^{13} \mathrm{C}$ NMR (100 MHz, $\left.\mathrm{CDCl}_{3}, \delta\right):(\mathrm{C} 12)$ 156.55, (C11) 148.14, (C10) 130.66, (C9) 124.04, (C8) 118.79, (C7) 109.89, (C6) 70.94, (C5) 69.16, (C4) 63.89, (C3) 33.99, (C2) 24.17, (C1) $15.71 \mathrm{ppm}$. (See appendices A.13.1 and A.13.2)

MS-DART analysis: $225.1[\mathrm{M}]^{+}, 242.2[\mathrm{M}]^{+}$. (See appendix A.13.3)

\section{Compound 37}
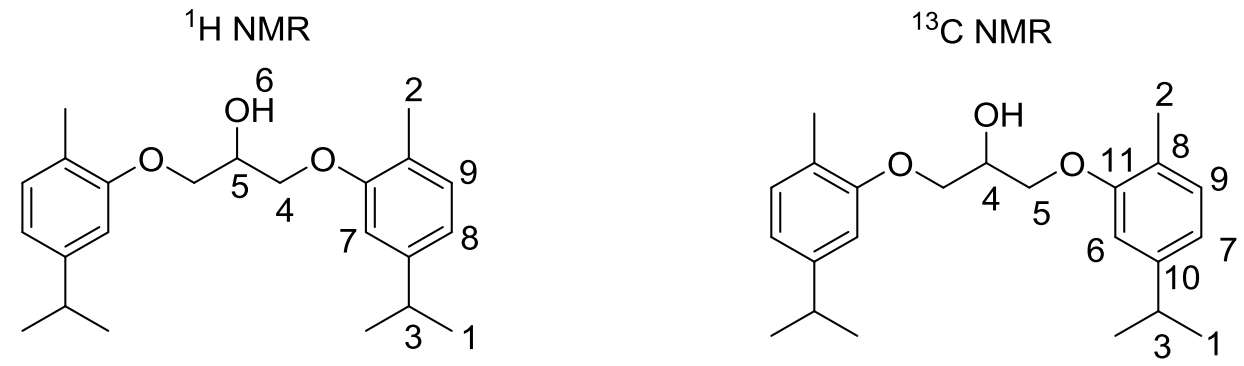

Yield: $19 \%$ (22.35 g). ${ }^{1} \mathbf{H}$ NMR (400 MHz, $\left.\mathrm{CDCl}_{3}, \delta\right): 7.28\left(\mathrm{~d},{ }^{3} J=7.3 \mathrm{~Hz}, 2 \mathrm{H}, \mathrm{H} 9\right), 6.99\left(\mathrm{~d},{ }^{3} J=\right.$ $7.3 \mathrm{~Hz}, 2 \mathrm{H}, \mathrm{H} 8), 6.98(\mathrm{~s}, 2 \mathrm{H}, \mathrm{H} 7), 4.57\left(\mathrm{~d},{ }^{3} J=4.7 \mathrm{~Hz}, 1 \mathrm{H}, \mathrm{H} 6\right), 4.44\left(\mathrm{~m},{ }^{3} J=4.4 \mathrm{~Hz}, 4 \mathrm{H}, \mathrm{H} 5\right)$, $3.23\left(\mathrm{~d},{ }^{3} J=4.6 \mathrm{~Hz}, 1 \mathrm{H}, \mathrm{H} 4\right), 3.08\left(\mathrm{~m},{ }^{3} J=7.1 \mathrm{~Hz}, 2 \mathrm{H}, \mathrm{H} 3\right), 2.44(\mathrm{~s}, 6 \mathrm{H}, \mathrm{H} 2), 1.47\left(\mathrm{~d},{ }^{3} J=7.0 \mathrm{~Hz}\right.$, 12H, H1) ppm. ${ }^{13} \mathbf{C}$ NMR (100 MHz, $\mathrm{CDCl}_{3}, \delta$ ): (C11) 156.68, (C10) 148.28, (C9) 130.85, (C8) 
124.25, (C7) 118.99, (C6) 109.99, (C5) 69.41, (C4) 69.14, (C4) 69.14, (C3) 34.31, (C2) 24.29, (C1) 16.02 ppm. (See appendices A.14.1 and A.14.2)

\subsubsection{Preparation of 4-(4-(2,3-dihydroxypropoxy)phenyl)butan-2-one 39}

In a $500 \mathrm{~mL} 3$ neck flask, $38(50.00 \mathrm{~g}, 0.31 \mathrm{~mol})$ along with $\mathbf{1 5}(37.04 \mathrm{~g}, 0.32 \mathrm{~mol})$ and $\mathbf{1 0}(0.25$ g, $0.002 \mathrm{~mol}$ ) were placed under an argon blanket. The reaction vessel was heated to $130^{\circ} \mathrm{C}$ for 30 min. After the 30 min mark, the temperature was increased by $10^{\circ} \mathrm{C}$ every 30 min until a temperature of $180^{\circ} \mathrm{C}$ was reached. The reaction was allowed to continue for another $2.5 \mathrm{hrs}$. The resulting material was washed $(1 \times 200 \mathrm{~mL})$ with water and extracted $(1 \times 500 \mathrm{~mL})$ with ethyl acetate. Solvent removal was performed using rotary evaporation. The liquid was left exposed to air for several days but did not solidify. Purification was accomplished using an HPLC with 3:1 hexane/ethyl acetate. Both $\mathbf{3 9}$ and by-product $\mathbf{4 0}$ were both isolated as yellow oils.

\section{Compound 39}
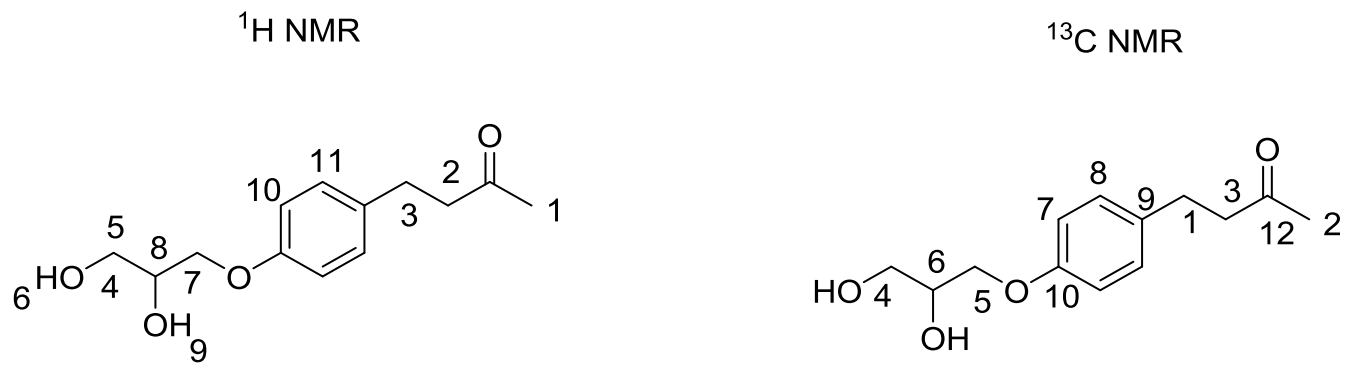

Yield: 75\% (55.40 g). ${ }^{1} \mathbf{H}$ NMR (400 MHz, $\left.\mathrm{CDCl}_{3}, \delta\right): 6.95\left(\mathrm{~d},{ }^{3} J=9.4 \mathrm{~Hz}, 2 \mathrm{H}, \mathrm{H} 11\right), 6.72\left(\mathrm{~d},{ }^{3} J\right.$ $=9.4 \mathrm{~Hz}, 2 \mathrm{H}, \mathrm{H} 10), 4.39(\mathrm{~m}, 1 \mathrm{H}, \mathrm{H} 9), 4.00(\mathrm{~m}, 1 \mathrm{H}, \mathrm{H} 8), 3.84\left(\mathrm{~d},{ }^{3} \mathrm{~J}=5.5 \mathrm{~Hz}, 2 \mathrm{H}, \mathrm{H} 7\right), 3.78(\mathrm{~m}$, 1H, H6), 3.86(m, 1H, H5), 3.63(m, 1H, H4), 2.69(t, $\left.{ }^{3} J=7.2 \mathrm{~Hz}, 2 \mathrm{H}, \mathrm{H} 3\right), 2.59\left(\mathrm{t},{ }^{3} J=7.2 \mathrm{~Hz}\right.$ 2H, H2), 2.01(s, 3H, H1) ppm. ${ }^{13} \mathbf{C}$ NMR (100 MHz, $\mathrm{CDCl}_{3}, \delta$ ): (C11) 209.00, (C10) 156.97, 
(C9) 133.29, (C8) 129.20, (C7) 114.62, (C6) 70.58, (C5) 69.06, (C4) 63.58, (C3) 45.13, (C2)

29.93, (C1) 28.77 ppm. (See appendices A.15.1 and A.15.2)

MS-DART analysis: $164.2[\text { Raspberry ketone }]^{+}, 238.1[\mathrm{M}]^{+}, 256.2\left[\mathrm{M}+\mathrm{NH}_{4}\right]^{+}$. (See appendix A.15.3)

Compound 40

${ }^{1} \mathrm{H}$ NMR

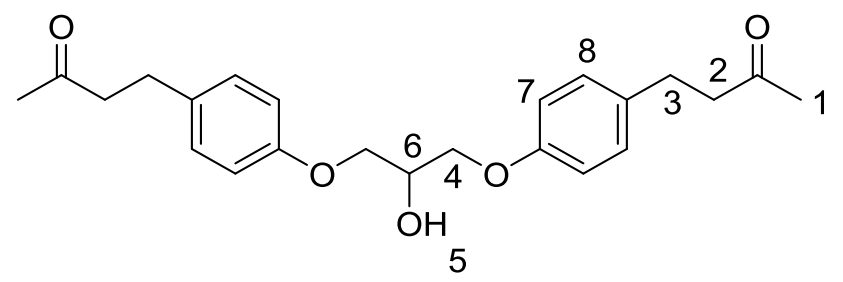

${ }^{13} \mathrm{C}$ NMR

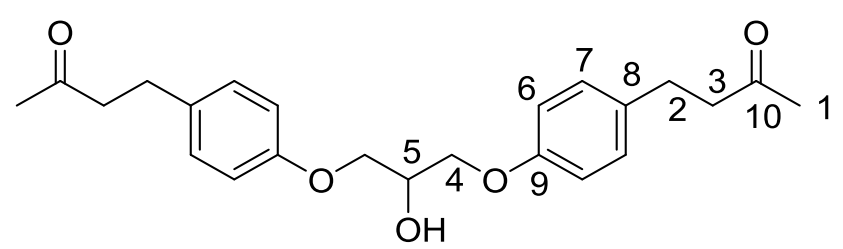

Yield: $25 \%$ (29.78g). ${ }^{1} \mathbf{H}$ NMR (400 MHz, $\left.\mathrm{CDCl}_{3}, \delta\right): 6.99\left(\mathrm{~d},{ }^{3} J=8.3 \mathrm{~Hz}, 4 \mathrm{H}, \mathrm{H} 8\right), 6.77\left(\mathrm{~d},{ }^{3} J=\right.$ $9.3 \mathrm{~Hz}, 4 \mathrm{H}, \mathrm{H} 7), 4.30\left(\mathrm{~m},{ }^{3} J=5.1 \mathrm{~Hz}, 1 \mathrm{H}, \mathrm{H} 6\right), 4.12\left(\mathrm{~d},{ }^{3} \mathrm{~J}=4.4 \mathrm{~Hz}, 1 \mathrm{H}, \mathrm{H} 5\right), 4.03\left(\mathrm{t},{ }^{3} \mathrm{~J}=5.1 \mathrm{~Hz}\right.$, 4H, H4), 2.71(t, $\left.{ }^{3} J=7.4 \mathrm{~Hz}, 4 \mathrm{H}, \mathrm{H} 3\right), 2.59\left(\mathrm{t},{ }^{3} \mathrm{~J}=7.4 \mathrm{~Hz}, 4 \mathrm{H}, \mathrm{H} 2\right), 2.00(\mathrm{~s}, 6 \mathrm{H}, \mathrm{H1}) \mathrm{ppm} .{ }^{13} \mathrm{C}$ NMR (100 MHz, $\mathrm{CDCl}_{3}, \delta$ ): (C10) 208.62, (C9) 157.02, (C8) 133.42, (C7) 129.25, (C6) 114.57, (C5) 69.11, (C4) 68.70, (C3) 45.10, (C2) 29.90, (C1) 28.81 ppm. (See appendices A.16.1 and A.16.2)

\subsubsection{Preparation of 3-(p-tolyloxy)propane-1,2-diol 45}

In a $500 \mathrm{~mL} 3$ neck flask, $44(50.00 \mathrm{~g}, 0.46 \mathrm{~mol})$ along with $15(56.25 \mathrm{~g}, 0.48 \mathrm{~mol})$ and $\mathbf{1 0}(0.25$ g, $0.002 \mathrm{~mol}$ ) were placed under an argon atmosphere. The reaction vessel was heated to $130^{\circ} \mathrm{C}$ for $30 \mathrm{~min}$. After $30 \mathrm{~min}$, the temperature was increased by $10^{\circ} \mathrm{C}$ every $30 \mathrm{~min}$ until a temperature of $180^{\circ} \mathrm{C}$ was reached. The reaction was allowed to continue for another $2.5 \mathrm{hrs}$. The resulting material was washed $(1 \times 200 \mathrm{~mL})$ with water and extracted $(1 \times 500 \mathrm{~mL})$ with ethyl acetate. Solvent removal was performed using rotary evaporation. The liquid was left 
exposed to air where it solidified it solidified after several hours generating a waxy, brownish yellow solid. Purification was accomplished using an HPLC with 3:1 hexane/ethyl acetate. Compounds $\mathbf{4 5}$ and the by product $\mathbf{4 6}$ were isolated as yellow solids.

\section{Compound 45}

${ }^{1} \mathrm{H}$ NMR

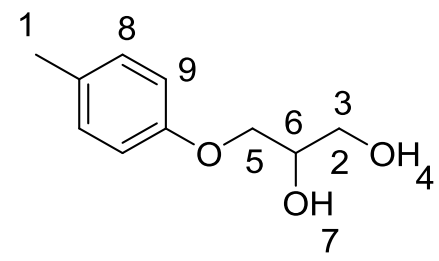

${ }^{13} \mathrm{C}$ NMR

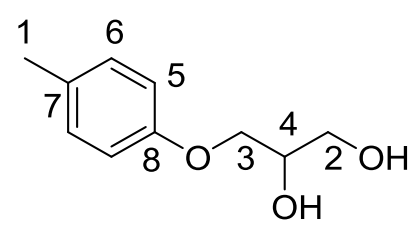

Yield: $75 \%$ (68.27g). ${ }^{1} \mathbf{H}$ NMR (400 MHz, $\left.\mathrm{CDCl}_{3}, \delta\right): 7.01\left(\mathrm{~d},{ }^{3} J=8.5 \mathrm{~Hz}, 2 \mathrm{H}, \mathrm{H} 9\right), 6.75\left(\mathrm{~d},{ }^{3} J=\right.$ $8.5 \mathrm{~Hz}, 2 \mathrm{H}, \mathrm{H} 8), 4.04(\mathrm{~m}, 1 \mathrm{H}, \mathrm{H} 7), 3.89\left(\mathrm{~m}, 3 \mathrm{H}, \mathrm{H} 5\right.$ and H6), H4 not observed, 3.79(dd, $J^{3}=3.4$ $\mathrm{Hz}, 1 \mathrm{H}, \mathrm{H} 3), 3.66(\mathrm{~m}, 1 \mathrm{H}, \mathrm{H} 2), 2.25(\mathrm{~s}, 3 \mathrm{H}, \mathrm{H} 1)$ ppm. ${ }^{13} \mathbf{C}$ NMR (100 MHz, $\left.\mathrm{CDCl}_{3}, \delta\right):(\mathrm{C} 8)$ 156.34, (C7) 130.40, (C6) 129.95, (C5) 114.41, (C4) 70.62, (C3) 69.13, (C2) 63.70, (C1) 20.43 ppm. (See appendices A.19.1 and A.19.2).

MS-DART analysis of 42: 183.1[M] ${ }^{+}, 200.1\left[\mathrm{M}+\mathrm{NH}_{4}\right]$. (See appendix A.19.3)

\section{Compound 46}

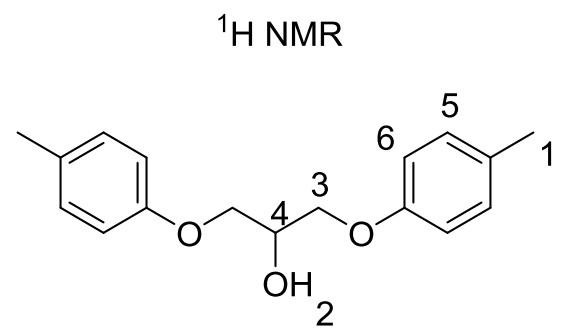

${ }^{13} \mathrm{C}$ NMR - Not available 
Yield: $25 \%$ (272.34 g). ${ }^{1} \mathbf{H}$ NMR (400 MHz, $\left.\mathrm{CDCl}_{3}, \delta\right): 7.17\left(\mathrm{~d},{ }^{3} J=8.6 \mathrm{~Hz}, 4 \mathrm{H}, \mathrm{H6}\right), 6.92\left(\mathrm{~d},{ }^{3} J\right.$ $=8.6 \mathrm{~Hz}, 4 \mathrm{H}, \mathrm{H} 5), 4.46\left(\mathrm{q},{ }^{3} J=5.1 \mathrm{~Hz}, 1 \mathrm{H}, \mathrm{H} 4\right), 4.20\left(\mathrm{~m},{ }^{3} J=5.5 \mathrm{~Hz}, 4 \mathrm{H}, \mathrm{H} 3\right), 3.18\left(\mathrm{~d},{ }^{3} J=5.0\right.$ $\mathrm{Hz}, 1 \mathrm{H}, \mathrm{H} 2)$ 2.38(s, 6H, H1) ppm. (See appendix A.20.1)

\subsubsection{Preparation of 3-(4-(2-(2-methoxyphenoxy)ethyl)phenoxy)propane-1,2-diol 47}

Under an argon blanket, in a $250 \mathrm{~mL} 3$ neck flask, 13 (10.00 g, $0.041 \mathrm{~mol}), 15$ (5.00 g, 0.042 mol) and $10(0.15 \mathrm{~g}, 0.001 \mathrm{~mol})$ were heated to $130^{\circ} \mathrm{C}$. At a temperature of $130^{\circ} \mathrm{C}$, the reaction was allowed to run for $30 \mathrm{~min}$. The reaction was a clear solution. The temperature was increased by $10^{\circ} \mathrm{C}$ every 30 min until a temperature of $180^{\circ} \mathrm{C}$ was reached. The reaction was then allowed to run for an additional $18 \mathrm{hrs}$. The resulting material was washed $(1 \times 100 \mathrm{~mL})$ with water and extracted $(1 \times 200 \mathrm{~mL})$ with ethyl acetate. Solvent removal was performed rotary evaporation. The resulting material was viscous orange oil. Compound $\mathbf{4 7}$ was isolated as a white solid using HPLC with a solvent composition of 3:1 ethyl acetate/hexane.
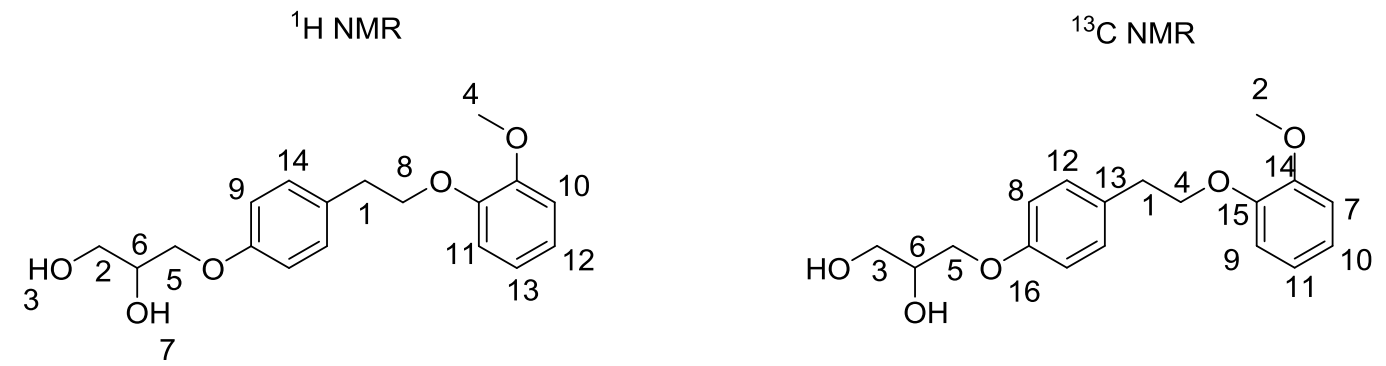

Yield: $23 \%$ (3.00g). ${ }^{1} \mathbf{H}$ NMR (400 MHz, $\left.\mathrm{CDCl}_{3}, \delta\right): 7.16\left(\mathrm{~d},{ }^{3} \mathrm{~J}=8.6 \mathrm{~Hz}, 2 \mathrm{H}, \mathrm{H14}\right), 6.87(\mathrm{~m}, 4 \mathrm{H}$, H10, H11, H12 and H13), 6.82(d, $\left.{ }^{3} J=8.6 \mathrm{~Hz}, 2 \mathrm{H}, \mathrm{H} 9\right), 4.14\left(\mathrm{t},{ }^{3} J=7.3 \mathrm{~Hz}, 2 \mathrm{H}, \mathrm{H} 8\right), \mathrm{H} 7 \mathrm{not}$ observed, 4.06(m, 1H, H6), 3.95(d, $\left.{ }^{3} J=5.4 \mathrm{~Hz}, 2 \mathrm{H}, \mathrm{H} 5\right), 3.83(\mathrm{~s}, 3 \mathrm{H}, \mathrm{H} 4), 3.76(\mathrm{~m}, 1 \mathrm{H}, \mathrm{H} 3)$, 3.36(m, 2H, H2), 3.06(t, $\left.{ }^{3} J=7.3 \mathrm{~Hz}, 2 \mathrm{H}, \mathrm{H1}\right) \mathrm{ppm} .{ }^{13} \mathbf{C}$ NMR $\left(\mathrm{CDCl}_{3}, \delta\right):(\mathrm{C} 16) 157.21,(\mathrm{C} 15)$ 149.51, (C14) 148.30, (C13) 130.77, (C12) 130.14, (C11) 121.40, (C10) 121.00, (C9) 114.66, 
(C8) 133.50, (C7) 112.15, (C6) 70.59, (C5) 69.98, (C4) 69.15, (C3) 63.72, (C2) 56.03, (C1)

34.89 ppm. (See appendices A.21.1 and A.21.2)

MS-DART analysis of 47: $318.2[\mathrm{M}]^{+}, 336.3\left[\mathrm{M}+\mathrm{NH}_{4}\right]^{+}$. (See appendix A.21.3)

\subsection{Polymer Synthesis}

\subsubsection{Polymerization monitoring techniques}

Monitoring the polymerization was accomplished using acid values (A.V.) and softening points $\left(\mathrm{T}_{\mathrm{s}}\right)$. A.V. values were obtained by removing a small amount of molten material, usually between $0.25-0.5 \mathrm{~g}$. The exact mass was recorded. The molten material, which solidified almost immediately upon removal from the reaction vessel, was dissolved in THF. 2 drops of phenophathalene were added to the solution. The solution was titrated with $0.1 \mathrm{~N} \mathrm{KOH}$. The required volume of $\mathrm{KOH}$ was then multiplied by 5.611 . This value was then divided by the mass

of the dissolved material to generate the current acid value of the system. Reactions were considered complete once the A.V of the system was below 15. Softening points were determined using a Mettler-Toledo instrument. The instrument was set at an initial temperature of $100^{\circ} \mathrm{C}$ and once engaged would increase at a rate of $1^{\circ} \mathrm{C}$ per min. All other default settings were kept. Molten material was removed from the reaction vessel and placed into the circular holder. Once the resulting sample had cooled, it was then inserted into the instrument. Softening points below $100^{\circ} \mathrm{C}$ were simply recorded as such. Softening points greater than $100^{\circ} \mathrm{C}$ were recorded to the exact value.

\subsubsection{Polymerization of 3-(2-methoxyphenoxy)propane-1,2-diol}

In a $500 \mathrm{~mL} 3$ neck flask, $26(50.00 \mathrm{~g}, 0.25 \mathrm{~mol})$ with $\mathbf{5 0}(25.32 \mathrm{~g}, 0.21 \mathrm{~mol})$ resulting in a 1.15 to 1 ratio of diol to acid, along with Fascat 410049 (0.50 g, $0.002 \mathrm{~mol})$ were added. Independent experiments were also performed using other acids which include isoterephthalic acid $\mathbf{5 2}$ (35.62 
g, $0.21 \mathrm{~mol})$ and terephathalic acid $54(35.62 \mathrm{~g}, 0.21 \mathrm{~mol})$ along with $26(50.00 \mathrm{~g}, 0.25 \mathrm{~mol})$. Polymerizations involving compounds $\mathbf{5 2}$ and $\mathbf{5 4}$ followed an almost identical protocol with the exception of lengthier heating requirements. All polymerizations were carried out under and argon blanket. Using a mechanical stirring rod, the reagents in the ratios mentioned above were heated to $140^{\circ} \mathrm{C}$ resulting in a melt. The temperature was kept at $140^{\circ} \mathrm{C}$ for $1 \mathrm{hr}$. After the 1 hour mark, the temperature was raised by $5^{\circ} \mathrm{C} /$ hour until a temperature of $180^{\circ} \mathrm{C}$ was reached. The reaction then was left overnight to react (11-13 hrs). The reaction temperature was then increased from $180^{\circ} \mathrm{C}$ to $185^{\circ} \mathrm{C}$ and allowed to run for one hour. The temperature was then increased $5^{\circ} \mathrm{C}$ / hour until $200^{\circ} \mathrm{C}$ was reached. It was then allowed to react again over night (14$16 \mathrm{hrs})$. The temperature was then increased by $5^{\circ} \mathrm{C}$ an hour until a temperature of $240^{\circ} \mathrm{C}$ was reached. The reaction was then allowed to run for 14-30 hrs. Experiments involving 52 and $\mathbf{5 4}$ were left to run at $240^{\circ} \mathrm{C}$ until the A.V. $\approx 15$ and a maximum softening point was reached. The color of the material when the reaction was performed without the use of argon was a glossy black material. When argon was employed, the resulting material was a clear with a yellowish tint as seen below.

\section{Compound 51}
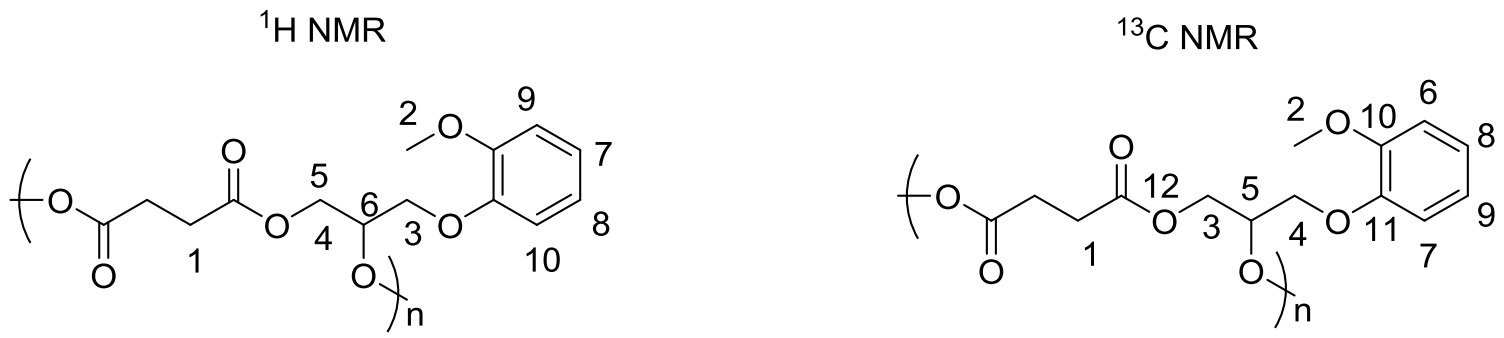

Yield: $91 \%$ (70.75 g). ${ }^{1} \mathbf{H}$ NMR (400 MHz, $\mathrm{CDCl}_{3}, \delta$ ): 6.94(m, 2H, H8 and H9), 6.90(m, 2H, H7 and $\mathrm{H} 8), 5.42(\mathrm{~m}, 1 \mathrm{H}, \mathrm{H} 6), 4.50(\mathrm{~m}, 1 \mathrm{H}, \mathrm{H} 5), 4.37(\mathrm{~m}, 1 \mathrm{H}, \mathrm{H} 4), 4.17(\mathrm{~m}, 2 \mathrm{H}, \mathrm{H} 3), 3.83(\mathrm{~s}, 3 \mathrm{H}, \mathrm{H} 2)$, 2.66(s, 4H, H1) ppm. ${ }^{13} \mathrm{C}$ NMR (100 MHz, $\left.\mathrm{CDCl}_{3}, \delta\right):(\mathrm{C} 13)$ 171.85, (C12) 171.56, (C11) 
150.08, (C10) 147.91, (C9) 122.50, (C8) 120.96, (C7) 115.47, (C6) 112.49, (C5) 70.26, (C4) 67.79, (C3) 62.82, (C2) 55.91, (C1) 28.90 ppm. (See appendices A.22.1 and A.22.2)

\section{Compound $\mathbf{5 3}$}
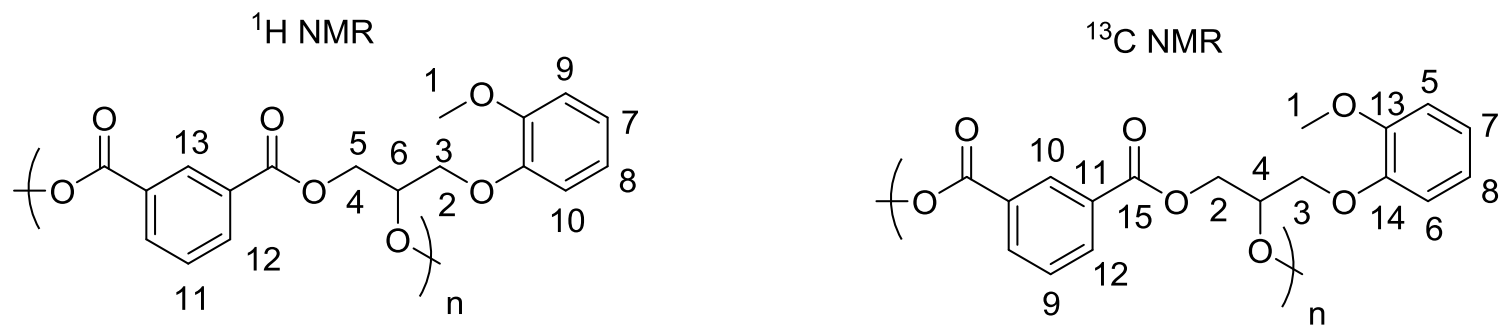

Yield: $94 \%$ (81.07 g). ${ }^{1} \mathbf{H}$ NMR (400 MHz, $\left.\mathrm{CDCl}_{3}, \delta\right): 8.68\left(\mathrm{~d},{ }^{3} J=7.5 \mathrm{~Hz}, 1 \mathrm{H}, \mathrm{H} 13\right), 8.19\left(\mathrm{~d},{ }^{3} J\right.$ $=7.2 \mathrm{~Hz}, 2 \mathrm{H}, \mathrm{H} 12), 7.46(\mathrm{~m}, 1 \mathrm{H}, \mathrm{H} 11), 6.94(\mathrm{~m}, 2 \mathrm{H}, \mathrm{H} 9$ and $\mathrm{H} 10), 6.86(\mathrm{~m}, 2 \mathrm{H}, \mathrm{H} 7$ and $\mathrm{H} 8)$, 5.79(m, 1H, H6), 4.85(m, 1H, H5), 4.76(m, 1H, H4), 4.39(m, 2H, H2 and H3), 3.76(s, 3H, H1) ppm. ${ }^{13} \mathrm{C}$ NMR (100 MHz, $\left.\mathrm{CDCl}_{3}, \delta\right):(\mathrm{C} 18)$ 165.20, (C17) 164.89, (C16) 150.23, (C15) 147.86, (C13 and C14) 134.19, (C11 and C12) 131.03, (C10) 130.20, (C9) 128.75, (C8) 122.71, (C7) 120.95, (C6) 115.95, (C5) 112.47, (C4) 71.08, (C3) 68.20, (C2) 63.63, (C1) 55.81 ppm. (See appendices A.23.1 and A.23.2)

\section{Compound $\mathbf{5 5}$}

${ }^{1} \mathrm{H}$ NMR

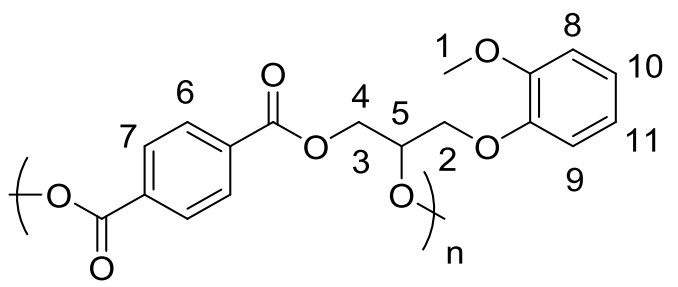

${ }^{13} \mathrm{C} N M R$

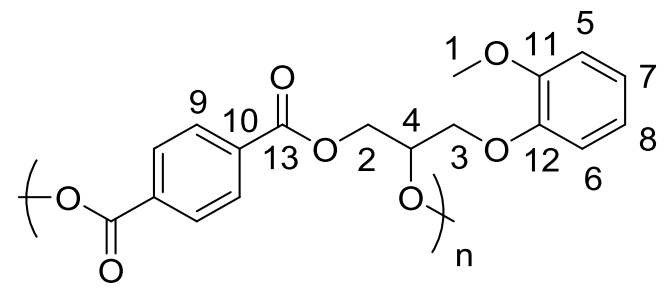

Yield: 89\% (76.76 g). ${ }^{1} \mathbf{H}$ NMR (400 MHz, $\mathrm{CDCl}_{3}, \delta$ ): 8.04(m, 4H, H8 and H9), 6.96(m, 2H, H7), 6.87(m, 2H, H6), 5.78(m, 1H, H5), 4.85(m, 1H, H4), 4.76(m, 1H, H3), 4.40(m, 2H, H2), 3.76(s, 3H, H1) ppm. ${ }^{13} \mathrm{C}$ NMR (100 MHz, $\left.\mathrm{CDCl}_{3}, \delta\right):(\mathrm{C} 13)$ 164.95, (C12) 150.28, (C11) 
147.87, (C10) 133.63, (C9) 129.75, (C8) 122.84, (C7) 120.96, (C6) 116.04, (C5) 112.47, (C4)

71.16, (C3) 68.28, (C2) 63.63, (C1) 55.82 ppm. (See appendices A.24.1 and A.24.2)

\subsubsection{Evaluation of the Catalyst}

The polymerization of compound $\mathbf{2 6}$ with and $\mathbf{5 0}$ was repeated in the presence of a titanium catalyst $(0.50 \mathrm{~g}, 0.002 \mathrm{~mol})$. The resulting material appeared identical to the material depicted above.

${ }^{1} \mathrm{H}$ NMR

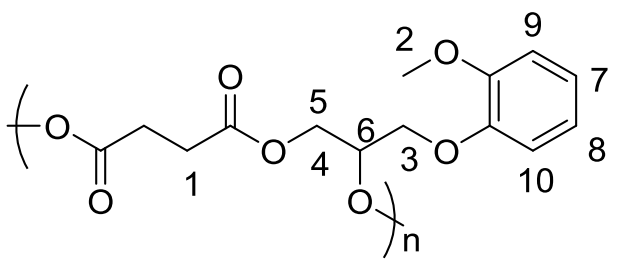

${ }^{13} \mathrm{C}$ NMR - Not available

Yield (N/A). ${ }^{1} \mathbf{H}$ NMR (400 MHz, $\left.\mathrm{CDCl}_{3}, \delta\right): 6.90(\mathrm{~m}, 2 \mathrm{H}, \mathrm{H} 8$ and $\mathrm{H} 9), 6.87(\mathrm{~m}, 2 \mathrm{H}, \mathrm{H} 7$ and H8), 5.37(m, 1H, H6), 4.44(m, 1H, H5), 4.34(m, 1H, H4), 4.13(m, 2H, H3), 3.80(s, 3H, H2), 2.62(s, 4H, H1) ppm. (See appendix A.25.1)

\section{$\underline{\text { 5.5.4 Polymerization of 3-(2-methoxy-4-propylphenoxy)propane-1,2-diol } 57}$}

In a $500 \mathrm{~mL} 3$ neck flask, $29(50.00 \mathrm{~g}, 0.21 \mathrm{~mol})$ along with $\mathbf{5 0}(20.89 \mathrm{~g}, 0.18 \mathrm{~mol})$, resulting in a 1.15 to 1 ratio of diol to acid and $49(0.50 \mathrm{~g}, 0.002 \mathrm{~mol})$ were added. Polymerizations were carried out under an argon blanket. Using a magnetic stirring rod, the reagents were heated to $140^{\circ} \mathrm{C}$ resulting in a melt. The temperature was kept at $140^{\circ} \mathrm{C}$ for $1 \mathrm{hr}$. After the $1 \mathrm{hr}$ mark, the temperature was raised by $5^{\circ} \mathrm{C}$ every hr until a temperature of $180^{\circ} \mathrm{C}$ was reached. The reaction then was left overnight to react (11-13 hrs). The color of the material did not noticeably change. The reaction temperature was increased from $180^{\circ} \mathrm{C}$ to $185^{\circ} \mathrm{C}$ and allowed to run for an hr. The temperature was then increased every hour by $5^{\circ} \mathrm{C}$ until $200^{\circ} \mathrm{C}$ was reached. It was then allowed 
to react again over night (14-16 hrs). The color of the material had not changed after the second day of reacting. The temperature was then increased by $5^{\circ} \mathrm{C}$ an $\mathrm{hr}$ until a temperature of $220^{\circ} \mathrm{C}$ was reached. The reaction was then allowed to run for 14-30 hrs. In all attempts, at some point after $48 \mathrm{hrs}$, the material in the melt crashes out and is neither soluble in any solvent nor is it capable of melting. Prior to solidifying, the resulting material was clear with a yellowish tint and was quite soft relative to the polymers mentioned above. The yield was $88 \%,(57.47 \mathrm{~g})$.

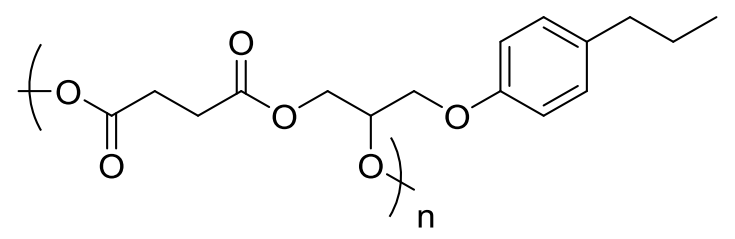

\section{$\underline{\text { 5.5.5 Polymerization of 3-(4-allyl-2-methoxyphenoxy)propane-1,2-diol } 58}$}

In a 500 mL 3 neck flask, $16(50.00 \mathrm{~g}, 0.21 \mathrm{~mol})$ along with $\mathbf{5 0}(21.06 \mathrm{~g}, 0.18 \mathrm{~mol})$, resulting in a 1.15 to 1 ratio of diol to acid and $49(0.5 \mathrm{~g}, 0.002 \mathrm{~mol})$ were added. Polymerizations were carried out under and argon blanket. Using a magnetic stirring rod, the reagents were heated to $140^{\circ} \mathrm{C}$ resulting in a melt. The temperature was kept at $140^{\circ} \mathrm{C}$ for $1 \mathrm{hr}$. After the $1 \mathrm{hr}$ mark, the temperature was raised by $5^{\circ} \mathrm{C}$ every $\mathrm{hr}$ until a temperature of $180^{\circ} \mathrm{C}$ was reached. The reaction then was left overnight to react (11-13 hrs). At this point, the material had gone from a yellowish orange color to a dark orange. The reaction temperature was increased from $180^{\circ} \mathrm{C}$ to $185^{\circ} \mathrm{C}$ and allowed to run for an hour. The temperature was then increased every hour by $5^{\circ} \mathrm{C}$ until $200^{\circ} \mathrm{C}$ was reached. It was then allowed to react again over night (14-16 hrs). The color of the material which was orange had not changed after the second day of reacting. The temperature was then increased by $5^{\circ} \mathrm{C}$ an hour until a temperature of $220^{\circ} \mathrm{C}$ was reached. The reaction was then allowed to run for 14-30 hrs. In all attempts, at some point throughout the reaction, the material in the melt crashes out and is neither soluble in any solvent nor is it capable 
of melting. Prior to the material being rendered unusable, it was clear, orange, solidified rapidly upon removal from the reaction vessel and unlike all other synthetically generated polymers, incredibly sticky.

\section{Compound 58}
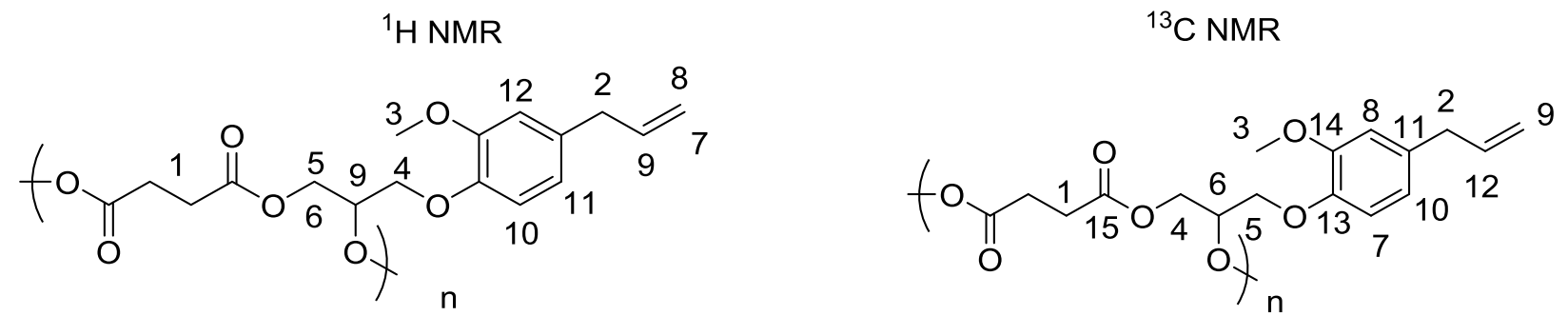

Yield: 90\% (65.02 g). ${ }^{1} \mathbf{H}$ NMR (400 MHz, $\mathrm{CDCl}_{3}, \delta$ ): 6.86(m, 1H, H12), 6.69(s, 2H, H11), 5.94(m, 1H, H10), 5.36(m, 1H, H9), 5.06(m, 2H, H7 and H8), 4.45(m, 1H, H6), 4.32(m, 2H, H5), 4.12(m, 2H, H4), 3.79(s, 3H, H3), 3.30(d, $\left.{ }^{3} \mathrm{~J}=5.2 \mathrm{~Hz}, 2 \mathrm{H}, \mathrm{H} 2\right), 2.63(\mathrm{~s}, 4 \mathrm{H}, \mathrm{H} 1) \mathrm{ppm} .{ }^{13} \mathrm{C}$ NMR (100 MHz, $\left.\mathrm{CDCl}_{3}, \delta\right):(\mathrm{C} 15)$ 171.85, (C14) 152.85, (C13) 150.00, (C12) 146.22, (C11) 137.52, (C10) 134.43, (C9) 120.65, (C8) 115.76, (C7) 112.87, (C6) 70.26, (C5) 67.99, (C4) 62.86, (C3) 55.91, (C2) 39.82, (C1) 28.70 ppm. (See appendices A.26.1 A.26.2).

\subsubsection{Depolymerization of unusable materials}

The reaction vessel containing the cross linked polymer was filled with glycerol 59. To this mixture, $49(1.00 \mathrm{~g}, 0.004 \mathrm{~mol})$ was added. The temperature was increased to $180^{\circ} \mathrm{C}$. The reaction was allowed to continue until the cross linked material had completed dissolved. Another method of depolymerisation was to reflux the cross linked material in methanol. This method returns the polymer to a flowing resin. 


\subsubsection{Self polymerization of vanillin based material}

To a $150 \mathrm{~mL}$ reaction vessel, 30 (50.00 g, $0.33 \mathrm{~mol})$ was added along with 15 (39.95 g, $0.34 \mathrm{~mol})$ and $10(0.25 \mathrm{~g}, 0.002 \mathrm{~mol})$. The reaction mixture was then placed under an argon blanket. With the use of a mechanical stirring rod, the reaction mixture was mixed while the temperature was increased to $130^{\circ} \mathrm{C}$ and allowed to run for $30 \mathrm{~min}$. The reaction temperature was then increased by $10^{\circ} \mathrm{C}$ every 30 min until a maximum temperature of $180^{\circ} \mathrm{C}$ was reached. After $24 \mathrm{hrs}$, there was no evidence of $\mathbf{3 0}$. The reaction was allowed to run for $48 \mathrm{hrs}$ after which there was no evidence of compounds $\mathbf{3 0}$ or $\mathbf{3 1}$. Material $\mathbf{5 9}$ was hard reddish-brown material. The application of heat returns the solid material back into a liquid state.

\section{Compound 59}
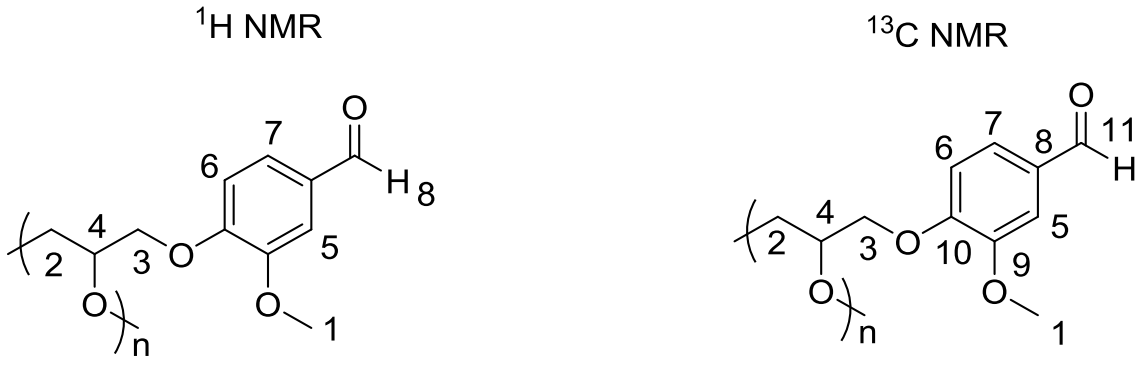

Yield (74\%). ${ }^{\mathbf{1}} \mathbf{H}$ NMR (400 MHz, $\left.\mathrm{CDCl}_{3}, \delta\right): 9.79(\mathrm{~s}, 1 \mathrm{H}, \mathrm{H} 8), 7.42(\mathrm{~m}, 1 \mathrm{H}, \mathrm{H} 7), 7.37(\mathrm{~m}, 1 \mathrm{H}$, H6), 7.18 (s, 1H, H5), (H4-H2 not resolved) 3.87(s, 3H, H1). ${ }^{13} \mathbf{C ~ N M R}\left(100 \mathrm{MHz}, \mathrm{CDCl}_{3}, \delta\right)$ : (C11) 190.93, (C10) 151.43, (C9) 149.95, (C8) 132.64, (C7) 130.57, (C6) 111.72, (C5) 109.37 (C4) 71.20, (C3) 69.84, (C2) 63.53, (C1) 55.94 ppm (See appendices A.26.1 A.26.2). 


\subsection{Appendices}

\section{List of Appendix figures}

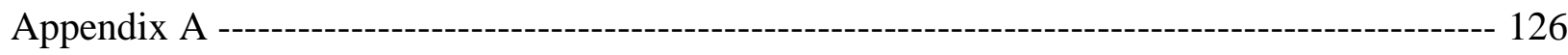

A.1.1: ${ }^{1} \mathrm{H}$ NMR of 2-(4-(tert-butoxy)phenyl)ethan-1-ol (5) -------------------------------- 126

A.1.2: ${ }^{13} \mathrm{C}$ NMR of 2-(4-(tert-butoxy)phenyl)ethan-1-ol (5) -

A.2.1: ${ }^{1} \mathrm{H}$ of 4-(tert-butoxy)phenethyl 4-methylbenzenesulfonate (8) ----------------------- 128

A.3.1: ${ }^{1} \mathrm{H}$ NMR of 1-(4-(tert-butoxy)phenethoxy)-2-methoxybenzene (11) ----------------- 129

A.4.1: ${ }^{1} \mathrm{H}$ NMR of 4-(2-(2-methoxyphenoxy)ethyl)phenol (13) -------- 130

A.4.2: ${ }^{13} \mathrm{C}$ NMR of 4-(2-(2-methoxyphenoxy)ethyl)phenol (13) --- 131

A.4.3: MS-Dart analysis of 4-(2-(2-methoxyphenoxy)ethyl)phenol (13) -------------------- 132

A.5.1: ${ }^{1} \mathrm{H}$ NMR of 3-(4-allyl-2-methoxyphenoxy)propane-1,2-diol (16) -------------------- 133

A.5.2: ${ }^{13} \mathrm{C}$ NMR of 3-(4-allyl-2-methoxyphenoxy)propane-1,2-diol (16) ----------------- 134

A.5.3: MS-DART analsisA.5.3 of 3-(4-allyl-2-methoxyphenoxy)propane-1,2-diol (16) ------- 135

A.6.1: ${ }^{1} \mathrm{H}$ NMR of (4-allyl-2-methoxyphenoxy)trimethylsilane (23) ---------------------- 136

A.6.2: ${ }^{13} \mathrm{C}$ NMR of (4-allyl-2-methoxyphenoxy)trimethylsilane (23) ---------------------- 137

A.6.3: ${ }^{29} \mathrm{Si} \mathrm{NMR}$ of (4-allyl-2-methoxyphenoxy)trimethylsilane (23) ----------------------- 138

A.7.1: ${ }^{1} \mathrm{H}$ NMR of 2-methoxy-4-(2-(2-methoxyphenoxy)propyl)phenol (25) ----------------- 139

A.7.2: ${ }^{13}$ C NMR of 2-methoxy-4-(2-(2-methoxyphenoxy)propyl)phenol (25) -------------- 140

A.7.3: MS-Dart analysis of 2-methoxy-4-(2-(2-methoxyphenoxy)propyl)phenol (25) --------- 141

A.8.1: ${ }^{1} \mathrm{H}$ NMR of 3-(2-methoxyphenoxy)propane-1,2-diol (26) --------------------- 142

A.8.2: ${ }^{13} \mathrm{C}$ NMR of 3-(2-methoxyphenoxy)propane-1,2-diol (26) ------ 143

A.9.1: ${ }^{1} \mathrm{H}$ NMR of 3-(2-methoxy-4-propylphenoxy)propane-1,2-diol (29) ------------------- 144

A.9.2: ${ }^{13} \mathrm{C}$ NMR of 3-(2-methoxy-4-propylphenoxy)propane-1,2-diol (29) -------------- 145

A.9.3: MS-DART analysis of 3-(2-methoxy-4-propylphenoxy)propane-1,2-diol (29) --------- 146

A.10.1: ${ }^{1}$ H NMR of 4-(2,3-dihydroxypropoxy)-3-methoxybenzaldehyde (31) ----------------- 147 
A.10.2: ${ }^{13}$ C NMR of 4-(2,3-dihydroxypropoxy)-3-methoxybenzaldehyde (31) ------------- 148

A.10.3: MS-DART analysis of 4-(2,3-dihydroxypropoxy)benzaldehyde (31) ------------------- 149

A.11.1: ${ }^{1} \mathrm{H}$ NMR of 3-(2-isopropyl-5-methylphenoxy)propane-1,2-diol (33) --------------- 150

A.11.2: ${ }^{13}$ C NMR of 3-(2-isopropyl-5-methylphenoxy)propane-1,2-diol (33) -------------- 151

A.11.3: MS-DART analysis of 3-(2-isopropyl-5-methylphenoxy)propane-1,2-diol (33) ----- 152

A.12.1: ${ }^{1} \mathrm{H}$ NMR of 1,3-bis(2-isopropyl-5-methylphenoxy)propan-2-ol (34) --------------- 153

A.12.2: ${ }^{13} \mathrm{C}$ NMR of 1,3-bis(2-isopropyl-5-methylphenoxy)propan-2-ol (34) ---------------- 154

A.12.3: MS-DART analysis of 1,3-bis(2-isopropyl-5-methylphenoxy)propan-2-ol (34) ------- 155

A.13.1: ${ }^{1}$ H NMR of 3-(5-isopropyl-2-methylphenoxy)propane-1,2-diol (36) ------------------ 156

A.13.2: ${ }^{13} \mathrm{C}$ NMR of 3-(5-isopropyl-2-methylphenoxy)propane-1,2-diol (36) ---------------- 157

A.13.3: MS-DART analysis of 3-(5-isopropyl-2-methylphenoxy)propane-1,2-diol (36) ------ 158

A.14.1: ${ }^{1} \mathrm{H}$ NMR of 1,3-bis(5-isopropyl-2-methylphenoxy)propan-2-ol (37) ----------------- 159

A.14.2: ${ }^{13} \mathrm{C}$ NMR of 1,3-bis(5-isopropyl-2-methylphenoxy)propan-2-ol (37) ---------------- 160

A.15.1: ${ }^{1} \mathrm{H}$ NMR of 4-(4-(2,3-dihydroxypropoxy)phenyl)butan-2-one (39) ------------------ 161

A.15.2: ${ }^{13}$ C NMR of 4-(4-(2,3-dihydroxypropoxy)phenyl)butan-2-one (39) ---------------- 162

A.15.3: MS-DART analysis of 4-(4-(2,3-dihydroxypropoxy)phenyl)butan-2-one (39) -------- 163

A.16.1: ${ }^{1} \mathrm{H}$ NMR of 4,4'-(((2-hydroxypropane-1,3-diyl)bis(oxy))bis(4,1-phenylene))bis

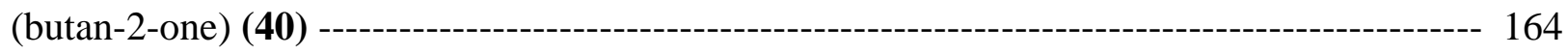

A.16.2: ${ }^{13} \mathrm{C}$ NMR of 4,4'-(((2-hydroxypropane-1,3-diyl)bis(oxy))bis(4,1-phenylene))bis (butan-2-one) (40) --- 165

A.17.1: ${ }^{13} \mathrm{C}$ NMR of 3-(4-methoxyphenoxy)propane-1,2-diol (42) ----- 166

A. 18.1: ${ }^{1} \mathrm{H}$ NMR of 1,3-bis(4-methoxyphenoxy)propan-2-ol (43) ---------------------- 167

A. 18.2: ${ }^{13} \mathrm{C}$ NMR of 1,3-bis(4-methoxyphenoxy)propan-2-ol (43) -------- 168

A. 19.1: ${ }^{1} \mathrm{H}$ NMR of 3-(p-tolyloxy)propane-1,2-diol (45) ----- 169

A. 19.2: ${ }^{13} \mathrm{C}$ NMR of 3-(p-tolyloxy)propane-1,2-diol (45) ------------- 170

A. 19.3: MS-DART of 3-(p-tolyloxy)propane-1,2-diol (45) --------------------------- 171 
A.20.1: ${ }^{1} \mathrm{H}$ NMR of 1,3-bis(p-tolyloxy)propan-2-ol (46) --- 172

A.21.1: ${ }^{1} \mathrm{H}$ NMR of 3-(4-(2-(2-methoxyphenoxy)ethyl)phenoxy)propane-1,2-diol (47) ------ 173

A.21.2: ${ }^{13}$ C NMR of 3-(4-(2-(2-methoxyphenoxy)ethyl)phenoxy)propane-1,2-diol (47) ------ 174

A.21.3: MS-DART analysis of 3-(4-(2-(2-methoxyphenoxy)ethyl)phenoxy)

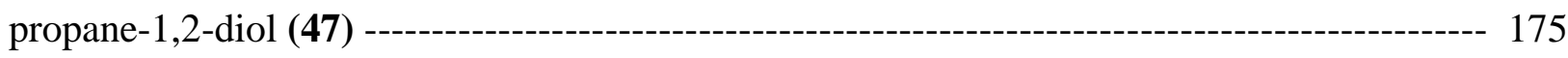

A.22.1: ${ }^{1} \mathrm{H}$ NMR of a polyester based resin (51) from 3-(2-methoxyphenoxy)

propane-1,2-diol (26) and succinic acid (50)

A.22.2: ${ }^{13} \mathrm{C}$ NMR of polyester resin (51) from 3-(2-methoxyphenoxy)propane-1,2-diol (26)

and succinic acid (50) ------o 177

A.23.1: ${ }^{1} \mathrm{H}$ NMR of polyester resin (53) from 3-(2-methoxyphenoxy)propane-1,2-diol (26) and terephathalic acid (52) -------- 178

A.23.2: ${ }^{13} \mathrm{C}$ NMR of polyester resin (53) from 3-(2-methoxyphenoxy)propane-1,2-diol (26)

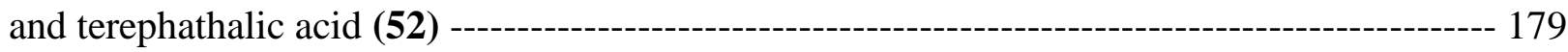

A.24.1: ${ }^{1} \mathrm{H}$ NMR of polyester resin (55) from 3-(2-methoxyphenoxy)propane-1,2-diol (26) and isoterephathalic acid (54) ----on 180

A.24.2: ${ }^{12} \mathrm{C}$ NMR of polyester resin (55) from 3-(2-methoxyphenoxy)propane-1,2-diol (26)

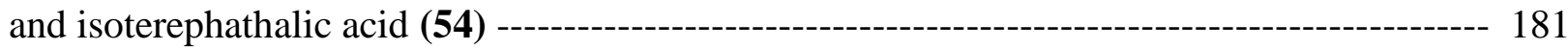

A.25.1: ${ }^{1} \mathrm{H}$ NMR of a polyester based resin (51) from 3-(2-methoxyphenoxy)

propane-1,2-diol (26) and succinic acid (50) employing (56) ------------------------- 182

A.26.1: ${ }^{1} \mathrm{H}$ NMR of polyester resin (58) from 3-(4-allylphenoxy)propane-1,2-diol (16)

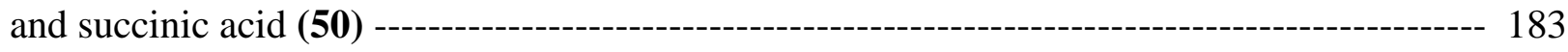

A.26.2: ${ }^{13} \mathrm{C}$ NMR of polyester resin (58) from 3-(4-allylphenoxy)propane-1,2-diol (16) and succinic acid (50) --- 184

A.27.1: ${ }^{1} \mathrm{H}$ NMR of resin (59) from 4-(2,3-dihydroxypropoxy)benzaldehyde (31) ------------ 185

A.27.2: ${ }^{13} \mathrm{C}$ NMR of resin (59) from 4-(2,3-dihydroxypropoxy)benzaldehyde (31) ---------- 186

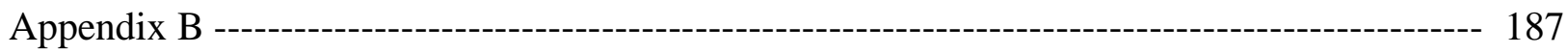

B.1: X-Ray Crystallography results for 4-(2-(2-methoxyphenoxy)ethyl)phenol (13) ---------- 187

B.2: X-Ray Crystallography results of 3-(4-allyl-2-methoxyphenoxy)

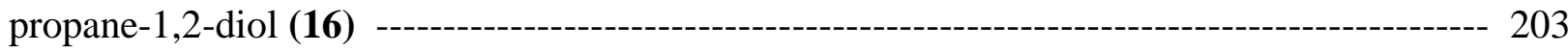




\section{Appendix A}

A.1.1 ${ }^{1}$ H NMR of 2-(4-(tert-butoxy)phenyl)ethan-1-ol (5)

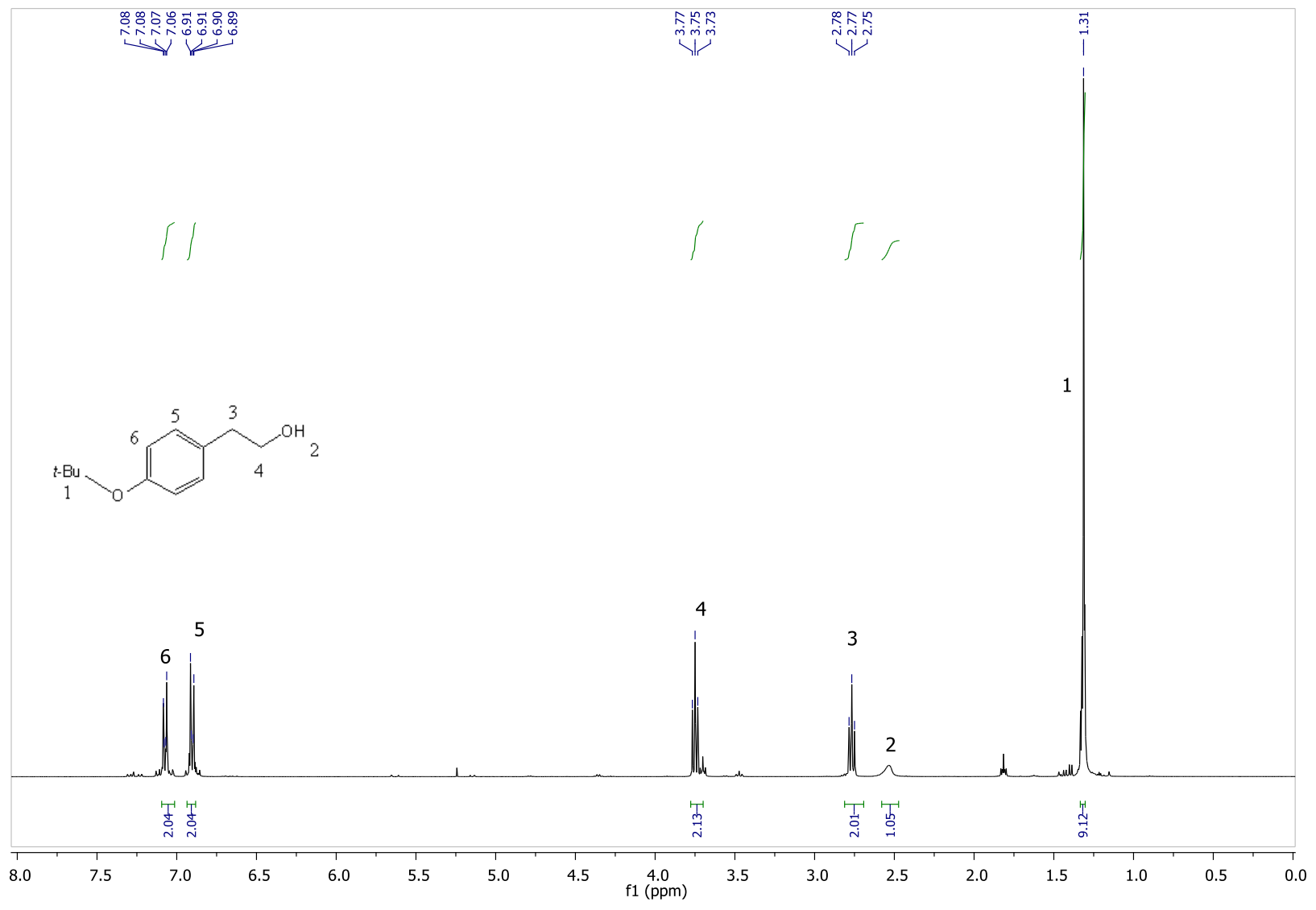


A.1.2 ${ }^{13} \mathrm{C}$ NMR of 2-(4-(tert-butoxy)phenyl)ethan-1-ol (5)

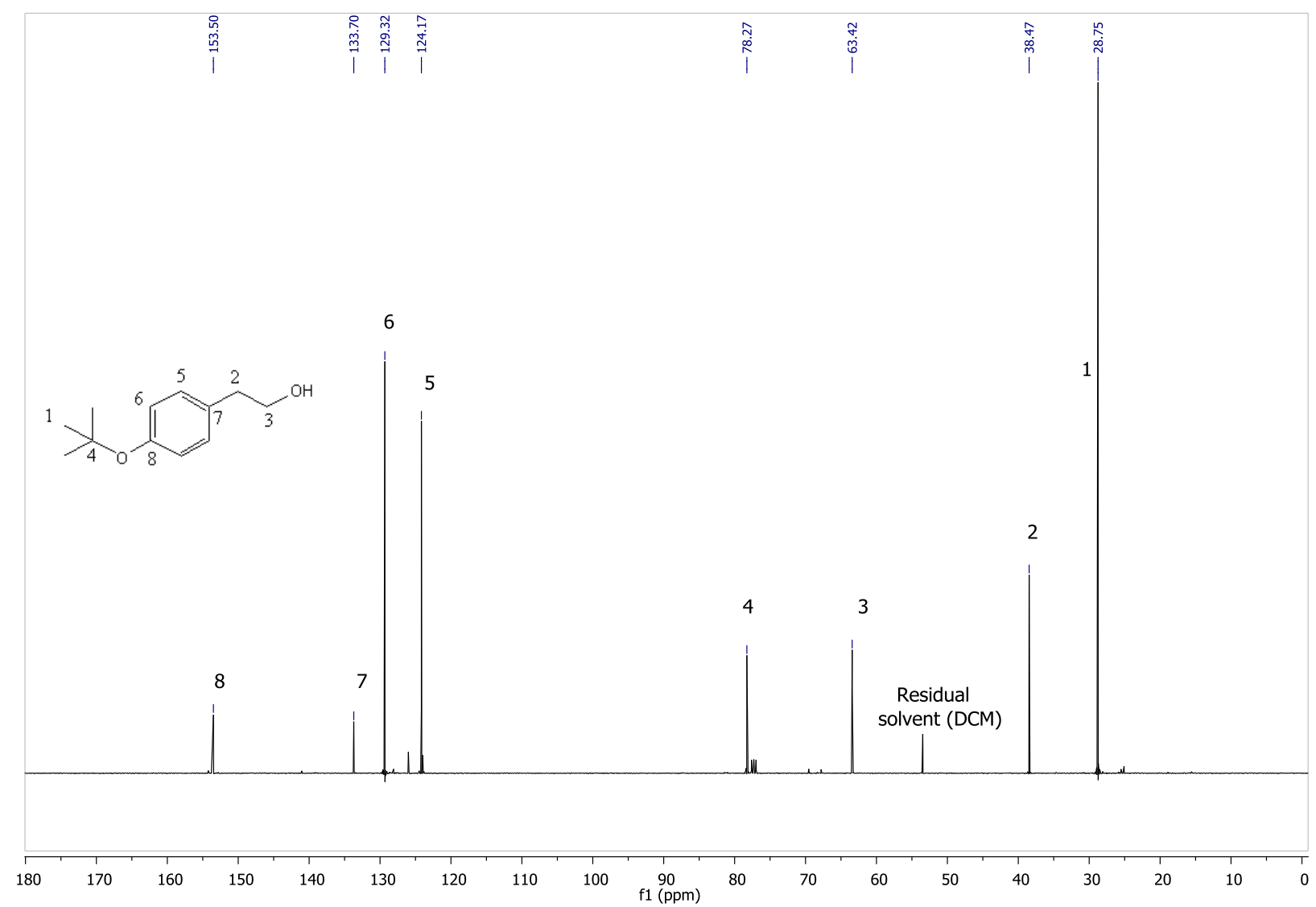


A.2.1 ${ }^{1} \mathrm{H}$ of 4-(tert-butoxy)phenethyl 4-methylbenzenesulfonate (8)

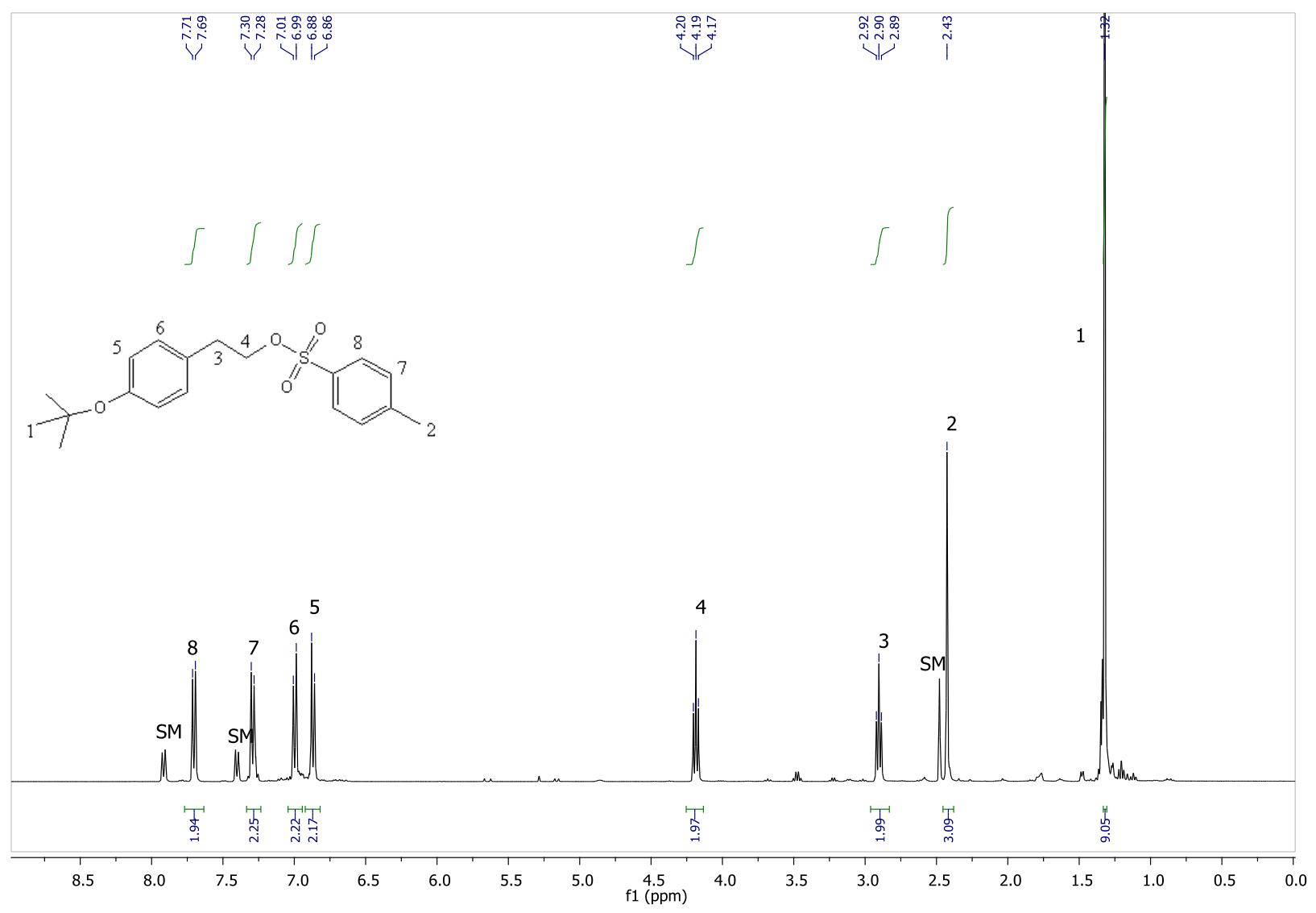


A.3.1 ${ }^{1}$ H NMR of 1-(4-(tert-butoxy)phenethoxy)-2-methoxybenzene (11)

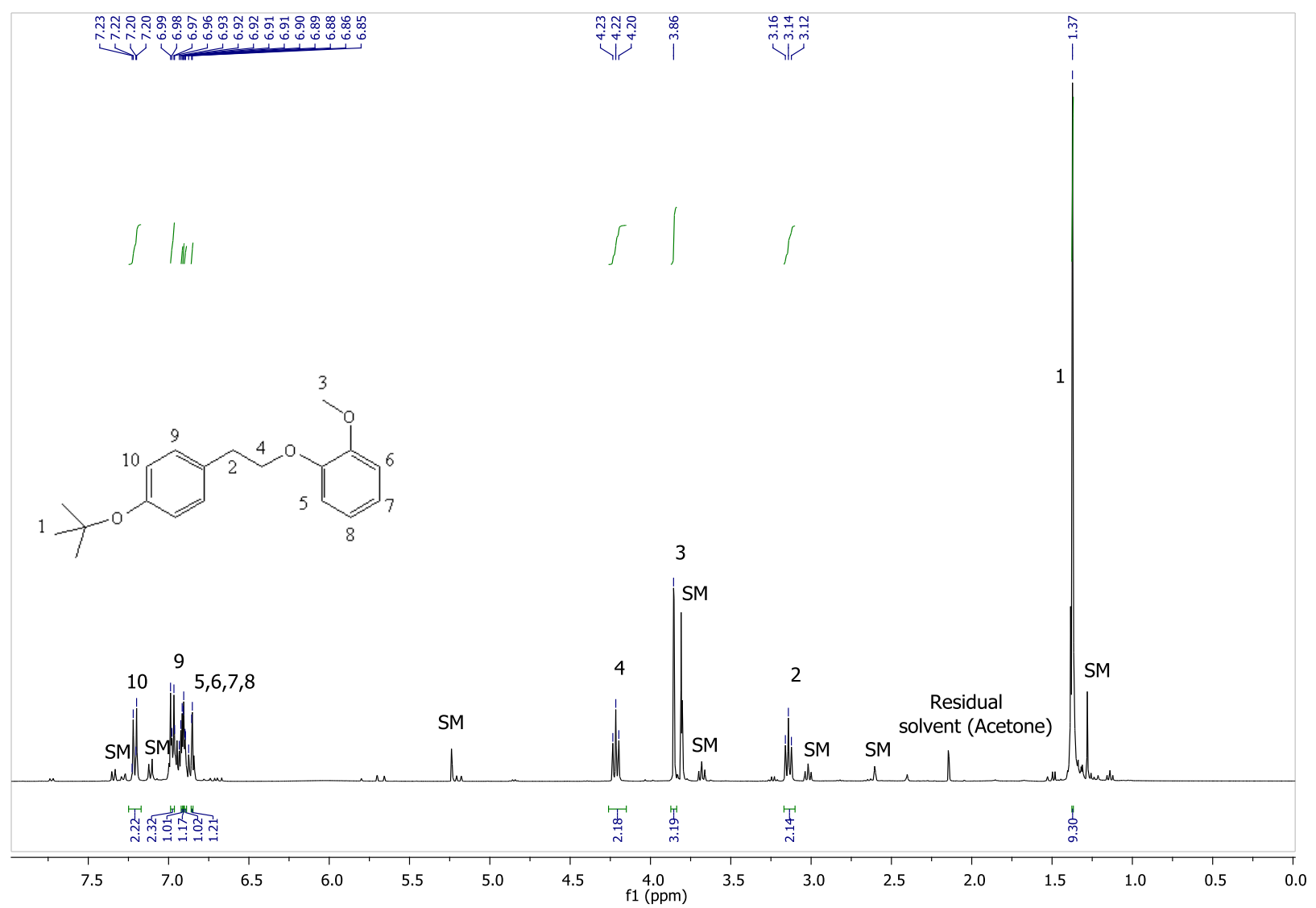


A.4.1 ${ }^{1}$ H NMR of 4-(2-(2-methoxyphenoxy)ethyl)phenol (13)

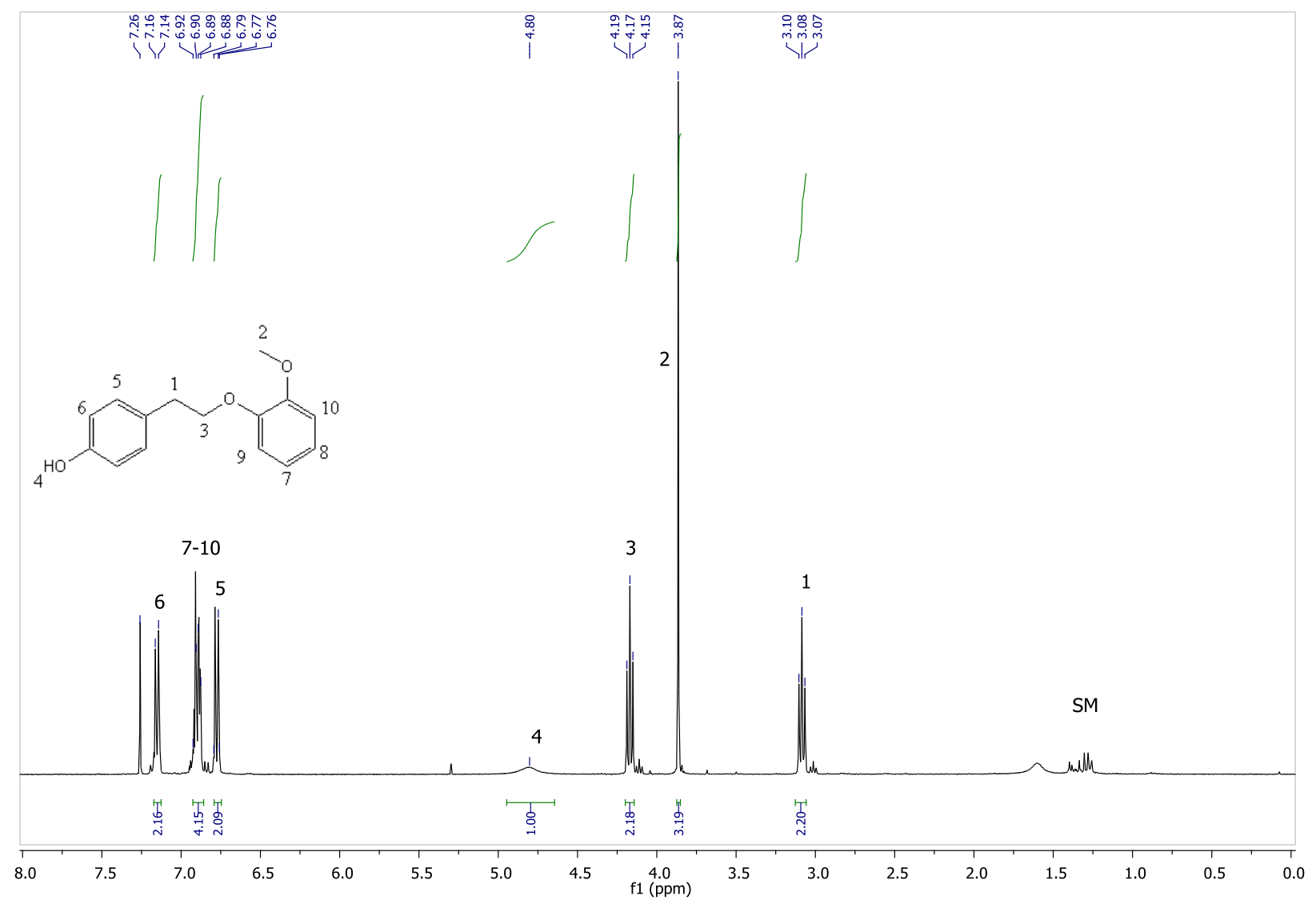


A.4. ${ }^{13}$ C NMR of 4-(2-(2-methoxyphenoxy)ethyl)phenol (13)

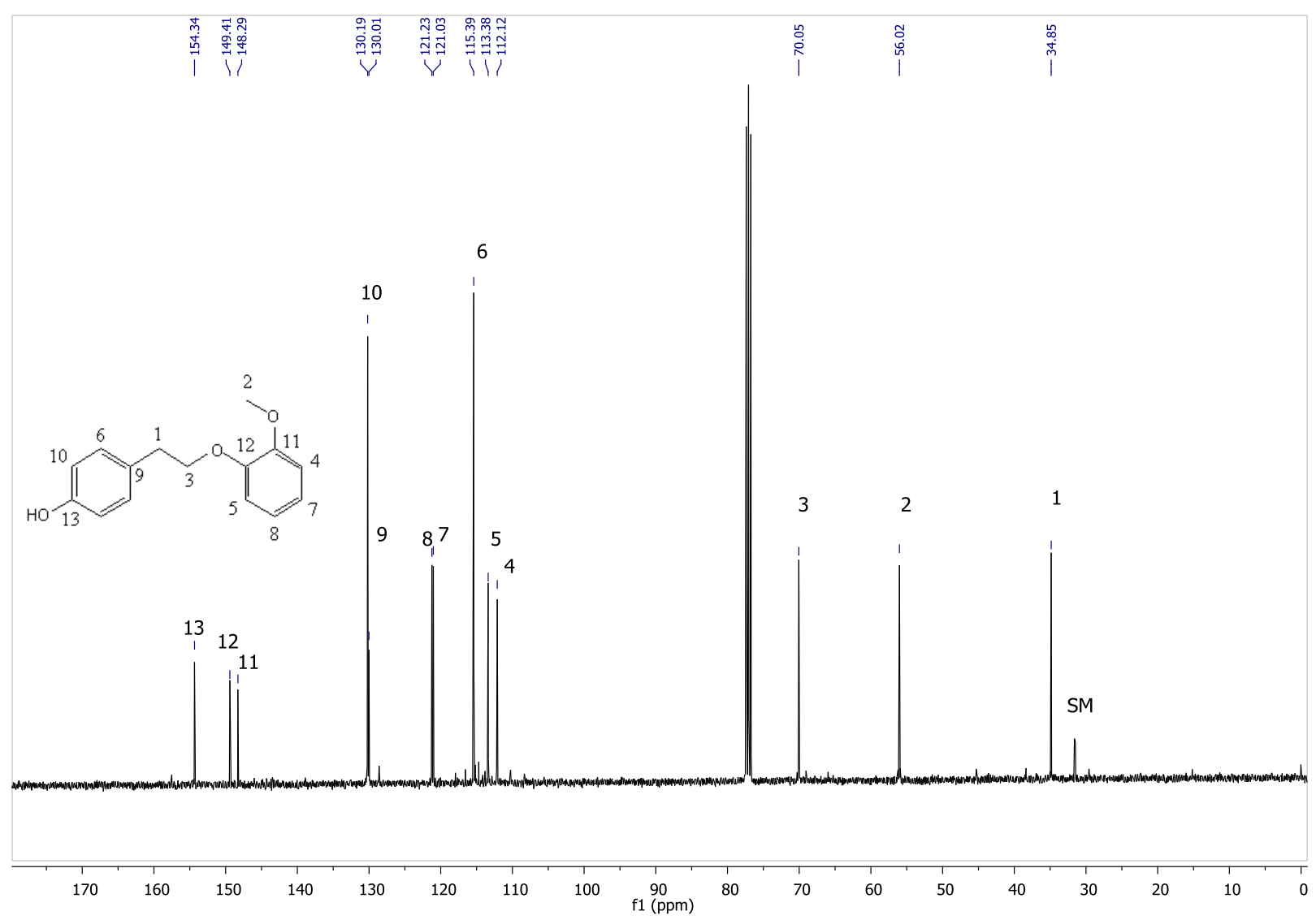


A.4.3 MS-Dart analysis of 4-(2-(2-methoxyphenoxy)ethyl)phenol (13)

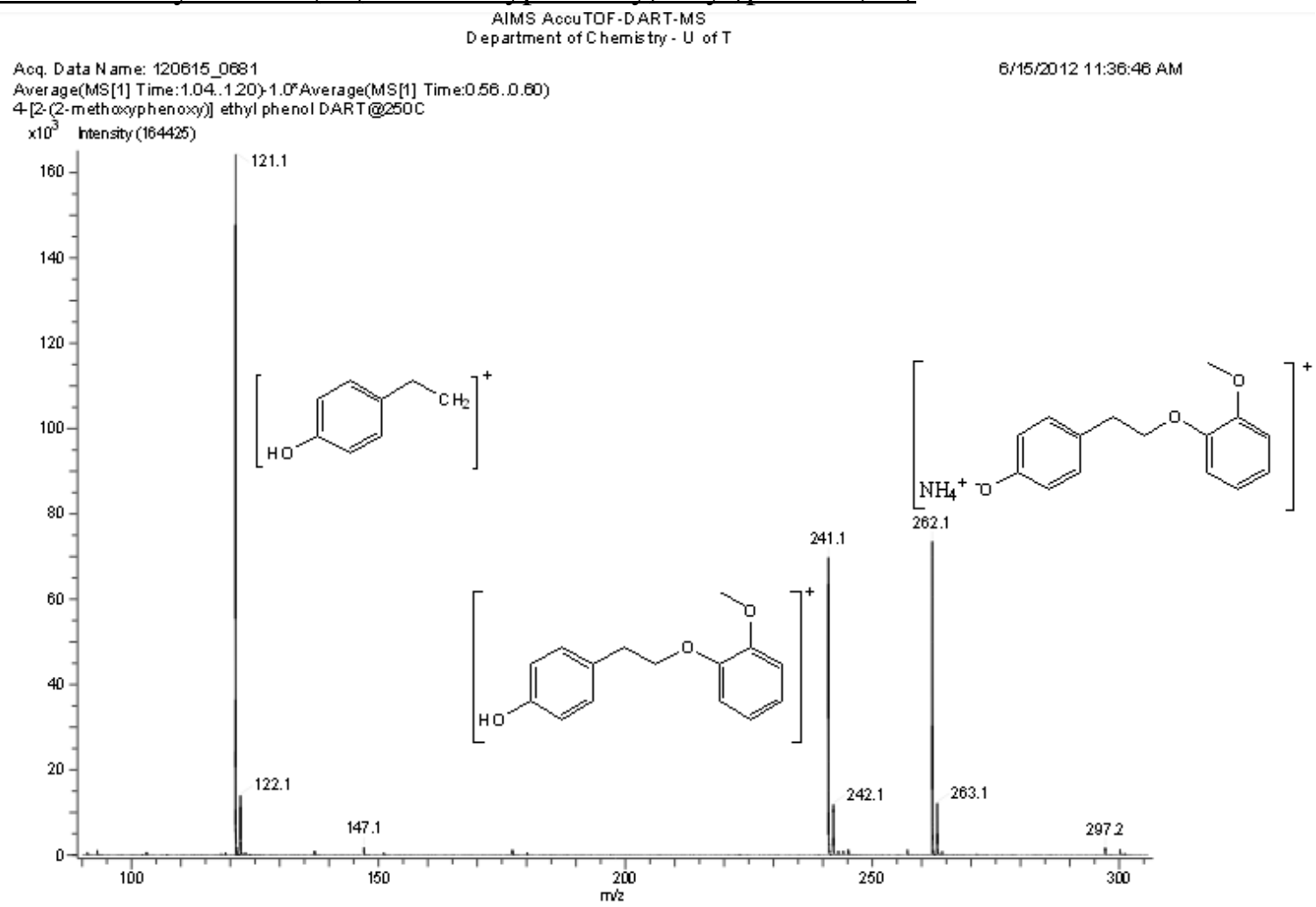


A.5.1 ${ }^{1}$ H NMR of 3-(4-allyl-2-methoxyphenoxy)propane-1,2-diol (16)

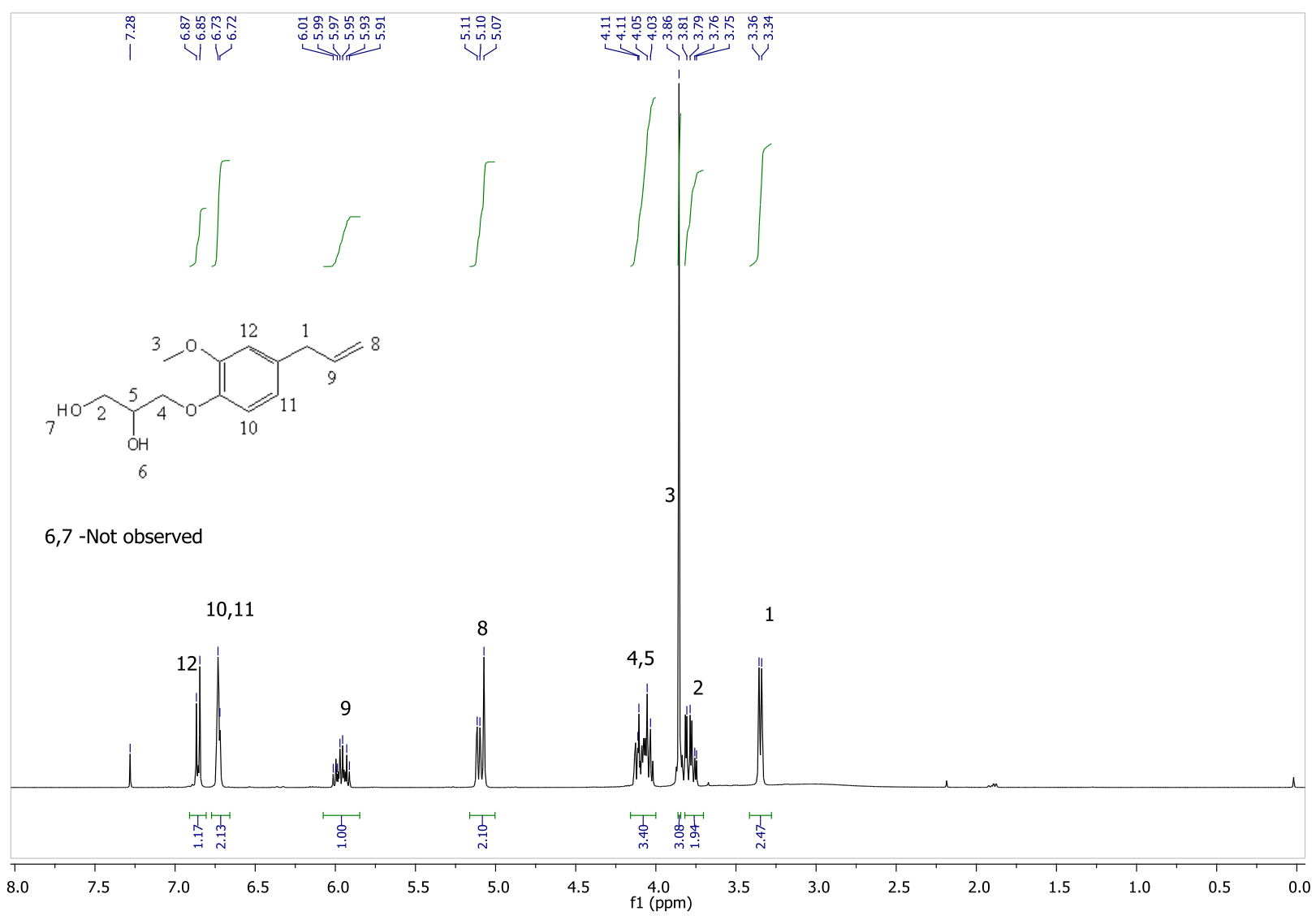


A.5.2 ${ }^{13} \mathrm{C}$ NMR of 3-(4-allyl-2-methoxyphenoxy)propane-1,2-diol (16)

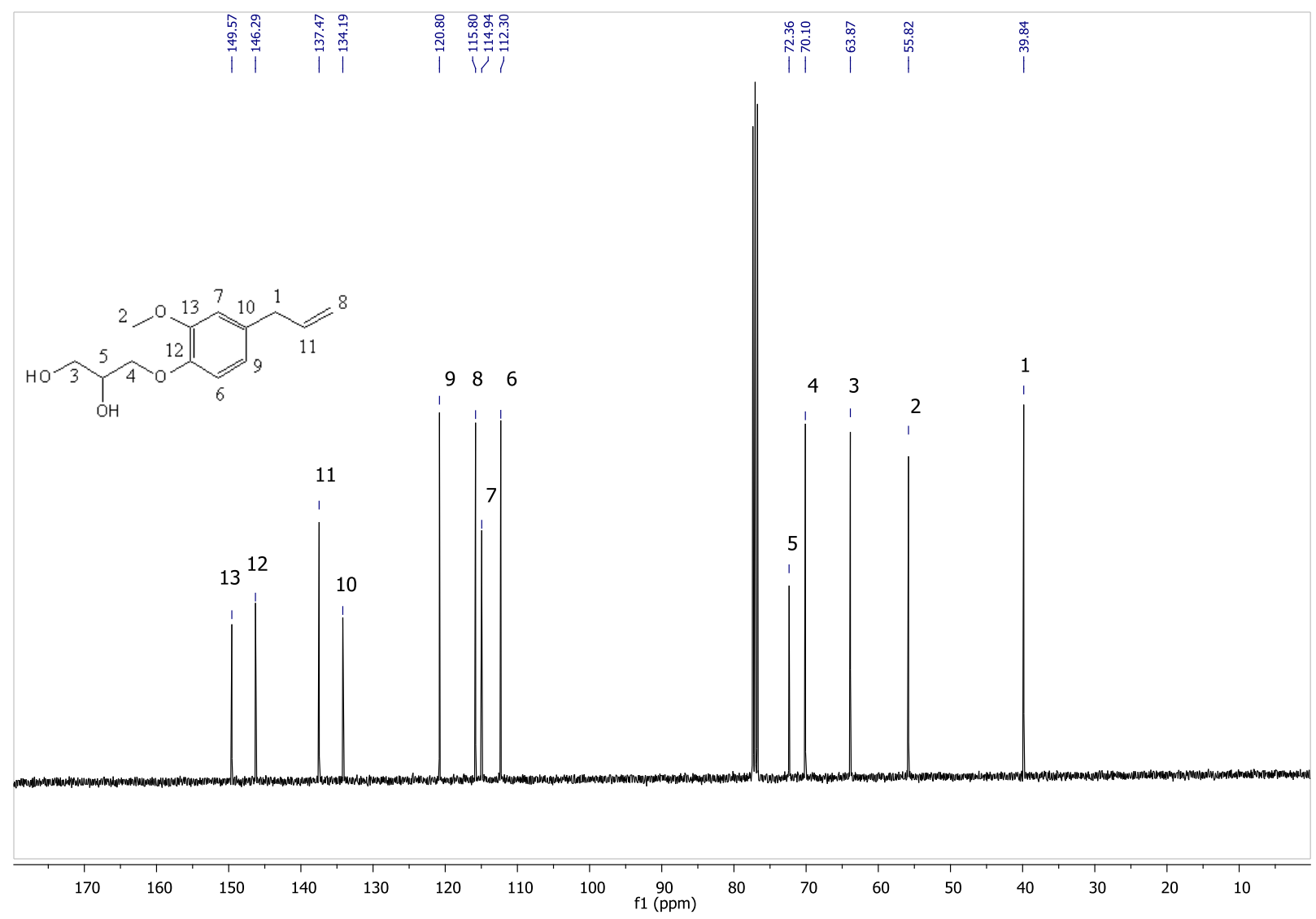


A.5.3 MS-DART analsisA.5.3 of 3-(4-allyl-2-methoxyphenoxy)propane-1,2-diol (16)

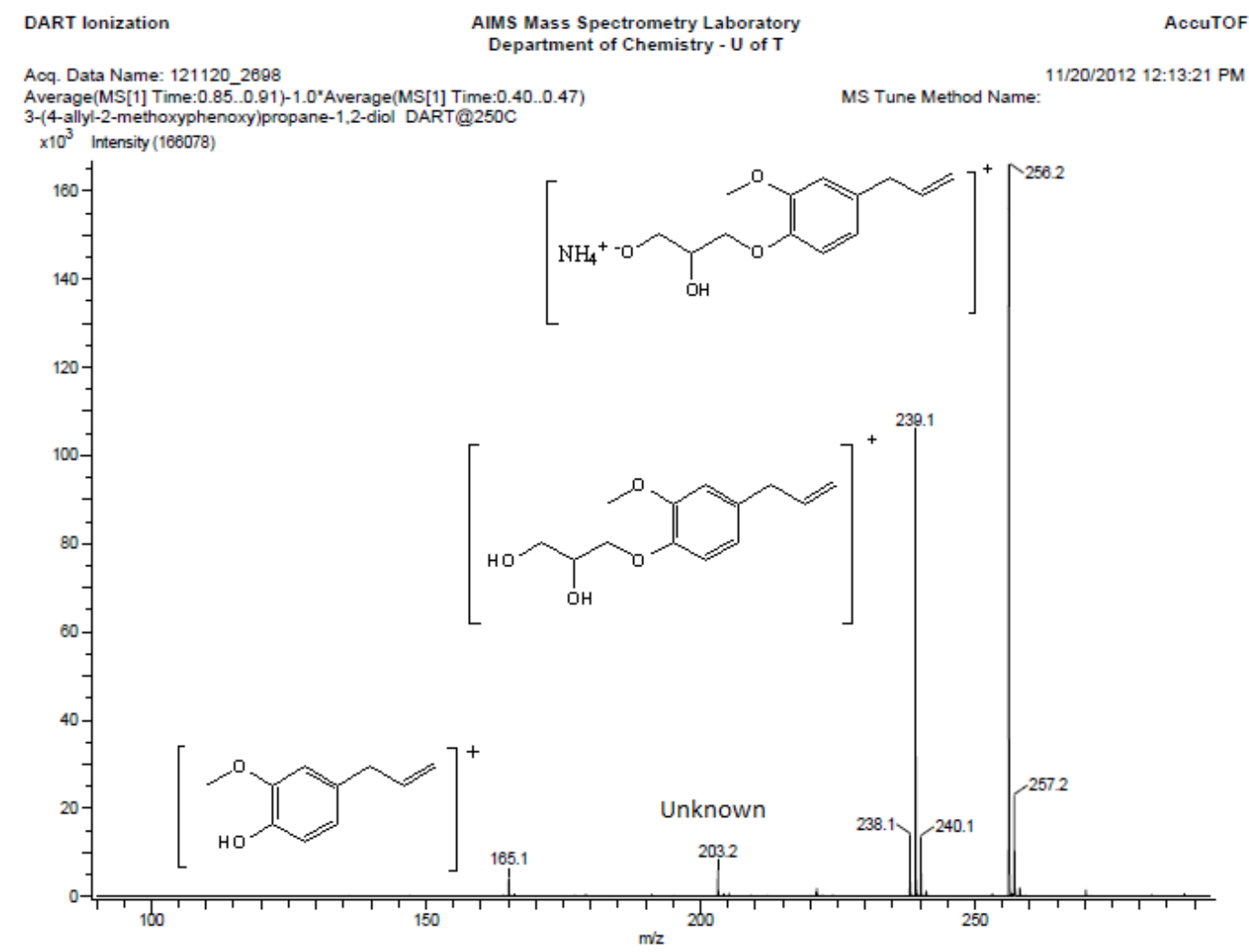

ION MODE: POSITIVE 
A.6.1 ${ }^{1} \mathrm{H}$ NMR of (4-allyl-2-methoxyphenoxy)trimethylsilane (23)

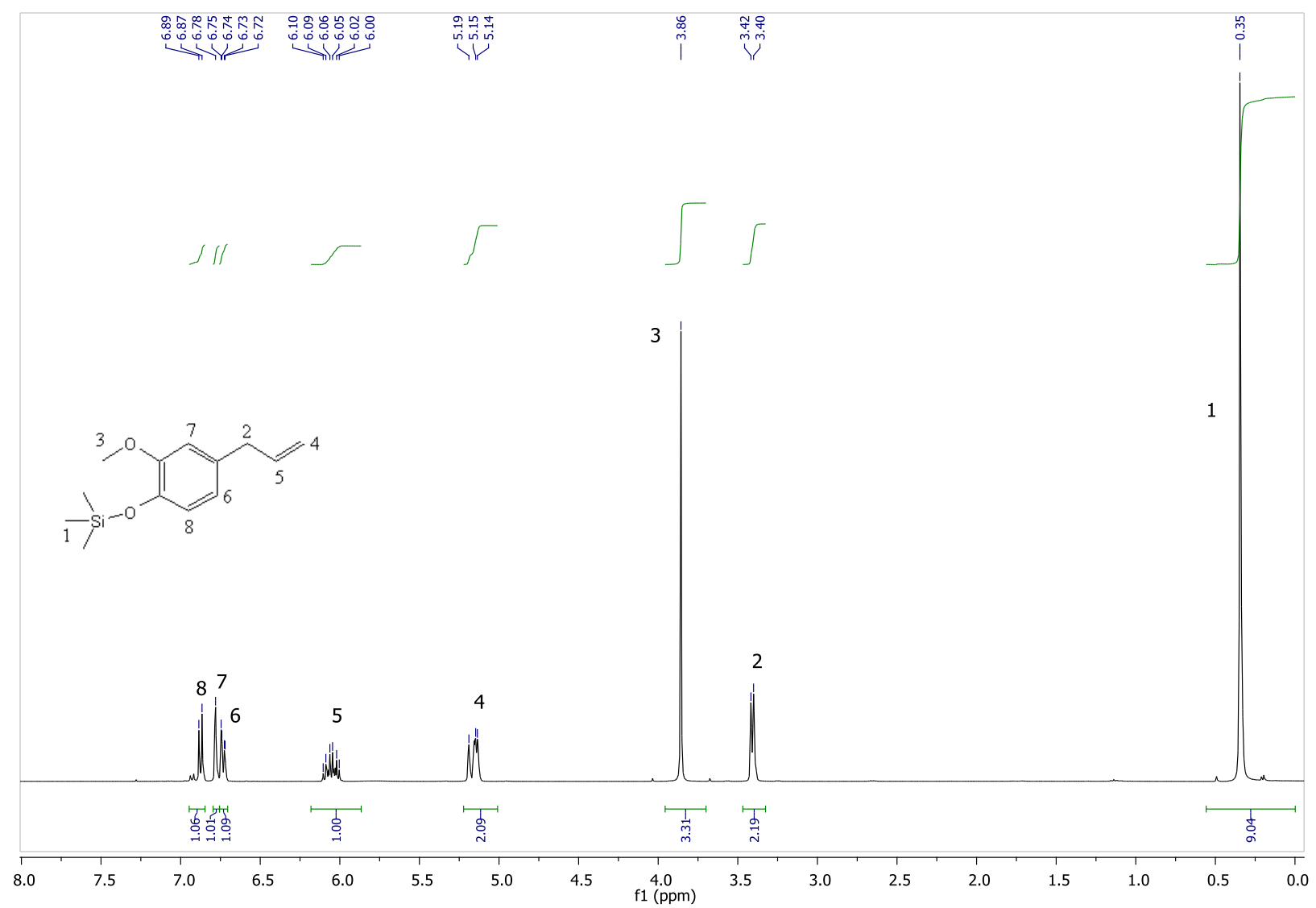


A.6.2 ${ }^{13} \mathrm{C}$ NMR of (4-allyl-2-methoxyphenoxy)trimethylsilane (23)

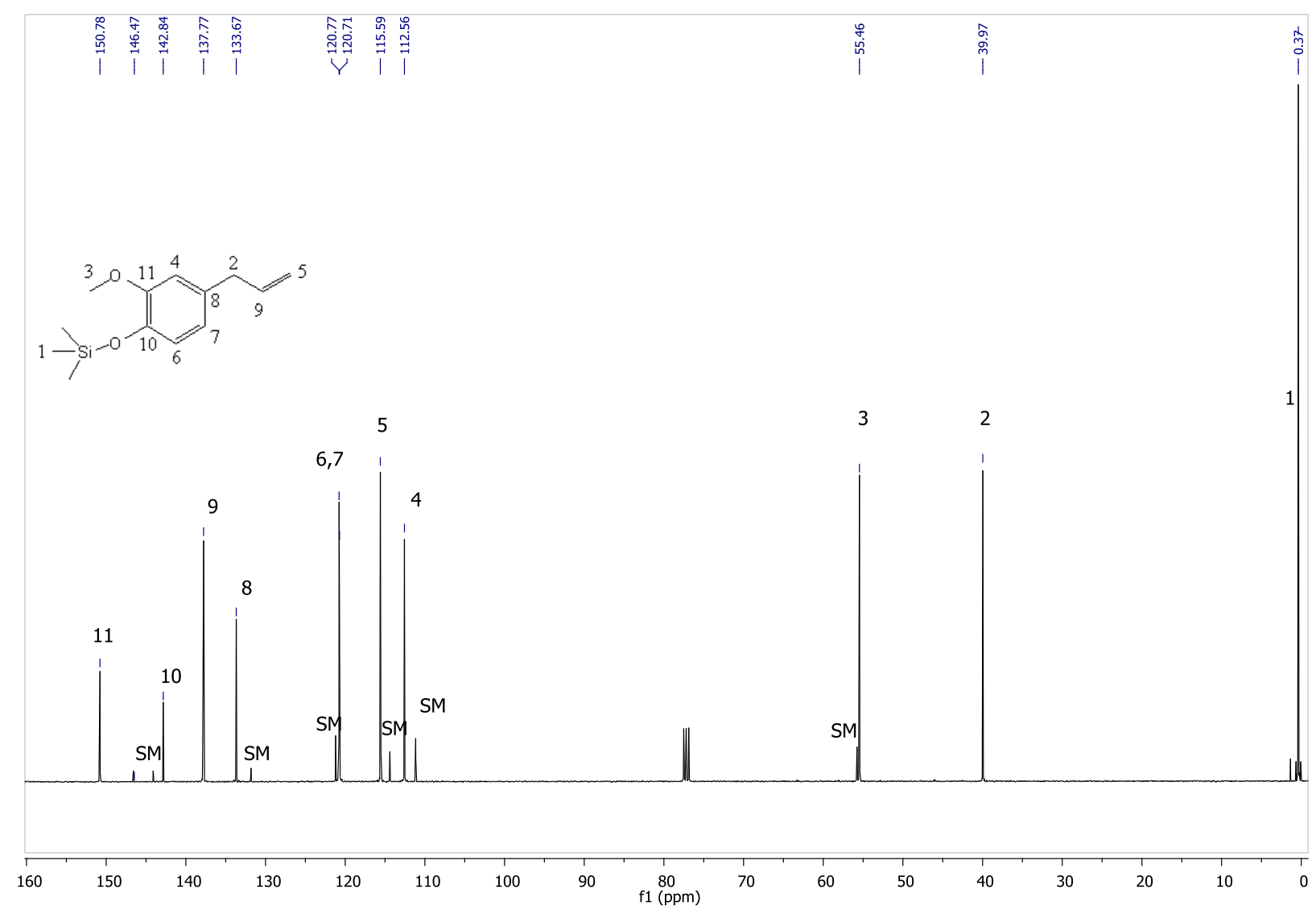


A.6.3 ${ }^{29} \mathrm{Si}$ NMR of (4-allyl-2-methoxyphenoxy)trimethylsilane (23)

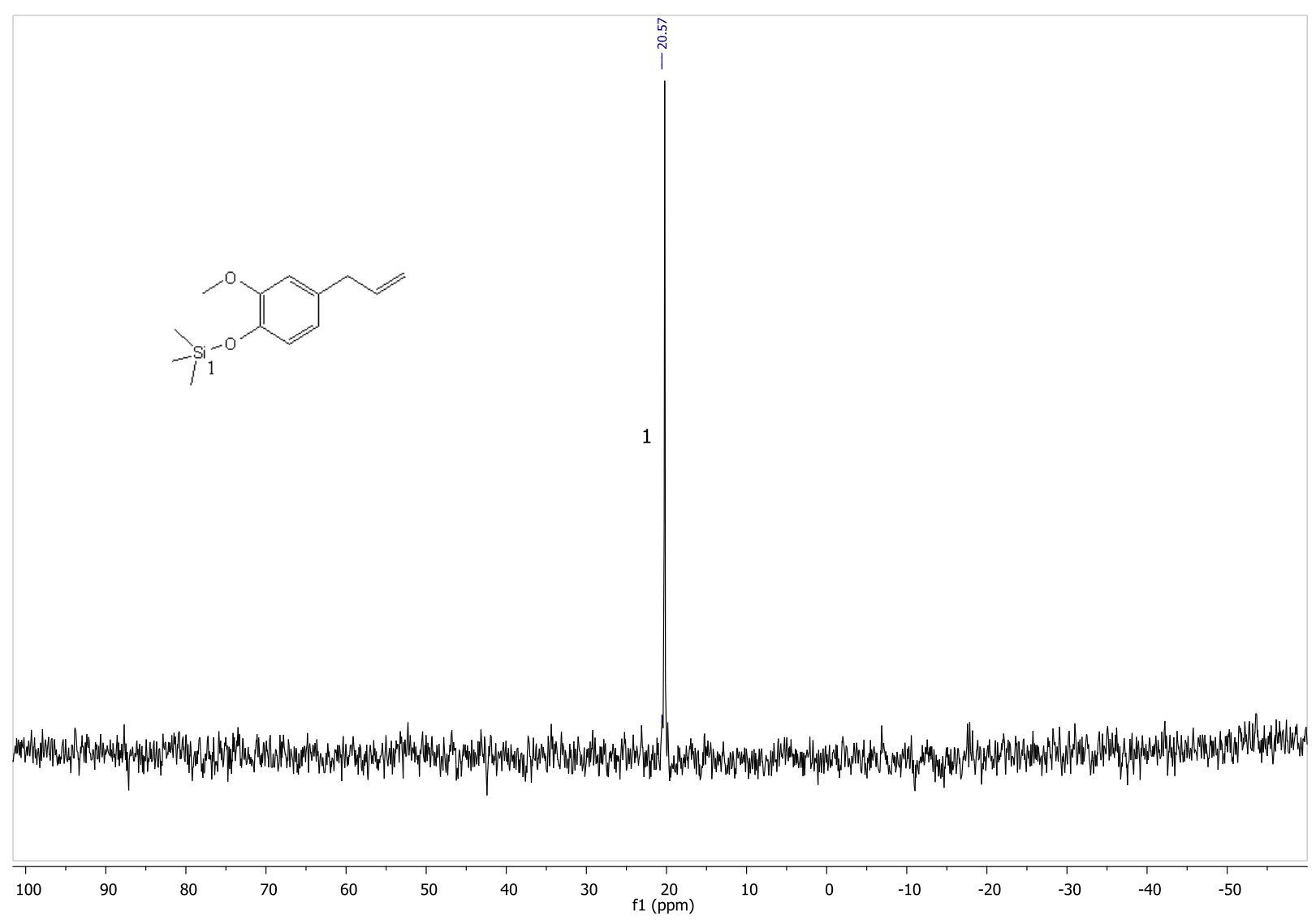


A.7.1 ${ }^{1}$ H NMR of 2-methoxy-4-(2-(2-methoxyphenoxy)propyl)phenol (25)

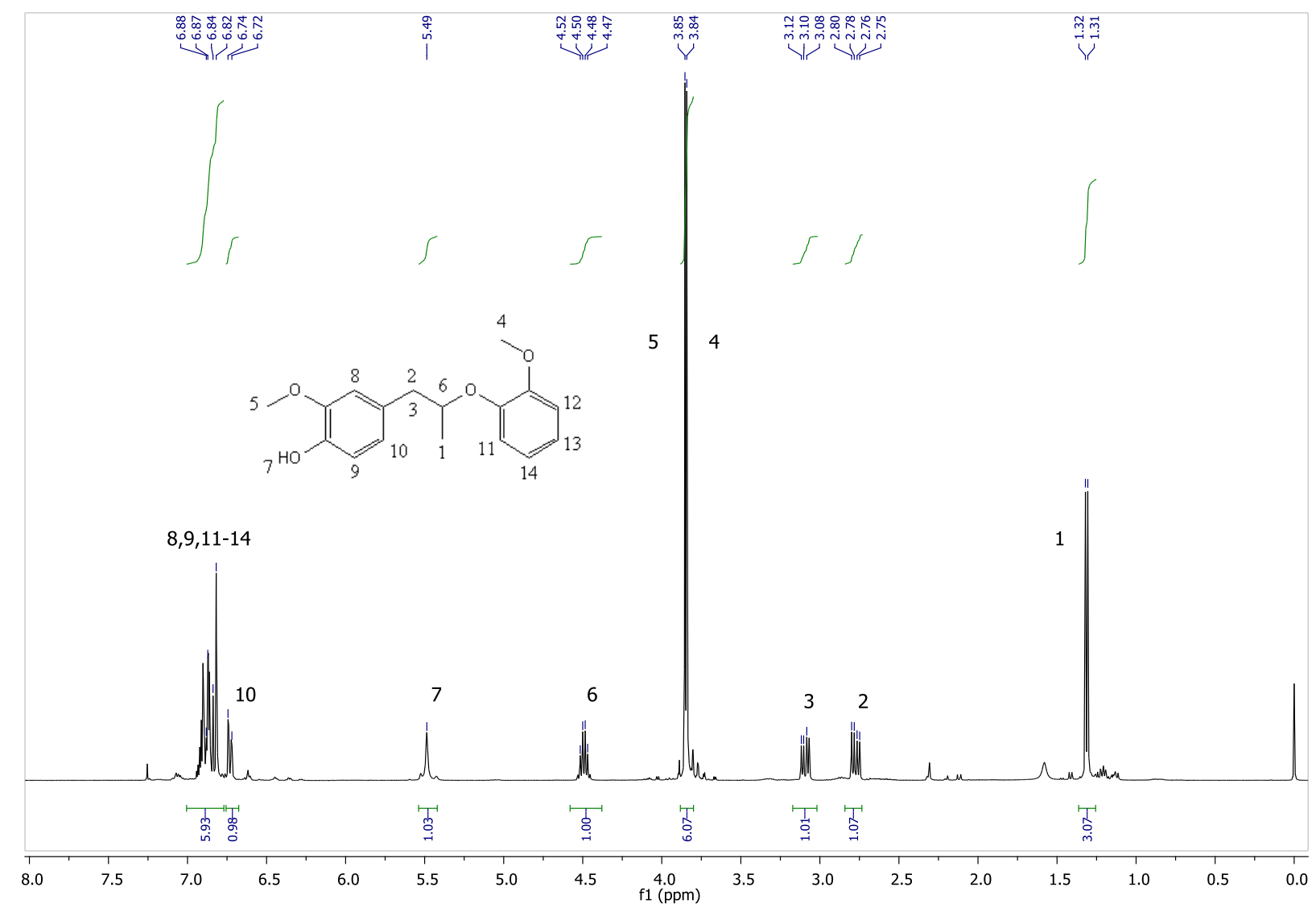


A.7.2 ${ }^{13}$ C NMR of 2-methoxy-4-(2-(2-methoxyphenoxy)propyl)phenol (25)

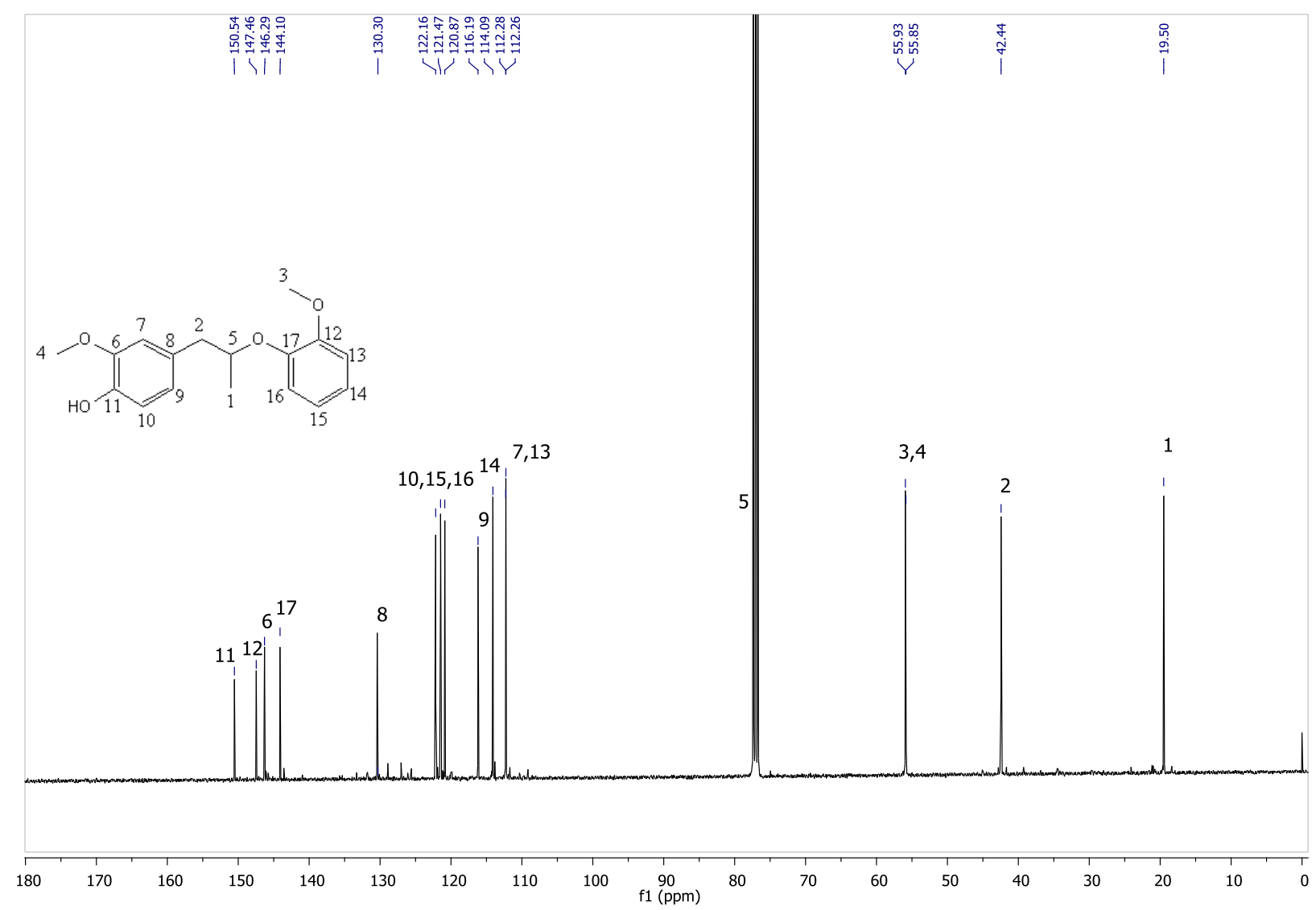


A.7.3 MS-Dart analysis of 2-methoxy-4-(2-(2-methoxyphenoxy)propyl)phenol (25)

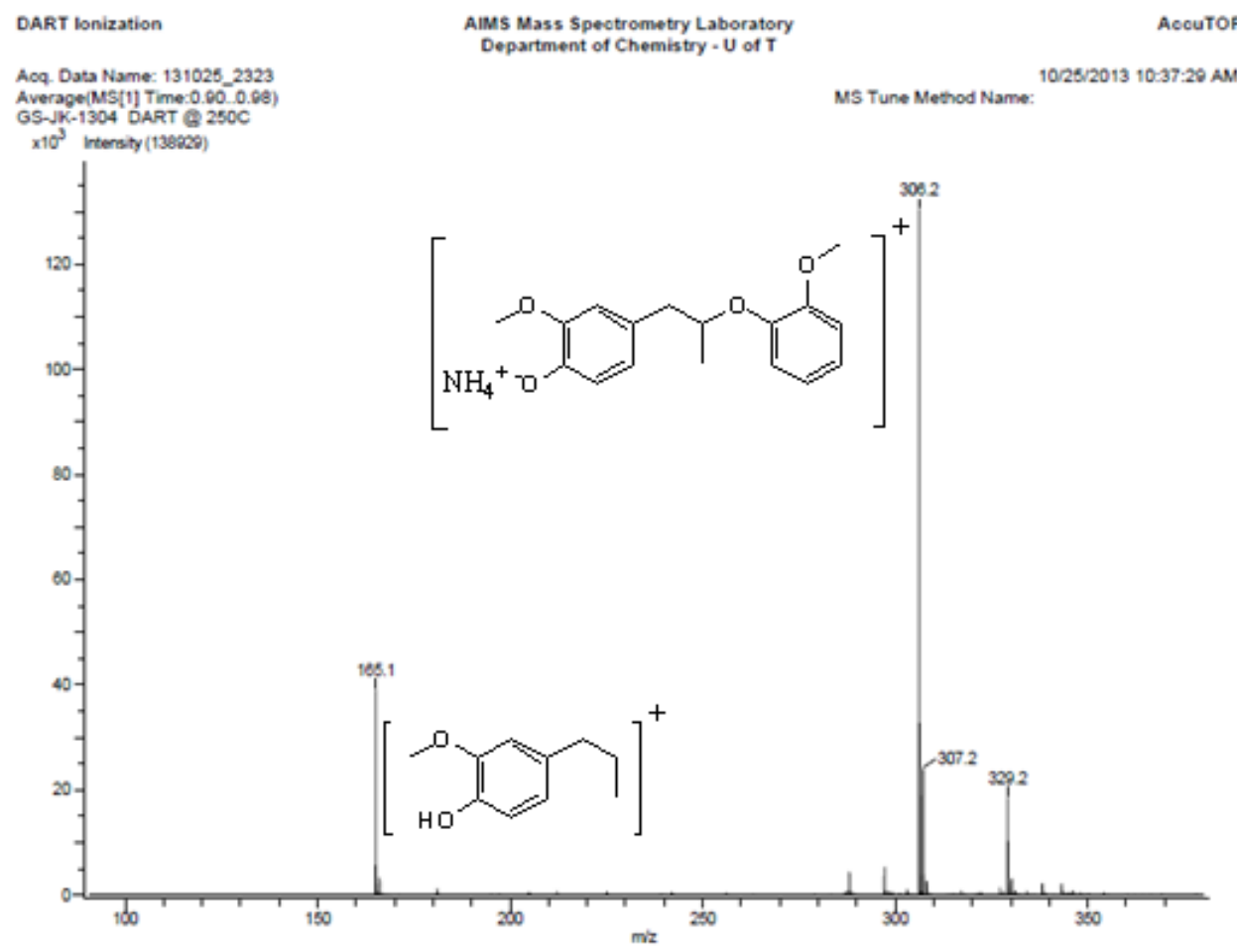

ION MODE: POSITIVE 
A.8.1 ${ }^{1}$ H NMR of 3-(2-methoxyphenoxy)propane-1,2-diol (26)

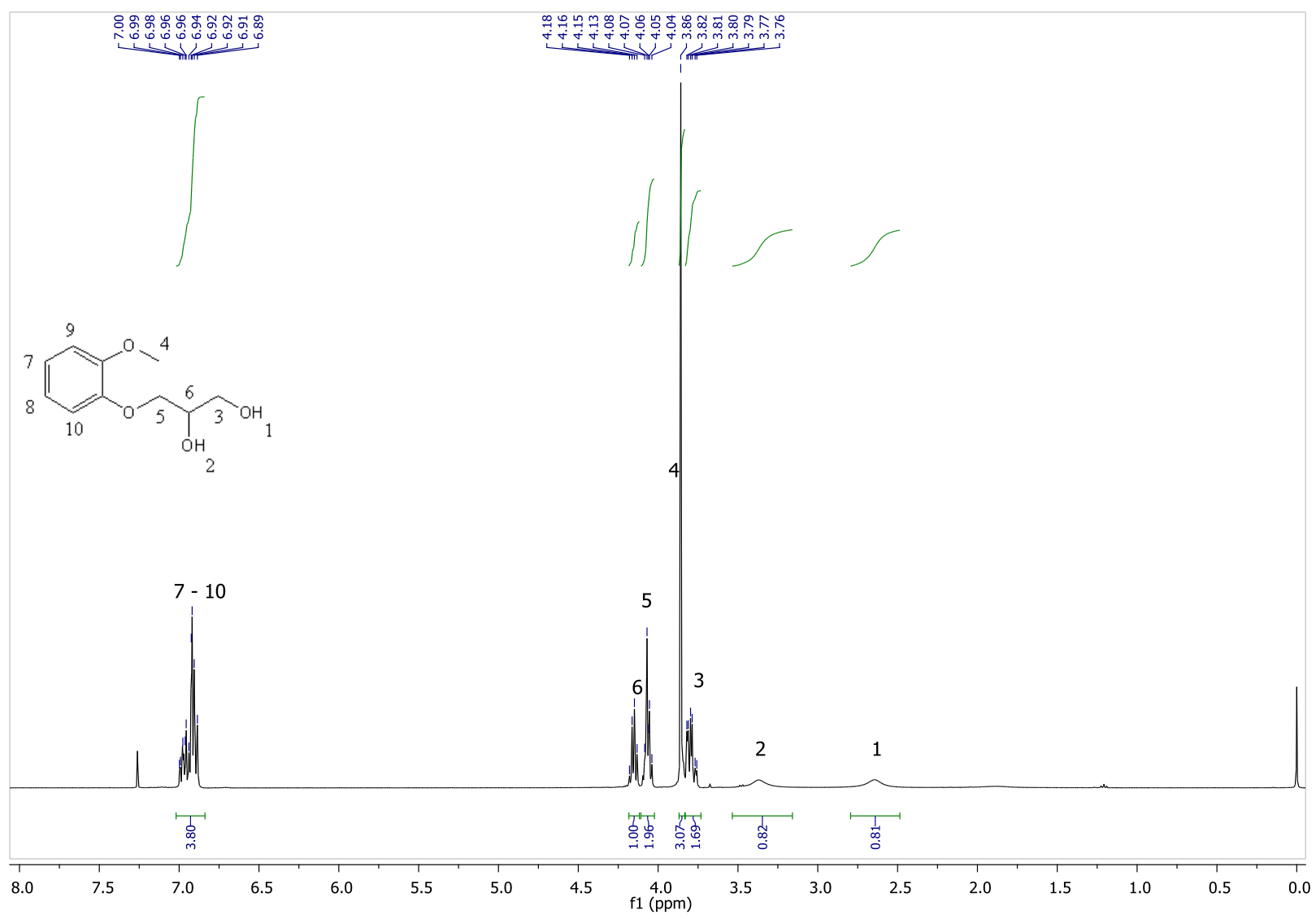


A.8.2 ${ }^{13} \mathrm{C}$ NMR of 3-(2-methoxyphenoxy)propane-1,2-diol (26)

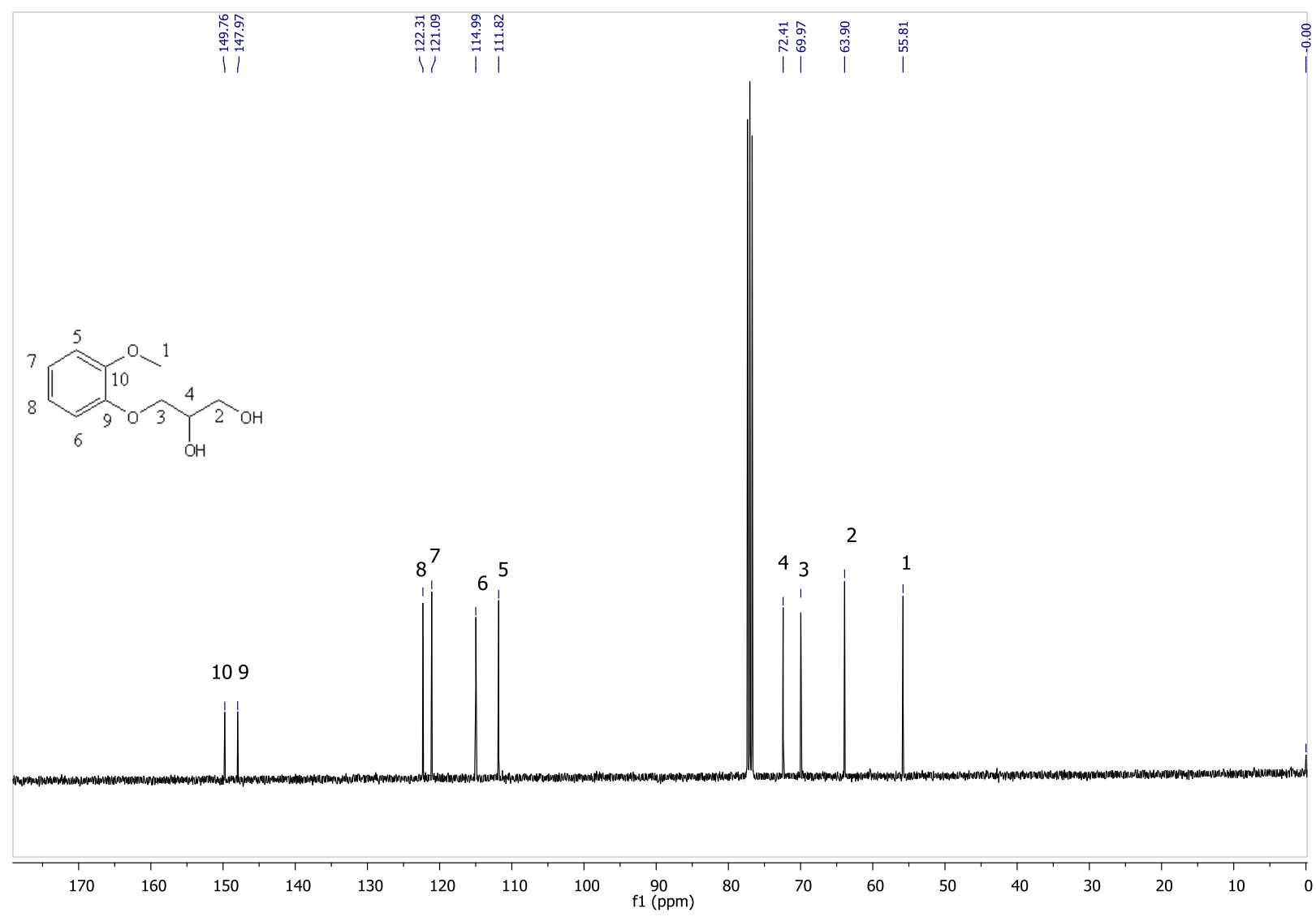


A.9.1 ${ }^{1}$ H NMR of 3-(2-methoxy-4-propylphenoxy)propane-1,2-diol (29)

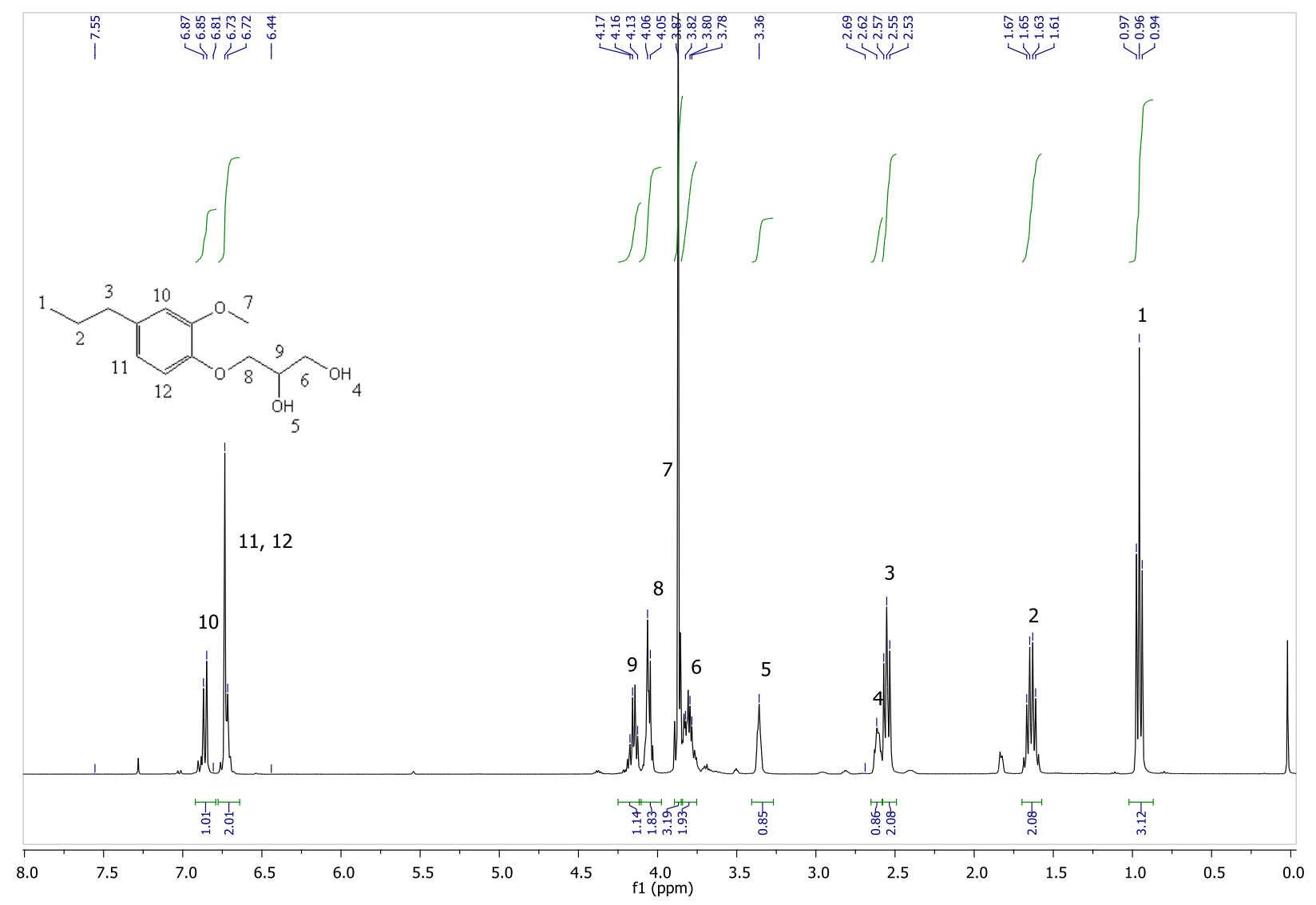


A.9.2 ${ }^{13}$ C NMR of 3-(2-methoxy-4-propylphenoxy)propane-1,2-diol (29)

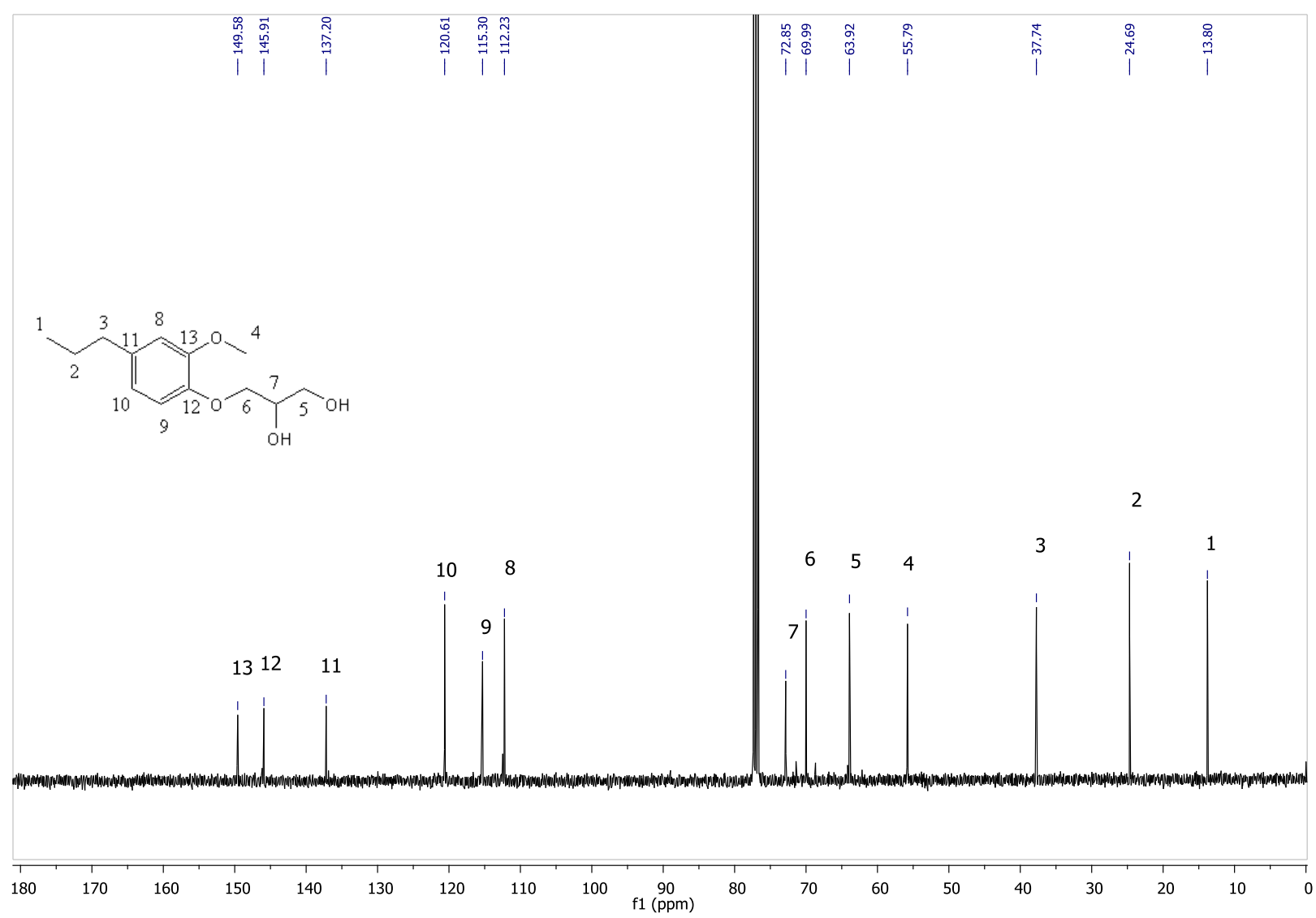


A.9.3 MS-DART analysis of 3-(2-methoxy-4-propylphenoxy)propane-1,2-diol (29)

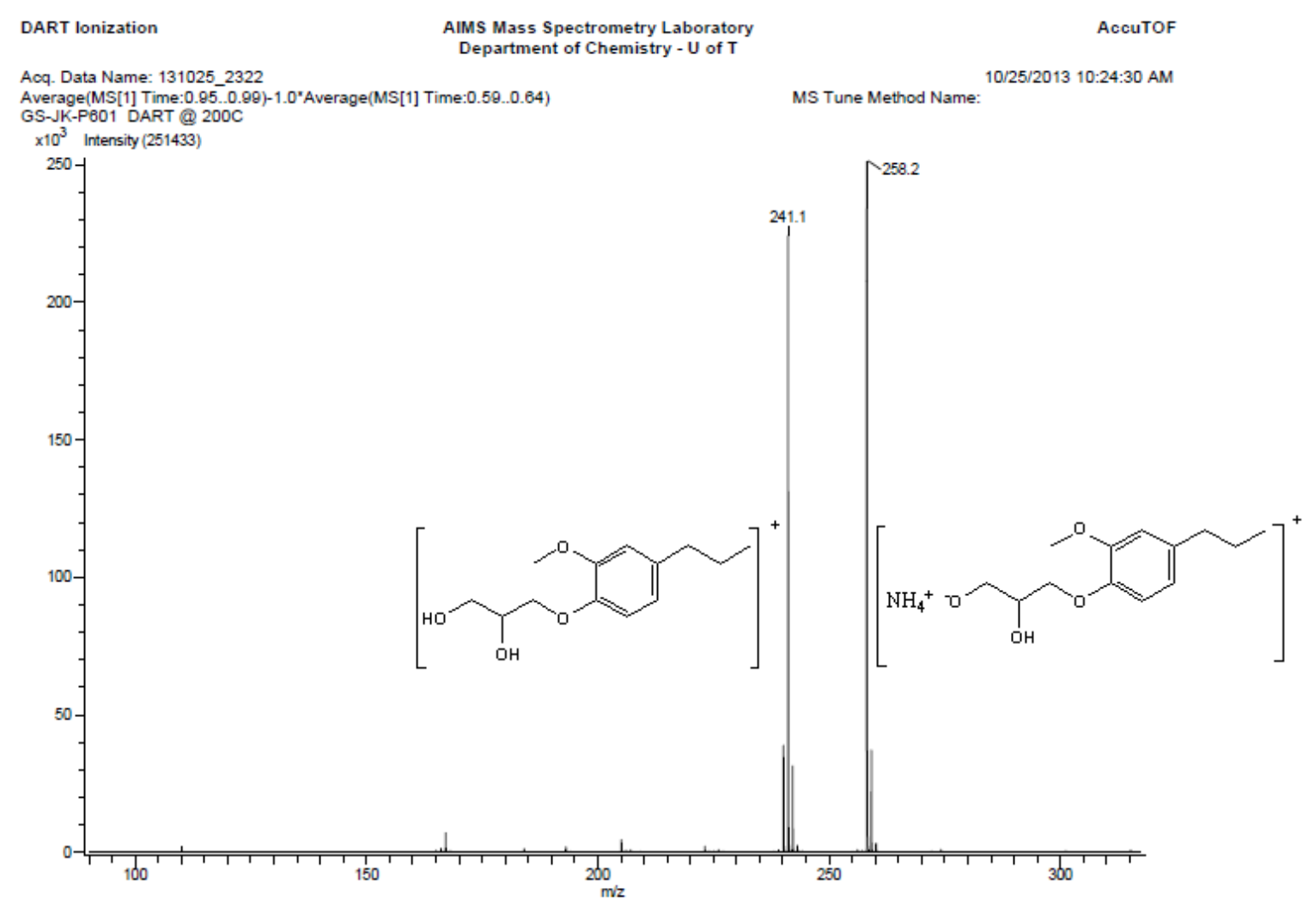

ION MODE: POSITIVE 
A.10.1 ${ }^{1} \mathrm{H}$ NMR of 4-(2,3-dihydroxypropoxy)-3-methoxybenzaldehyde (31)

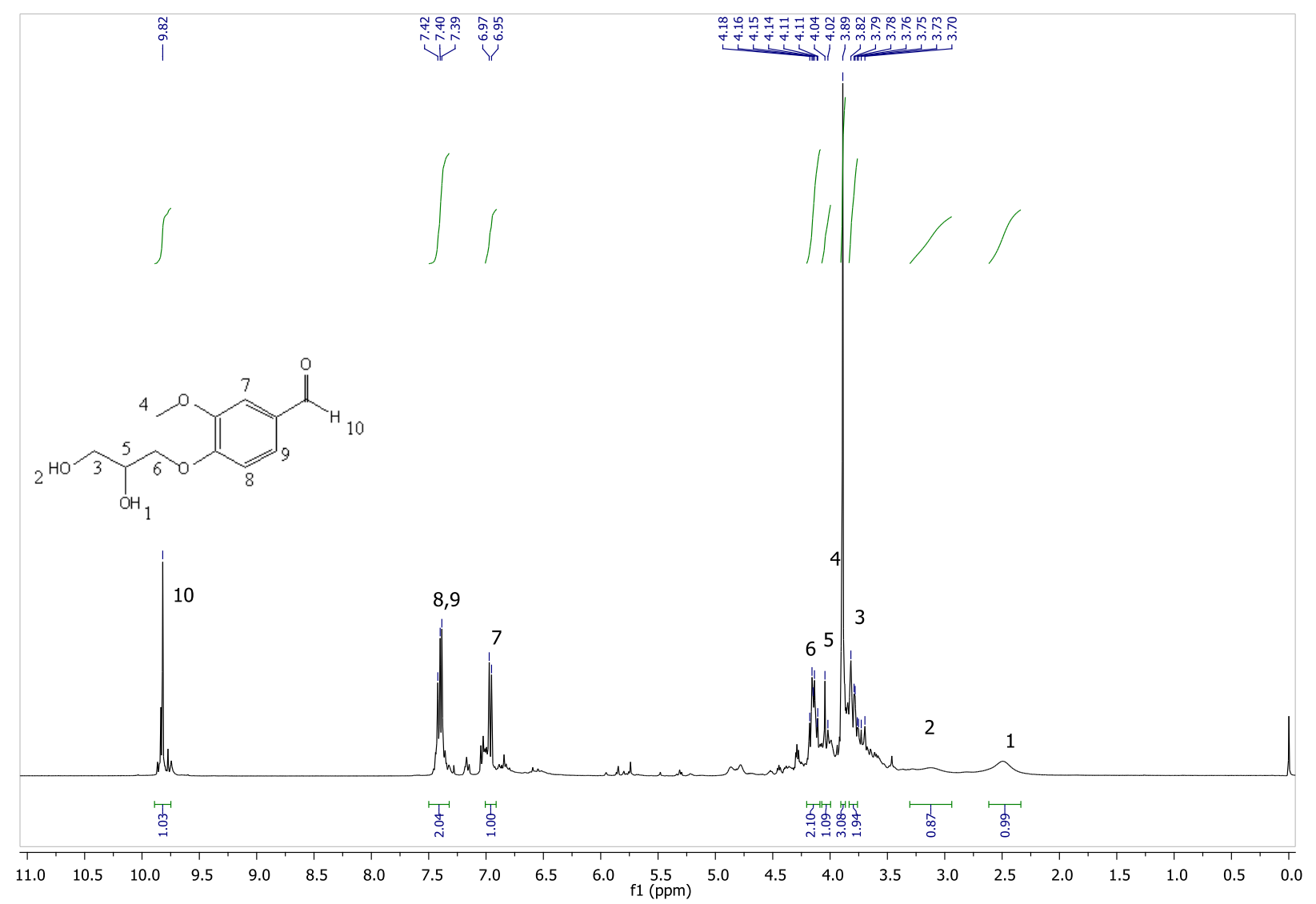


A.10.2 ${ }^{13}$ C NMR of 4-(2,3-dihydroxypropoxy)-3-methoxybenzaldehyde (31)

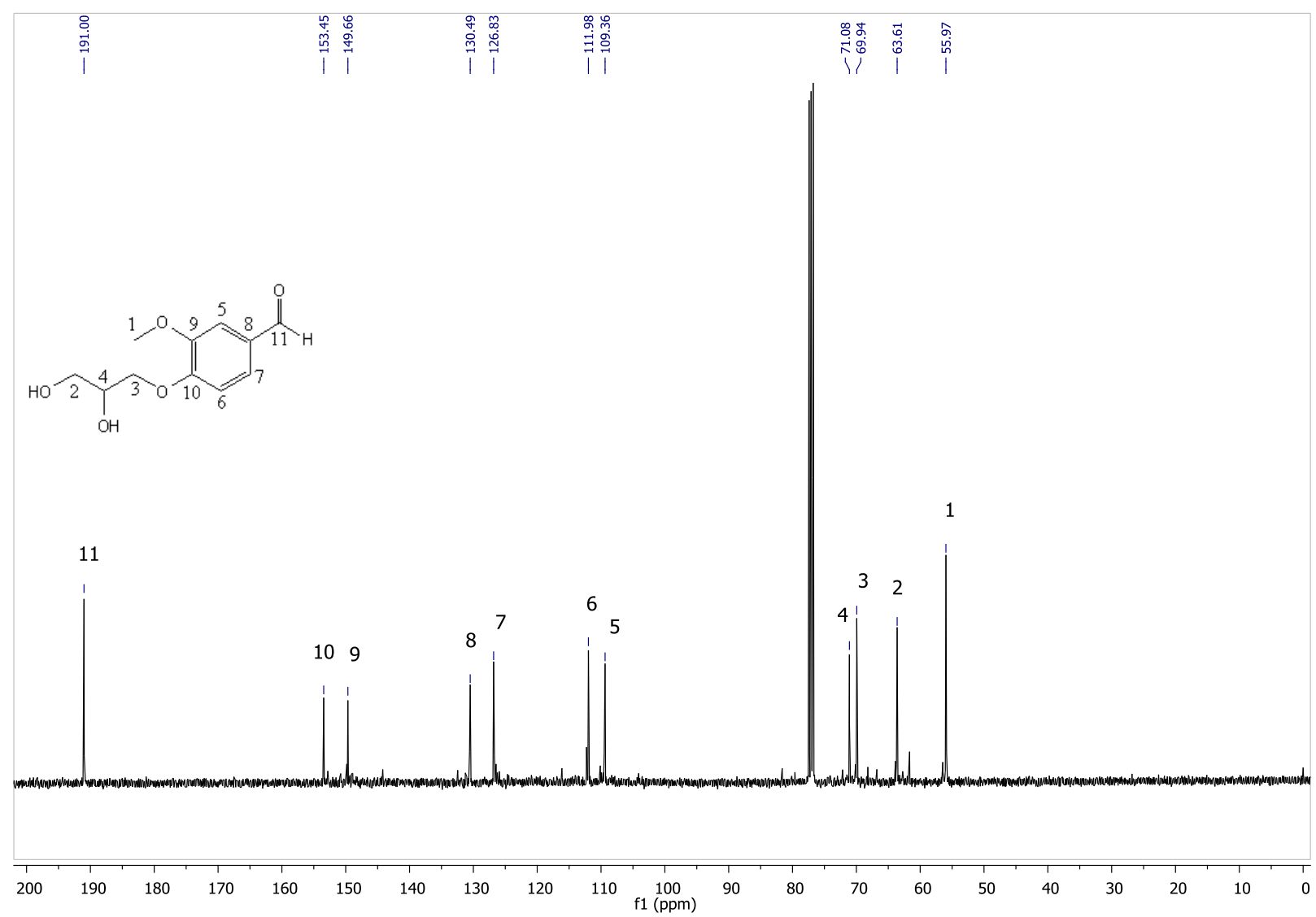


A.10.3 MS-DART analysis of 4-(2,3-dihydroxypropoxy)benzaldehyde (31)

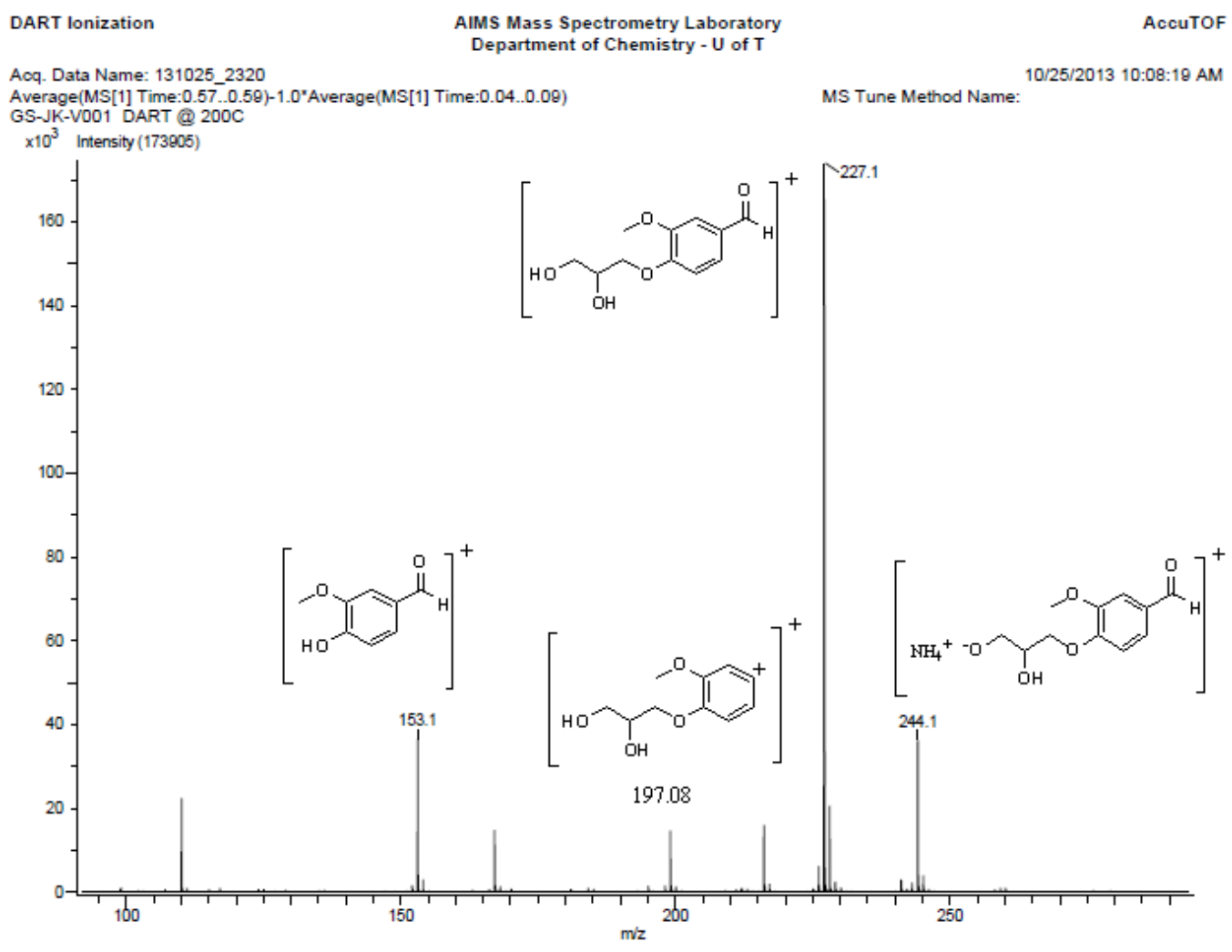

ION MODE: POSITIVE 
A.11.1. ${ }^{1} \mathrm{H}$ NMR of 3-(2-isopropyl-5-methylphenoxy)propane-1,2-diol (33)

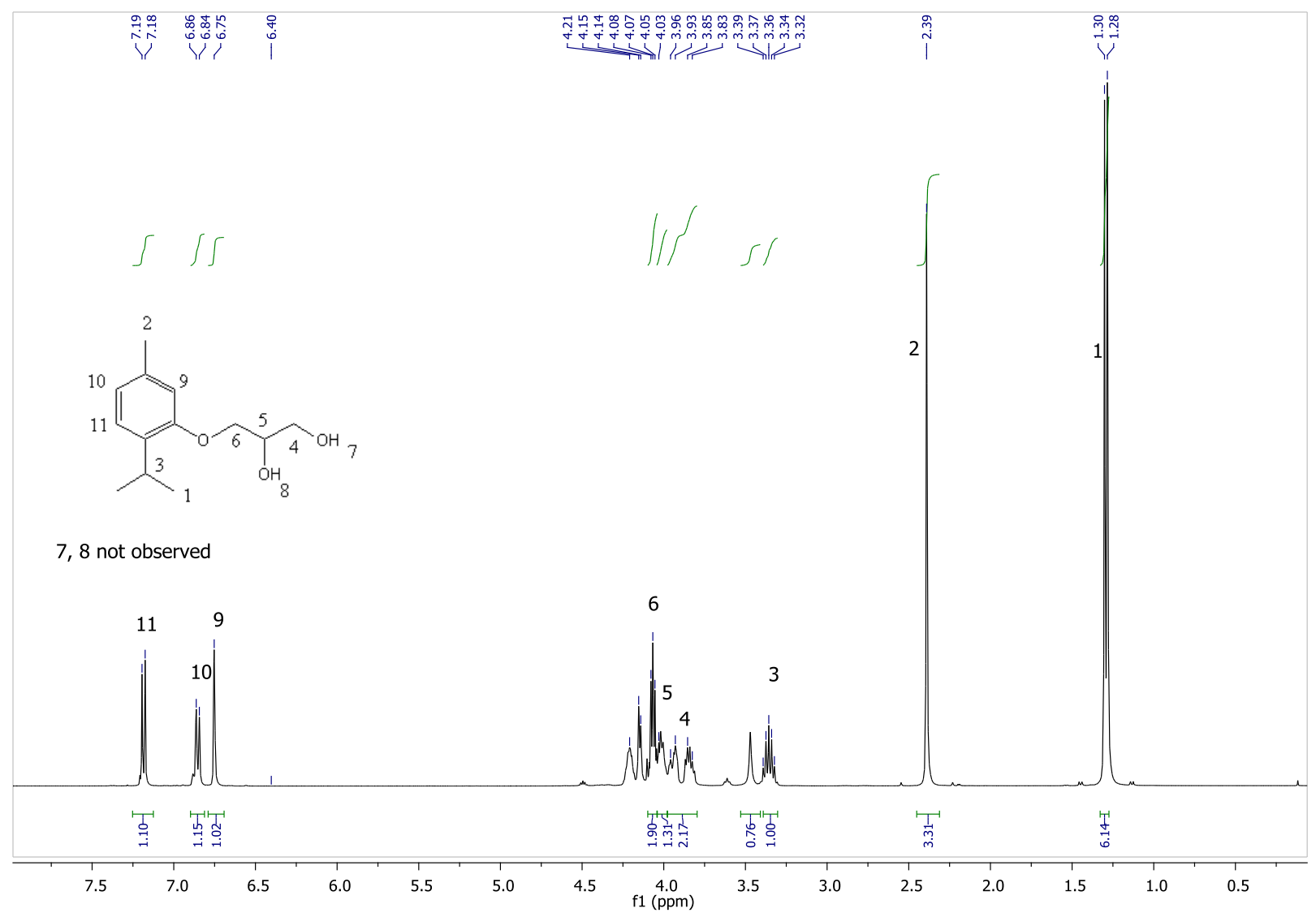


A.11.2. ${ }^{13} \mathrm{C}$ NMR of 3-(2-isopropyl-5-methylphenoxy)propane-1,2-diol (33)

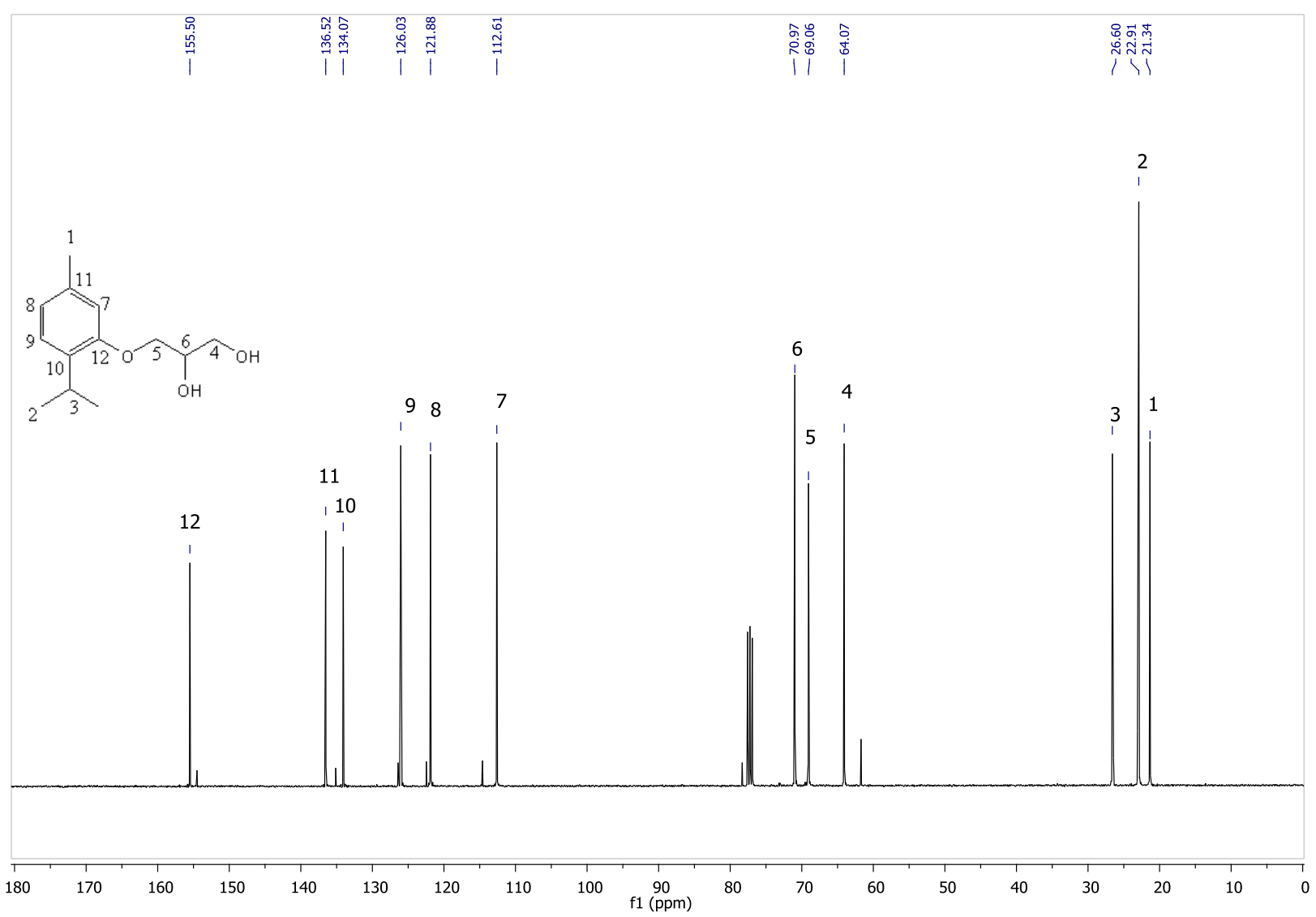


A.11.3. MS-DART analysis of 3-(2-isopropyl-5-methylphenoxy)propane-1,2-diol (33)

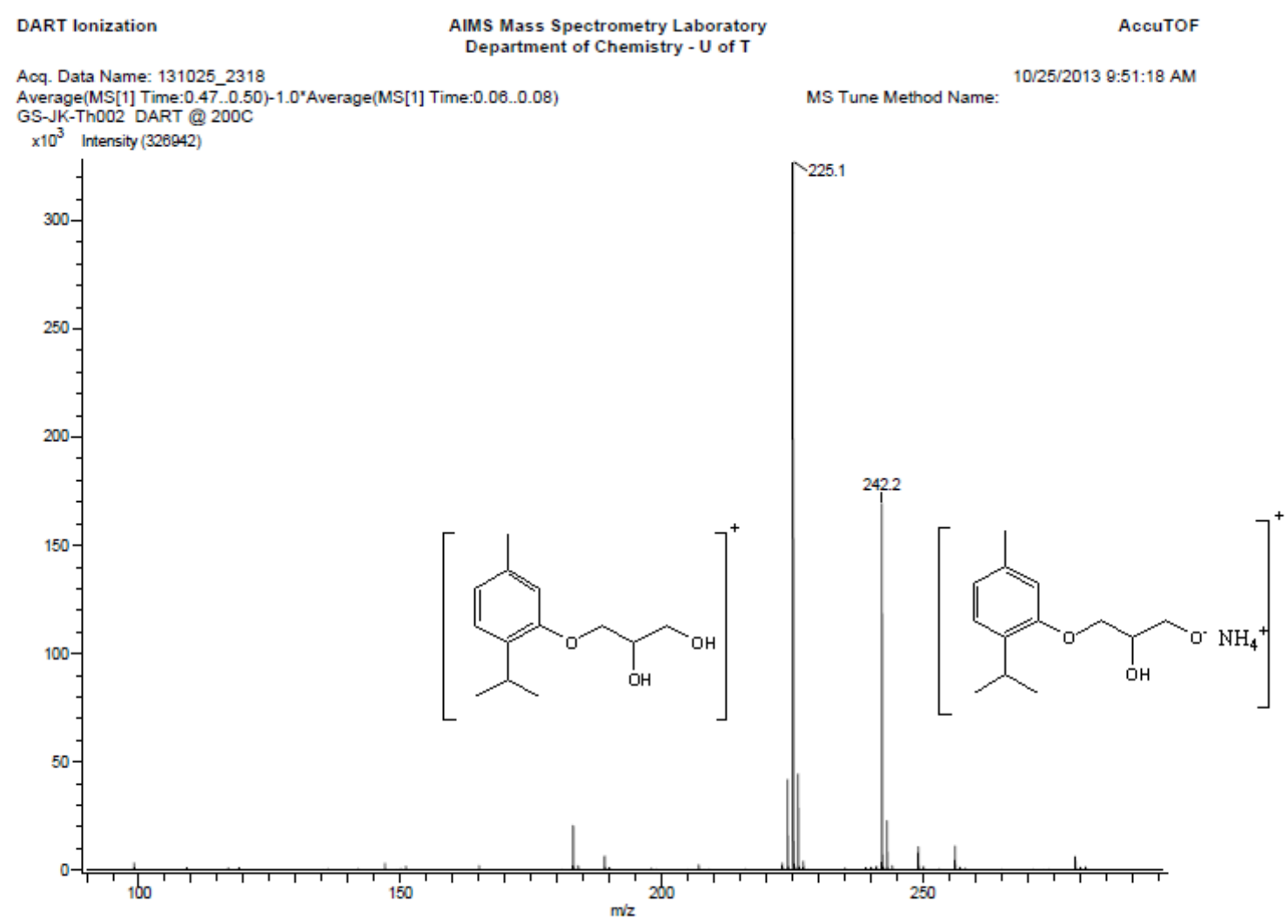

ION MODE: POSITIVE 
A.12.1. ${ }^{1}$ H NMR of 1,3-bis(2-isopropyl-5-methylphenoxy)propan-2-ol (34)

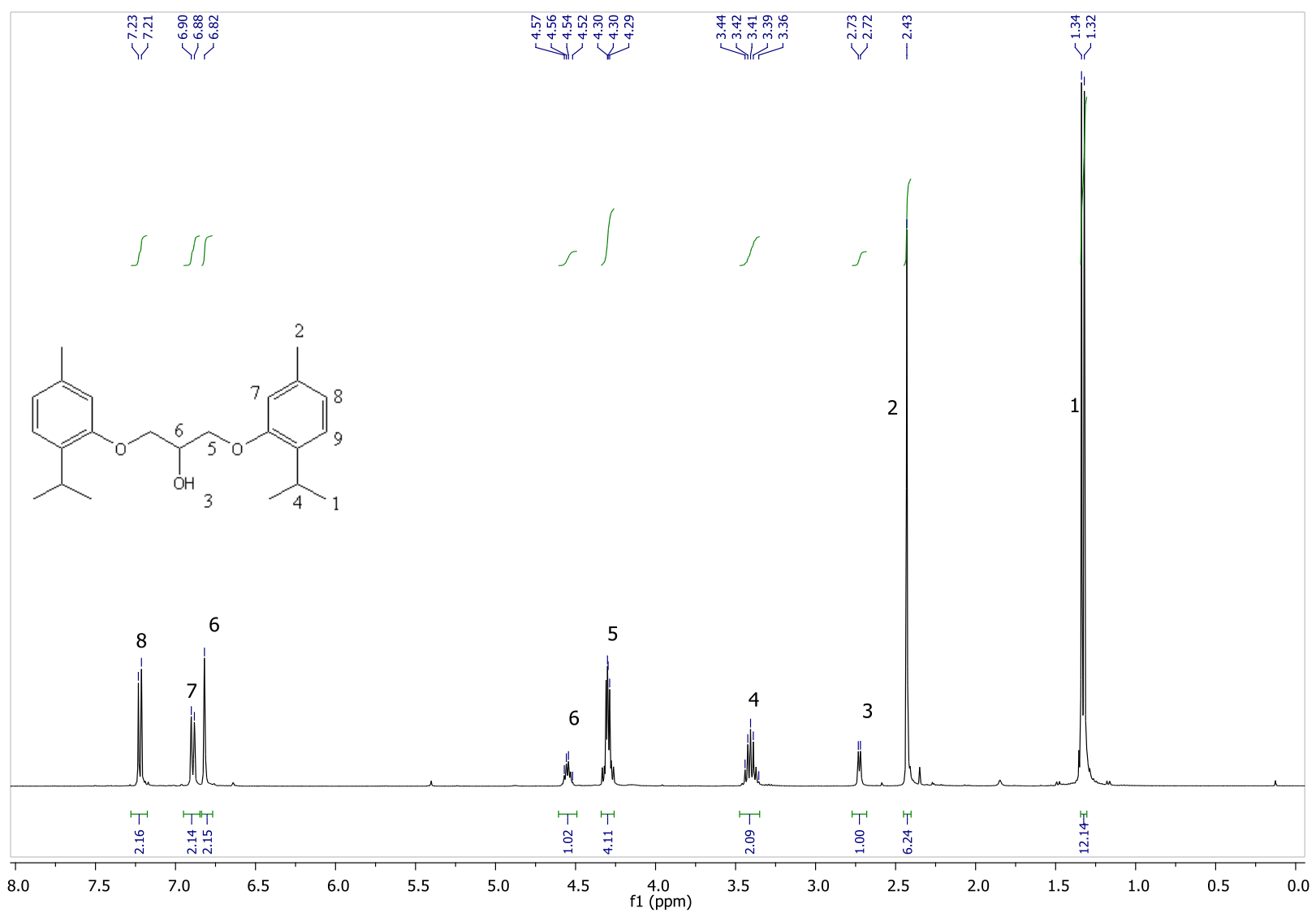


A.12.2 ${ }^{13} \mathrm{C}$ NMR of 1,3-bis(2-isopropyl-5-methylphenoxy)propan-2-ol (34)

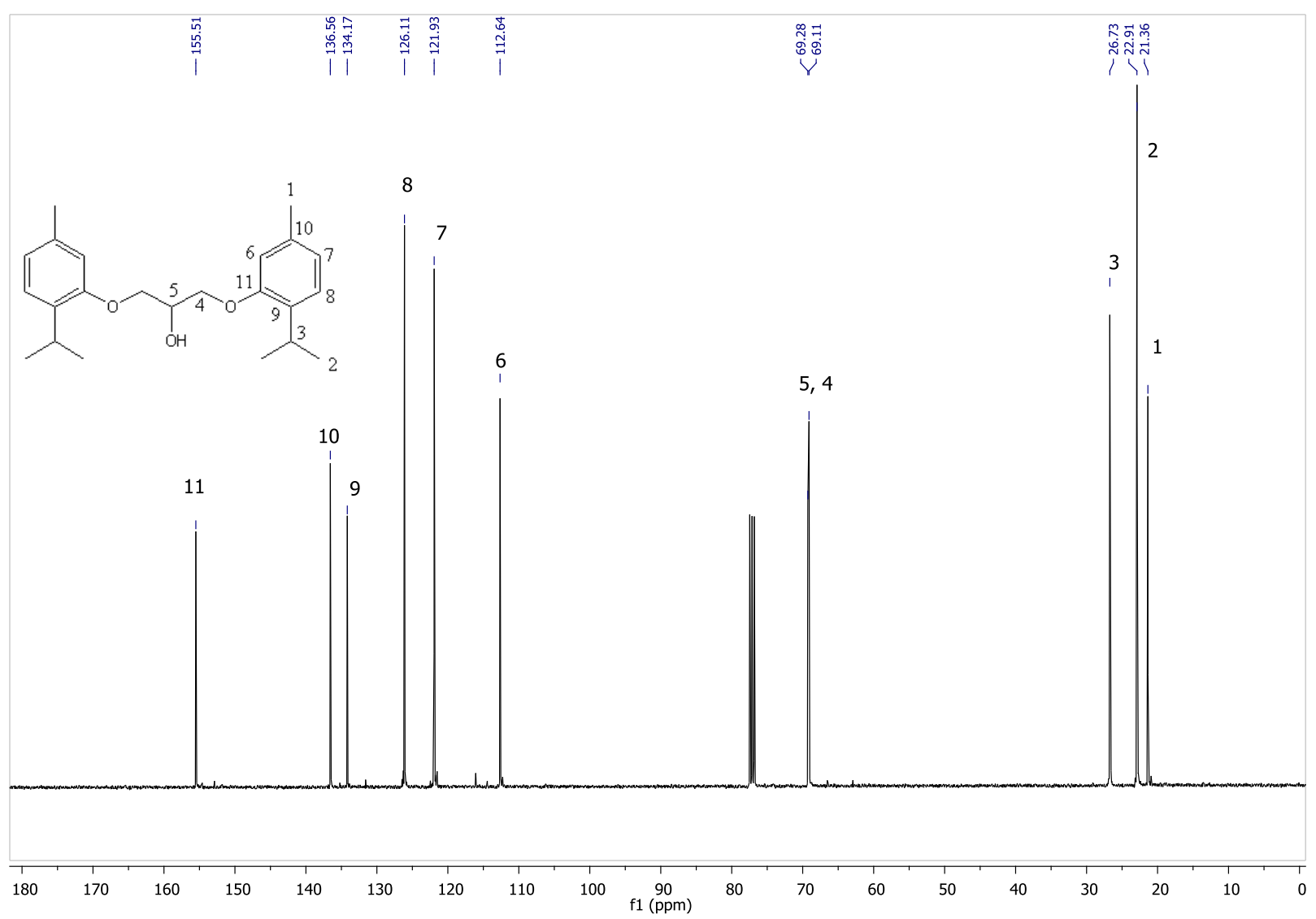


A.12.3 MS-DART analysis of 1,3-bis(2-isopropyl-5-methylphenoxy)propan-2-ol (34)

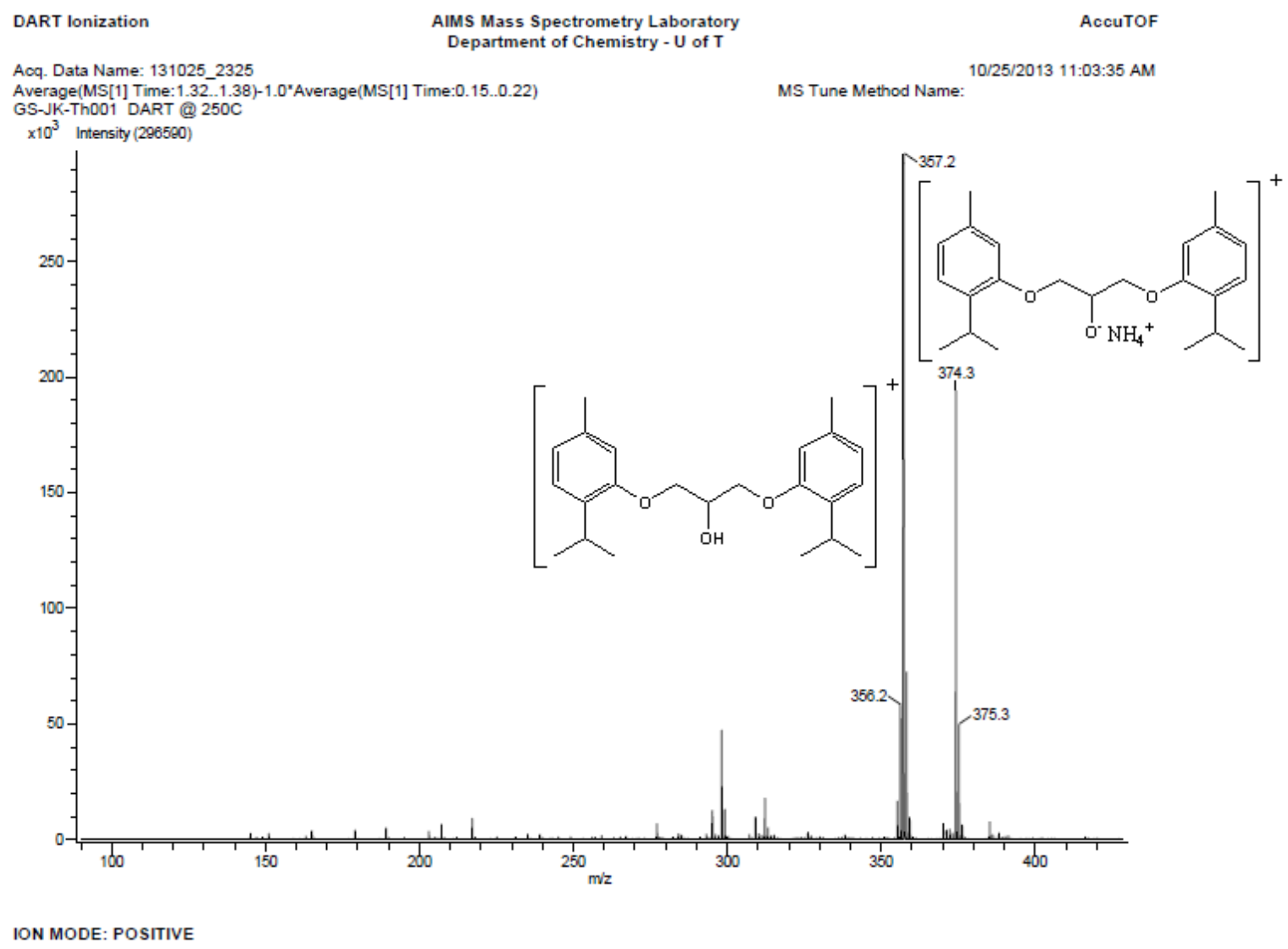


A.13.1. ${ }^{1}$ H NMR of 3-(5-isopropyl-2-methylphenoxy)propane-1,2-diol (36)

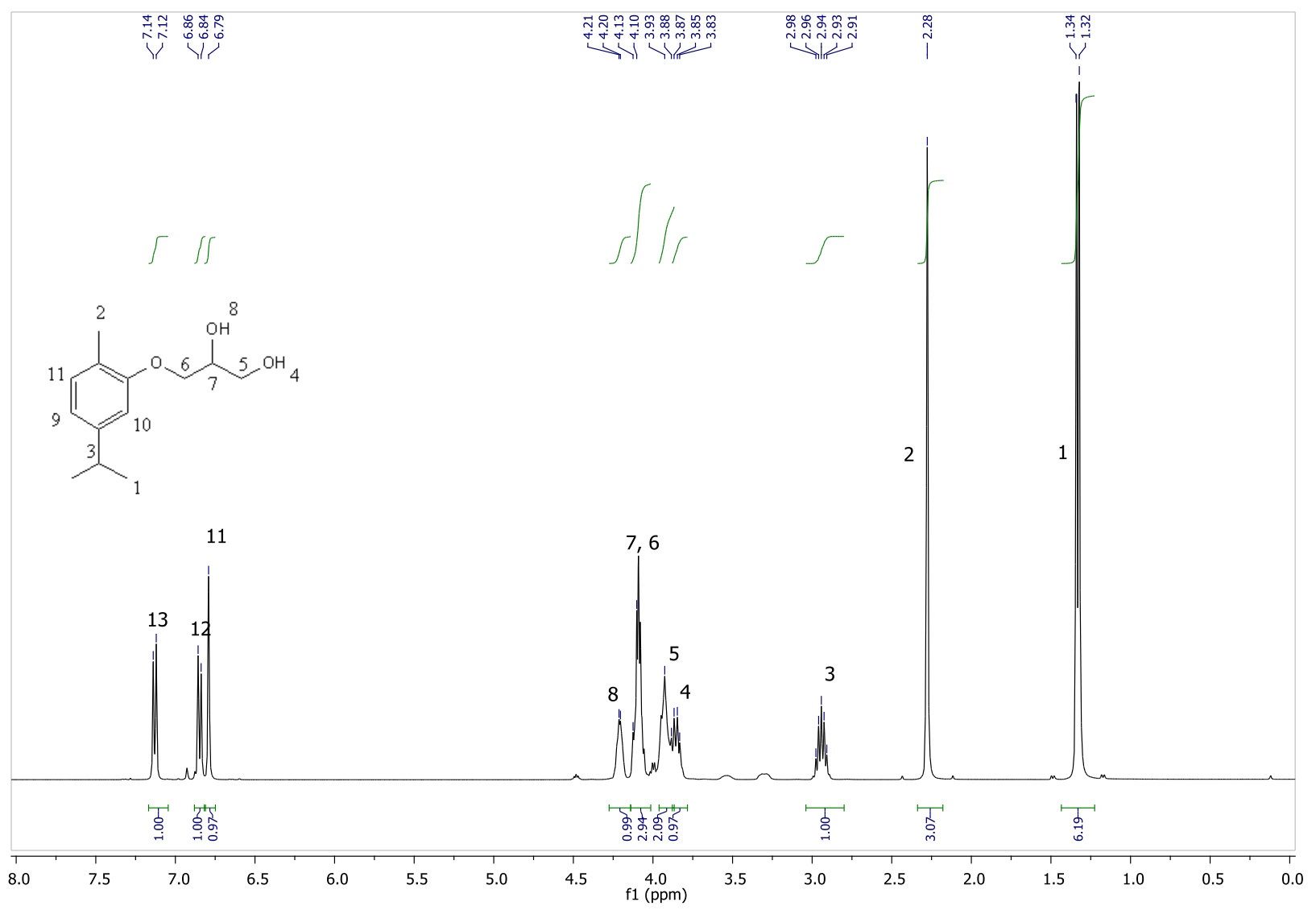


A.13.2. ${ }^{13} \mathrm{C}$ NMR of 3-(5-isopropyl-2-methylphenoxy)propane-1,2-diol (36)

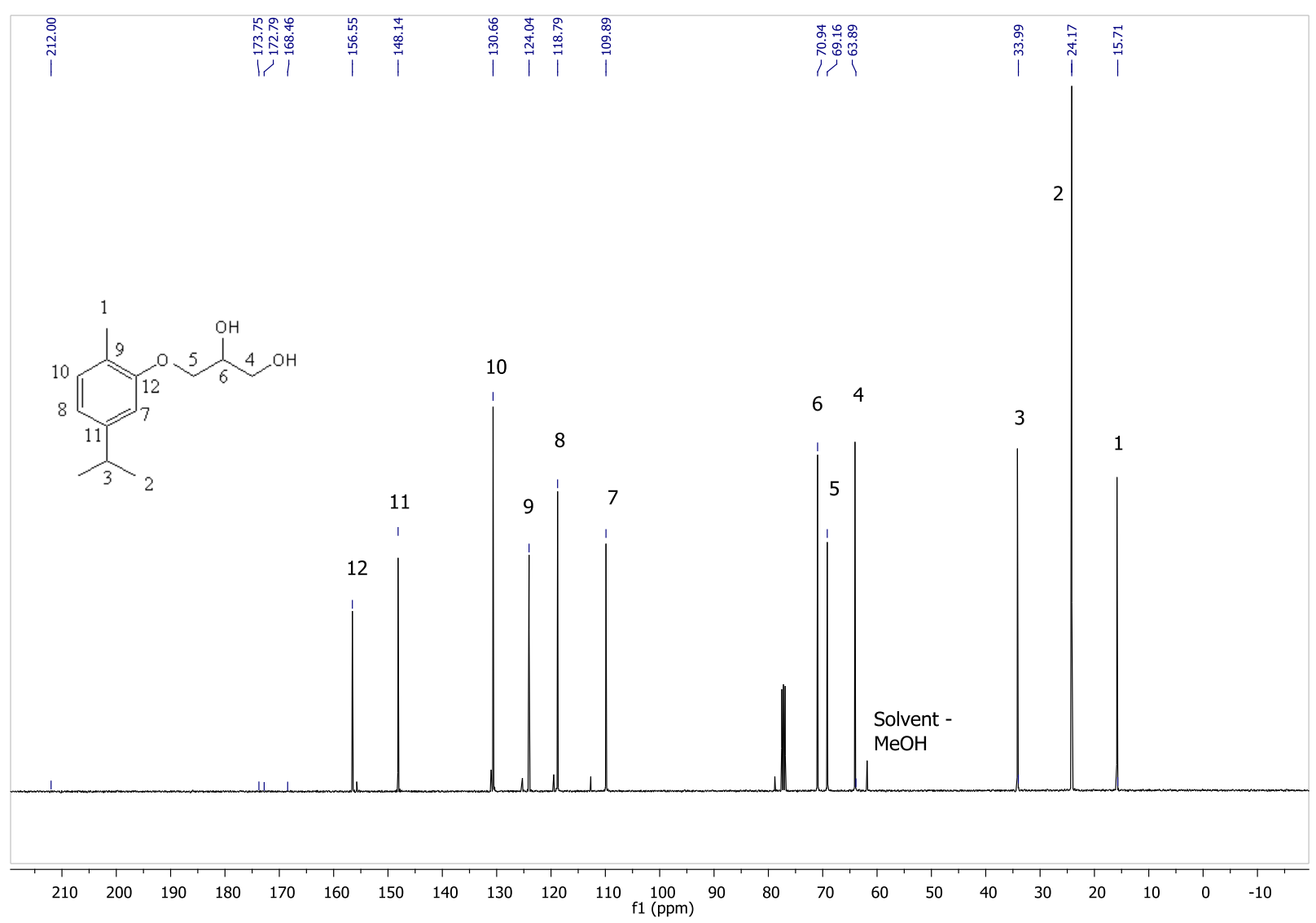


A.13.3 MS-DART analysis of 3-(5-isopropyl-2-methylphenoxy)propane-1,2-diol (36)

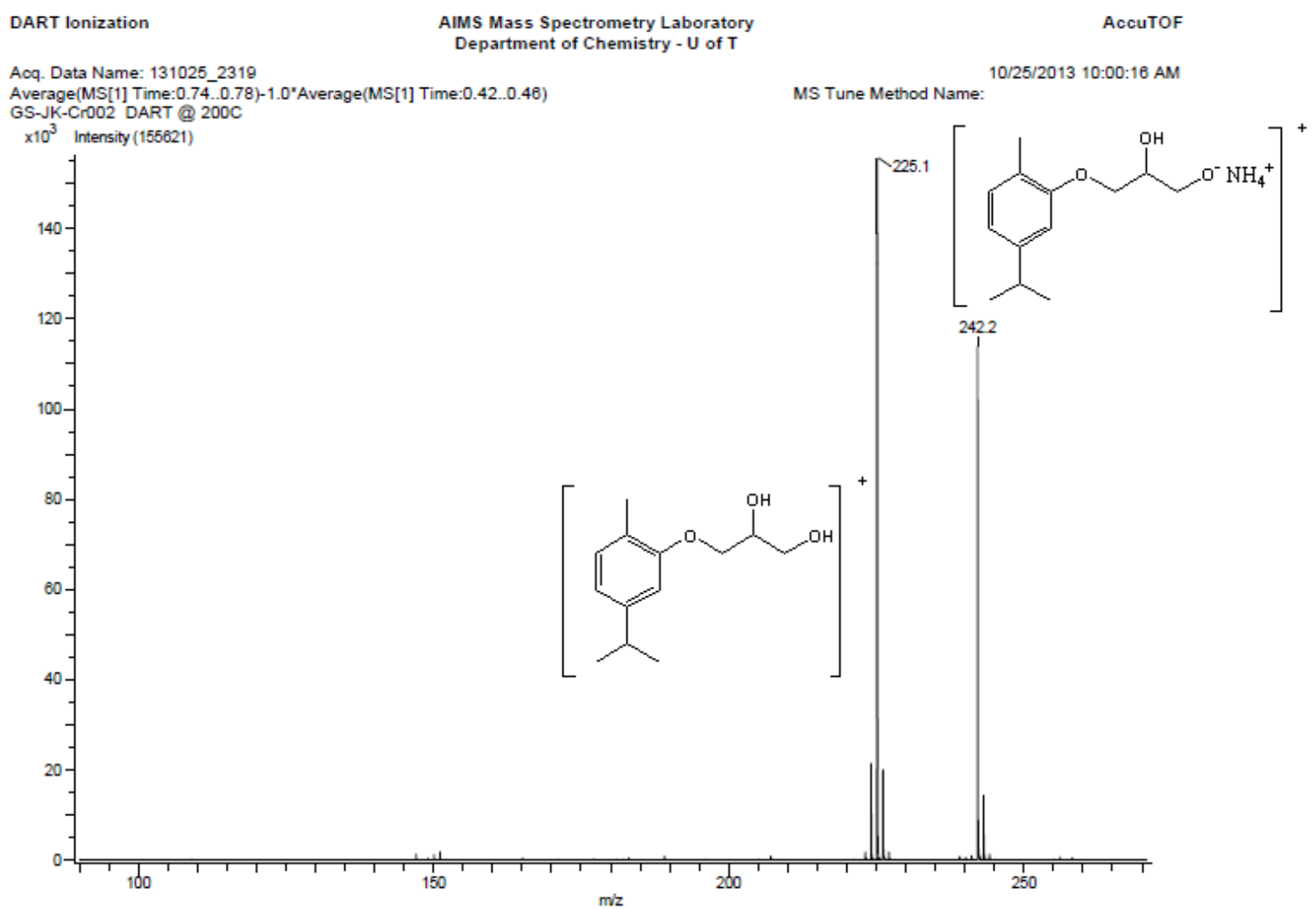

ION MODE: POSITIVE 
A.14.1 ${ }^{1} \mathrm{H}$ NMR of 1,3-bis(5-isopropyl-2-methylphenoxy)propan-2-ol (37)

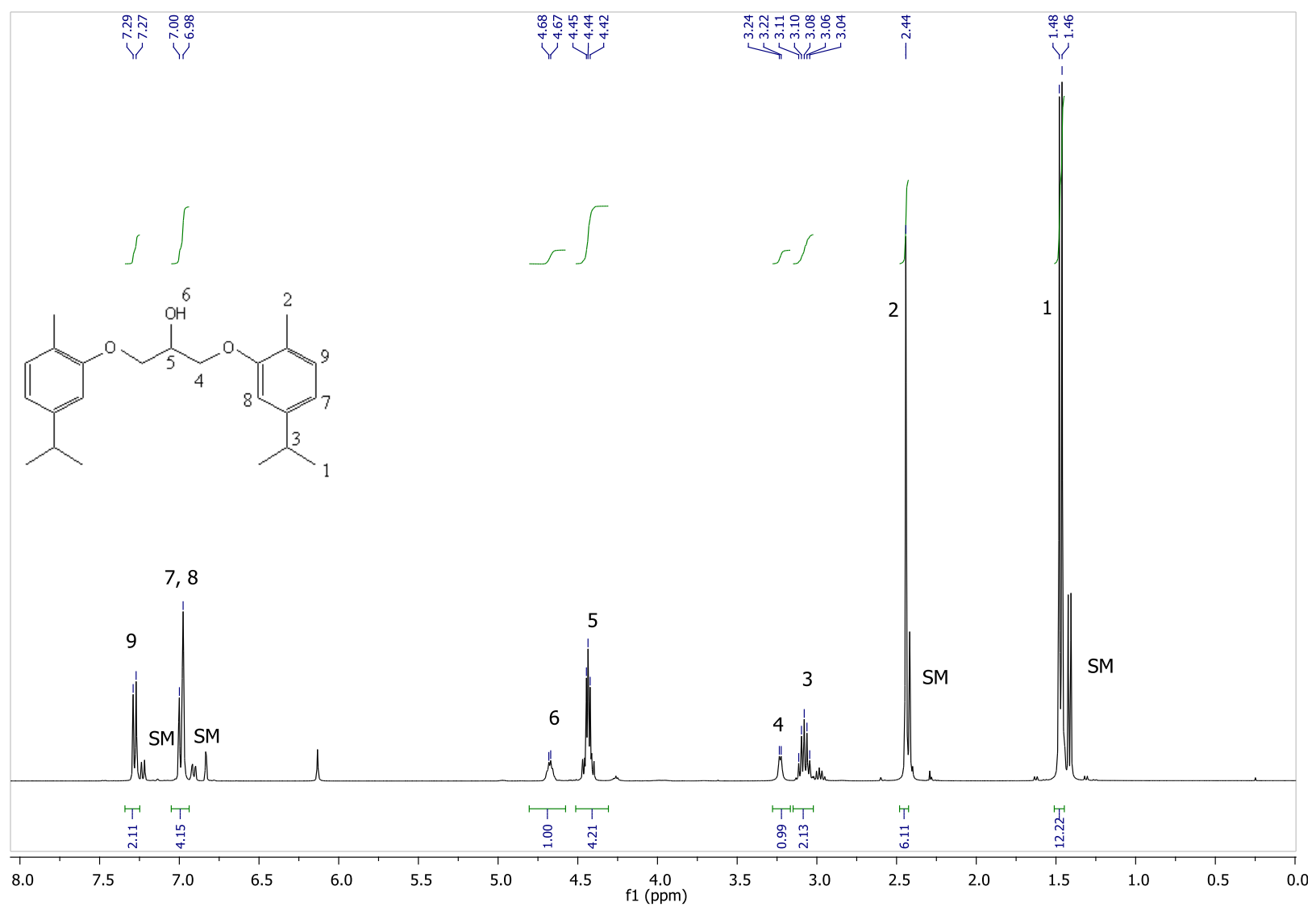


A.14.2 ${ }^{13} \mathrm{C}$ NMR of 1,3-bis(5-isopropyl-2-methylphenoxy)propan-2-ol (37)

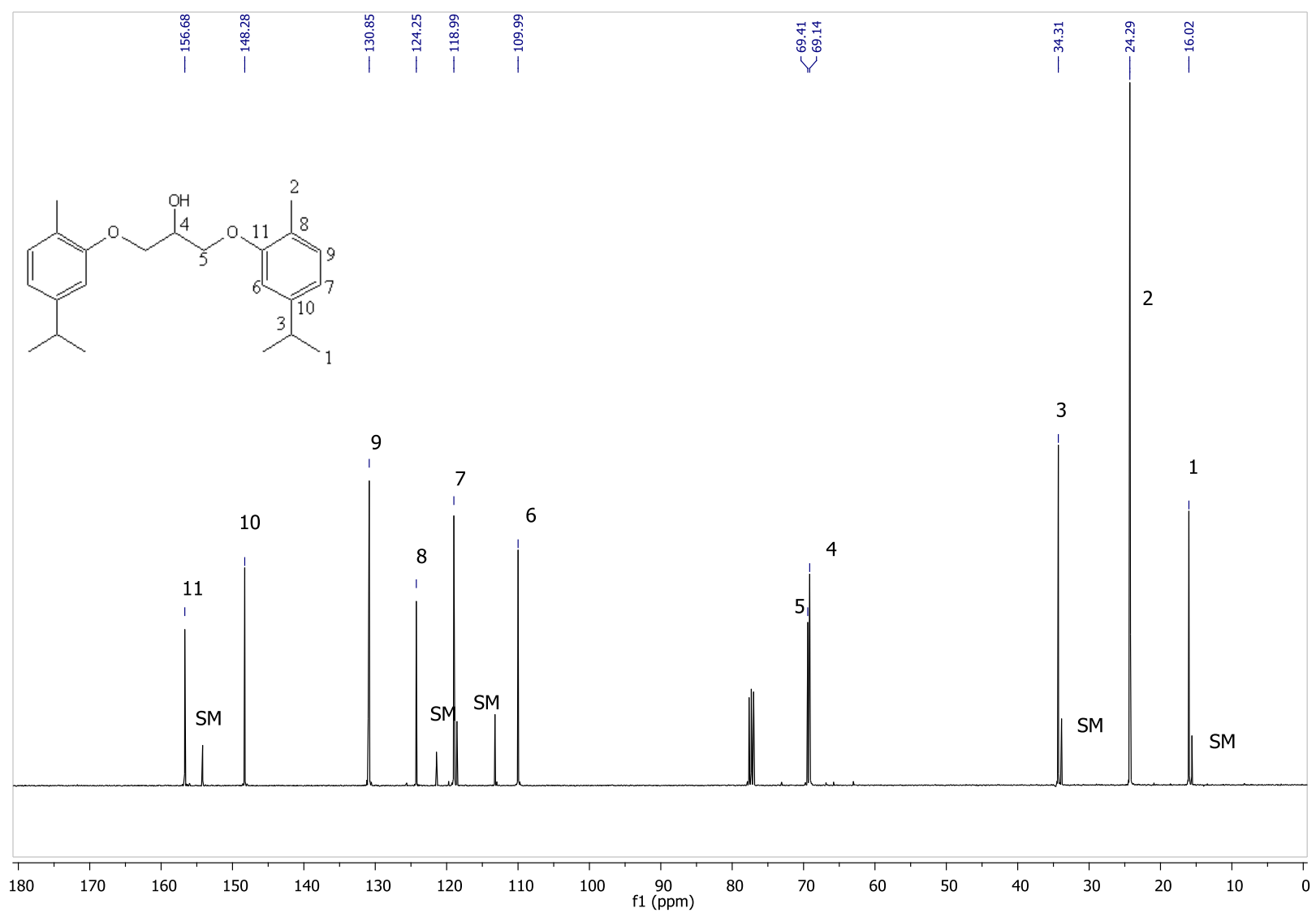


A.15.1 ${ }^{1}$ H NMR of 4-(4-(2,3-dihydroxypropoxy)phenyl)butan-2-one (39)

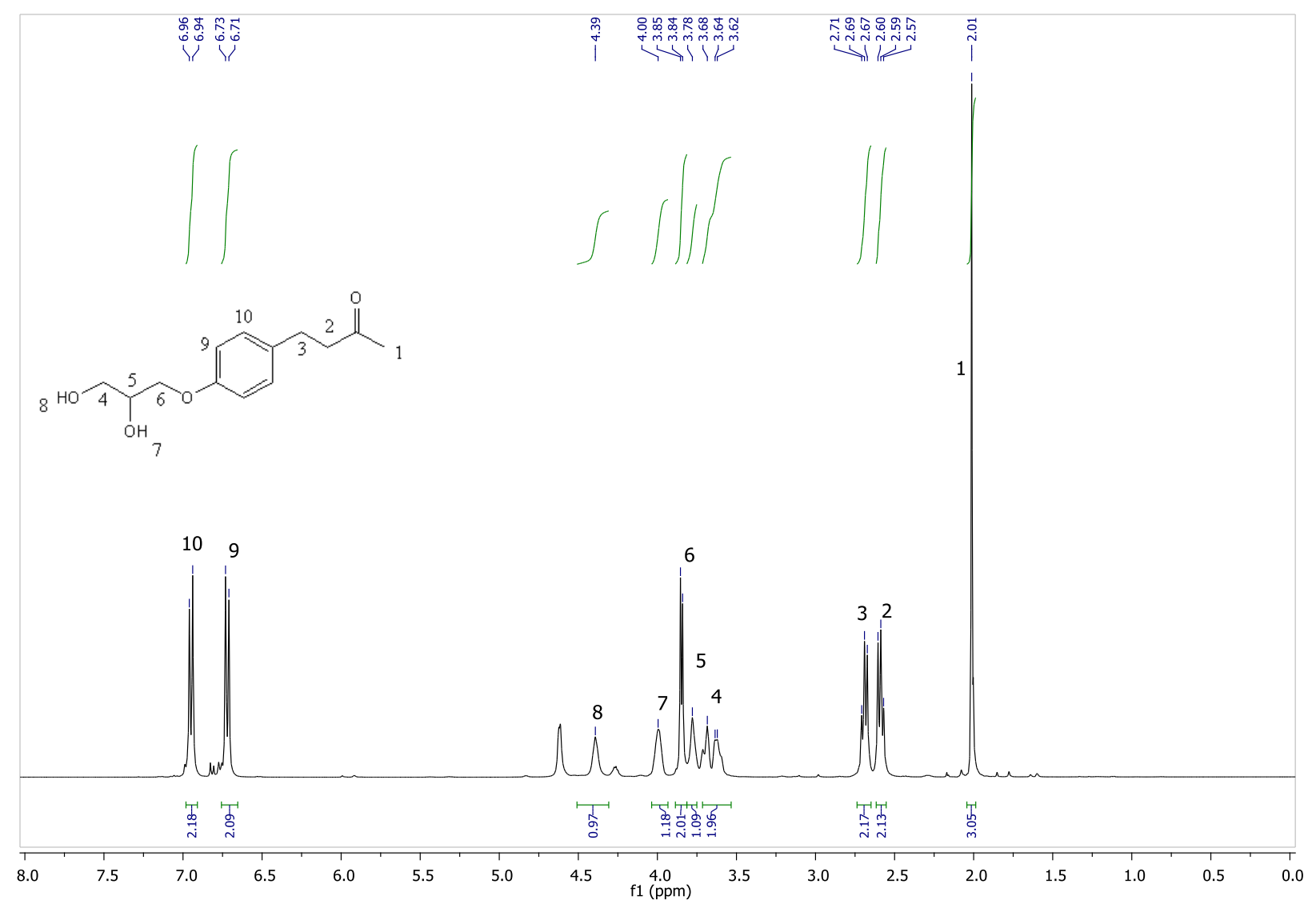


A.15.2 ${ }^{13} \mathrm{C}$ NMR of 4-(4-(2,3-dihydroxypropoxy)phenyl)butan-2-one (39)

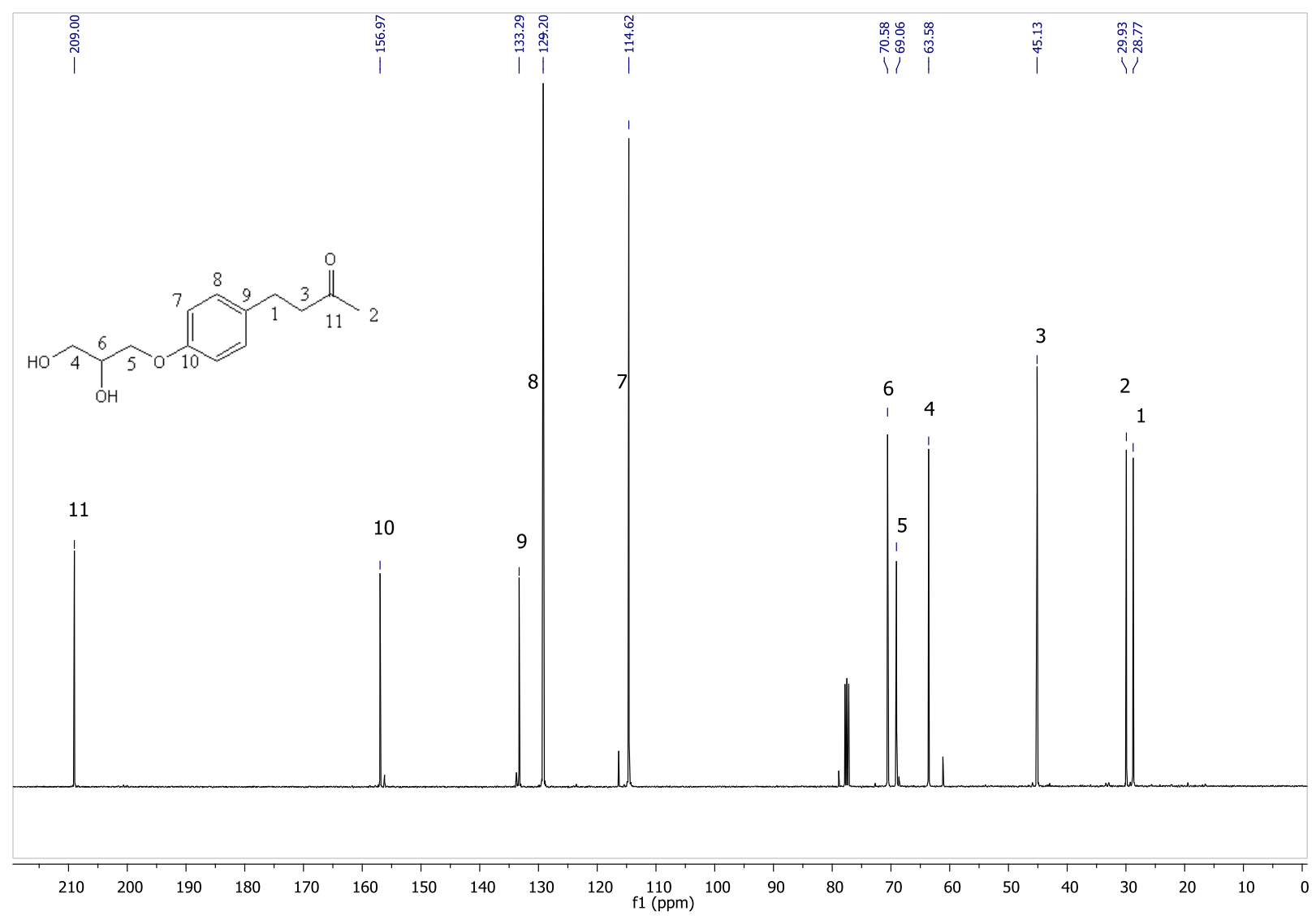


A.15.3 MS-DART analysis of 4-(4-(2,3-dihydroxypropoxy)phenyl)butan-2-one (39)

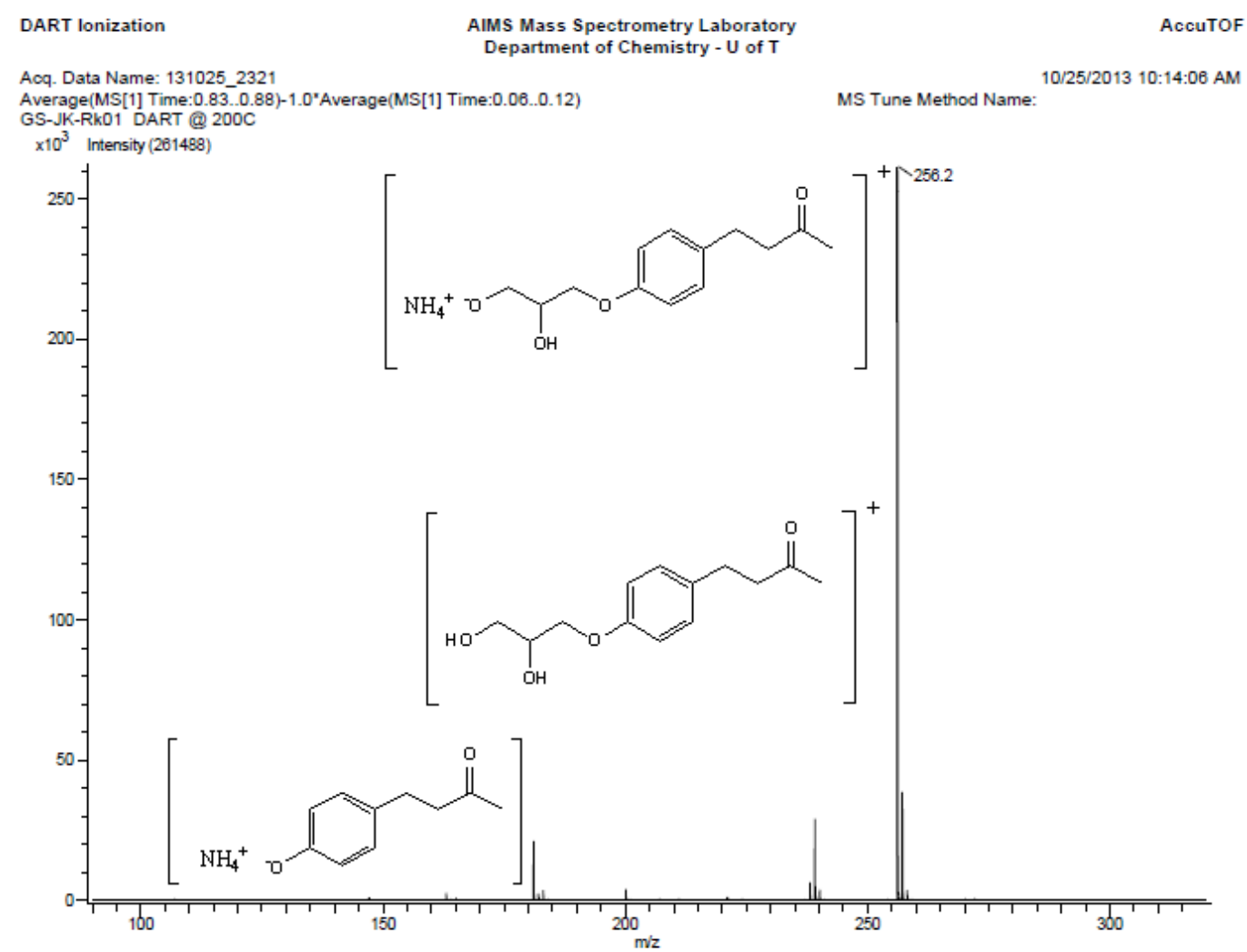

ION MODE: POSITIVE 
A.16.1 ${ }^{1} \mathrm{H}$ NMR of 4,4'-(((2-hydroxypropane-1,3-diyl)bis(oxy))bis(4,1-phenylene))bis(butan-2one) (40)

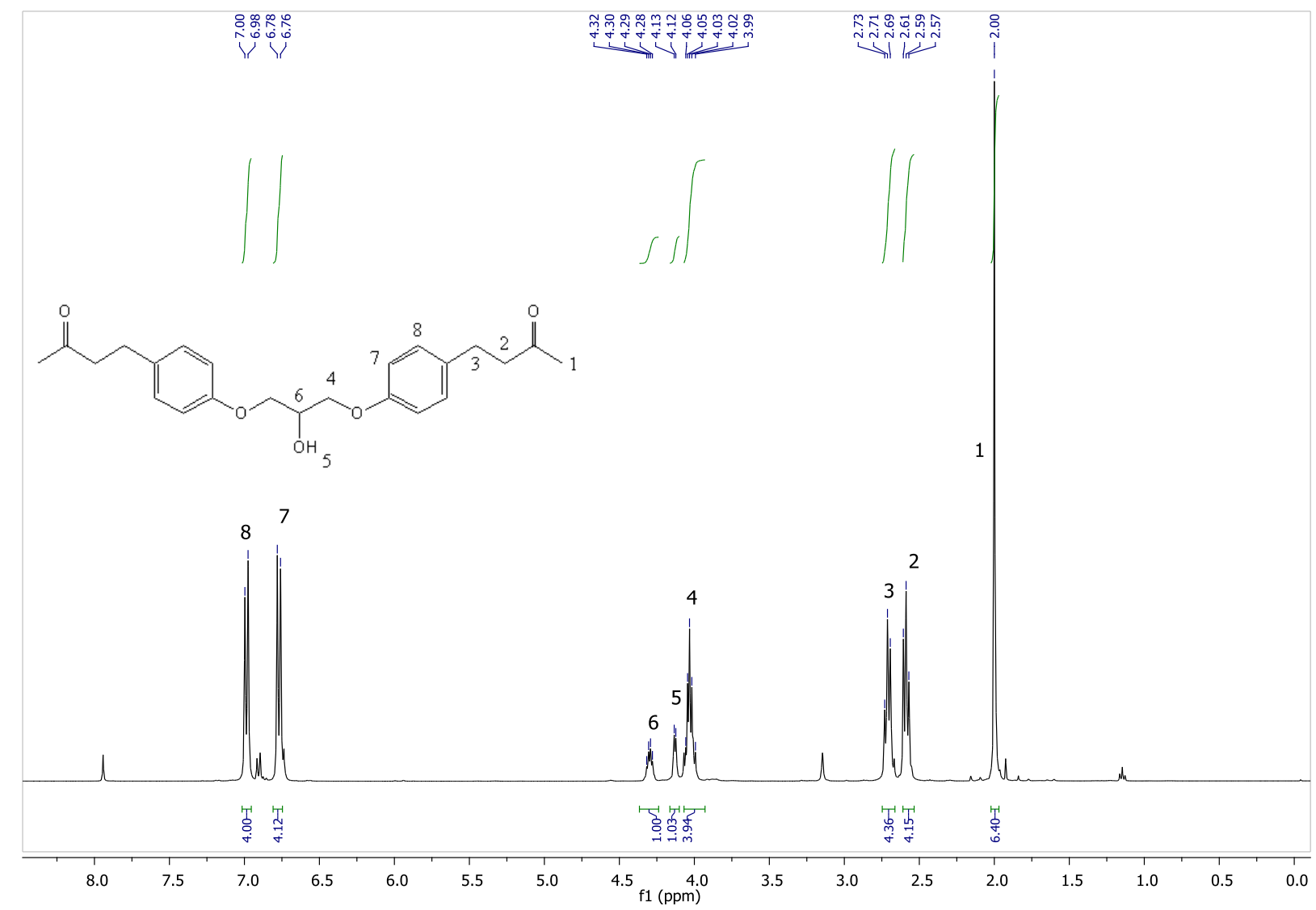


A.16.2 ${ }^{13}$ C NMR of 4,4'-(((2-hydroxypropane-1,3-diyl)bis(oxy))bis(4,1-phenylene) )bis(butan-2one) (40)

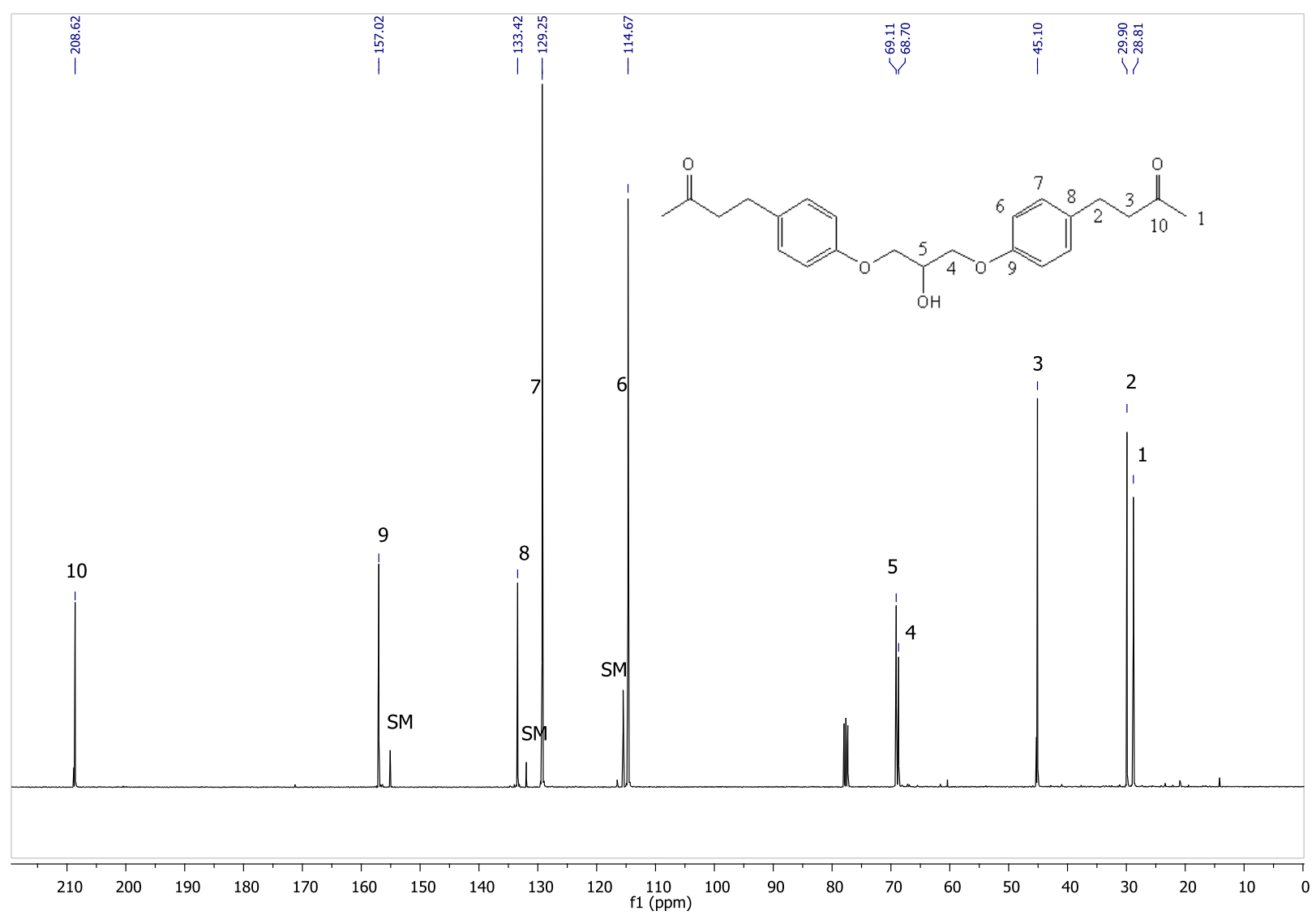


A.17.1 ${ }^{13}$ C NMR of 3-(4-methoxyphenoxy)propane-1,2-diol (42)

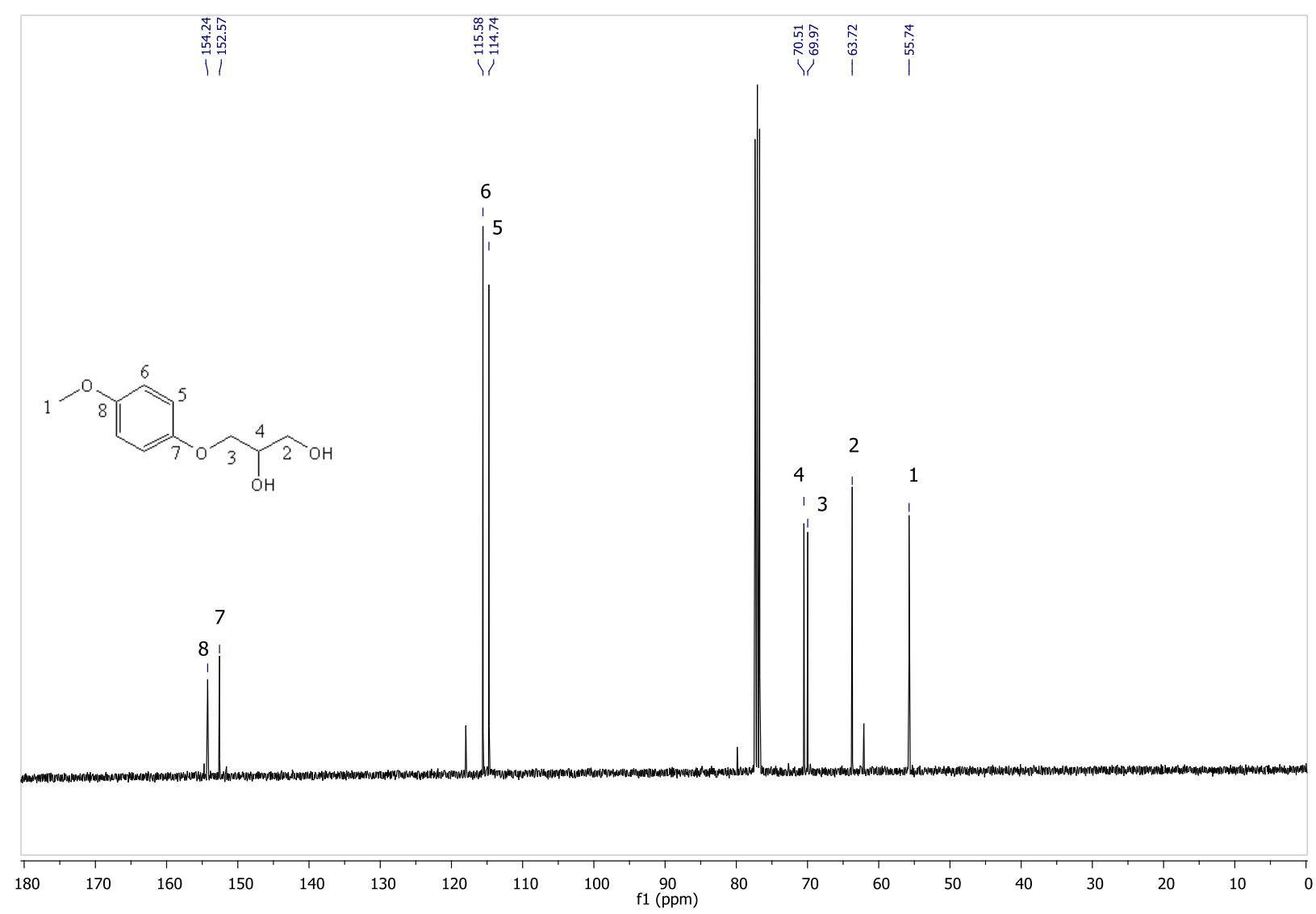


A. 18.1 ${ }^{1}$ H NMR of 1,3-bis(4-methoxyphenoxy)propan-2-ol (43)

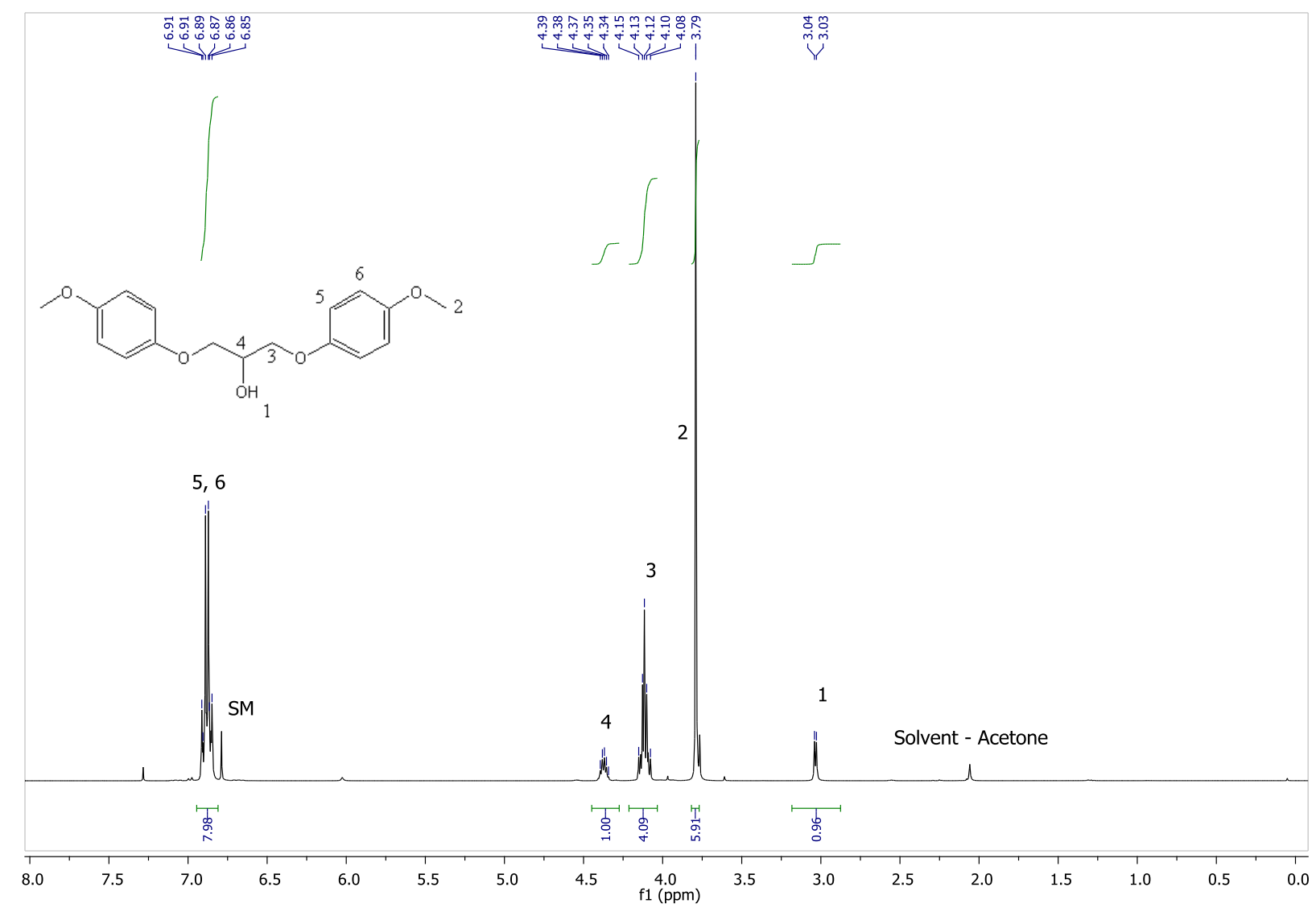


A. $18.2{ }^{13} \mathrm{C}$ NMR of 1,3-bis(4-methoxyphenoxy)propan-2-ol (43)

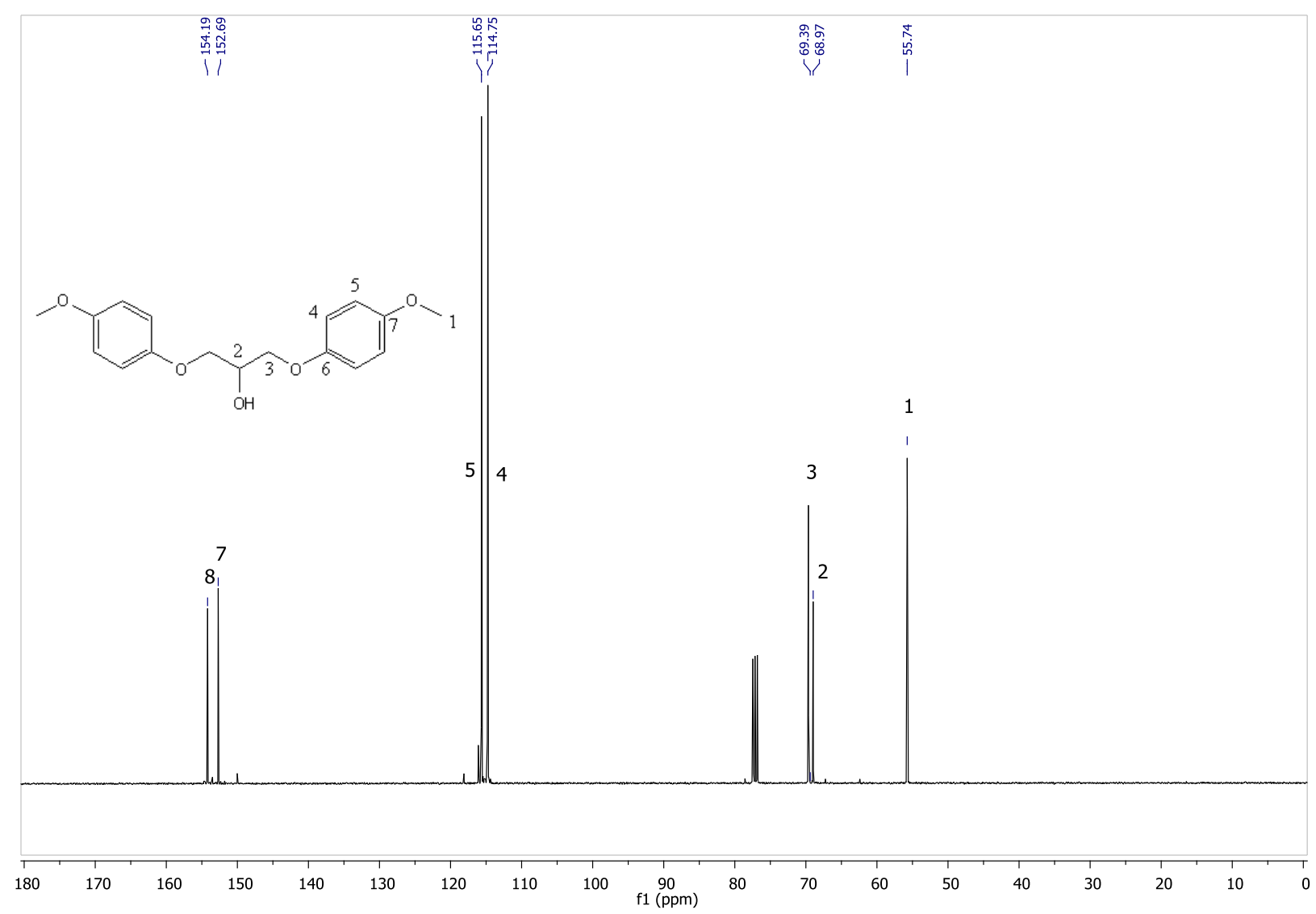


A. $19.1{ }^{1} \mathrm{H}$ NMR of 3-(p-tolyloxy)propane-1,2-diol (45)

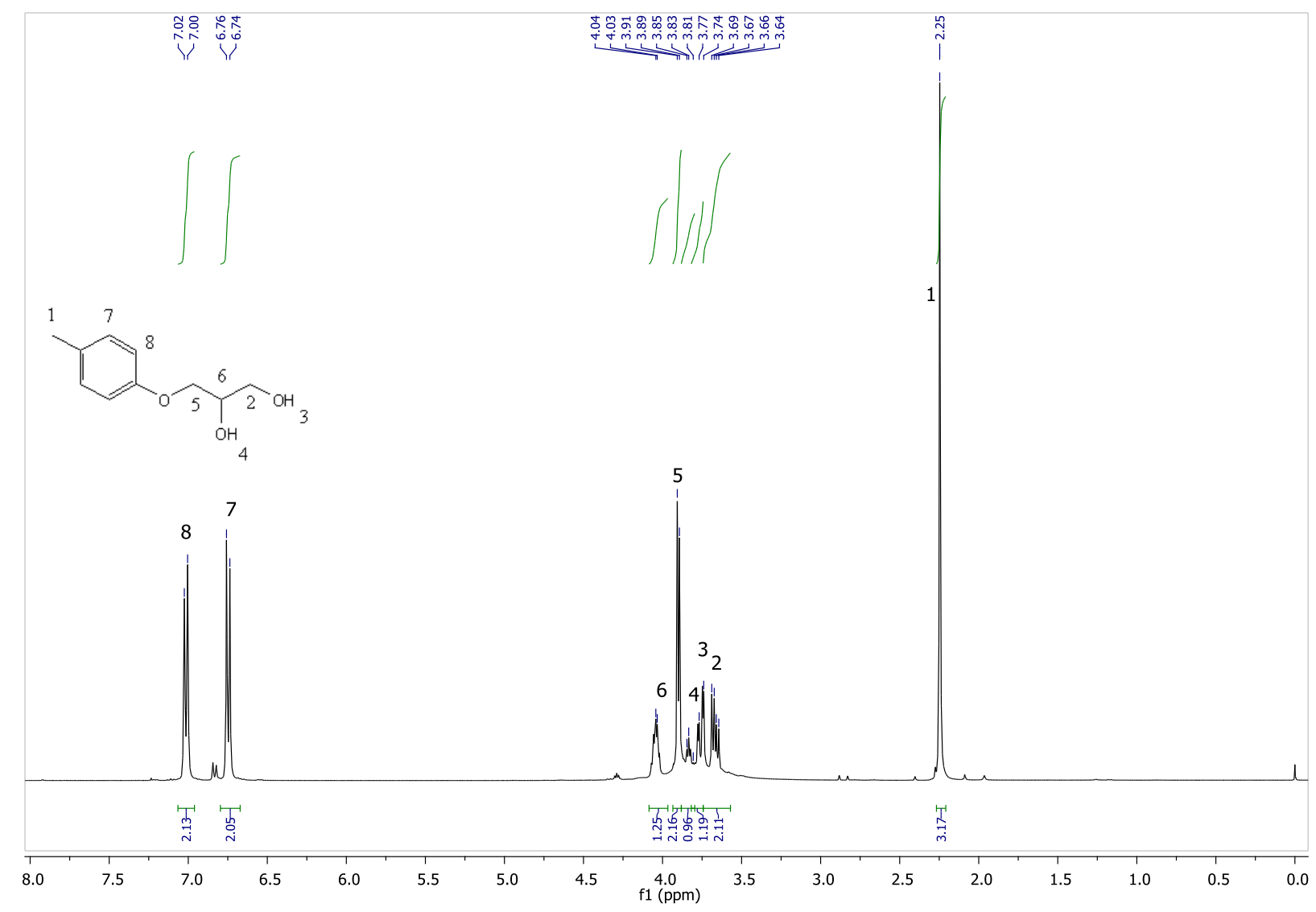


A. $19.2{ }^{13} \mathrm{C}$ NMR of 3-(p-tolyloxy)propane-1,2-diol (45)

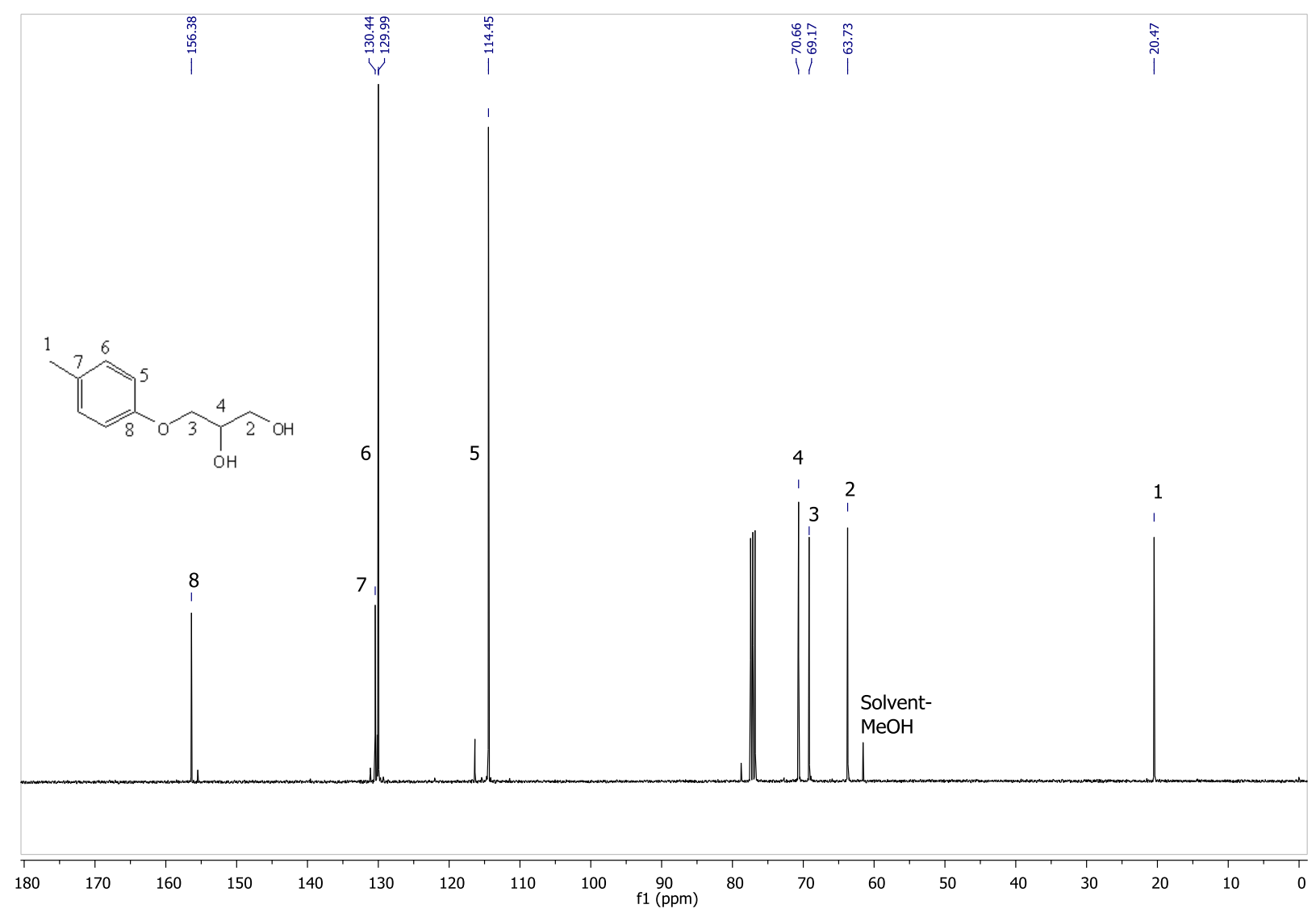

b 
A. 19.3 MS-DART of 3-(p-tolyloxy)propane-1,2-diol (45)

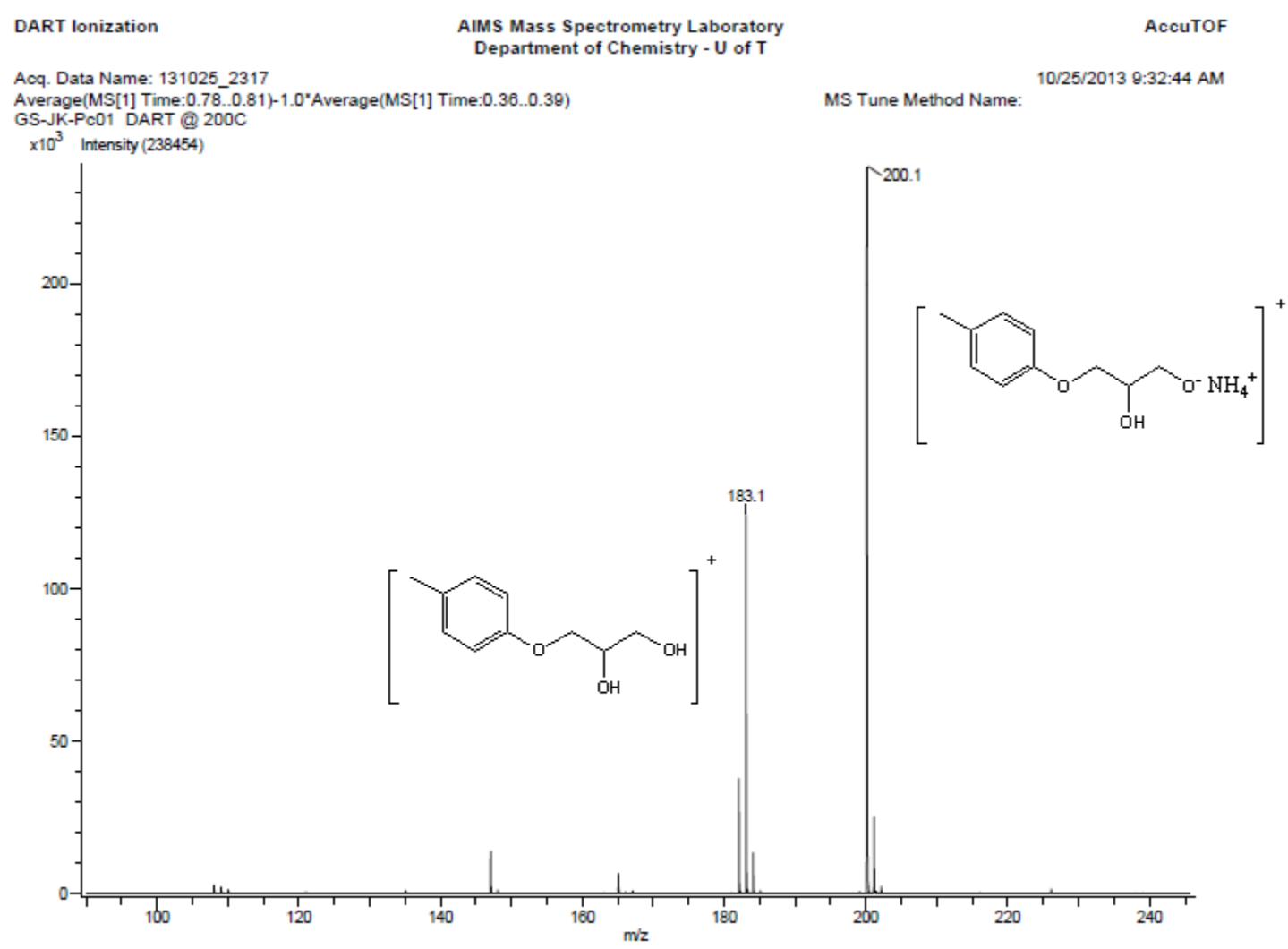

ION MODE: POSITIVE 
A.20.1 ${ }^{1} \mathrm{H}$ NMR of 1,3-bis(p-tolyloxy)propan-2-ol (46)

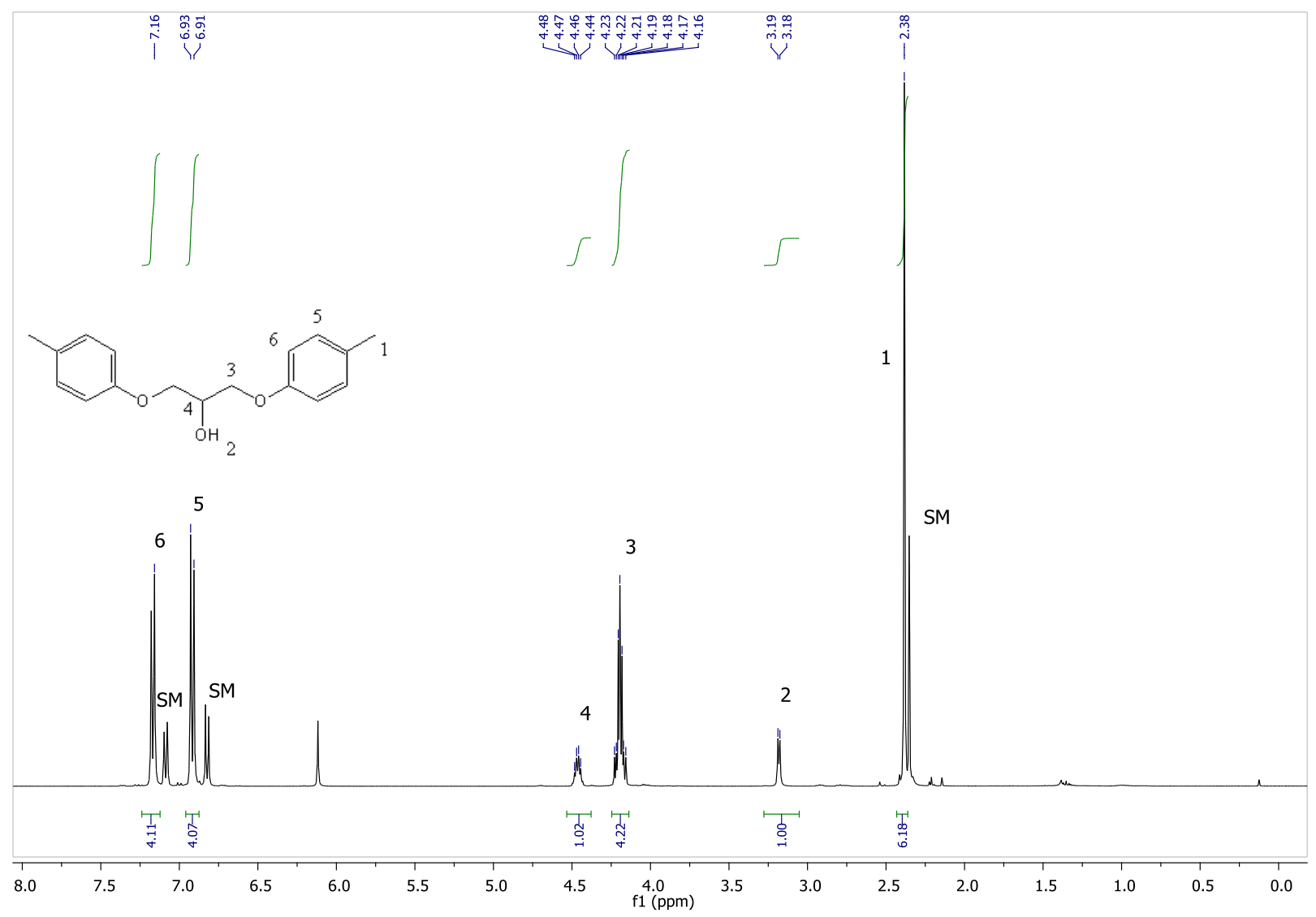


A.21.1 ${ }^{1} \mathrm{H}$ NMR of 3-(4-(2-(2-methoxyphenoxy)ethyl)phenoxy)propane-1,2-diol (47)

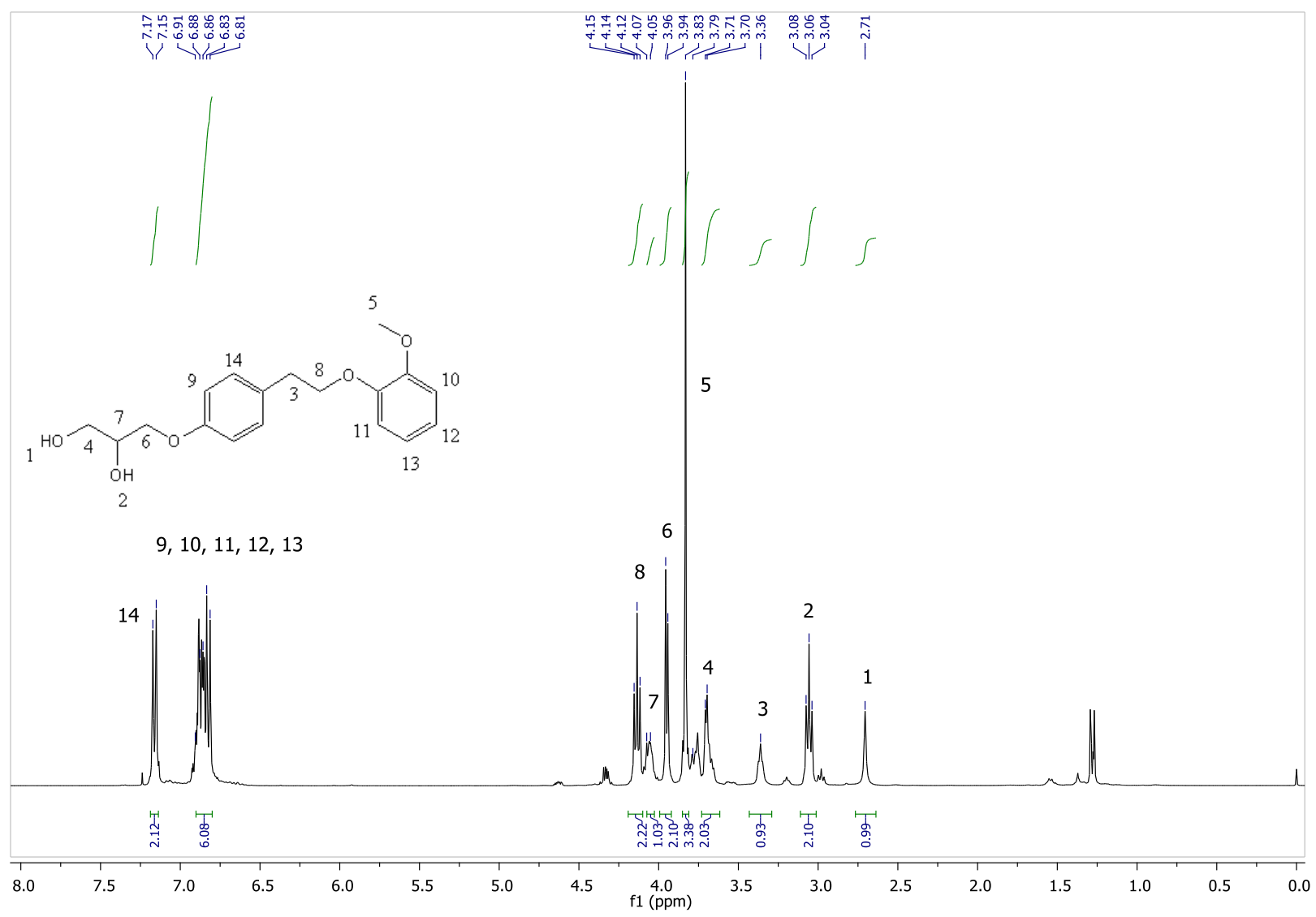


A.21.2 ${ }^{13}$ C NMR of 3-(4-(2-(2-methoxyphenoxy)ethyl)phenoxy)propane-1,2-diol (47)

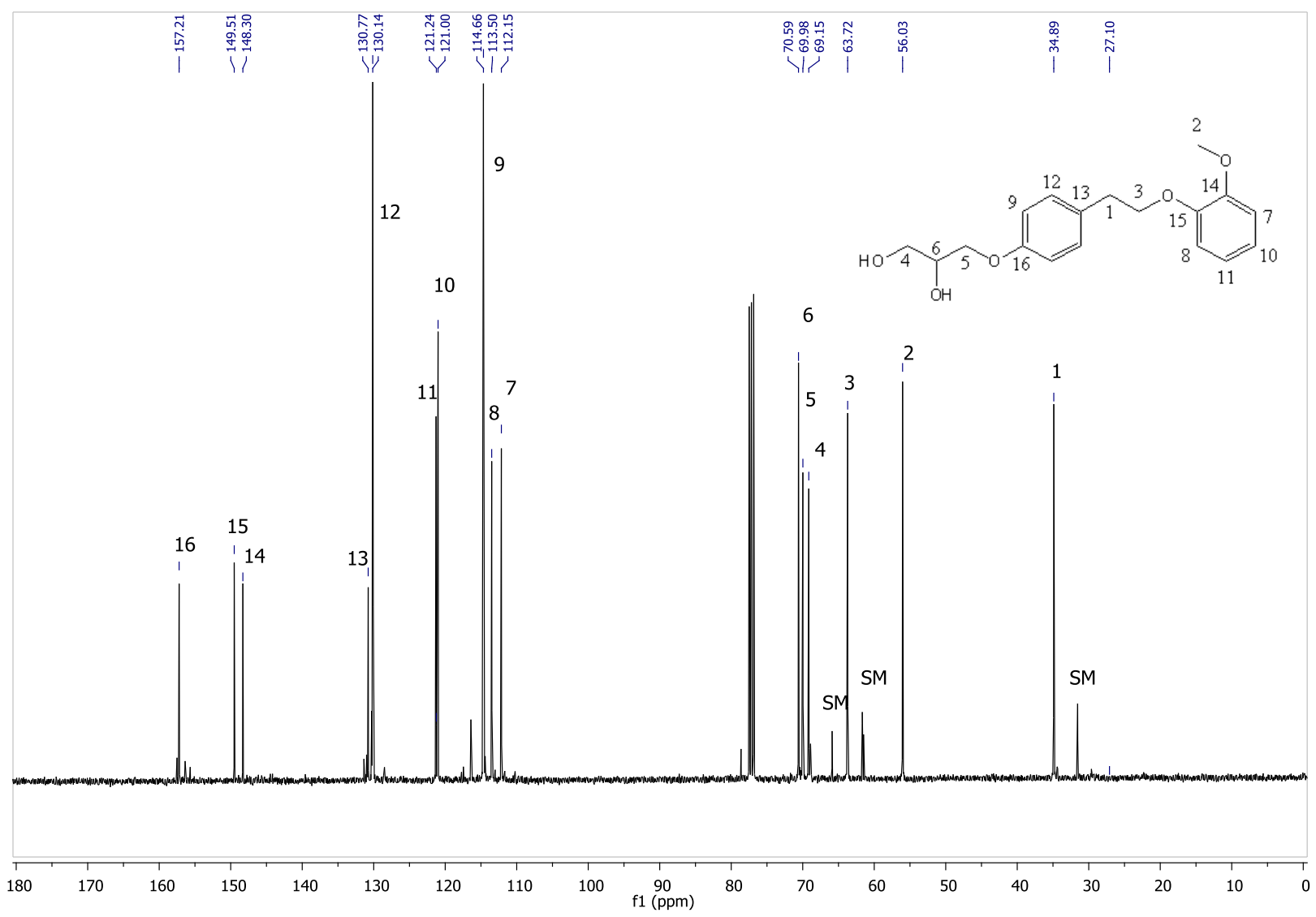


A.21.3 MS-DART analysis of 3-(4-(2-(2-methoxyphenoxy)ethyl)phenoxy)propane-1,2-diol (47)

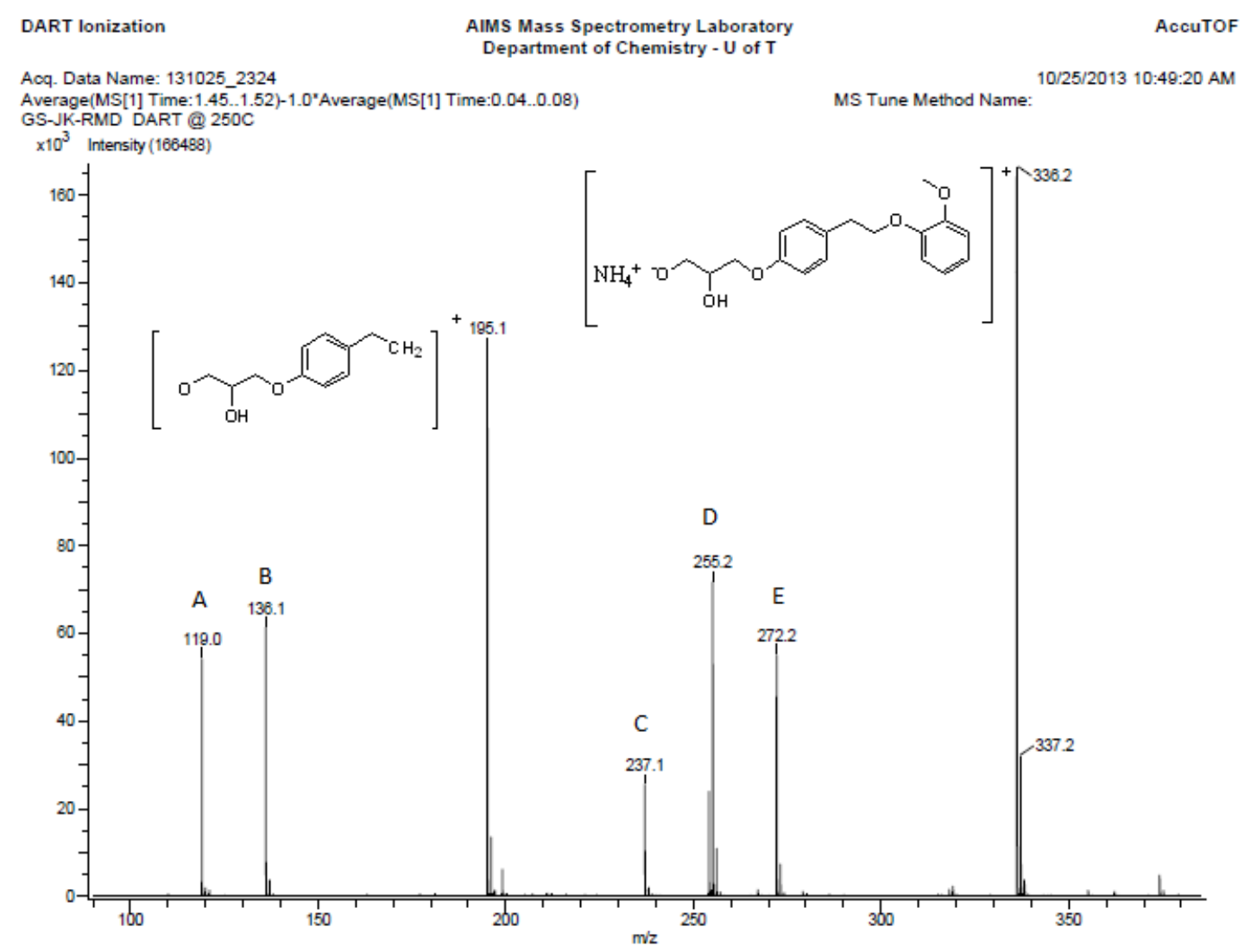

ION MODE: POSITIVE

A-E: Assumed to be various impurities and ammoniated impurities from the synthesis of $\mathbf{1 3}$. 
A.22.1. ${ }^{1} \mathrm{H}$ NMR of a polyester based resin (51) from 3-(2-methoxyphenoxy)propane-1,2-diol (26) and succinic acid (50)

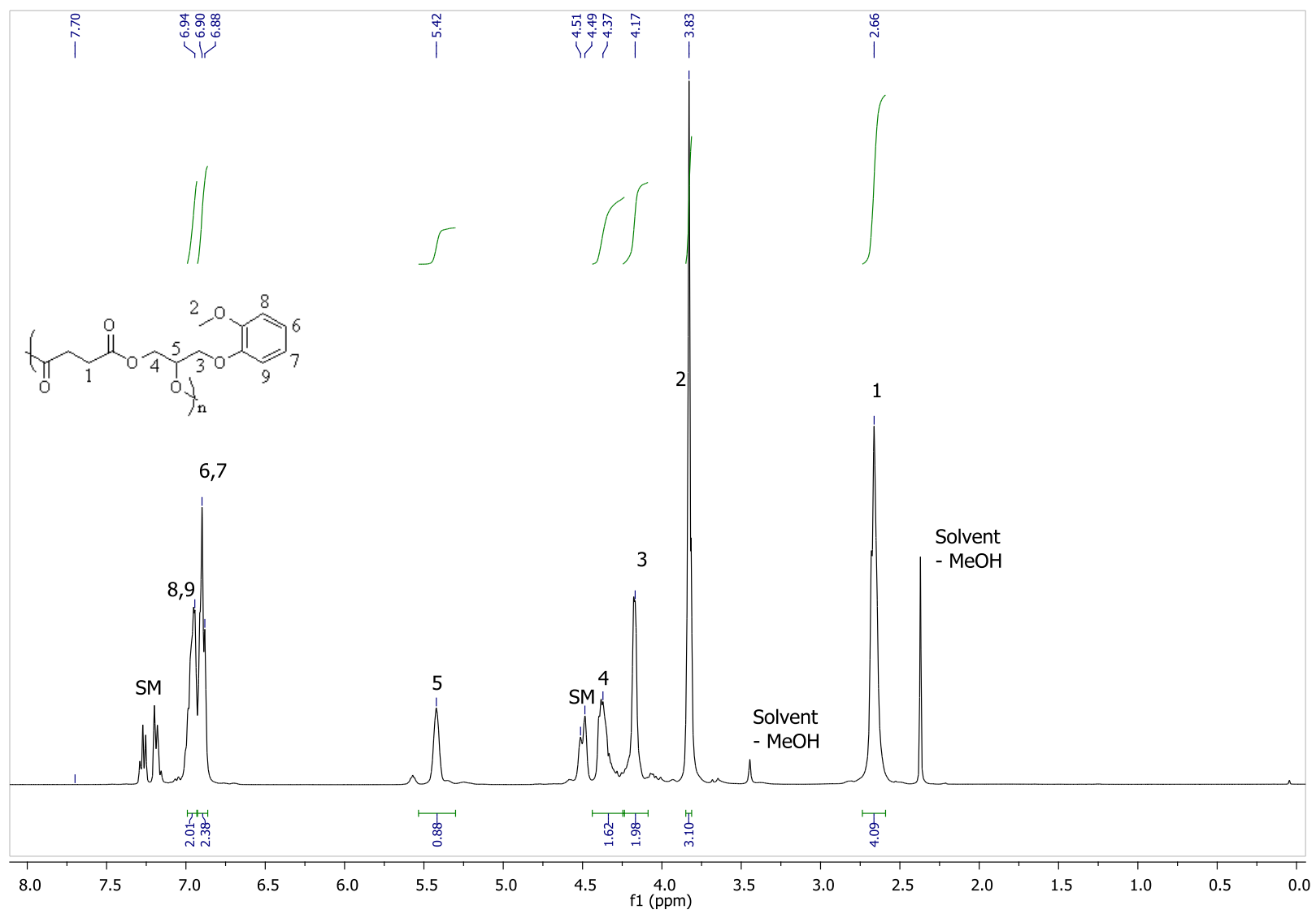


A.22.2. ${ }^{13} \mathrm{C}$ NMR of polyester resin (51) from 3-(2-methoxyphenoxy)propane-1,2-diol (26) and $\underline{\text { succinic acid (50) }}$

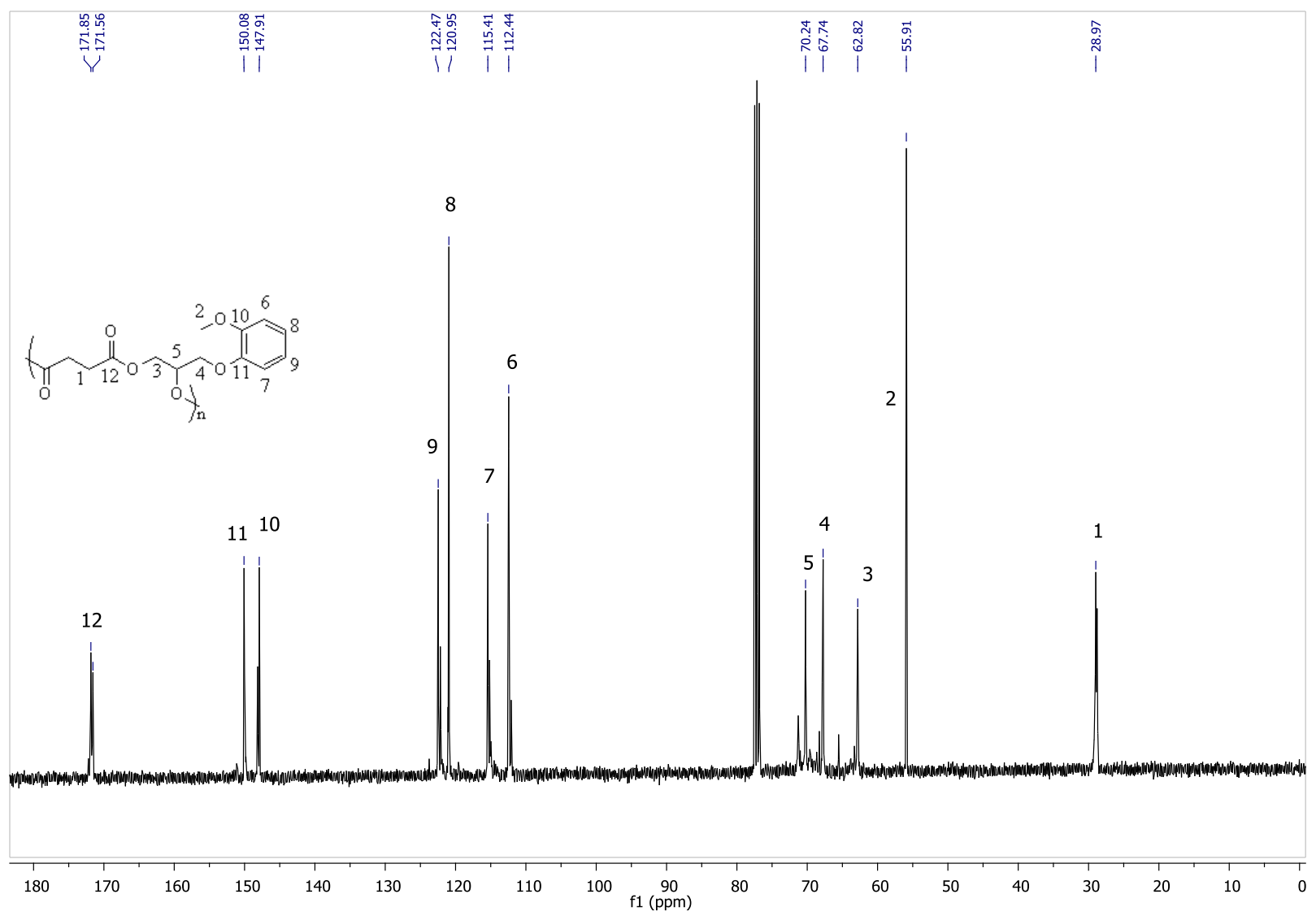


A.23.1. ${ }^{1}$ H NMR of polyester resin (53) from 3-(2-methoxyphenoxy)propane-1,2-diol (26) and terephathalic acid (52)

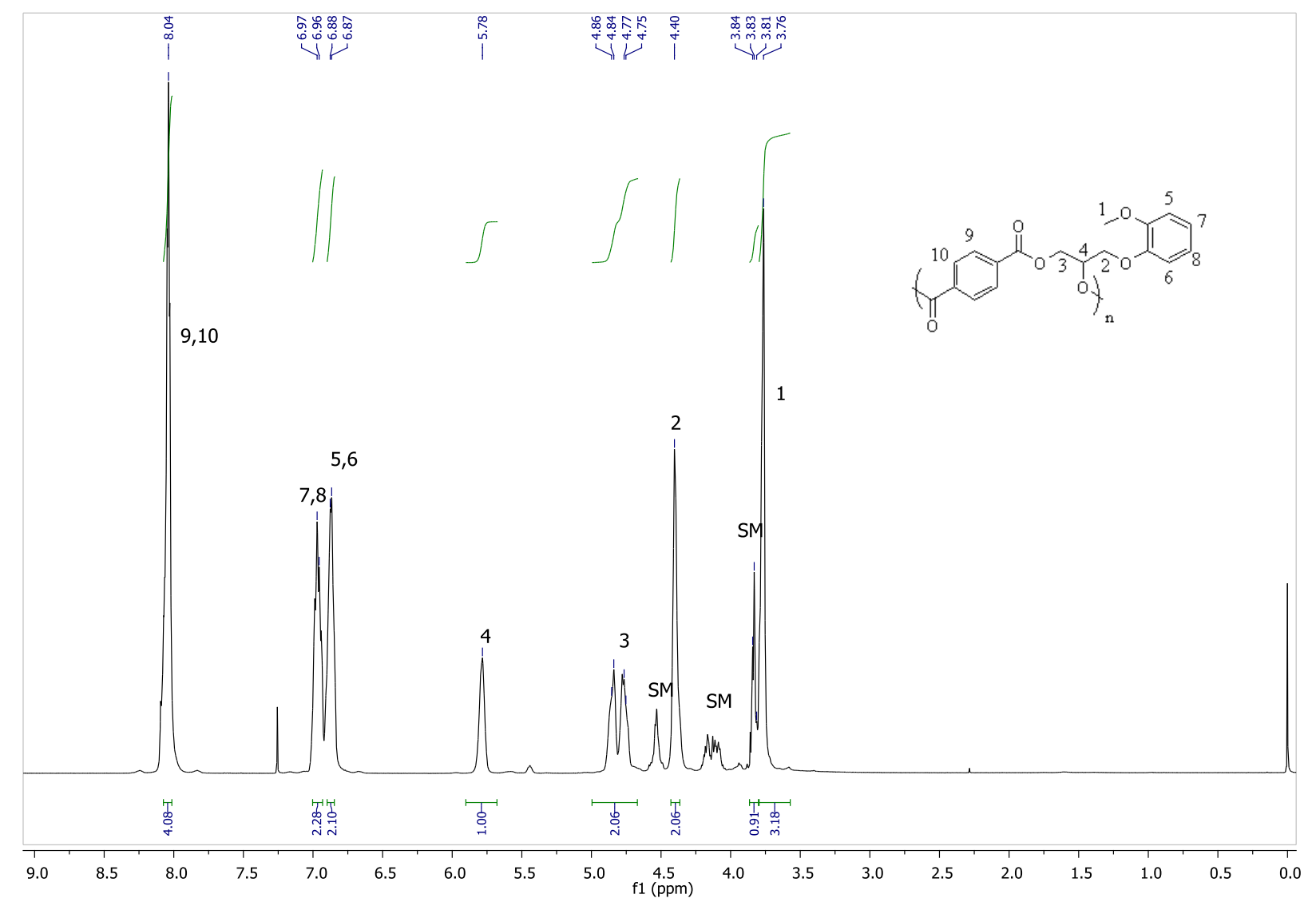


A.23.2. ${ }^{13} \mathrm{C}$ NMR of polyester resin (53) from 3-(2-methoxyphenoxy)propane-1,2-diol (26) and terephathalic acid (52)

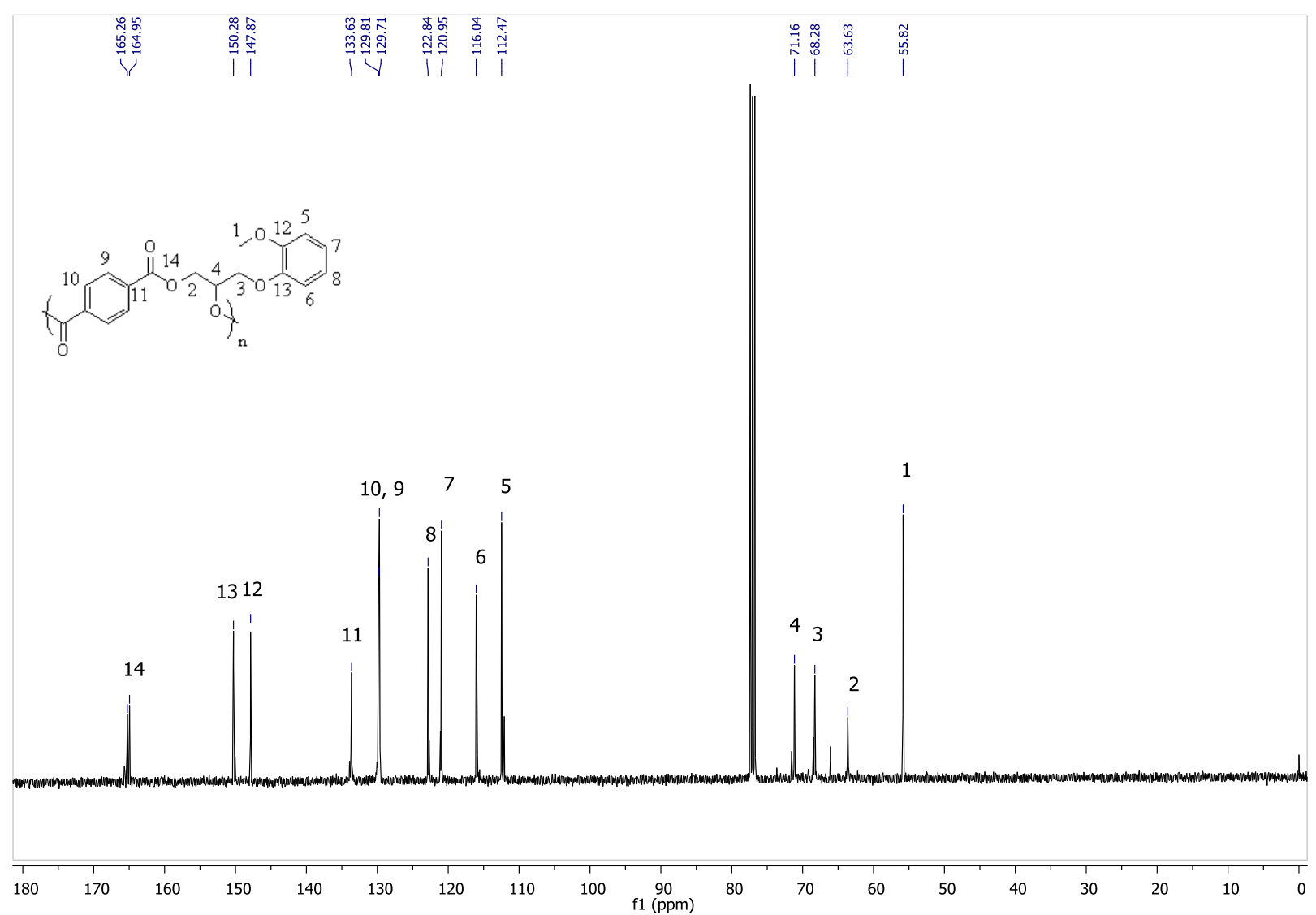


A.24.1. ${ }^{1} \mathrm{H}$ NMR of polyester resin (55) from 3-(2-methoxyphenoxy)propane-1,2-diol (26) and isoterephathalic acid (54)

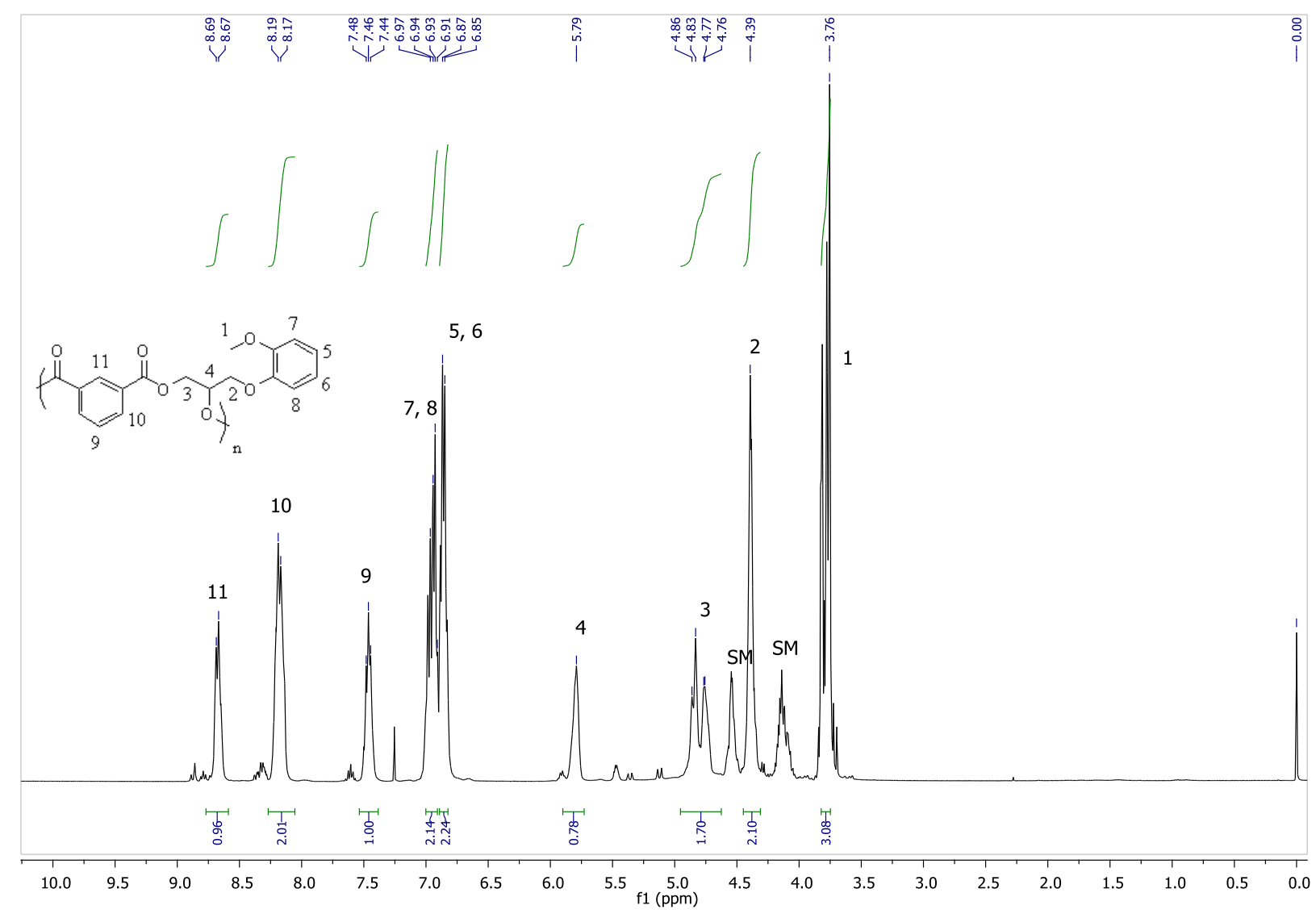


A.24.2. ${ }^{12} \mathrm{C}$ NMR of polyester resin (55) from 3-(2-methoxyphenoxy)propane-1,2-diol (26) and isoterephathalic acid (54)

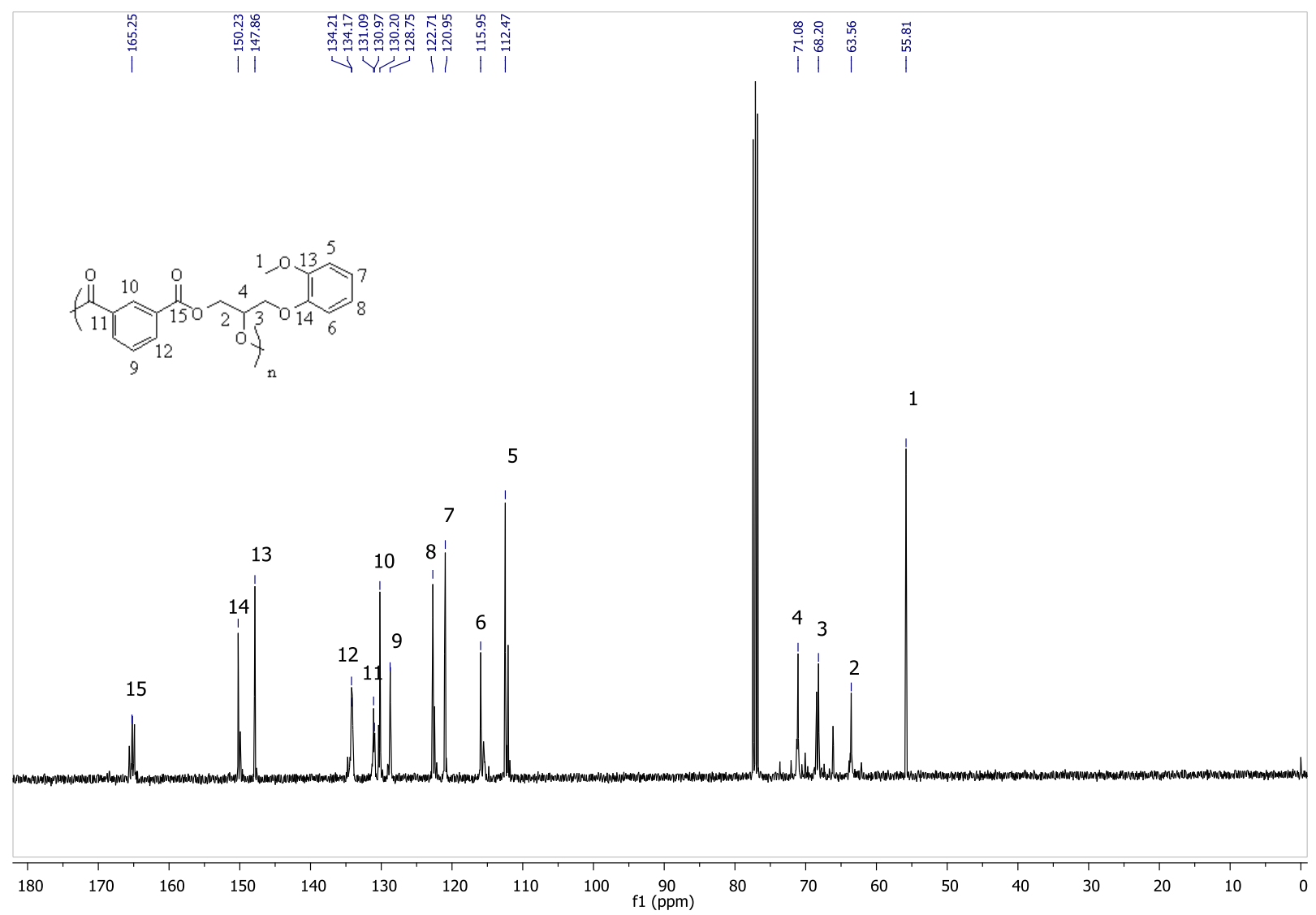


A.25.1 ${ }^{1} \mathrm{H}$ NMR of a polyester based resin (51) from 3-(2-methoxyphenoxy)propane-1,2-diol (26) and succinic acid (50) employing (56)

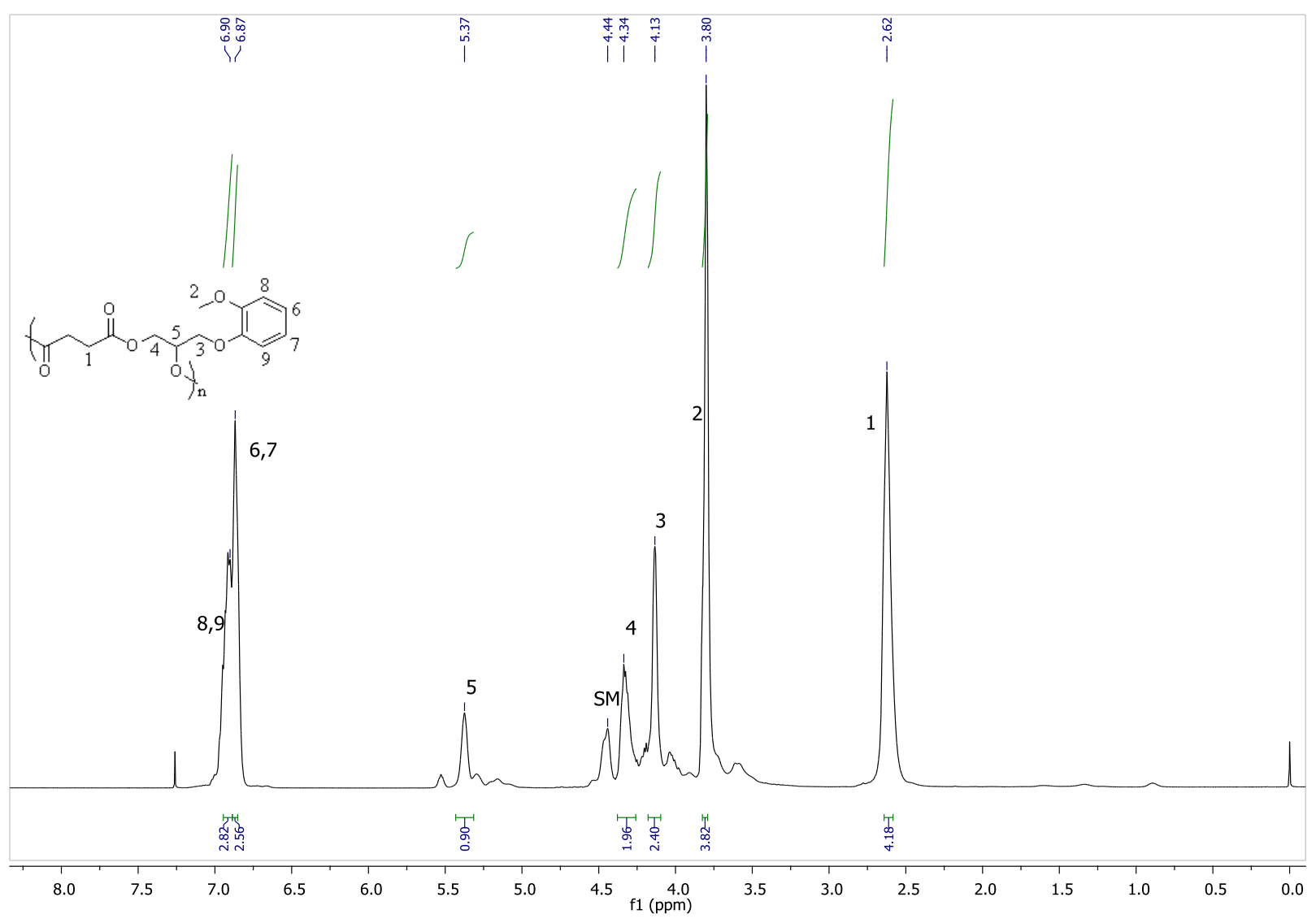


A.26.1 ${ }^{1} \mathrm{H}$ NMR of polyester resin (58) from 3-(4-allylphenoxy)propane-1,2-diol (16) and succinic acid (50)

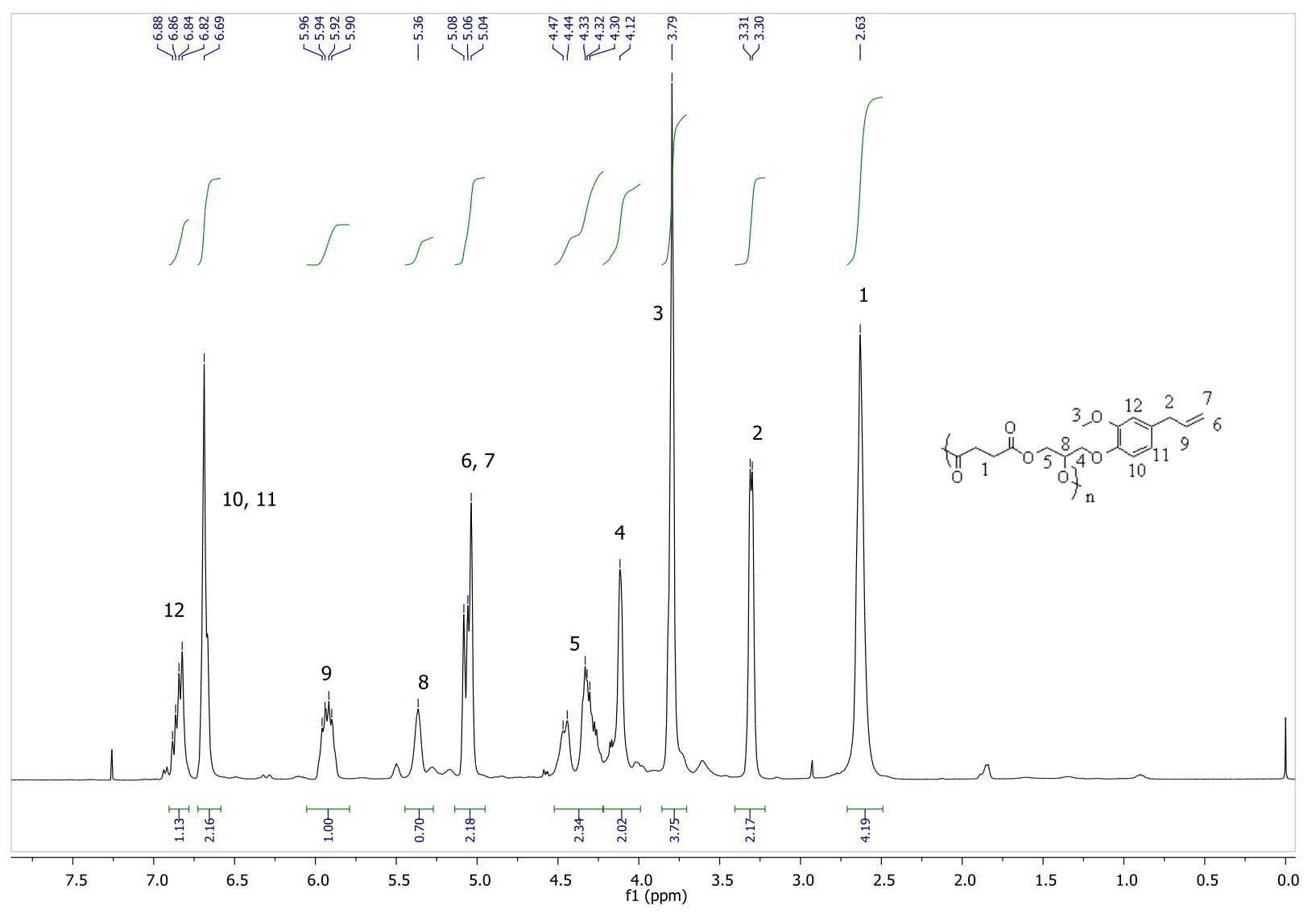


A.26.2 ${ }^{13} \mathrm{C}$ NMR of polyester resin (58) from 3-(4-allylphenoxy)propane-1,2-diol (16) and succinic acid (50)

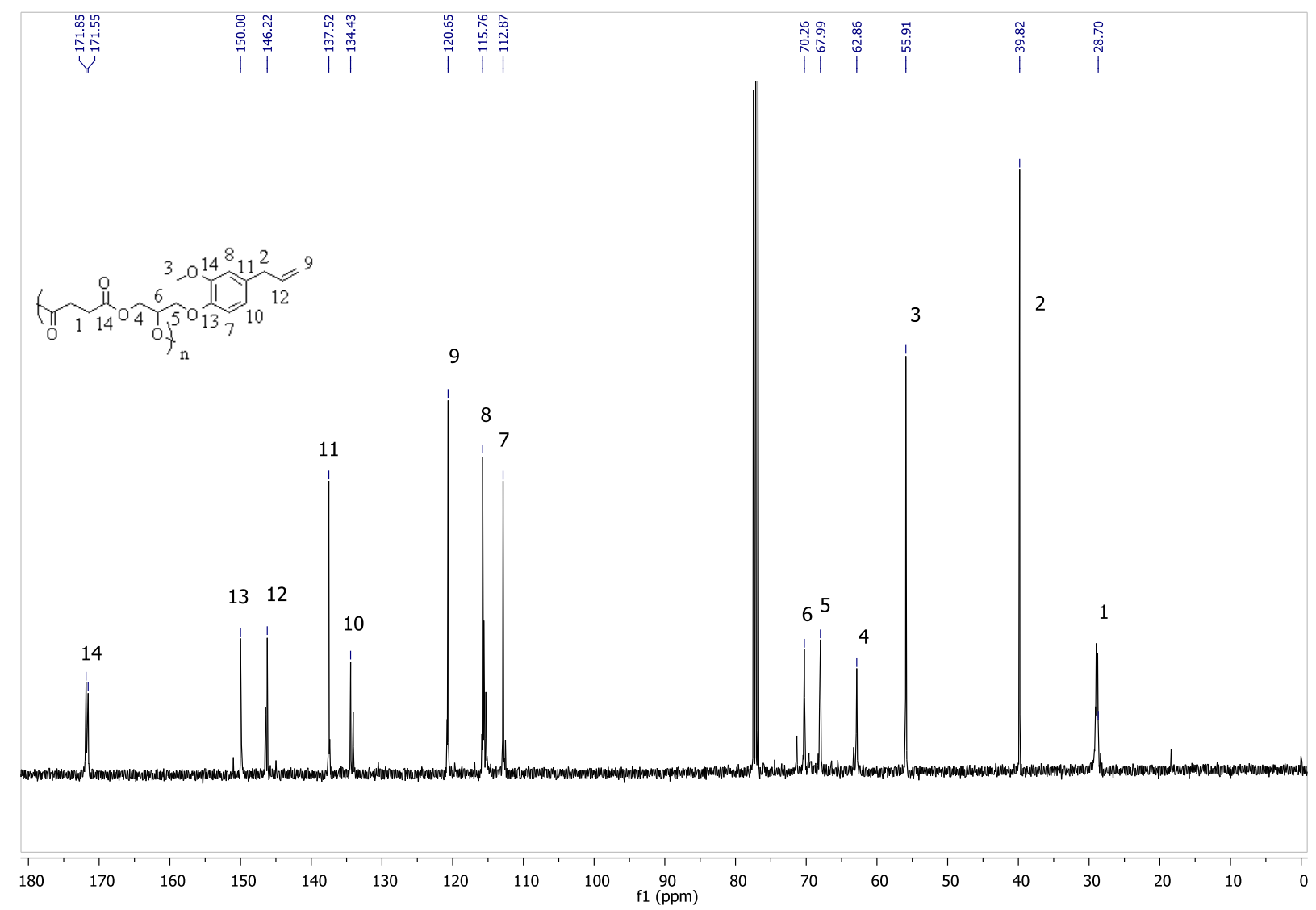




\section{A.27.1 ${ }^{1} \mathrm{H}$ NMR of resin (59) from 4-(2,3-dihydroxypropoxy)benzaldehyde (31)}

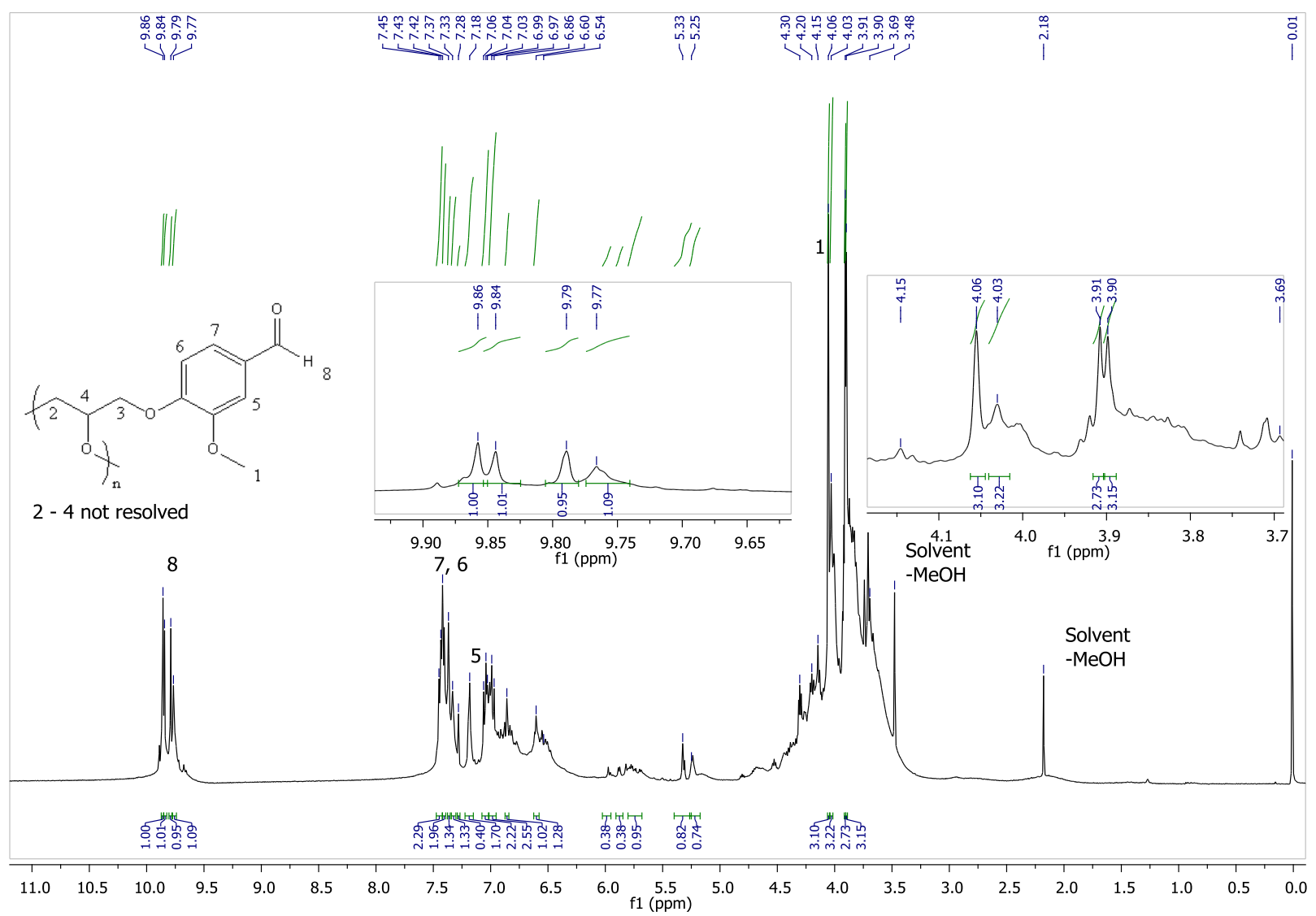


$\underline{\text { A.27.2 }}{ }^{13}$ C NMR of resin (59) from 4-(2,3-dihydroxypropoxy)benzaldehyde (31)

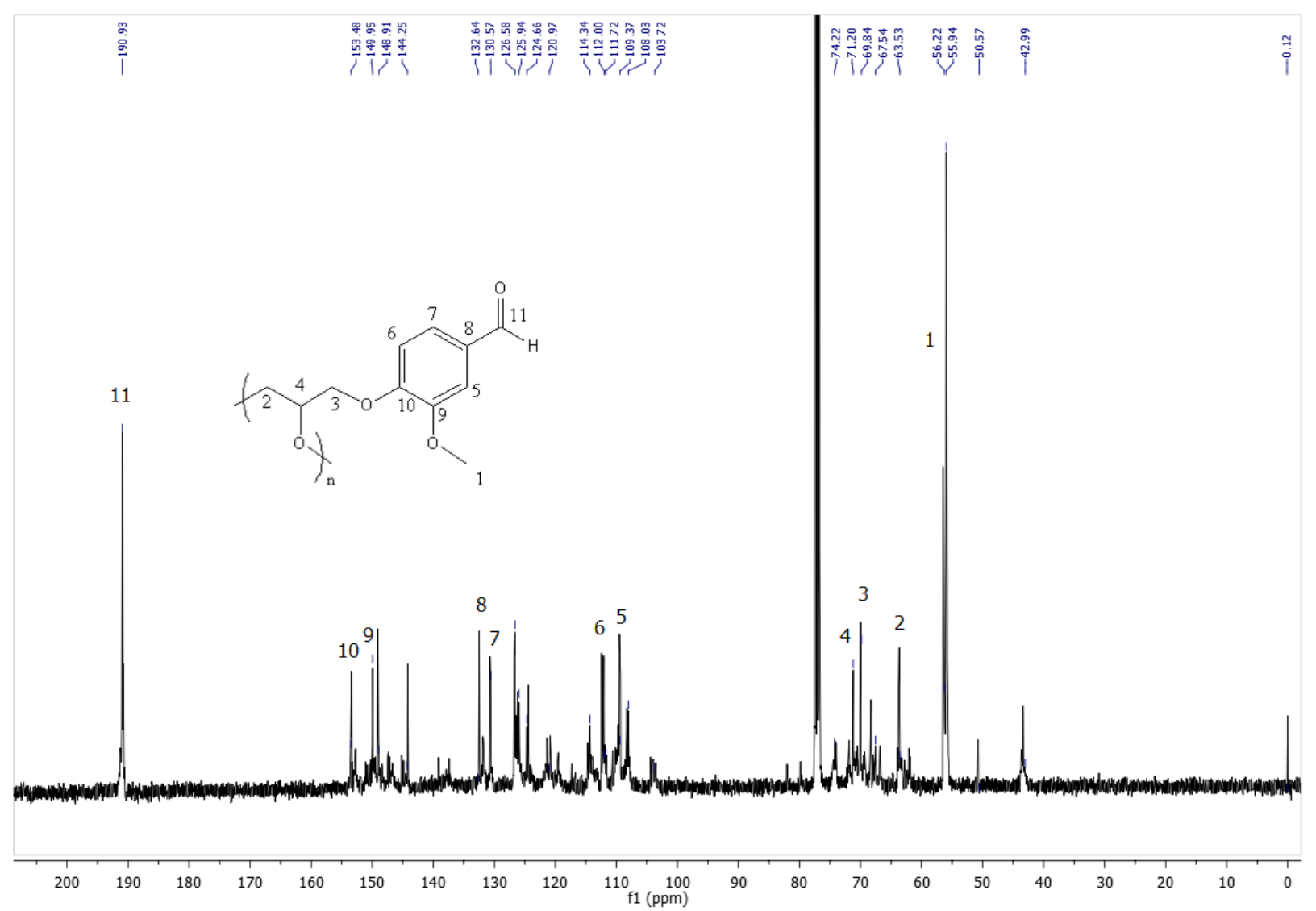




\section{$\underline{\text { Appendix B }}$}

\section{B.1 X-Ray Crystallography results for 4-(2-(2-methoxyphenoxy)ethyl)phenol (13)}

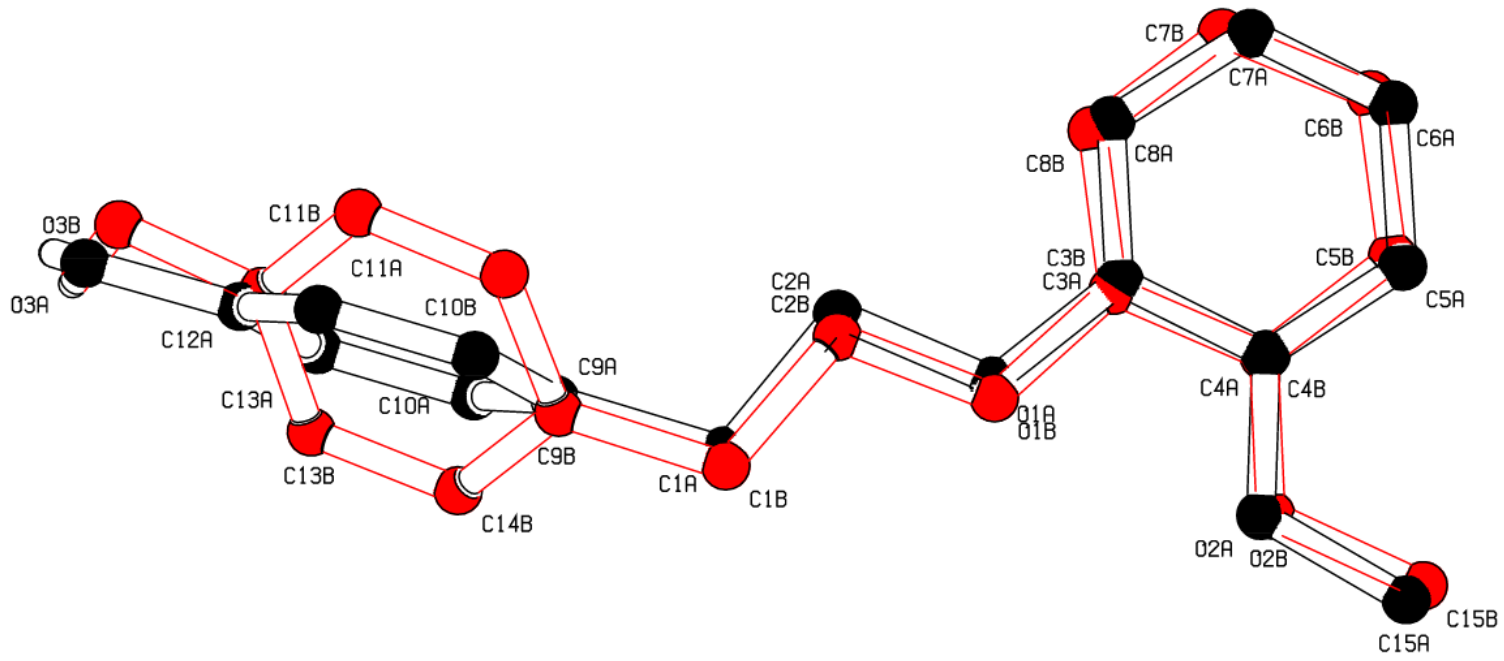

Table 1. Crystal data and structure refinement for d 12244 .

Identification code

d12244

Empirical formula

C15 H16 O3

Formula weight

244.28

Temperature

200(2) K

Wavelength

$1.54178 \AA$

Crystal system

Monoclinic

Space group

P 21/c

Unit cell dimensions

$\mathrm{a}=21.7909(5) \AA$

$\alpha=90^{\circ}$.

$\mathrm{b}=5.7689(1) \AA$

$\beta=116.919(1)^{\circ}$.

$\mathrm{c}=23.0966(6) \AA$

$\gamma=90^{\circ}$.

Volume

2588.86(10) $\AA^{3}$

Z 
Density (calculated)

Absorption coefficient

$\mathrm{F}(000)$

Crystal size

Theta range for data collection

Index ranges

Reflections collected

Independent reflections

Completeness to theta $=66.34^{\circ}$

Absorption correction

Max. and min. transmission

Refinement method

Data / restraints / parameters

Goodness-of-fit on $\mathrm{F}^{2}$

Final $R$ indices [I $>2 \operatorname{sigma}(\mathrm{I})]$

$\mathrm{R}$ indices (all data)

Largest diff. peak and hole
$1.253 \mathrm{Mg} / \mathrm{m}^{3}$

$0.702 \mathrm{~mm}^{-1}$

1040

$0.20 \times 0.16 \times 0.06 \mathrm{~mm}^{3}$

4.29 to $66.34^{\circ}$.

$-25<=\mathrm{h}<=25,-6<=\mathrm{k}<=2,-26<=1<=27$

17277

$4426[\mathrm{R}($ int $)=0.0378]$

$97.5 \%$

Semi-empirical from equivalents

0.7528 and 0.6610

Full-matrix least-squares on $\mathrm{F}^{2}$

4426 / 0 / 335

1.043

$\mathrm{R} 1=0.0389, \mathrm{wR} 2=0.1036$

$\mathrm{R} 1=0.0449, \mathrm{wR} 2=0.1082$

0.178 and -0.175 e. $\AA^{-3}$ 
Table 2. Atomic coordinates ( $\mathrm{x} 10^{4}$ ) and equivalent isotropic displacement parameters $\left(\AA^{2} \times 10^{3}\right)$ for $\mathrm{d} 12244$. $\mathrm{U}(\mathrm{eq})$ is defined as one third of the trace of the orthogonalized $\mathrm{U}^{\mathrm{ij}}$ tensor.

\begin{tabular}{|c|c|c|c|c|}
\hline & $\mathrm{x}$ & $\mathrm{y}$ & $\mathrm{z}$ & $\mathrm{U}(\mathrm{eq})$ \\
\hline $\mathrm{O}(1 \mathrm{~B})$ & $5955(1)$ & 1522(2) & $3988(1)$ & $46(1)$ \\
\hline $\mathrm{O}(2 \mathrm{~B})$ & $5345(1)$ & 4942(2) & $4214(1)$ & $49(1)$ \\
\hline $\mathrm{O}(3 \mathrm{~B})$ & $8505(1)$ & $-6217(2)$ & 3491(1) & $55(1)$ \\
\hline $\mathrm{C}(1 \mathrm{~B})$ & 7021(1) & $-608(3)$ & $4435(1)$ & $45(1)$ \\
\hline $\mathrm{C}(2 \mathrm{~B})$ & 6321(1) & $-296(3)$ & $3854(1)$ & $46(1)$ \\
\hline $\mathrm{C}(3 \mathrm{~B})$ & $5276(1)$ & 1831(2) & $3542(1)$ & $40(1)$ \\
\hline $\mathrm{C}(4 \mathrm{~B})$ & 4944(1) & $3669(2)$ & $3682(1)$ & $40(1)$ \\
\hline$C(5 B)$ & $4249(1)$ & 4034(3) & $3285(1)$ & $49(1)$ \\
\hline$C(6 B)$ & $3890(1)$ & 2594(3) & 2754(1) & $52(1)$ \\
\hline$C(7 B)$ & $4224(1)$ & $833(3)$ & $2615(1)$ & $54(1)$ \\
\hline $\mathrm{C}(8 \mathrm{~B})$ & 4921(1) & $450(3)$ & $3006(1)$ & $49(1)$ \\
\hline C(9B) & $7458(1)$ & $-2150(3)$ & $4246(1)$ & $41(1)$ \\
\hline$C(10 B)$ & $7234(1)$ & $-4353(2)$ & $3996(1)$ & $45(1)$ \\
\hline$C(11 B)$ & $7584(1)$ & $-5674(3)$ & $3744(1)$ & $45(1)$ \\
\hline$C(12 B)$ & $8182(1)$ & $-4838(3)$ & $3750(1)$ & $42(1)$ \\
\hline$C(13 B)$ & $8427(1)$ & $-2673(3)$ & 4014(1) & $42(1)$ \\
\hline$C(14 B)$ & $8066(1)$ & $-1361(3)$ & $4258(1)$ & $43(1)$ \\
\hline$C(15 B)$ & $5018(1)$ & $6749(3)$ & $4396(1)$ & $56(1)$ \\
\hline $\mathrm{O}(1 \mathrm{~A})$ & 777(1) & $2647(2)$ & $1959(1)$ & $56(1)$ \\
\hline $\mathrm{O}(2 \mathrm{~A})$ & 112(1) & $-305(2)$ & $1076(1)$ & $69(1)$ \\
\hline $\mathrm{O}(3 \mathrm{~A})$ & $3832(1)$ & 9151(2) & $4716(1)$ & $52(1)$ \\
\hline$C(1 \mathrm{~A})$ & $1930(1)$ & $3600(3)$ & 2663(1) & $58(1)$ \\
\hline$C(2 A)$ & 1192(1) & 4305(3) & $2445(1)$ & $50(1)$ \\
\hline $\mathrm{C}(3 \mathrm{~A})$ & $76(1)$ & 2871(3) & $1683(1)$ & $51(1)$ \\
\hline $\mathrm{C}(4 \mathrm{~A})$ & $-290(1)$ & 1261(3) & $1197(1)$ & $53(1)$ \\
\hline$C(5 A)$ & $-1000(1)$ & $1315(4)$ & $880(1)$ & $68(1)$ \\
\hline$C(6 A)$ & $-1348(1)$ & 2957(4) & $1050(1)$ & $82(1)$ \\
\hline $\mathrm{C}(7 \mathrm{~A})$ & $-994(1)$ & 4509(5) & $1526(1)$ & $86(1)$ \\
\hline $\mathrm{C}(8 \mathrm{~A})$ & $-275(1)$ & 4497(4) & $1849(1)$ & $69(1)$ \\
\hline$C(9 A)$ & 2431(1) & 5064(3) & $3218(1)$ & $44(1)$ \\
\hline$C(10 A)$ & $2660(1)$ & 7172(3) & $3103(1)$ & $49(1)$ \\
\hline
\end{tabular}




\begin{tabular}{lrrrr}
$\mathrm{C}(11 \mathrm{~A})$ & $3122(1)$ & $8526(3)$ & $3605(1)$ & $46(1)$ \\
$\mathrm{C}(12 \mathrm{~A})$ & $3362(1)$ & $7772(2)$ & $4237(1)$ & $40(1)$ \\
$\mathrm{C}(13 \mathrm{~A})$ & $3143(1)$ & $5678(3)$ & $4366(1)$ & $43(1)$ \\
$\mathrm{C}(14 \mathrm{~A})$ & $2679(1)$ & $4341(3)$ & $3855(1)$ & $46(1)$ \\
$\mathrm{C}(15 \mathrm{~A})$ & $-221(1)$ & $-1955(4)$ & $566(1)$ & $89(1)$ \\
\hline
\end{tabular}


Table 3. Bond lengths $[\AA]$ and angles $\left[{ }^{\circ}\right]$ for $\mathrm{d} 12244$.

\begin{tabular}{|c|c|}
\hline $\mathrm{O}(1 \mathrm{~B})-\mathrm{C}(3 \mathrm{~B})$ & $1.3798(17)$ \\
\hline $\mathrm{O}(1 \mathrm{~B})-\mathrm{C}(2 \mathrm{~B})$ & $1.4333(17)$ \\
\hline $\mathrm{O}(2 \mathrm{~B})-\mathrm{C}(4 \mathrm{~B})$ & $1.3579(17)$ \\
\hline $\mathrm{O}(2 \mathrm{~B})-\mathrm{C}(15 \mathrm{~B})$ & $1.4291(18)$ \\
\hline $\mathrm{O}(3 \mathrm{~B})-\mathrm{C}(12 \mathrm{~B})$ & $1.3681(18)$ \\
\hline $\mathrm{O}(3 \mathrm{~B})-\mathrm{H}(3 \mathrm{OB})$ & $0.87(3)$ \\
\hline $\mathrm{C}(1 \mathrm{~B})-\mathrm{C}(9 \mathrm{~B})$ & $1.506(2)$ \\
\hline $\mathrm{C}(1 \mathrm{~B})-\mathrm{C}(2 \mathrm{~B})$ & $1.519(2)$ \\
\hline $\mathrm{C}(1 \mathrm{~B})-\mathrm{H}(1 \mathrm{BA})$ & 0.9900 \\
\hline $\mathrm{C}(1 \mathrm{~B})-\mathrm{H}(1 \mathrm{BB})$ & 0.9900 \\
\hline $\mathrm{C}(2 \mathrm{~B})-\mathrm{H}(2 \mathrm{BA})$ & 0.9900 \\
\hline $\mathrm{C}(2 \mathrm{~B})-\mathrm{H}(2 \mathrm{BB})$ & 0.9900 \\
\hline $\mathrm{C}(3 \mathrm{~B})-\mathrm{C}(8 \mathrm{~B})$ & $1.377(2)$ \\
\hline $\mathrm{C}(3 \mathrm{~B})-\mathrm{C}(4 \mathrm{~B})$ & $1.401(2)$ \\
\hline $\mathrm{C}(4 \mathrm{~B})-\mathrm{C}(5 \mathrm{~B})$ & $1.386(2)$ \\
\hline $\mathrm{C}(5 \mathrm{~B})-\mathrm{C}(6 \mathrm{~B})$ & $1.393(2)$ \\
\hline $\mathrm{C}(5 \mathrm{~B})-\mathrm{H}(5 \mathrm{BA})$ & 0.9500 \\
\hline $\mathrm{C}(6 \mathrm{~B})-\mathrm{C}(7 \mathrm{~B})$ & $1.370(2)$ \\
\hline $\mathrm{C}(6 \mathrm{~B})-\mathrm{H}(6 \mathrm{BA})$ & 0.9500 \\
\hline $\mathrm{C}(7 \mathrm{~B})-\mathrm{C}(8 \mathrm{~B})$ & $1.388(2)$ \\
\hline $\mathrm{C}(7 \mathrm{~B})-\mathrm{H}(7 \mathrm{BA})$ & 0.9500 \\
\hline $\mathrm{C}(8 \mathrm{~B})-\mathrm{H}(8 \mathrm{BA})$ & 0.9500 \\
\hline$C(9 B)-C(14 B)$ & $1.389(2)$ \\
\hline $\mathrm{C}(9 \mathrm{~B})-\mathrm{C}(10 \mathrm{~B})$ & $1.390(2)$ \\
\hline $\mathrm{C}(10 \mathrm{~B})-\mathrm{C}(11 \mathrm{~B})$ & $1.379(2)$ \\
\hline $\mathrm{C}(10 \mathrm{~B})-\mathrm{H}(10 \mathrm{~A})$ & 0.9500 \\
\hline $\mathrm{C}(11 \mathrm{~B})-\mathrm{C}(12 \mathrm{~B})$ & $1.382(2)$ \\
\hline $\mathrm{C}(11 \mathrm{~B})-\mathrm{H}(11 \mathrm{~A})$ & 0.9500 \\
\hline $\mathrm{C}(12 \mathrm{~B})-\mathrm{C}(13 \mathrm{~B})$ & $1.386(2)$ \\
\hline $\mathrm{C}(13 \mathrm{~B})-\mathrm{C}(14 \mathrm{~B})$ & $1.381(2)$ \\
\hline $\mathrm{C}(13 \mathrm{~B})-\mathrm{H}(13 \mathrm{~A})$ & 0.9500 \\
\hline $\mathrm{C}(14 \mathrm{~B})-\mathrm{H}(14 \mathrm{~A})$ & 0.9500 \\
\hline $\mathrm{C}(15 \mathrm{~B})-\mathrm{H}(15 \mathrm{~A})$ & 0.9800 \\
\hline $\mathrm{C}(15 \mathrm{~B})-\mathrm{H}(15 \mathrm{~B})$ & 0.9800 \\
\hline
\end{tabular}




\begin{tabular}{|c|c|}
\hline $\mathrm{C}(3 \mathrm{~B})-\mathrm{O}(1 \mathrm{~B})-\mathrm{C}(2 \mathrm{~B})$ & $116.50(11)$ \\
\hline $\mathrm{C}(4 \mathrm{~B})-\mathrm{O}(2 \mathrm{~B})-\mathrm{C}(15 \mathrm{~B})$ & $117.33(11)$ \\
\hline $\mathrm{C}(12 \mathrm{~B})-\mathrm{O}(3 \mathrm{~B})-\mathrm{H}(3 \mathrm{OB})$ & $107.7(16)$ \\
\hline $\mathrm{C}(9 \mathrm{~B})-\mathrm{C}(1 \mathrm{~B})-\mathrm{C}(2 \mathrm{~B})$ & $109.16(12)$ \\
\hline $\mathrm{C}(9 \mathrm{~B})-\mathrm{C}(1 \mathrm{~B})-\mathrm{H}(1 \mathrm{BA})$ & 109.8 \\
\hline $\mathrm{C}(2 \mathrm{~B})-\mathrm{C}(1 \mathrm{~B})-\mathrm{H}(1 \mathrm{BA})$ & 109.8 \\
\hline $\mathrm{C}(9 \mathrm{~B})-\mathrm{C}(1 \mathrm{~B})-\mathrm{H}(1 \mathrm{BB})$ & 109.8 \\
\hline $\mathrm{C}(2 \mathrm{~B})-\mathrm{C}(1 \mathrm{~B})-\mathrm{H}(1 \mathrm{BB})$ & 109.8 \\
\hline $\mathrm{H}(1 \mathrm{BA})-\mathrm{C}(1 \mathrm{~B})-\mathrm{H}(1 \mathrm{BB})$ & 108.3 \\
\hline $\mathrm{O}(1 \mathrm{~B})-\mathrm{C}(2 \mathrm{~B})-\mathrm{C}(1 \mathrm{~B})$ & $109.28(12)$ \\
\hline $\mathrm{O}(1 \mathrm{~B})-\mathrm{C}(2 \mathrm{~B})-\mathrm{H}(2 \mathrm{BA})$ & 109.8 \\
\hline$C(1 B)-C(2 B)-H(2 B A)$ & 109.8 \\
\hline $\mathrm{O}(1 \mathrm{~B})-\mathrm{C}(2 \mathrm{~B})-\mathrm{H}(2 \mathrm{BB})$ & 109.8 \\
\hline $\mathrm{C}(1 \mathrm{~B})-\mathrm{C}(2 \mathrm{~B})-\mathrm{H}(2 \mathrm{BB})$ & 109.8 \\
\hline $\mathrm{H}(2 \mathrm{BA})-\mathrm{C}(2 \mathrm{~B})-\mathrm{H}(2 \mathrm{BB})$ & 108.3 \\
\hline $\mathrm{C}(8 \mathrm{~B})-\mathrm{C}(3 \mathrm{~B})-\mathrm{O}(1 \mathrm{~B})$ & $124.97(13)$ \\
\hline $\mathrm{C}(8 \mathrm{~B})-\mathrm{C}(3 \mathrm{~B})-\mathrm{C}(4 \mathrm{~B})$ & $120.40(13)$ \\
\hline $\mathrm{O}(1 \mathrm{~B})-\mathrm{C}(3 \mathrm{~B})-\mathrm{C}(4 \mathrm{~B})$ & $114.59(12)$ \\
\hline $\mathrm{O}(2 \mathrm{~B})-\mathrm{C}(4 \mathrm{~B})-\mathrm{C}(5 \mathrm{~B})$ & $125.34(13)$ \\
\hline $\mathrm{O}(2 \mathrm{~B})-\mathrm{C}(4 \mathrm{~B})-\mathrm{C}(3 \mathrm{~B})$ & $115.55(12)$ \\
\hline $\mathrm{C}(5 \mathrm{~B})-\mathrm{C}(4 \mathrm{~B})-\mathrm{C}(3 \mathrm{~B})$ & $119.10(13)$ \\
\hline$C(4 B)-C(5 B)-C(6 B)$ & $120.10(15)$ \\
\hline $\mathrm{C}(4 \mathrm{~B})-\mathrm{C}(5 \mathrm{~B})-\mathrm{H}(5 \mathrm{BA})$ & 119.9 \\
\hline $\mathrm{C}(6 \mathrm{~B})-\mathrm{C}(5 \mathrm{~B})-\mathrm{H}(5 \mathrm{BA})$ & 119.9 \\
\hline$C(7 B)-C(6 B)-C(5 B)$ & $120.13(14)$ \\
\hline$C(7 B)-C(6 B)-H(6 B A)$ & 119.9 \\
\hline $\mathrm{C}(5 \mathrm{~B})-\mathrm{C}(6 \mathrm{~B})-\mathrm{H}(6 \mathrm{BA})$ & 119.9 \\
\hline$C(6 B)-C(7 B)-C(8 B)$ & $120.44(15)$ \\
\hline $\mathrm{C}(6 \mathrm{~B})-\mathrm{C}(7 \mathrm{~B})-\mathrm{H}(7 \mathrm{BA})$ & 119.8 \\
\hline $\mathrm{C}(8 \mathrm{~B})-\mathrm{C}(7 \mathrm{~B})-\mathrm{H}(7 \mathrm{BA})$ & 119.8 \\
\hline$C(3 B)-C(8 B)-C(7 B)$ & $119.78(15)$ \\
\hline $\mathrm{C}(3 \mathrm{~B})-\mathrm{C}(8 \mathrm{~B})-\mathrm{H}(8 \mathrm{BA})$ & 120.1 \\
\hline $\mathrm{C}(7 \mathrm{~B})-\mathrm{C}(8 \mathrm{~B})-\mathrm{H}(8 \mathrm{BA})$ & 120.1 \\
\hline $\mathrm{C}(14 \mathrm{~B})-\mathrm{C}(9 \mathrm{~B})-\mathrm{C}(10 \mathrm{~B})$ & $117.45(14)$ \\
\hline$C(14 B)-C(9 B)-C(1 B)$ & $121.57(14)$ \\
\hline
\end{tabular}




\begin{tabular}{|c|c|}
\hline $\mathrm{C}(10 \mathrm{~B})-\mathrm{C}(9 \mathrm{~B})-\mathrm{C}(1 \mathrm{~B})$ & $120.73(14)$ \\
\hline$C(11 B)-C(10 B)-C(9 B)$ & $121.49(14)$ \\
\hline $\mathrm{C}(11 \mathrm{~B})-\mathrm{C}(10 \mathrm{~B})-\mathrm{H}(10 \mathrm{~A})$ & 119.3 \\
\hline $\mathrm{C}(9 \mathrm{~B})-\mathrm{C}(10 \mathrm{~B})-\mathrm{H}(10 \mathrm{~A})$ & 119.3 \\
\hline $\mathrm{C}(10 \mathrm{~B})-\mathrm{C}(11 \mathrm{~B})-\mathrm{C}(12 \mathrm{~B})$ & $120.10(14)$ \\
\hline$C(10 B)-C(11 B)-H(11 A)$ & 120.0 \\
\hline $\mathrm{C}(12 \mathrm{~B})-\mathrm{C}(11 \mathrm{~B})-\mathrm{H}(11 \mathrm{~A})$ & 120.0 \\
\hline $\mathrm{O}(3 \mathrm{~B})-\mathrm{C}(12 \mathrm{~B})-\mathrm{C}(11 \mathrm{~B})$ & $117.54(14)$ \\
\hline $\mathrm{O}(3 \mathrm{~B})-\mathrm{C}(12 \mathrm{~B})-\mathrm{C}(13 \mathrm{~B})$ & $122.95(14)$ \\
\hline $\mathrm{C}(11 \mathrm{~B})-\mathrm{C}(12 \mathrm{~B})-\mathrm{C}(13 \mathrm{~B})$ & $119.51(14)$ \\
\hline $\mathrm{C}(14 \mathrm{~B})-\mathrm{C}(13 \mathrm{~B})-\mathrm{C}(12 \mathrm{~B})$ & $119.72(14)$ \\
\hline $\mathrm{C}(14 \mathrm{~B})-\mathrm{C}(13 \mathrm{~B})-\mathrm{H}(13 \mathrm{~A})$ & 120.1 \\
\hline $\mathrm{C}(12 \mathrm{~B})-\mathrm{C}(13 \mathrm{~B})-\mathrm{H}(13 \mathrm{~A})$ & 120.1 \\
\hline $\mathrm{C}(13 \mathrm{~B})-\mathrm{C}(14 \mathrm{~B})-\mathrm{C}(9 \mathrm{~B})$ & $121.69(14)$ \\
\hline $\mathrm{C}(13 \mathrm{~B})-\mathrm{C}(14 \mathrm{~B})-\mathrm{H}(14 \mathrm{~A})$ & 119.2 \\
\hline $\mathrm{C}(9 \mathrm{~B})-\mathrm{C}(14 \mathrm{~B})-\mathrm{H}(14 \mathrm{~A})$ & 119.2 \\
\hline $\mathrm{O}(2 \mathrm{~B})-\mathrm{C}(15 \mathrm{~B})-\mathrm{H}(15 \mathrm{~A})$ & 109.5 \\
\hline $\mathrm{O}(2 \mathrm{~B})-\mathrm{C}(15 \mathrm{~B})-\mathrm{H}(15 \mathrm{~B})$ & 109.5 \\
\hline $\mathrm{H}(15 \mathrm{~A})-\mathrm{C}(15 \mathrm{~B})-\mathrm{H}(15 \mathrm{~B})$ & 109.5 \\
\hline $\mathrm{O}(2 \mathrm{~B})-\mathrm{C}(15 \mathrm{~B})-\mathrm{H}(15 \mathrm{C})$ & 109.5 \\
\hline $\mathrm{H}(15 \mathrm{~A})-\mathrm{C}(15 \mathrm{~B})-\mathrm{H}(15 \mathrm{C})$ & 109.5 \\
\hline $\mathrm{H}(15 \mathrm{~B})-\mathrm{C}(15 \mathrm{~B})-\mathrm{H}(15 \mathrm{C})$ & 109.5 \\
\hline $\mathrm{C}(3 \mathrm{~A})-\mathrm{O}(1 \mathrm{~A})-\mathrm{C}(2 \mathrm{~A})$ & $118.38(12)$ \\
\hline $\mathrm{C}(4 \mathrm{~A})-\mathrm{O}(2 \mathrm{~A})-\mathrm{C}(15 \mathrm{~A})$ & $118.29(15)$ \\
\hline $\mathrm{C}(12 \mathrm{~A})-\mathrm{O}(3 \mathrm{~A})-\mathrm{H}(3 \mathrm{OA})$ & $108.6(16)$ \\
\hline$C(2 A)-C(1 A)-C(9 A)$ & $112.63(13)$ \\
\hline $\mathrm{C}(2 \mathrm{~A})-\mathrm{C}(1 \mathrm{~A})-\mathrm{H}(1 \mathrm{AA})$ & 109.1 \\
\hline $\mathrm{C}(9 \mathrm{~A})-\mathrm{C}(1 \mathrm{~A})-\mathrm{H}(1 \mathrm{AA})$ & 109.1 \\
\hline $\mathrm{C}(2 \mathrm{~A})-\mathrm{C}(1 \mathrm{~A})-\mathrm{H}(1 \mathrm{AB})$ & 109.1 \\
\hline $\mathrm{C}(9 \mathrm{~A})-\mathrm{C}(1 \mathrm{~A})-\mathrm{H}(1 \mathrm{AB})$ & 109.1 \\
\hline $\mathrm{H}(1 \mathrm{AA})-\mathrm{C}(1 \mathrm{~A})-\mathrm{H}(1 \mathrm{AB})$ & 107.8 \\
\hline $\mathrm{O}(1 \mathrm{~A})-\mathrm{C}(2 \mathrm{~A})-\mathrm{C}(1 \mathrm{~A})$ & $106.29(13)$ \\
\hline $\mathrm{O}(1 \mathrm{~A})-\mathrm{C}(2 \mathrm{~A})-\mathrm{H}(2 \mathrm{AA})$ & 110.5 \\
\hline$C(1 \mathrm{~A})-\mathrm{C}(2 \mathrm{~A})-\mathrm{H}(2 \mathrm{AA})$ & 110.5 \\
\hline $\mathrm{O}(1 \mathrm{~A})-\mathrm{C}(2 \mathrm{~A})-\mathrm{H}(2 \mathrm{AB})$ & 110.5 \\
\hline $\mathrm{C}(1 \mathrm{~A})-\mathrm{C}(2 \mathrm{~A})-\mathrm{H}(2 \mathrm{AB})$ & 110.5 \\
\hline
\end{tabular}




\begin{tabular}{|c|c|}
\hline $\mathrm{H}(2 \mathrm{AA})-\mathrm{C}(2 \mathrm{~A})-\mathrm{H}(2 \mathrm{AB})$ & 108.7 \\
\hline $\mathrm{O}(1 \mathrm{~A})-\mathrm{C}(3 \mathrm{~A})-\mathrm{C}(8 \mathrm{~A})$ & $125.51(15)$ \\
\hline $\mathrm{O}(1 \mathrm{~A})-\mathrm{C}(3 \mathrm{~A})-\mathrm{C}(4 \mathrm{~A})$ & $114.93(15)$ \\
\hline $\mathrm{C}(8 \mathrm{~A})-\mathrm{C}(3 \mathrm{~A})-\mathrm{C}(4 \mathrm{~A})$ & $119.56(16)$ \\
\hline $\mathrm{O}(2 \mathrm{~A})-\mathrm{C}(4 \mathrm{~A})-\mathrm{C}(5 \mathrm{~A})$ & $124.90(17)$ \\
\hline $\mathrm{O}(2 \mathrm{~A})-\mathrm{C}(4 \mathrm{~A})-\mathrm{C}(3 \mathrm{~A})$ & $114.73(14)$ \\
\hline $\mathrm{C}(5 \mathrm{~A})-\mathrm{C}(4 \mathrm{~A})-\mathrm{C}(3 \mathrm{~A})$ & $120.37(18)$ \\
\hline$C(6 A)-C(5 A)-C(4 A)$ & 119.62(19) \\
\hline $\mathrm{C}(6 \mathrm{~A})-\mathrm{C}(5 \mathrm{~A})-\mathrm{H}(5 \mathrm{AA})$ & 120.2 \\
\hline $\mathrm{C}(4 \mathrm{~A})-\mathrm{C}(5 \mathrm{~A})-\mathrm{H}(5 \mathrm{AA})$ & 120.2 \\
\hline$C(7 A)-C(6 A)-C(5 A)$ & $120.04(18)$ \\
\hline $\mathrm{C}(7 \mathrm{~A})-\mathrm{C}(6 \mathrm{~A})-\mathrm{H}(6 \mathrm{AA})$ & 120.0 \\
\hline $\mathrm{C}(5 \mathrm{~A})-\mathrm{C}(6 \mathrm{~A})-\mathrm{H}(6 \mathrm{AA})$ & 120.0 \\
\hline $\mathrm{C}(6 \mathrm{~A})-\mathrm{C}(7 \mathrm{~A})-\mathrm{C}(8 \mathrm{~A})$ & $121.3(2)$ \\
\hline $\mathrm{C}(6 \mathrm{~A})-\mathrm{C}(7 \mathrm{~A})-\mathrm{H}(7 \mathrm{AA})$ & 119.4 \\
\hline C(8A)-C(7A)-H(7AA) & 119.4 \\
\hline $\mathrm{C}(3 \mathrm{~A})-\mathrm{C}(8 \mathrm{~A})-\mathrm{C}(7 \mathrm{~A})$ & $119.1(2)$ \\
\hline $\mathrm{C}(3 \mathrm{~A})-\mathrm{C}(8 \mathrm{~A})-\mathrm{H}(8 \mathrm{AA})$ & 120.4 \\
\hline $\mathrm{C}(7 \mathrm{~A})-\mathrm{C}(8 \mathrm{~A})-\mathrm{H}(8 \mathrm{AA})$ & 120.4 \\
\hline$C(14 A)-C(9 A)-C(10 A)$ & $117.85(13)$ \\
\hline$C(14 A)-C(9 A)-C(1 A)$ & $121.21(15)$ \\
\hline$C(10 A)-C(9 A)-C(1 A)$ & $120.94(15)$ \\
\hline $\mathrm{C}(11 \mathrm{~A})-\mathrm{C}(10 \mathrm{~A})-\mathrm{C}(9 \mathrm{~A})$ & $121.70(14)$ \\
\hline $\mathrm{C}(11 \mathrm{~A})-\mathrm{C}(10 \mathrm{~A})-\mathrm{H}(10 \mathrm{~B})$ & 119.2 \\
\hline $\mathrm{C}(9 \mathrm{~A})-\mathrm{C}(10 \mathrm{~A})-\mathrm{H}(10 \mathrm{~B})$ & 119.2 \\
\hline$C(12 A)-C(11 A)-C(10 A)$ & $119.46(15)$ \\
\hline $\mathrm{C}(12 \mathrm{~A})-\mathrm{C}(11 \mathrm{~A})-\mathrm{H}(11 \mathrm{~B})$ & 120.3 \\
\hline $\mathrm{C}(10 \mathrm{~A})-\mathrm{C}(11 \mathrm{~A})-\mathrm{H}(11 \mathrm{~B})$ & 120.3 \\
\hline $\mathrm{O}(3 \mathrm{~A})-\mathrm{C}(12 \mathrm{~A})-\mathrm{C}(11 \mathrm{~A})$ & $117.27(14)$ \\
\hline $\mathrm{O}(3 \mathrm{~A})-\mathrm{C}(12 \mathrm{~A})-\mathrm{C}(13 \mathrm{~A})$ & $122.57(13)$ \\
\hline$C(11 A)-C(12 A)-C(13 A)$ & $120.14(13)$ \\
\hline $\mathrm{C}(12 \mathrm{~A})-\mathrm{C}(13 \mathrm{~A})-\mathrm{C}(14 \mathrm{~A})$ & $119.55(14)$ \\
\hline $\mathrm{C}(12 \mathrm{~A})-\mathrm{C}(13 \mathrm{~A})-\mathrm{H}(13 \mathrm{~B})$ & 120.2 \\
\hline $\mathrm{C}(14 \mathrm{~A})-\mathrm{C}(13 \mathrm{~A})-\mathrm{H}(13 \mathrm{~B})$ & 120.2 \\
\hline $\mathrm{C}(9 \mathrm{~A})-\mathrm{C}(14 \mathrm{~A})-\mathrm{C}(13 \mathrm{~A})$ & $121.29(15)$ \\
\hline $\mathrm{C}(9 \mathrm{~A})-\mathrm{C}(14 \mathrm{~A})-\mathrm{H}(14 \mathrm{~B})$ & 119.4 \\
\hline
\end{tabular}




$\begin{array}{ll}\text { C(13A)-C(14A)-H(14B) } & 119.4 \\ \text { O(2A)-C(15A)-H(15D) } & 109.5 \\ \text { O(2A)-C(15A)-H(15E) } & 109.5 \\ \text { H(15D)-C(15A)-H(15E) } & 109.5 \\ \text { O(2A)-C(15A)-H(15F) } & 109.5 \\ \text { H(15D)-C(15A)-H(15F) } & 109.5 \\ \text { H(15E)-C(15A)-H(15F) } & 109.5\end{array}$

Symmetry transformations used to generate equivalent atoms: 
Table 4. Anisotropic displacement parameters $\left(\AA^{2} \times 10^{3}\right)$ for $\mathrm{d} 12244$. The anisotropic displacement factor exponent takes the form: $-2 \pi^{2}\left[h^{2} a^{* 2} U^{11}+\ldots+2 h k a^{*} b^{*} U^{12}\right]$

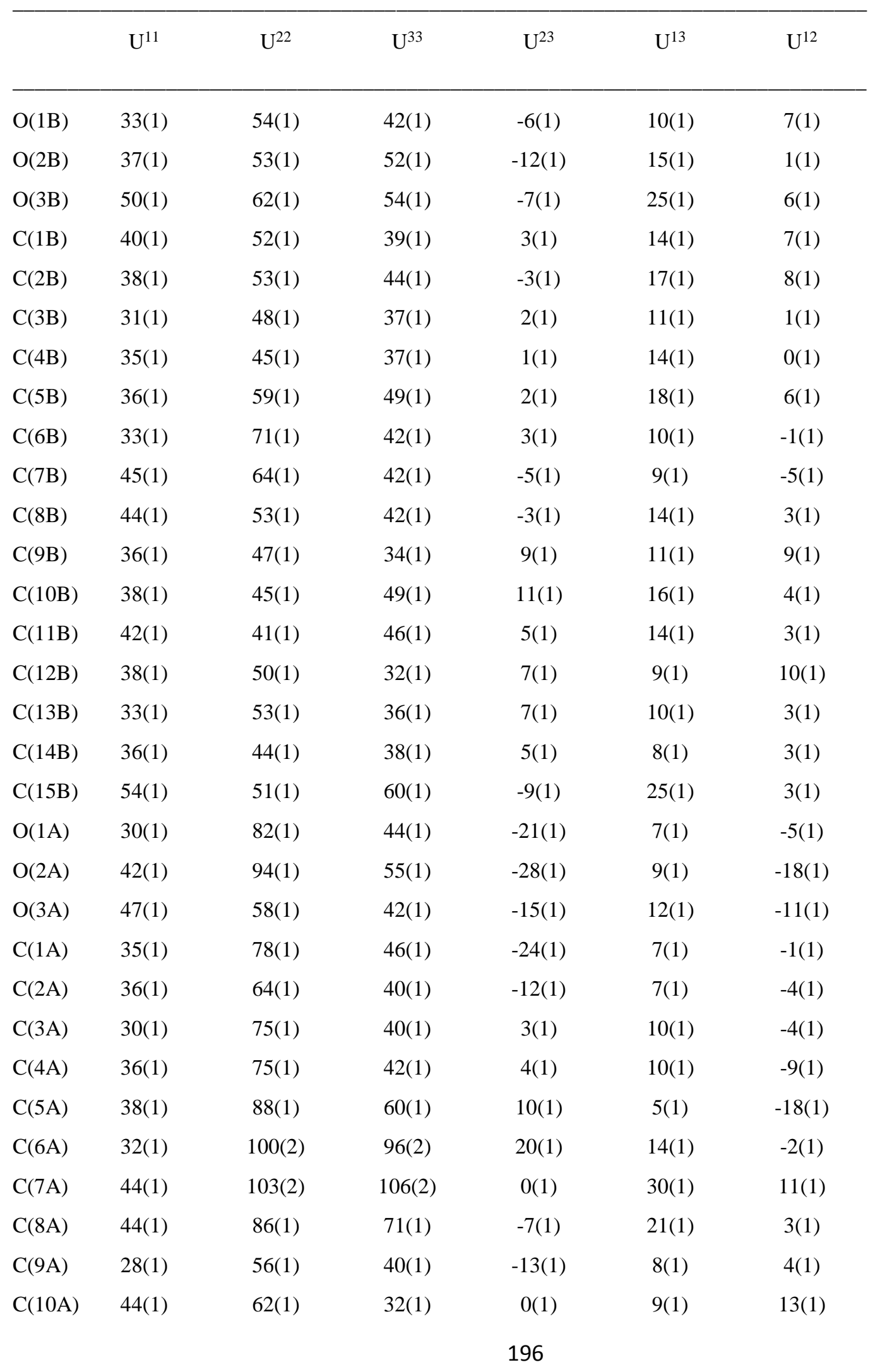




\begin{tabular}{lllllll}
$\mathrm{C}(11 \mathrm{~A})$ & $46(1)$ & $45(1)$ & $42(1)$ & $0(1)$ & $16(1)$ & $4(1)$ \\
$\mathrm{C}(12 \mathrm{~A})$ & $31(1)$ & $47(1)$ & $36(1)$ & $-10(1)$ & $9(1)$ & $2(1)$ \\
$\mathrm{C}(13 \mathrm{~A})$ & $37(1)$ & $53(1)$ & $33(1)$ & $-2(1)$ & $10(1)$ & $0(1)$ \\
$\mathrm{C}(14 \mathrm{~A})$ & $37(1)$ & $51(1)$ & $43(1)$ & $-6(1)$ & $12(1)$ & $-5(1)$ \\
$\mathrm{C}(15 \mathrm{~A})$ & $73(1)$ & $108(2)$ & $65(1)$ & $-37(1)$ & $13(1)$ & $-34(1)$ \\
\hline
\end{tabular}


Table 5. Hydrogen coordinates ( x 10 $)$ and isotropic displacement parameters $\left(\AA^{2} \times 10^{3}\right)$ for d 12244 .

\begin{tabular}{|c|c|c|c|c|}
\hline & $\mathrm{x}$ & $\mathrm{y}$ & $\mathrm{z}$ & $\mathrm{U}(\mathrm{eq})$ \\
\hline $\mathrm{H}(1 \mathrm{BA})$ & 7247 & 919 & 4579 & 54 \\
\hline $\mathrm{H}(1 \mathrm{BB})$ & 6966 & -1315 & 4799 & 54 \\
\hline $\mathrm{H}(2 \mathrm{BA})$ & 6379 & 102 & 3465 & 55 \\
\hline $\mathrm{H}(2 \mathrm{BB})$ & 6056 & -1759 & 3766 & 55 \\
\hline $\mathrm{H}(5 \mathrm{BA})$ & 4018 & 5270 & 3376 & 59 \\
\hline $\mathrm{H}(6 \mathrm{BA})$ & 3412 & 2833 & 2487 & 62 \\
\hline $\mathrm{H}(7 \mathrm{BA})$ & 3978 & -133 & 2249 & 65 \\
\hline $\mathrm{H}(8 \mathrm{BA})$ & 5152 & -760 & 2905 & 58 \\
\hline $\mathrm{H}(10 \mathrm{~A})$ & 6830 & -4963 & 3998 & 54 \\
\hline $\mathrm{H}(11 \mathrm{~A})$ & 7415 & -7160 & 3567 & 54 \\
\hline $\mathrm{H}(13 \mathrm{~A})$ & 8841 & -2095 & 4027 & 51 \\
\hline $\mathrm{H}(14 \mathrm{~A})$ & 8239 & 119 & 4439 & 51 \\
\hline $\mathrm{H}(15 \mathrm{~A})$ & 5356 & 7498 & 4794 & 83 \\
\hline $\mathrm{H}(15 \mathrm{~B})$ & 4647 & 6091 & 4473 & 83 \\
\hline $\mathrm{H}(15 \mathrm{C})$ & 4827 & 7898 & 4046 & 83 \\
\hline $\mathrm{H}(1 \mathrm{AA})$ & 2039 & 3733 & 2292 & 69 \\
\hline $\mathrm{H}(1 \mathrm{AB})$ & 1987 & 1955 & 2800 & 69 \\
\hline $\mathrm{H}(2 \mathrm{AA})$ & 1081 & 4281 & 2815 & 60 \\
\hline $\mathrm{H}(2 \mathrm{AB})$ & 1111 & 5889 & 2259 & 60 \\
\hline $\mathrm{H}(5 \mathrm{AA})$ & -1247 & 227 & 546 & 81 \\
\hline $\mathrm{H}(6 \mathrm{AA})$ & -1837 & 3002 & 834 & 98 \\
\hline H(7AA) & -1239 & 5626 & 1642 & 103 \\
\hline $\mathrm{H}(8 \mathrm{AA})$ & -33 & 5602 & 2180 & 83 \\
\hline $\mathrm{H}(10 \mathrm{~B})$ & 2496 & 7700 & 2669 & 59 \\
\hline $\mathrm{H}(11 \mathrm{~B})$ & 3274 & 9964 & 3515 & 55 \\
\hline $\mathrm{H}(13 \mathrm{~B})$ & 3308 & 5156 & 4801 & 52 \\
\hline $\mathrm{H}(14 \mathrm{~B})$ & 2528 & 2902 & 3946 & 55 \\
\hline $\mathrm{H}(15 \mathrm{D})$ & 127 & -2922 & 525 & 134 \\
\hline $\mathrm{H}(15 \mathrm{E})$ & -491 & -1137 & 156 & 134 \\
\hline $\mathrm{H}(15 \mathrm{~F})$ & -526 & -2937 & 668 & 134 \\
\hline
\end{tabular}


H(3OA)

3898(12)

8600(40)

5089(12)

$86(7)$

$\mathrm{H}(3 \mathrm{OB})$

8859(13)

$-5450(40)$

3509(12)

94(8) 
Table 6. Torsion angles $\left[{ }^{\circ}\right]$ for $\mathrm{d} 12244$.

\begin{tabular}{|c|c|}
\hline $\mathrm{C}(3 \mathrm{~B})-\mathrm{O}(1 \mathrm{~B})-\mathrm{C}(2 \mathrm{~B})-\mathrm{C}(1 \mathrm{~B})$ & $-172.14(12)$ \\
\hline $\mathrm{C}(9 \mathrm{~B})-\mathrm{C}(1 \mathrm{~B})-\mathrm{C}(2 \mathrm{~B})-\mathrm{O}(1 \mathrm{~B})$ & $-168.40(12)$ \\
\hline $\mathrm{C}(2 \mathrm{~B})-\mathrm{O}(1 \mathrm{~B})-\mathrm{C}(3 \mathrm{~B})-\mathrm{C}(8 \mathrm{~B})$ & $3.9(2)$ \\
\hline $\mathrm{C}(2 \mathrm{~B})-\mathrm{O}(1 \mathrm{~B})-\mathrm{C}(3 \mathrm{~B})-\mathrm{C}(4 \mathrm{~B})$ & $-178.18(13)$ \\
\hline $\mathrm{C}(15 \mathrm{~B})-\mathrm{O}(2 \mathrm{~B})-\mathrm{C}(4 \mathrm{~B})-\mathrm{C}(5 \mathrm{~B})$ & $2.6(2)$ \\
\hline $\mathrm{C}(15 \mathrm{~B})-\mathrm{O}(2 \mathrm{~B})-\mathrm{C}(4 \mathrm{~B})-\mathrm{C}(3 \mathrm{~B})$ & $-176.44(13)$ \\
\hline $\mathrm{C}(8 \mathrm{~B})-\mathrm{C}(3 \mathrm{~B})-\mathrm{C}(4 \mathrm{~B})-\mathrm{O}(2 \mathrm{~B})$ & $-178.91(13)$ \\
\hline $\mathrm{O}(1 \mathrm{~B})-\mathrm{C}(3 \mathrm{~B})-\mathrm{C}(4 \mathrm{~B})-\mathrm{O}(2 \mathrm{~B})$ & $3.10(18)$ \\
\hline $\mathrm{C}(8 \mathrm{~B})-\mathrm{C}(3 \mathrm{~B})-\mathrm{C}(4 \mathrm{~B})-\mathrm{C}(5 \mathrm{~B})$ & $2.0(2)$ \\
\hline $\mathrm{O}(1 \mathrm{~B})-\mathrm{C}(3 \mathrm{~B})-\mathrm{C}(4 \mathrm{~B})-\mathrm{C}(5 \mathrm{~B})$ & $-176.02(13)$ \\
\hline $\mathrm{O}(2 \mathrm{~B})-\mathrm{C}(4 \mathrm{~B})-\mathrm{C}(5 \mathrm{~B})-\mathrm{C}(6 \mathrm{~B})$ & $-179.38(14)$ \\
\hline $\mathrm{C}(3 \mathrm{~B})-\mathrm{C}(4 \mathrm{~B})-\mathrm{C}(5 \mathrm{~B})-\mathrm{C}(6 \mathrm{~B})$ & $-0.4(2)$ \\
\hline $\mathrm{C}(4 \mathrm{~B})-\mathrm{C}(5 \mathrm{~B})-\mathrm{C}(6 \mathrm{~B})-\mathrm{C}(7 \mathrm{~B})$ & $-1.0(2)$ \\
\hline $\mathrm{C}(5 \mathrm{~B})-\mathrm{C}(6 \mathrm{~B})-\mathrm{C}(7 \mathrm{~B})-\mathrm{C}(8 \mathrm{~B})$ & $0.8(3)$ \\
\hline $\mathrm{O}(1 \mathrm{~B})-\mathrm{C}(3 \mathrm{~B})-\mathrm{C}(8 \mathrm{~B})-\mathrm{C}(7 \mathrm{~B})$ & $175.54(14)$ \\
\hline $\mathrm{C}(4 \mathrm{~B})-\mathrm{C}(3 \mathrm{~B})-\mathrm{C}(8 \mathrm{~B})-\mathrm{C}(7 \mathrm{~B})$ & $-2.2(2)$ \\
\hline $\mathrm{C}(6 \mathrm{~B})-\mathrm{C}(7 \mathrm{~B})-\mathrm{C}(8 \mathrm{~B})-\mathrm{C}(3 \mathrm{~B})$ & $0.9(3)$ \\
\hline $\mathrm{C}(2 \mathrm{~B})-\mathrm{C}(1 \mathrm{~B})-\mathrm{C}(9 \mathrm{~B})-\mathrm{C}(14 \mathrm{~B})$ & $117.74(15)$ \\
\hline $\mathrm{C}(2 \mathrm{~B})-\mathrm{C}(1 \mathrm{~B})-\mathrm{C}(9 \mathrm{~B})-\mathrm{C}(10 \mathrm{~B})$ & $-56.31(18)$ \\
\hline $\mathrm{C}(14 \mathrm{~B})-\mathrm{C}(9 \mathrm{~B})-\mathrm{C}(10 \mathrm{~B})-\mathrm{C}(11 \mathrm{~B})$ & $-2.6(2)$ \\
\hline $\mathrm{C}(1 \mathrm{~B})-\mathrm{C}(9 \mathrm{~B})-\mathrm{C}(10 \mathrm{~B})-\mathrm{C}(11 \mathrm{~B})$ & $171.73(13)$ \\
\hline $\mathrm{C}(9 \mathrm{~B})-\mathrm{C}(10 \mathrm{~B})-\mathrm{C}(11 \mathrm{~B})-\mathrm{C}(12 \mathrm{~B})$ & $1.4(2)$ \\
\hline $\mathrm{C}(10 \mathrm{~B})-\mathrm{C}(11 \mathrm{~B})-\mathrm{C}(12 \mathrm{~B})-\mathrm{O}(3 \mathrm{~B})$ & $-179.56(13)$ \\
\hline $\mathrm{C}(10 \mathrm{~B})-\mathrm{C}(11 \mathrm{~B})-\mathrm{C}(12 \mathrm{~B})-\mathrm{C}(13 \mathrm{~B})$ & $0.4(2)$ \\
\hline $\mathrm{O}(3 \mathrm{~B})-\mathrm{C}(12 \mathrm{~B})-\mathrm{C}(13 \mathrm{~B})-\mathrm{C}(14 \mathrm{~B})$ & $178.91(13)$ \\
\hline $\mathrm{C}(11 \mathrm{~B})-\mathrm{C}(12 \mathrm{~B})-\mathrm{C}(13 \mathrm{~B})-\mathrm{C}(14 \mathrm{~B})$ & $-1.1(2)$ \\
\hline $\mathrm{C}(12 \mathrm{~B})-\mathrm{C}(13 \mathrm{~B})-\mathrm{C}(14 \mathrm{~B})-\mathrm{C}(9 \mathrm{~B})$ & $-0.1(2)$ \\
\hline $\mathrm{C}(10 \mathrm{~B})-\mathrm{C}(9 \mathrm{~B})-\mathrm{C}(14 \mathrm{~B})-\mathrm{C}(13 \mathrm{~B})$ & $1.9(2)$ \\
\hline $\mathrm{C}(1 \mathrm{~B})-\mathrm{C}(9 \mathrm{~B})-\mathrm{C}(14 \mathrm{~B})-\mathrm{C}(13 \mathrm{~B})$ & $-172.35(13)$ \\
\hline $\mathrm{C}(3 \mathrm{~A})-\mathrm{O}(1 \mathrm{~A})-\mathrm{C}(2 \mathrm{~A})-\mathrm{C}(1 \mathrm{~A})$ & $179.05(14)$ \\
\hline $\mathrm{C}(9 \mathrm{~A})-\mathrm{C}(1 \mathrm{~A})-\mathrm{C}(2 \mathrm{~A})-\mathrm{O}(1 \mathrm{~A})$ & $-175.07(14)$ \\
\hline $\mathrm{C}(2 \mathrm{~A})-\mathrm{O}(1 \mathrm{~A})-\mathrm{C}(3 \mathrm{~A})-\mathrm{C}(8 \mathrm{~A})$ & $-3.0(3)$ \\
\hline $\mathrm{C}(2 \mathrm{~A})-\mathrm{O}(1 \mathrm{~A})-\mathrm{C}(3 \mathrm{~A})-\mathrm{C}(4 \mathrm{~A})$ & $177.27(14)$ \\
\hline$C(15 A)-O(2 A)-C(4 A)-C(5 A)$ & $2.7(3)$ \\
\hline
\end{tabular}




\begin{tabular}{|c|c|}
\hline $\mathrm{C}(15 \mathrm{~A})-\mathrm{O}(2 \mathrm{~A})-\mathrm{C}(4 \mathrm{~A})-\mathrm{C}(3 \mathrm{~A})$ & $-177.50(17)$ \\
\hline $\mathrm{O}(1 \mathrm{~A})-\mathrm{C}(3 \mathrm{~A})-\mathrm{C}(4 \mathrm{~A})-\mathrm{O}(2 \mathrm{~A})$ & $0.5(2)$ \\
\hline $\mathrm{C}(8 \mathrm{~A})-\mathrm{C}(3 \mathrm{~A})-\mathrm{C}(4 \mathrm{~A})-\mathrm{O}(2 \mathrm{~A})$ & $-179.19(16)$ \\
\hline $\mathrm{O}(1 \mathrm{~A})-\mathrm{C}(3 \mathrm{~A})-\mathrm{C}(4 \mathrm{~A})-\mathrm{C}(5 \mathrm{~A})$ & $-179.69(15)$ \\
\hline $\mathrm{C}(8 \mathrm{~A})-\mathrm{C}(3 \mathrm{~A})-\mathrm{C}(4 \mathrm{~A})-\mathrm{C}(5 \mathrm{~A})$ & $0.6(3)$ \\
\hline $\mathrm{O}(2 \mathrm{~A})-\mathrm{C}(4 \mathrm{~A})-\mathrm{C}(5 \mathrm{~A})-\mathrm{C}(6 \mathrm{~A})$ & $179.16(18)$ \\
\hline$C(3 A)-C(4 A)-C(5 A)-C(6 A)$ & $-0.6(3)$ \\
\hline $\mathrm{C}(4 \mathrm{~A})-\mathrm{C}(5 \mathrm{~A})-\mathrm{C}(6 \mathrm{~A})-\mathrm{C}(7 \mathrm{~A})$ & $0.0(3)$ \\
\hline $\mathrm{C}(5 \mathrm{~A})-\mathrm{C}(6 \mathrm{~A})-\mathrm{C}(7 \mathrm{~A})-\mathrm{C}(8 \mathrm{~A})$ & $0.5(4)$ \\
\hline $\mathrm{O}(1 \mathrm{~A})-\mathrm{C}(3 \mathrm{~A})-\mathrm{C}(8 \mathrm{~A})-\mathrm{C}(7 \mathrm{~A})$ & $-179.74(19)$ \\
\hline $\mathrm{C}(4 \mathrm{~A})-\mathrm{C}(3 \mathrm{~A})-\mathrm{C}(8 \mathrm{~A})-\mathrm{C}(7 \mathrm{~A})$ & $0.0(3)$ \\
\hline $\mathrm{C}(6 \mathrm{~A})-\mathrm{C}(7 \mathrm{~A})-\mathrm{C}(8 \mathrm{~A})-\mathrm{C}(3 \mathrm{~A})$ & $-0.5(4)$ \\
\hline $\mathrm{C}(2 \mathrm{~A})-\mathrm{C}(1 \mathrm{~A})-\mathrm{C}(9 \mathrm{~A})-\mathrm{C}(14 \mathrm{~A})$ & $95.89(19)$ \\
\hline $\mathrm{C}(2 \mathrm{~A})-\mathrm{C}(1 \mathrm{~A})-\mathrm{C}(9 \mathrm{~A})-\mathrm{C}(10 \mathrm{~A})$ & $-84.48(19)$ \\
\hline$C(14 A)-C(9 A)-C(10 A)-C(11 A)$ & $0.1(2)$ \\
\hline$C(1 A)-C(9 A)-C(10 A)-C(11 A)$ & $-179.53(14)$ \\
\hline $\mathrm{C}(9 \mathrm{~A})-\mathrm{C}(10 \mathrm{~A})-\mathrm{C}(11 \mathrm{~A})-\mathrm{C}(12 \mathrm{~A})$ & $-0.2(2)$ \\
\hline$C(10 A)-C(11 A)-C(12 A)-O(3 A)$ & $178.58(13)$ \\
\hline $\mathrm{C}(10 \mathrm{~A})-\mathrm{C}(11 \mathrm{~A})-\mathrm{C}(12 \mathrm{~A})-\mathrm{C}(13 \mathrm{~A})$ & $0.1(2)$ \\
\hline $\mathrm{O}(3 \mathrm{~A})-\mathrm{C}(12 \mathrm{~A})-\mathrm{C}(13 \mathrm{~A})-\mathrm{C}(14 \mathrm{~A})$ & $-178.44(14)$ \\
\hline $\mathrm{C}(11 \mathrm{~A})-\mathrm{C}(12 \mathrm{~A})-\mathrm{C}(13 \mathrm{~A})-\mathrm{C}(14 \mathrm{~A})$ & $-0.1(2)$ \\
\hline$C(10 A)-C(9 A)-C(14 A)-C(13 A)$ & $-0.1(2)$ \\
\hline$C(1 A)-C(9 A)-C(14 A)-C(13 A)$ & $179.58(14)$ \\
\hline $\mathrm{C}(12 \mathrm{~A})-\mathrm{C}(13 \mathrm{~A})-\mathrm{C}(14 \mathrm{~A})-\mathrm{C}(9 \mathrm{~A})$ & $0.1(2)$ \\
\hline
\end{tabular}

Symmetry transformations used to generate equivalent atoms: 
Table 7. Hydrogen bonds for d12244 [ $\AA$ and $\left.{ }^{\circ}\right]$.

\begin{tabular}{lllll}
\hline D-H...A & d(D-H) & $d(H \ldots A)$ & $d(D \ldots A)$ & $<($ DHA $)$ \\
\hline $\mathrm{O}(3 \mathrm{~A})-\mathrm{H}(3 \mathrm{OA}) \ldots \mathrm{O}(1 \mathrm{~B}) \# 1$ & $0.87(2)$ & $2.01(2)$ & $2.8399(16)$ & $161(2)$ \\
$\mathrm{O}(3 \mathrm{~B})-\mathrm{H}(3 \mathrm{OB}) \ldots \mathrm{O}(2 \mathrm{~A}) \# 2$ & $0.87(3)$ & $2.00(3)$ & $2.7628(18)$ & $145(2)$ \\
$\mathrm{O}(3 \mathrm{~B})-\mathrm{H}(3 \mathrm{OB}) \ldots \mathrm{O}(1 \mathrm{~A}) \# 2$ & $0.87(3)$ & $2.40(3)$ & $3.1572(18)$ & $145(2)$ \\
& & & & \\
\hline
\end{tabular}

Symmetry transformations used to generate equivalent atoms:

$\# 1-x+1,-y+1,-z+1 \quad \# 2-x+1, y-1 / 2,-z+1 / 2$ 


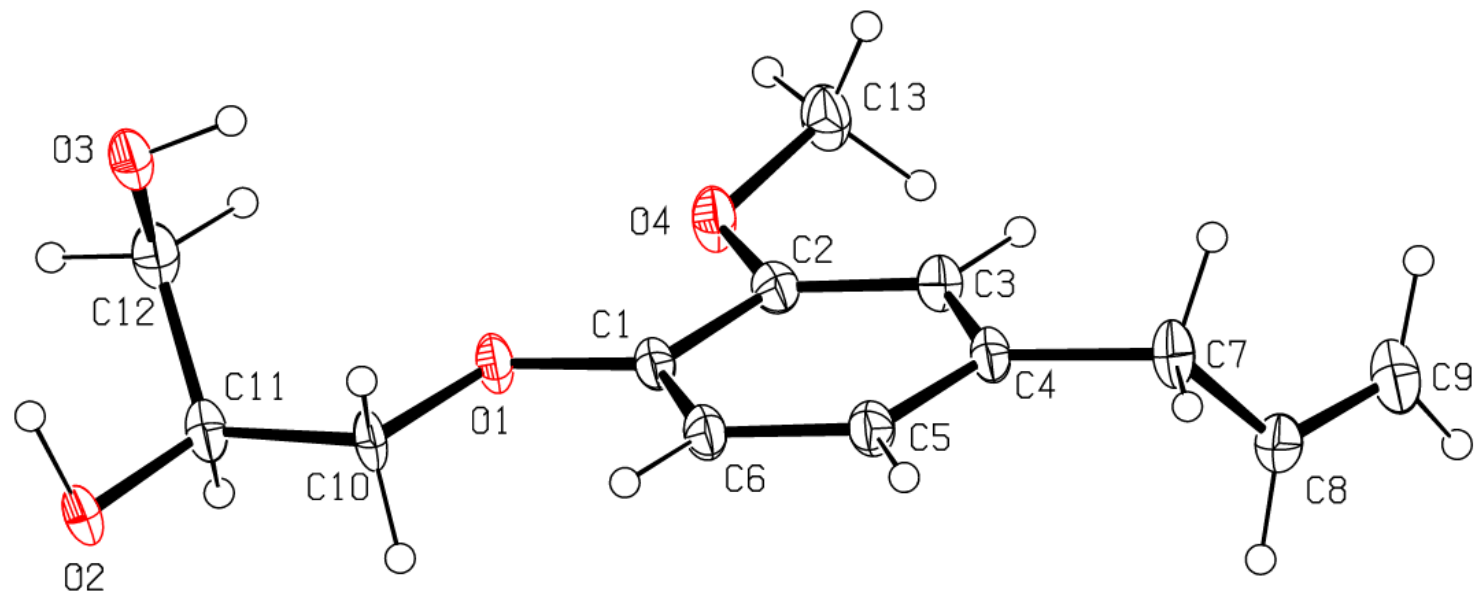

Table 1. Crystal data and structure refinement for $\mathrm{d} 12317$.

Identification code

Empirical formula

Formula weight

Temperature

Wavelength

Crystal system

Space group

Unit cell dimensions

Volume

$\mathrm{Z}$

Density (calculated)

Absorption coefficient

$\mathrm{F}(000)$

Crystal size

Theta range for data collection

Index ranges

Reflections collected

Independent reflections

Completeness to theta $=67.09^{\circ}$

Absorption correction d12317

C13 $\mathrm{H} 18 \mathrm{O} 4$

238.27

147(2) K

$1.54178 \AA$

Triclinic

$\mathrm{P}-1$

$\mathrm{a}=4.9024(8) \AA$ $\alpha=67.943(8)^{\circ}$.

$\mathrm{b}=10.7512(12) \AA$ $\beta=89.165(10)^{\circ}$.

$c=12.7785(15) \AA$ $\gamma=82.908(10)^{\circ}$.
2

$1.278 \mathrm{Mg} / \mathrm{m}^{3}$

$0.774 \mathrm{~mm}^{-1}$

256

$0.10 \times 0.06 \times 0.02 \mathrm{~mm}^{3}$

6.83 to $67.09^{\circ}$.

$-4<=\mathrm{h}<=5,-12<=\mathrm{k}<=8,-15<=1<=14$

26763

$2100[\mathrm{R}(\mathrm{int})=0.086]$

$94.9 \%$

Semi-empirical from equivalents 
Max. and min. transmission

Refinement method

Data / restraints / parameters

Goodness-of-fit on $\mathrm{F}^{2}$

Final $\mathrm{R}$ indices [I $>2 \operatorname{sigma}(\mathrm{I})]$

$\mathrm{R}$ indices (all data)

Largest diff. peak and hole
0.7527 and 0.5703

Full-matrix least-squares on $\mathrm{F}^{2}$

$2100 / 0 / 163$

1.173

$\mathrm{R} 1=0.0944, \mathrm{wR} 2=0.3040$

$\mathrm{R} 1=0.1198, w \mathrm{R} 2=0.3157$

0.442 and -0.457 e. $\AA^{-3}$ 
Table 2. Atomic coordinates ( $\mathrm{x} 10^{4}$ ) and equivalent isotropic displacement parameters $\left(\AA^{2} \times 10^{3}\right)$ for $\mathrm{d} 12317$. $\mathrm{U}(\mathrm{eq})$ is defined as one third of the trace of the orthogonalized $\mathrm{U}^{\mathrm{ij}}$ tensor.

\begin{tabular}{lrrrr}
\hline & $\mathrm{x}$ & $\mathrm{y}$ & $\mathrm{z}$ & $\mathrm{U}(\mathrm{eq})$ \\
\hline $\mathrm{O}(1)$ & $6860(8)$ & $2081(4)$ & $2304(3)$ & $31(1)$ \\
$\mathrm{O}(2)$ & $1831(8)$ & $1181(4)$ & $739(4)$ & $35(1)$ \\
$\mathrm{O}(3)$ & $7362(9)$ & $-169(5)$ & $926(4)$ & $39(1)$ \\
$\mathrm{O}(4)$ & $10140(9)$ & $1695(4)$ & $3999(3)$ & $35(1)$ \\
$\mathrm{C}(1)$ & $8200(11)$ & $3152(6)$ & $2235(5)$ & $29(1)$ \\
$\mathrm{C}(2)$ & $9963(11)$ & $2958(6)$ & $3156(5)$ & $29(1)$ \\
$\mathrm{C}(3)$ & $11377(12)$ & $3981(6)$ & $3168(5)$ & $32(1)$ \\
$\mathrm{C}(4)$ & $11092(12)$ & $5241(6)$ & $2254(5)$ & $31(1)$ \\
$\mathrm{C}(5)$ & $9376(12)$ & $5422(6)$ & $1347(5)$ & $32(1)$ \\
$\mathrm{C}(6)$ & $7950(12)$ & $4386(6)$ & $1332(5)$ & $32(1)$ \\
$\mathrm{C}(7)$ & $12595(14)$ & $6365(6)$ & $2310(6)$ & $40(2)$ \\
$\mathrm{C}(8)$ & $11798(13)$ & $6758(6)$ & $3273(5)$ & $38(2)$ \\
$\mathrm{C}(9)$ & $13409(15)$ & $6627(7)$ & $4131(6)$ & $47(2)$ \\
$\mathrm{C}(10)$ & $5061(12)$ & $2266(6)$ & $1363(5)$ & $31(1)$ \\
$\mathrm{C}(11)$ & $3742(12)$ & $974(6)$ & $1659(5)$ & $34(1)$ \\
$\mathrm{C}(12)$ & $5800(13)$ & $-257(6)$ & $1883(5)$ & $38(2)$ \\
$\mathrm{C}(13)$ & $12221(13)$ & $1379(6)$ & $4862(5)$ & $39(2)$ \\
\hline & & & & \\
\hline
\end{tabular}


Table 3. Bond lengths $[\AA]$ and angles $\left[{ }^{\circ}\right]$ for d12317.

\begin{tabular}{|c|c|}
\hline $\mathrm{O}(1)-\mathrm{C}(1)$ & $1.369(6)$ \\
\hline $\mathrm{O}(1)-\mathrm{C}(10)$ & $1.439(6)$ \\
\hline $\mathrm{O}(2)-\mathrm{C}(11)$ & $1.447(7)$ \\
\hline $\mathrm{O}(2)-\mathrm{H}(2 \mathrm{O})$ & $1.10(10)$ \\
\hline $\mathrm{O}(3)-\mathrm{C}(12)$ & $1.412(8)$ \\
\hline $\mathrm{O}(3)-\mathrm{H}(30)$ & $0.90(7)$ \\
\hline $\mathrm{O}(4)-\mathrm{C}(2)$ & $1.374(7)$ \\
\hline $\mathrm{O}(4)-\mathrm{C}(13)$ & $1.428(7)$ \\
\hline $\mathrm{C}(1)-\mathrm{C}(6)$ & $1.385(8)$ \\
\hline $\mathrm{C}(1)-\mathrm{C}(2)$ & $1.406(8)$ \\
\hline $\mathrm{C}(2)-\mathrm{C}(3)$ & $1.375(8)$ \\
\hline $\mathrm{C}(3)-\mathrm{C}(4)$ & $1.410(8)$ \\
\hline $\mathrm{C}(3)-\mathrm{H}(3 \mathrm{~A})$ & 0.9500 \\
\hline $\mathrm{C}(4)-\mathrm{C}(5)$ & $1.380(8)$ \\
\hline$C(4)-C(7)$ & $1.516(7)$ \\
\hline$C(5)-C(6)$ & $1.393(7)$ \\
\hline $\mathrm{C}(5)-\mathrm{H}(5 \mathrm{~A})$ & 0.9500 \\
\hline $\mathrm{C}(6)-\mathrm{H}(6 \mathrm{~A})$ & 0.9500 \\
\hline $\mathrm{C}(7)-\mathrm{C}(8)$ & $1.477(9)$ \\
\hline $\mathrm{C}(7)-\mathrm{H}(7 \mathrm{~A})$ & 0.9900 \\
\hline $\mathrm{C}(7)-\mathrm{H}(7 \mathrm{~B})$ & 0.9900 \\
\hline $\mathrm{C}(8)-\mathrm{C}(9)$ & $1.314(9)$ \\
\hline $\mathrm{C}(8)-\mathrm{H}(8 \mathrm{~A})$ & 0.9500 \\
\hline $\mathrm{C}(9)-\mathrm{H}(9 \mathrm{~A})$ & 0.9500 \\
\hline $\mathrm{C}(9)-\mathrm{H}(9 \mathrm{~B})$ & 0.9500 \\
\hline$C(10)-C(11)$ & $1.520(7)$ \\
\hline $\mathrm{C}(10)-\mathrm{H}(10 \mathrm{~A})$ & 0.9900 \\
\hline $\mathrm{C}(10)-\mathrm{H}(10 \mathrm{~B})$ & 0.9900 \\
\hline $\mathrm{C}(11)-\mathrm{C}(12)$ & $1.499(9)$ \\
\hline $\mathrm{C}(11)-\mathrm{H}(11 \mathrm{~A})$ & 1.0000 \\
\hline $\mathrm{C}(12)-\mathrm{H}(12 \mathrm{~A})$ & 0.9900 \\
\hline $\mathrm{C}(12)-\mathrm{H}(12 \mathrm{~B})$ & 0.9900 \\
\hline $\mathrm{C}(13)-\mathrm{H}(13 \mathrm{~A})$ & 0.9800 \\
\hline $\mathrm{C}(13)-\mathrm{H}(13 \mathrm{~B})$ & 0.9800 \\
\hline
\end{tabular}




\begin{tabular}{|c|c|}
\hline $\mathrm{C}(13)-\mathrm{H}(13 \mathrm{C})$ & 0.9800 \\
\hline $\mathrm{C}(1)-\mathrm{O}(1)-\mathrm{C}(10)$ & $116.8(4)$ \\
\hline $\mathrm{C}(11)-\mathrm{O}(2)-\mathrm{H}(2 \mathrm{O})$ & $104(5)$ \\
\hline $\mathrm{C}(12)-\mathrm{O}(3)-\mathrm{H}(30)$ & $107(4)$ \\
\hline $\mathrm{C}(2)-\mathrm{O}(4)-\mathrm{C}(13)$ & $116.7(4)$ \\
\hline $\mathrm{O}(1)-\mathrm{C}(1)-\mathrm{C}(6)$ & $124.9(5)$ \\
\hline $\mathrm{O}(1)-\mathrm{C}(1)-\mathrm{C}(2)$ & $116.4(5)$ \\
\hline $\mathrm{C}(6)-\mathrm{C}(1)-\mathrm{C}(2)$ & $118.7(5)$ \\
\hline $\mathrm{O}(4)-\mathrm{C}(2)-\mathrm{C}(3)$ & $124.6(5)$ \\
\hline $\mathrm{O}(4)-\mathrm{C}(2)-\mathrm{C}(1)$ & $114.8(5)$ \\
\hline $\mathrm{C}(3)-\mathrm{C}(2)-\mathrm{C}(1)$ & $120.6(5)$ \\
\hline $\mathrm{C}(2)-\mathrm{C}(3)-\mathrm{C}(4)$ & $120.5(5)$ \\
\hline $\mathrm{C}(2)-\mathrm{C}(3)-\mathrm{H}(3 \mathrm{~A})$ & 119.7 \\
\hline $\mathrm{C}(4)-\mathrm{C}(3)-\mathrm{H}(3 \mathrm{~A})$ & 119.7 \\
\hline C(5)-C(4)-C(3) & $118.7(5)$ \\
\hline C(5)-C(4)-C(7) & $122.0(5)$ \\
\hline C(3)-C(4)-C(7) & $119.3(5)$ \\
\hline$C(4)-C(5)-C(6)$ & $120.9(5)$ \\
\hline $\mathrm{C}(4)-\mathrm{C}(5)-\mathrm{H}(5 \mathrm{~A})$ & 119.6 \\
\hline $\mathrm{C}(6)-\mathrm{C}(5)-\mathrm{H}(5 \mathrm{~A})$ & 119.6 \\
\hline$C(1)-C(6)-C(5)$ & $120.6(5)$ \\
\hline $\mathrm{C}(1)-\mathrm{C}(6)-\mathrm{H}(6 \mathrm{~A})$ & 119.7 \\
\hline $\mathrm{C}(5)-\mathrm{C}(6)-\mathrm{H}(6 \mathrm{~A})$ & 119.7 \\
\hline $\mathrm{C}(8)-\mathrm{C}(7)-\mathrm{C}(4)$ & $113.0(5)$ \\
\hline $\mathrm{C}(8)-\mathrm{C}(7)-\mathrm{H}(7 \mathrm{~A})$ & 109.0 \\
\hline $\mathrm{C}(4)-\mathrm{C}(7)-\mathrm{H}(7 \mathrm{~A})$ & 109.0 \\
\hline $\mathrm{C}(8)-\mathrm{C}(7)-\mathrm{H}(7 \mathrm{~B})$ & 109.0 \\
\hline $\mathrm{C}(4)-\mathrm{C}(7)-\mathrm{H}(7 \mathrm{~B})$ & 109.0 \\
\hline $\mathrm{H}(7 \mathrm{~A})-\mathrm{C}(7)-\mathrm{H}(7 \mathrm{~B})$ & 107.8 \\
\hline $\mathrm{C}(9)-\mathrm{C}(8)-\mathrm{C}(7)$ & $126.2(7)$ \\
\hline $\mathrm{C}(9)-\mathrm{C}(8)-\mathrm{H}(8 \mathrm{~A})$ & 116.9 \\
\hline $\mathrm{C}(7)-\mathrm{C}(8)-\mathrm{H}(8 \mathrm{~A})$ & 116.9 \\
\hline $\mathrm{C}(8)-\mathrm{C}(9)-\mathrm{H}(9 \mathrm{~A})$ & 120.0 \\
\hline $\mathrm{C}(8)-\mathrm{C}(9)-\mathrm{H}(9 \mathrm{~B})$ & 120.0 \\
\hline $\mathrm{H}(9 \mathrm{~A})-\mathrm{C}(9)-\mathrm{H}(9 \mathrm{~B})$ & 120.0 \\
\hline
\end{tabular}




\begin{tabular}{|c|c|}
\hline $\mathrm{O}(1)-\mathrm{C}(10)-\mathrm{C}(11)$ & $106.9(5)$ \\
\hline $\mathrm{O}(1)-\mathrm{C}(10)-\mathrm{H}(10 \mathrm{~A})$ & 110.3 \\
\hline $\mathrm{C}(11)-\mathrm{C}(10)-\mathrm{H}(10 \mathrm{~A})$ & 110.3 \\
\hline $\mathrm{O}(1)-\mathrm{C}(10)-\mathrm{H}(10 \mathrm{~B})$ & 110.3 \\
\hline $\mathrm{C}(11)-\mathrm{C}(10)-\mathrm{H}(10 \mathrm{~B})$ & 110.3 \\
\hline $\mathrm{H}(10 \mathrm{~A})-\mathrm{C}(10)-\mathrm{H}(10 \mathrm{~B})$ & 108.6 \\
\hline $\mathrm{O}(2)-\mathrm{C}(11)-\mathrm{C}(12)$ & $111.9(5)$ \\
\hline $\mathrm{O}(2)-\mathrm{C}(11)-\mathrm{C}(10)$ & $107.1(5)$ \\
\hline $\mathrm{C}(12)-\mathrm{C}(11)-\mathrm{C}(10)$ & 113.1(5) \\
\hline $\mathrm{O}(2)-\mathrm{C}(11)-\mathrm{H}(11 \mathrm{~A})$ & 108.2 \\
\hline $\mathrm{C}(12)-\mathrm{C}(11)-\mathrm{H}(11 \mathrm{~A})$ & 108.2 \\
\hline $\mathrm{C}(10)-\mathrm{C}(11)-\mathrm{H}(11 \mathrm{~A})$ & 108.2 \\
\hline $\mathrm{O}(3)-\mathrm{C}(12)-\mathrm{C}(11)$ & $111.8(5)$ \\
\hline $\mathrm{O}(3)-\mathrm{C}(12)-\mathrm{H}(12 \mathrm{~A})$ & 109.3 \\
\hline $\mathrm{C}(11)-\mathrm{C}(12)-\mathrm{H}(12 \mathrm{~A})$ & 109.3 \\
\hline $\mathrm{O}(3)-\mathrm{C}(12)-\mathrm{H}(12 \mathrm{~B})$ & 109.3 \\
\hline $\mathrm{C}(11)-\mathrm{C}(12)-\mathrm{H}(12 \mathrm{~B})$ & 109.3 \\
\hline $\mathrm{H}(12 \mathrm{~A})-\mathrm{C}(12)-\mathrm{H}(12 \mathrm{~B})$ & 107.9 \\
\hline $\mathrm{O}(4)-\mathrm{C}(13)-\mathrm{H}(13 \mathrm{~A})$ & 109.5 \\
\hline $\mathrm{O}(4)-\mathrm{C}(13)-\mathrm{H}(13 \mathrm{~B})$ & 109.5 \\
\hline $\mathrm{H}(13 \mathrm{~A})-\mathrm{C}(13)-\mathrm{H}(13 \mathrm{~B})$ & 109.5 \\
\hline $\mathrm{O}(4)-\mathrm{C}(13)-\mathrm{H}(13 \mathrm{C})$ & 109.5 \\
\hline $\mathrm{H}(13 \mathrm{~A})-\mathrm{C}(13)-\mathrm{H}(13 \mathrm{C})$ & 109.5 \\
\hline $\mathrm{H}(13 \mathrm{~B})-\mathrm{C}(13)-\mathrm{H}(13 \mathrm{C})$ & 109.5 \\
\hline
\end{tabular}

Symmetry transformations used to generate equivalent atoms: 
Table 4. Anisotropic displacement parameters $\left(\AA^{2} \times 10^{3}\right)$ for $\mathrm{d} 12317$. The anisotropic displacement factor exponent takes the form: $-2 \pi^{2}\left[h^{2} a^{* 2} U^{11}+\ldots+2 h k a^{*} b^{*} U^{12}\right]$

\begin{tabular}{lllllll}
\hline & $\mathrm{U}^{11}$ & $\mathrm{U}^{22}$ & $\mathrm{U}^{33}$ & $\mathrm{U}^{23}$ & $\mathrm{U}^{13}$ & $\mathrm{U}^{12}$ \\
\hline $\mathrm{O}(1)$ & $34(2)$ & $25(2)$ & $35(2)$ & $-10(2)$ & $-11(2)$ & $-10(2)$ \\
$\mathrm{O}(2)$ & $28(2)$ & $43(2)$ & $44(2)$ & $-23(2)$ & $-7(2)$ & $-12(2)$ \\
$\mathrm{O}(3)$ & $32(2)$ & $46(3)$ & $48(3)$ & $-27(2)$ & $-3(2)$ & $-12(2)$ \\
$\mathrm{O}(4)$ & $44(2)$ & $28(2)$ & $34(2)$ & $-9(2)$ & $-12(2)$ & $-11(2)$ \\
$\mathrm{C}(1)$ & $26(3)$ & $27(3)$ & $36(3)$ & $-14(2)$ & $-3(2)$ & $-8(2)$ \\
$\mathrm{C}(2)$ & $28(3)$ & $31(3)$ & $31(3)$ & $-13(2)$ & $-2(2)$ & $-5(2)$ \\
$\mathrm{C}(3)$ & $33(3)$ & $34(3)$ & $35(3)$ & $-18(3)$ & $-2(2)$ & $-7(2)$ \\
$\mathrm{C}(4)$ & $29(3)$ & $29(3)$ & $39(3)$ & $-16(3)$ & $-3(2)$ & $-10(2)$ \\
$\mathrm{C}(5)$ & $32(3)$ & $27(3)$ & $38(3)$ & $-12(2)$ & $-4(2)$ & $-7(2)$ \\
$\mathrm{C}(6)$ & $31(3)$ & $31(3)$ & $37(3)$ & $-16(3)$ & $-8(2)$ & $-6(2)$ \\
$\mathrm{C}(7)$ & $43(4)$ & $36(3)$ & $48(4)$ & $-20(3)$ & $0(3)$ & $-19(3)$ \\
$\mathrm{C}(8)$ & $36(3)$ & $34(3)$ & $50(4)$ & $-22(3)$ & $2(3)$ & $-10(3)$ \\
$\mathrm{C}(9)$ & $47(4)$ & $54(4)$ & $49(4)$ & $-26(3)$ & $2(3)$ & $-23(3)$ \\
$\mathrm{C}(10)$ & $32(3)$ & $35(3)$ & $33(3)$ & $-18(2)$ & $-7(2)$ & $-14(2)$ \\
$\mathrm{C}(11)$ & $34(3)$ & $37(3)$ & $38(3)$ & $-18(3)$ & $0(3)$ & $-16(3)$ \\
$\mathrm{C}(12)$ & $42(4)$ & $37(3)$ & $39(3)$ & $-15(3)$ & $-6(3)$ & $-13(3)$ \\
$\mathrm{C}(13)$ & $45(4)$ & $34(3)$ & $36(3)$ & $-10(3)$ & $-14(3)$ & $-8(3)$ \\
& & & & & & \\
\hline
\end{tabular}


Table 5. Hydrogen coordinates ( x $\left.10^{4}\right)$ and isotropic displacement parameters $\left(\AA^{2} \times 10^{3}\right)$ for d12317.

\begin{tabular}{|c|c|c|c|c|}
\hline & $\mathrm{x}$ & $\mathrm{y}$ & $\mathrm{z}$ & $\mathrm{U}(\mathrm{eq})$ \\
\hline $\mathrm{H}(3 \mathrm{~A})$ & 12554 & 3838 & 3798 & 39 \\
\hline $\mathrm{H}(5 \mathrm{~A})$ & 9165 & 6266 & 725 & 38 \\
\hline $\mathrm{H}(6 \mathrm{~A})$ & 6796 & 4526 & 697 & 38 \\
\hline $\mathrm{H}(7 \mathrm{~A})$ & 14599 & 6068 & 2370 & 48 \\
\hline $\mathrm{H}(7 \mathrm{~B})$ & 12208 & 7167 & 1599 & 48 \\
\hline $\mathrm{H}(8 \mathrm{~A})$ & 9945 & 7142 & 3273 & 46 \\
\hline $\mathrm{H}(9 \mathrm{~A})$ & 15279 & 6249 & 4169 & 56 \\
\hline $\mathrm{H}(9 \mathrm{~B})$ & 12704 & 6911 & 4713 & 56 \\
\hline $\mathrm{H}(10 \mathrm{~A})$ & 6119 & 2433 & 668 & 37 \\
\hline $\mathrm{H}(10 \mathrm{~B})$ & 3633 & 3049 & 1235 & 37 \\
\hline $\mathrm{H}(11 \mathrm{~A})$ & 2672 & 844 & 2357 & 41 \\
\hline $\mathrm{H}(12 \mathrm{~A})$ & 7052 & -366 & 2521 & 46 \\
\hline $\mathrm{H}(12 \mathrm{~B})$ & 4825 & -1067 & 2105 & 46 \\
\hline $\mathrm{H}(13 \mathrm{~A})$ & 12208 & 445 & 5395 & 58 \\
\hline $\mathrm{H}(13 \mathrm{~B})$ & 11859 & 1997 & 5264 & 58 \\
\hline $\mathrm{H}(13 \mathrm{C})$ & 14023 & 1480 & 4520 & 58 \\
\hline $\mathrm{H}(30)$ & $8750(150)$ & $300(70)$ & $930(60)$ & $37(17)$ \\
\hline $\mathrm{H}(2 \mathrm{O})$ & $3060(190)$ & $810(90)$ & $170(80)$ & $80(30)$ \\
\hline
\end{tabular}


Table 6. Hydrogen bonds for d12317 [Å and ${ }^{\circ}$ ].

\begin{tabular}{lcccc}
\hline $\mathrm{D}-\mathrm{H} \ldots \mathrm{A}$ & $\mathrm{d}(\mathrm{D}-\mathrm{H})$ & $\mathrm{d}(\mathrm{H} \ldots \mathrm{A})$ & $\mathrm{d}(\mathrm{D} \ldots \mathrm{A})$ & $<(\mathrm{DHA})$ \\
\hline $\mathrm{O}(3)-\mathrm{H}(30) \ldots \mathrm{O}(2) \# 1$ & $0.90(7)$ & $1.85(7)$ & $2.733(6)$ & $170(6)$ \\
$\mathrm{O}(2)-\mathrm{H}(2 \mathrm{O}) \ldots \mathrm{O}(3) \# 2$ & $1.10(10)$ & $1.80(9)$ & $2.734(6)$ & $140(7)$ \\
$\mathrm{O}(2)-\mathrm{H}(2 \mathrm{O}) \ldots \mathrm{O}(3)$ & $1.10(10)$ & $2.29(9)$ & $2.881(6)$ & $112(6)$ \\
& & & & \\
\hline
\end{tabular}

Symmetry transformations used to generate equivalent atoms:

\#1 x+1,y,z \#2 -x+1,-y,-z 


\subsection{References}

${ }^{1}$ Environment Canada. (2013, November $\left.22^{\text {nd }}\right)$. Pulp and Paper. Retrieved from https://www.ec.gc.ca/Air/default.asp?lang=En\&n=CB1E071C-1

${ }^{2}$ Food and Agriculture Organization of the United Nations. (2005). Global Forest Resources Assessment 2005 Progress towards sustainable forest management. Food \& Agriculture Org. Rome.

${ }^{3}$ Food and Agriculture Organization of the United Nations. (2007). State of the World's forests 2007, p.129. Food \& Agriculture Org. Rome.

${ }^{4}$ Pettersen, R. C. (1984). The Chemical Composition of Wood. The Chemistry of Solid Wood, 57-126. US Department of Agriculture. Madison.

${ }^{5}$ Cui, C., Sadeghifar, H., Sen, S., Argyropoulos, D. S. (2013). Toward Thermoplastic Lignin Polymers; Part II: Thermal \& Polymer Characteristics of Kraft Lignin and \& Derivatives. Bioresources, 8, 864-886.

${ }^{6}$ Fromm, J., Rockel, B., Lautner, S., Windeisen, E., Wanner, G. (2003). Lignin Distribution in Wood Cell Walls Determined by TEM and backscattered SEM Techniques. Struct. Bio. 143, 77 84.

${ }^{7}$ Gosslink, R.J.A. de Jong, E.. Guran, B., Abacherli, A. (2004). Co-ordination network for lignin-standardisation, production and applications adapted to market requirements. Ind. Crops. Prod. 20, 121-129.

${ }^{8}$ Kandhal, P. S. (1992). Waste Materials in Hot Mix Asphalt: An Overview (No. NCAT Report No. 92-6). National Center for Asphalt Technology. Alabama.

${ }^{9}$ Strassberger, Z., Alberts, A., Louwerse, M., Tanase, S., Rothenberg, G. (2013). Catalytic Cleavage of Lignin $\beta$-O-4 link Mimics using Copper on Alumina and Magnesia-alumina. Green Chem. 15, 768-774.

${ }^{10}$ Martone, P., Estevez, J., Lu, F., Ruel, K., Denny, M., Somerville, C., Ralph, J. (2009). Discovery of Lignin in Seaweed Reveals Convergent Evolution of cell Wall. J. Curr. Biol. 19, 169-175.

${ }^{11}$ Nagy, M. (2009). Biofuels from Lignin and Novel Biodiesel Analysis. Georgia Institute of Technology, Atlanta, United States of America.

${ }^{12}$ Hackette, W.F., Kirk, K. T., Connors, W., Zeikus, J. (1977). Microbial Decomposition of Synthetically ${ }^{14} \mathrm{C}$ labeled Lignins in Nature: Lignin Biodegradation in a variety of Natural Materials. J. Environ. Appl. Micro. 33, 43-51. 
${ }^{13}$ Steffen, K. T., Hofrichter, M., Hatakka, A. (2002). Purification and characterization of manganese peroxidases from the litter-decomposing basidiomycetes Agrocybe praecox and Stropharia coronilla. Enzyme Microb. Techol. 30, 550-555.

${ }^{14}$ Goñi, M. A., \& Montgomery, S. (2000). Alkaline CuO oxidation with a microwave digestion system: Lignin analyses of geochemical samples. Anal. Chem. 72, 3116-3121.

${ }^{15}$ Priefert, H., Rabenhorst, J., Steinbuchel, A. (2001). Biotechnological Production of Vanillin. App. Microbiol. Biotechnol. 56, 296-314.

${ }^{16}$ Pinto, P. C. R., Costa, C., Rodrigues, A. E., (2012). Eucalyptus Globulus Lignin as a source of Syringaldehyde and Vanillin. The $45^{\text {th }}$ ABTCP International Pulp and Paper Congress and VII IberoAmerican Congress on Pulp and Paper Research Oct 9-11, Sao Paulo Brazil.

${ }^{17}$ Araújo, J. D., Grande, C. A., Rodrigues, A. E. (2010). Vanillin production from lignin oxidation in a batch reactor. Chem. Eng. Res. Design, 88, 1024-1032.

${ }^{18}$ Xu, H., Delling, M., Jun, J. C., Clapham, D. E. (2006). Oregano, thyme and clove-derived flavors and skin sensitizers activate specific TRP channels. Nature Neurosci. 9, 628-635.

${ }^{19}$ Ali, S. M., Khan, A. A., Ahmed, I., Musaddiq, M., Ahmed, K. S., Polasa, H., Ahmed, N. (2005). Antimicrobial activities of Eugenol and Cinnamaldehyde against the human gastric pathogen Helicobacter pylori. Ann. Clin. Microbiol. Antimicrob. 4, 20-27.

${ }^{20}$ Rothrock, H. (1943). Phenol-formaldehyde resin. U.S. Patent 2,321,627. Washington, DC: U.S. Patent and Trademark Office.

${ }^{21}$ Gao, J., Liu, Y., Wang, F. (2001). Structure and properties of boron-containing bisphenol-A formaldehyde resin. Eur. Polym. J. 37, 207-210.

${ }^{22}$ Nilvebrant, N. O., Reimann, A., Larsson, S., \& Jönsson, L. J. (2001). Detoxification of lignocellulose hydrolysates with ion-exchange resins. App. Biochem. Biotechnol. 91, 35-49.

${ }^{23}$ Amarasekara, A. S., Razzaq, A. (2012). Vanillin-Based Polymers—part II: Synthesis of Schiff Base Polymers of Divanillin and Their Chelation with Metal Ions. ISRN Polymer Science, 2012, $1-5$.

${ }^{24}$ Kwon, J., Kim, J., Park, S., Khang, G., Kang, P. M., Lee, D. (2013). Inflammation-responsive antioxidant nanoparticles based on a polymeric prodrug of vanillin. Biomacromolecules, 14 , 1618-1626.

${ }^{25}$ Stanzione III, J. F., Sadler, J. M., La Scala, J. J., Reno, K. H., Wool, R. P. (2012). Vanillinbased resin for use in composite applications. Green Chem. 14, 2346-2352. 
${ }^{26}$ Rojo, L., Vazquez, B., Parra, J., López Bravo, A., Deb, S., San Roman, J. (2006). From natural products to polymeric derivatives of "Eugenol": a new approach for preparation of dental composites and orthopedic bone cements. Biomacromolecules, 7, 2751-2761.

${ }^{27}$ El Qouatli, S., Ngono, R. T., Najih, R., \& Chtaini, A. (2011). Eugenol modified titanium electrode for the analysis of carbocysteine. Zaštita materijala, 52(4), 242-246.

${ }^{28}$ Rojo, L., Barcenilla, J. M., Vázquez, B., González, R., San Román, J. (2008). Intrinsically antibacterial materials based on polymeric derivatives of eugenol for biomedical applications. Biomacromolecules, 9, 2530-2535.

${ }^{29}$ Obst, J. R. (1983). Analytical pyrolysis of hardwood and softwood lignins and its use in lignintype determination of hardwood vessel elements. Wood Chem. Technol. 3, 377-397.

${ }^{30}$ Morimoto, C., Satoh, Y., Hara, M., Inoue, S., Tsujita, T., Okuda, H. (2005). Anti-obese action of raspberry ketone. Life Sci. 77, 194-204.

${ }^{31}$ Webster, D. C., Crain, A. L. (2000). Synthesis and applications of cyclic carbonate functional polymers in thermosetting coatings. Prog. Org. Coatings. 40, 275-282.

${ }^{32}$ Bayley, R. D., Foucher, D. A., Kittelberger, J. S., Li, D., Saban, M. D., Sacripante, G. G., Toth, A. E. (2000). U.S. Patent No. 6,063,827. Washington, DC: U.S. Patent and Trademark Office.

${ }^{33}$ Brown, H. C., \& Zweifel, G. (1959). A Stereospecific Cis Hydration of the Double Bond in Cyclic Derivatives. J. Am. Chem. Soc. 81, 247-247.

${ }^{34}$ Eglinton, G., \& Whiting, M. C. (1950). 721. Researches on acetylenic compounds. Part XXVII. The preparation and properties of the toluene-p-sulphonates of acetylenic alcohols. $J$. Chem. Soc. 3650-3656.

${ }^{35}$ Ding, R., He, Y., Wang, X., Xu, J., Chen, Y., Feng, M., Qi, C. (2011). Treatment of Alcohols with Tosyl Chloride Does Not always Lead to the Formation of Tosylates. Molecules, 16, 56655673.

${ }^{36}$ Li, B., Bemish, R., Buzon, R. A., Chiu, C. K. F., Colgan, S. T., Kissel, W., Roth, J. (2003). Aqueous phosphoric acid as a mild reagent for deprotection of the $t$-butoxycarbonyl group. Tetrahedron Lett. 44, 8113-8115.

${ }^{37}$ Li, Z., Zhang, J., Brouwer, C., Yang, C. G., Reich, N. W., \& He, C. (2006). Brønsted acid catalyzed addition of phenols, carboxylic acids, and tosylamides to simple olefins. Org Lett. 8, 4175-4178.

${ }^{38}$ Corminbœuf, C., Heine, T., Weber, J. (2002). ${ }^{29}$ Si NMR chemical shifts of silane derivatives. Chem. Phys. Lett. 357, 1-7. 
${ }^{39}$ Starks, C. M., Liotta, C. L., Halpern, M. E. (1994). Phase-Transfer Catalysis: Fundamentals I (pp. 23-47). Springer Netherlands.

${ }^{40}$ Chen, J., Shum, W. (1995). A practical synthetic route to enantiopure 3-aryloxy-1, 2propanediols from chiral glycidol. Tetrahedron Lett. 36, 2379-2380.

${ }^{41}$ Ochoa-Gómez, J. R., Gómez-Jiménez-Aberasturi, O., Maestro-Madurga, B., PesqueraRodríguez, A., Ramírez-López, C., Lorenzo-Ibarreta, L., Villarán-Velasco, M. C. (2009). Synthesis of glycerol carbonate from glycerol and dimethyl carbonate by transesterification: catalyst screening and reaction optimization. Appl. Catal. A: General, 366, 315-324.

${ }^{42}$ Hadimani, M. B., Purohit, M. K., Vanampally, C., Van der Ploeg, R., Arballo, V., Morrow, D., Frizzi, K. E., Calcutt, N., Fernyhough, P., Kotra, L. P. (2013). Guaifenesin derivatives promote neurite outgrowth and protect diabetic mice from neuropathy. J. Med. Chem. 56, 5071-5078.

${ }^{43}$ Truscello, A. M., Gambarotti, C., Lauria, M., Auricchio, S., Leonardi, G., Shisodia, S. U., Citterio, A. (2013). One-pot synthesis of aryloxypropanediols from glycerol: towards valuable chemicals from renewable sources. Green Chem. 15, 625-628.

${ }^{44}$ Engh, R. A., Huber, R. (1991). Accurate bond and angle parameters for X-ray protein structure refinement. Acta. Cryst. A:, 47, 392-400.

${ }^{45}$ Chicha, H., Kouakou, A., Rakib, E. M., Saadi, M., El Ammari, L. (2013). N-(2-Allyl-4-chloro2H-indazol-5-yl)-4-methoxybenzenesulfonamide hemihydrate. Acta. Cryst. E:, 69, 1353.

${ }^{46}$ Coombes, S. R., Hughes, L. P., Phillips, A. R., Wren, S. A. (2014). Proton NMR: a new tool for understanding dissolution. Anal. Chem. 86, 2474-2480.

${ }^{47}$ Chen, A. K., Lai, Z., Nosella, K. D., Ou, Z., \& Vanbesien, D. W. (2012). U.S. Patent No. 8,313,884. Washington, DC: U.S. Patent and Trademark Office. 